Cochrane Database of Systematic Reviews

\title{
Self management for patients with chronic obstructive pulmonary disease (Review)
}

Zwerink M, Brusse-Keizer M, van der Valk PDLPM, Zielhuis GA, Monninkhof EM, van der Palen J, Frith PA, Effing $T$

Zwerink M, Brusse-Keizer M, van der Valk PDLPM, Zielhuis GA, Monninkhof EM, van der Palen J, Frith PA, Effing T.

Self management for patients with chronic obstructive pulmonary disease.

Cochrane Database of Systematic Reviews 2014, Issue 3. Art. No.: CD002990.

DOI: 10.1002/14651858.CD002990.pub3.

www.cochranelibrary.com 
TABLE OF CONTENTS

HEADER

ABSTRACT

PLAIN LANGUAGE SUMMARY

SUMMARY OF FINDINGS

2

BACKGROUND

OBJECTIVES

METHODS

RESULTS

Figure 1.

Figure 2.

Figure 3.

Figure 4.

Figure 5.

Figure 6.

DISCUSSION

AUTHORS' CONCLUSIONS

ACKNOWLEDGEMENTS

REFERENCES

CHARACTERISTICS OF STUDIES

DATA AND ANALYSES

Analysis 1.1. Comparison 1 Self management versus control, Outcome $1 \mathrm{HRQ}$ oL: SGRQ.

Analysis 1.2. Comparison 1 Self management versus control, Outcome 2 HRQoL: SGRQ total score: change from baseline. .....

Analysis 1.3. Comparison 1 Self management versus control, Outcome 3 HRQoL: CRQ.

Analysis 1.4. Comparison 1 Self management versus control, Outcome 4 HRQoL: CCQ.

Analysis 1.5. Comparison 1 Self management versus control, Outcome 5 HRQoL: SIP total score.

Analysis 1.6. Comparison 1 Self management versus control, Outcome 6 HRQoL: SF-36.

Analysis 1.7. Comparison 1 Self management versus control, Outcome 7 Respiratory-related hospital admissions.

Analysis 1.8. Comparison 1 Self management versus control, Outcome 8 All-cause hospital admissions.

Analysis 1.9. Comparison 1 Self management versus control, Outcome 9 Respiratory-related hospital admissions: days. .......

Analysis 1.10. Comparison 1 Self management versus control, Outcome 10 All-cause hospital admissions: days.

Analysis 1.11. Comparison 1 Self management versus control, Outcome 11 Emergency department visits per person per year. .

Analysis 1.12. Comparison 1 Self management versus control, Outcome 12 Doctor and nurse visits: mean number per person per year.

Analysis 1.13. Comparison 1 Self management versus control, Outcome 13 Participants using at least one course of oral steroids.

Analysis 1.14. Comparison 1 Self management versus control, Outcome 14 Participants using at least one course of antibiotics.

Analysis 1.15. Comparison 1 Self management versus control, Outcome 15 (Modified) Medical Research Council Dyspnoea Scale ((m)MRC).

Analysis 1.16. Comparison 1 Self management versus control, Outcome 16 Days lost from work: mean number per person per year.

Analysis 1.17. Comparison 1 Self management versus control, Outcome 17 Lung function: FEV1 (litres).

Analysis 1.18. Comparison 1 Self management versus control, Outcome 18 Lung function: FEV1 (\% of predicted).

Analysis 1.19. Comparison 1 Self management versus control, Outcome 19 Exercise capacity: 6MWT.

Analysis 1.20. Comparison 1 Self management versus control, Outcome 20 Lung function: FEV1/FVC.

Analysis 1.21. Comparison 1 Self management versus control, Outcome 21 Mortality.

Analysis 2.1. Comparison 2 Sensitivity analyses with inclusion of CCTs, Outcome $1 \mathrm{HRQ}$ L: SGRQ (with CCTs).

Analysis 2.2. Comparison 2 Sensitivity analyses with inclusion of CCTs, Outcome 2 HRQoL: SGRQ total score: change from baseline (with CCTs).

Analysis 2.3. Comparison 2 Sensitivity analyses with inclusion of CCTs, Outcome 3 Respiratory-related hospital admissions (with CCTs).

Analysis 2.4. Comparison 2 Sensitivity analyses with inclusion of CCTs, Outcome 4 All-cause hospital admissions (with CCTs). .. 
Analysis 2.5. Comparison 2 Sensitivity analyses with inclusion of CCTs, Outcome 5 All-cause hospital admissions: days (with CCTs).

Analysis 2.6. Comparison 2 Sensitivity analyses with inclusion of CCTs, Outcome 6 (Modified) Medical Research Council Dyspnoea Scale ((m)MRC) (with CCTs).

Analysis 2.7. Comparison 2 Sensitivity analyses with inclusion of CCTs, Outcome 7 Lung function: FEV1 (liters) (with CCTs). .... Analysis 2.8. Comparison 2 Sensitivity analyses with inclusion of CCTs, Outcome 8 Lung function: FEV1 (\% of predicted) (with CCTs).

Analysis 2.9. Comparison 2 Sensitivity analyses with inclusion of CCTs, Outcome 9 Lung function: FEV1/FVC (with CCTs). ....... Analysis 2.10. Comparison 2 Sensitivity analyses with inclusion of CCTs, Outcome 10 Exercise capacity: 6MW (with CCTs). ....... Analysis 2.11. Comparison 2 Sensitivity analyses with inclusion of CCTs, Outcome 11 Mortality (with CCTs).

Analysis 3.1. Comparison 3 Subgroup analyses, Outcome 1 HRQOL: SGRQ total (subgroup by follow-up).

Analysis 3.2. Comparison 3 Subgroup analyses, Outcome 2 Respiratory-related hospital admissions (subgroup by follow-up). . Analysis 3.3. Comparison 3 Subgroup analyses, Outcome 3 HRQOL: SGRQ total (subgroup by exercise programme).

Analysis 3.4. Comparison 3 Subgroup analyses, Outcome 4 Respiratory-related hospital admissions (subgroup by exercise programme).

Analysis 3.5. Comparison 3 Subgroup analyses, Outcome 5 Exercise capacity: 6MW (subgroup exercise programme).

Analysis 3.6. Comparison 3 Subgroup analyses, Outcome 6 HRQOL: SGRQ total (behavioural components).

Analysis 3.7. Comparison 3 Subgroup analyses, Outcome 7 Respiratory-related hospital admissions (behavioural components). 
[Intervention Review]

\section{Self management for patients with chronic obstructive pulmonary disease}

Marlies Zwerink ${ }^{1}$, Marjolein Brusse-Keizer ${ }^{1}$, Paul DLPM van der Valk¹, Gerhard A Zielhuis², Evelyn M Monninkhof ${ }^{3}$, Job van der Palen ${ }^{1,4}$, Peter A Frith5,6, Tanja Effing5,6

1Department of Pulmonary Medicine, Medisch Spectrum Twente, Enschede, Netherlands. 2Department for Health Evidence, Radboud University Medical Center, Nijmegen, Netherlands. 3 Julius Center for Health Sciences and Primary Care, University Medical Center Utrecht, Utrecht, Netherlands. ${ }^{4}$ Department of Research Methodology, Measurement and Data Analysis, University of Twente, Enschede, Netherlands. ${ }^{5}$ Respiratory Clinical Research Unit, Repatriation General Hospital, Daw Park, Australia. ${ }^{6}$ School of Medicine, Flinders University, Adelaide, Australia

Contact address: Tanja Effing, Respiratory Clinical Research Unit, Repatriation General Hospital, Daw Park, South Australia, Australia. tanja.effing@health.sa.gov.au, tanjaeffing@gmail.com.

Editorial group: Cochrane Airways Group

Publication status and date: Edited (no change to conclusions), published in Issue 7, 2014.

Citation: Zwerink M, Brusse-Keizer M, van der Valk PDLPM, Zielhuis GA, Monninkhof EM, van der Palen J, Frith PA, Effing T. Self management for patients with chronic obstructive pulmonary disease. Cochrane Database of Systematic Reviews 2014, Issue 3. Art. No.: CD002990. DOI: 10.1002/14651858.CD002990.pub3.

Copyright @ 2014 The Cochrane Collaboration. Published by John Wiley \& Sons, Ltd.

\section{A B S T R A C T}

\section{Background}

Self management interventions help patients with chronic obstructive pulmonary disease (COPD) acquire and practise the skills they need to carry out disease-specific medical regimens, guide changes in health behaviour and provide emotional support to enable patients to control their disease. Since the first update of this review in 2007, several studies have been published. The results of the second update are reported here.

\section{Objectives}

1. To evaluate whether self management interventions in COPD lead to improved health outcomes.

2. To evaluate whether self management interventions in COPD lead to reduced healthcare utilisation.

\section{Search methods}

We searched the Cochrane Airways Group Specialised Register of trials (current to August 2011).

\section{Selection criteria}

Controlled trials (randomised and non-randomised) published after 1994, assessing the efficacy of self management interventions for individuals with COPD, were included. Interventions with fewer than two contact moments between study participants and healthcare providers were excluded.

\section{Data collection and analysis}

Two review authors independently assessed trial quality and extracted data. Investigators were contacted to ask for additional information. When appropriate, study results were pooled using a random-effects model. The primary outcomes of the review were health-related quality of life (HRQoL) and number of hospital admissions. 


\section{Main results}

Twenty-nine studies were included. Twenty-three studies on 3189 participants compared self management versus usual care; six studies on 499 participants compared different components of self management on a head-to-head basis. Although we included non-randomised controlled clinical trials as well as RCTs in this review, we restricted the primary analysis to RCTs only and reported these trials in the abstract.

In the 23 studies with a usual care control group, follow-up time ranged from two to 24 months. The content of the interventions was diverse. A statistically relevant effect of self management on HRQoL was found (St George's Respiratory Questionnaire (SGRQ) total score, mean difference (MD) -3.51, 95\% confidence interval (CI) -5.37 to -1.65, 10 studies, 1413 participants, moderate-quality evidence). Self management also led to a lower probability of respiratory-related hospitalisations (odds ratio (OR) $0.57,95 \% \mathrm{Cl} 0.43$ to 0.75 , nine studies, 1749 participants, moderate-quality evidence) and all cause hospitalisations (OR 0.60; 95\% $\mathrm{Cl} 0.40$ to $0.89,6$ studies, 1365 participants, moderate-quality evidence). Over one year of follow-up, eight $(95 \% \mathrm{Cl} 5$ to 14$)$ participants with a high baseline risk of respiratoryrelated hospital admission needed to be treated to prevent one participant with at least one hospital admission, and 20 (95\% $\mathrm{Cl} 15$ to 35 ) participants with a low baseline risk of hospitalisation needed to be treated to prevent one participant with at least one respiratory-related hospital admission.

No statistically significant effect of self management on mortality (OR $0.79,95 \% \mathrm{Cl} 0.58$ to $1.07,8$ studies, 2134 participants, very low-quality evidence) was detected. Also, dyspnoea measured by the (modified) Medical Research Council Scale ((m)MRC) was reduced in individuals who participated in self management (MD - $0.83,95 \% \mathrm{Cl}-1.36$ to $-0.30,3$ studies, 119 participants, low-quality evidence). The difference in exercise capacity as measured by the six-minute walking test was not statistically significant (MD $33.69 \mathrm{~m}, 95 \% \mathrm{Cl}-9.12$ to $76.50,6$ studies, 570 participants, very low-quality evidence). Subgroup analyses depending on the use of an exercise programme as part of the intervention revealed no statistically significant differences between studies with and without exercise programmes in our primary outcomes of HRQoL and respiratory-related hospital admissions.

We were unable to pool head-to-head trials because of heterogeneity among interventions and controls; thus results are presented narratively within the review.

\section{Authors' conclusions}

Self management interventions in patients with COPD are associated with improved health-related quality of life as measured by the SGRQ, a reduction in respiratory-related and all cause hospital admissions, and improvement in dyspnoea as measured by the ( $\mathrm{m}$ )MRC. No statistically significant differences were found in other outcome parameters. However, heterogeneity among interventions, study populations, follow-up time and outcome measures makes it difficult to formulate clear recommendations regarding the most effective form and content of self management in COPD.

\section{PLAIN LANGUAGE SUMMARY}

\section{Self management for patients with chronic obstructive pulmonary disease}

\section{Background}

Symptoms of patients with COPD slowly worsen over the years. This leads to loss of well-being in these patients. In research, another word for well-being is health-related quality of life. Self management training teaches patients the skills and behaviours they need to successfully manage their disease. Self-management training is becoming more and more important in the treatment of COPD. However, debate on the most effective content is ongoing. Therefore, we reviewed the evidence on the effects of self management on health-related quality of life and on healthcare use in patients with COPD. The evidence is current to August 2011.

\section{Study characteristics}

In this review, we assessed 29 studies that evaluated the effects of self management. Patients in these studies were followed for two to 24 months. Twenty-three studies had a control group that received usual care. A total of 3189 patients participated in these studies. In six studies, different components of self management were compared on a head-to-head basis. Content and duration of the self management programmes were diverse.

\section{Key results}

Analysis of the studies revealed that self management training improved health-related quality of life in patients with COPD compared with usual care. Also, the number of patients with at least one hospital admission related to lung disease and other causes was reduced among those who participated in a self management intervention. These patients also experienced less shortness of breath. We found trials that compared different types of self management interventions versus each other. We had hoped that these trials would help us identify the most effective components of self management. However, all interventions were different, and we were unable to draw out the key themes. 
The studies assessed in this review were diverse. Self management programmes differed in content and duration. Also, types of participants differed across studies. Therefore, no clear recommendations on the most effective content of self management training can be made at this time. 
SUMMARY OF FINDINGS

Summary of findings for the main comparison. Self management compared with control for participants with chronic obstructive pulmonary disease

Self management compared with control for participants with chronic obstructive pulmonary disease

Patient or population: patients with chronic obstructive pulmonary disease

Settings: community, primary care, hospital outpatient

Intervention: self management

Comparison: control

This table includes data from RCTs only; data from CCTs are presented in the review.

\begin{tabular}{|c|c|c|c|c|c|c|}
\hline \multirow[t]{3}{*}{ Outcomes } & \multicolumn{2}{|c|}{ Illustrative comparative risks* $(95 \% \mathrm{CI})$} & \multirow{3}{*}{$\begin{array}{l}\text { Relative effect } \\
(95 \% \mathrm{CI})\end{array}$} & \multirow{3}{*}{$\begin{array}{l}\text { No. of partic- } \\
\text { ipants } \\
\text { (studies) }\end{array}$} & \multirow{3}{*}{$\begin{array}{l}\text { Quality of the } \\
\text { evidence } \\
\text { (GRADE) }\end{array}$} & \multirow[t]{3}{*}{ Comments } \\
\hline & Assumed risk & Corresponding risk & & & & \\
\hline & Control & Self management & & & & \\
\hline $\begin{array}{l}\text { HRQoL: SGRQ total } \\
\text { score } \\
\text { Scale ranges from zero } \\
\text { to } 100 \text {. Lower score in- } \\
\text { dicates better HRQoL }\end{array}$ & $\begin{array}{l}\text { Range of mean SGRQ total } \\
\text { scores in the control group } \\
\text { varied from } 34.7 \text { to } 65.3 \\
\text { points }\end{array}$ & $\begin{array}{l}\text { Mean SGRQ total score in the interven- } \\
\text { tion group was } 3.51 \text { lower ( } 5.37 \text { to } 1.65 \\
\text { lower) }\end{array}$ & $\begin{array}{l}\text { MD -3.51 (-5.37 to } \\
-1.65)\end{array}$ & $\begin{array}{l}1413 \\
\text { (10 studies) }\end{array}$ & $\begin{array}{l}\oplus \oplus \oplus \odot \\
\text { moderate }^{1}\end{array}$ & \\
\hline $\begin{array}{l}\text { Respiratory-related } \\
\text { hospital admissions: } \\
\text { number of participants } \\
\text { with at least one respi- } \\
\text { ratory-related hospital } \\
\text { admission }\end{array}$ & 293 per 1000 & $\begin{array}{l}190 \text { per } 1000 \\
(151 \text { to } 237)\end{array}$ & $\begin{array}{l}\text { OR } 0.57 \text { (0.43 to } \\
0.75)\end{array}$ & $\begin{array}{l}1749 \\
\text { (9 studies) }\end{array}$ & $\begin{array}{l}\oplus \oplus \oplus \ominus \\
\text { moderate }^{2}\end{array}$ & \\
\hline $\begin{array}{l}\text { All-cause hospital ad- } \\
\text { missions: } \\
\text { number of participants } \\
\text { with at least one all- } \\
\text { cause hospital admis- } \\
\text { sion }\end{array}$ & 428 per 1000 & $\begin{array}{l}310 \text { per } 1000 \\
(230 \text { to } 400)\end{array}$ & $\begin{array}{l}\text { OR } 0.60 \text { ( } 0.40 \text { to } \\
0.89 \text { ) }\end{array}$ & $\begin{array}{l}1365 \\
\text { (6 studies) }\end{array}$ & $\begin{array}{l}\oplus \oplus \oplus \ominus \\
\text { moderate }^{2}\end{array}$ & \\
\hline
\end{tabular}




\begin{tabular}{|c|c|c|c|c|c|}
\hline $\begin{array}{l}\text { Dyspnoea: }(\mathrm{m}) \mathrm{MRC} \\
\text { score }\end{array}$ & $\begin{array}{l}\text { Range of mean }(\mathrm{m}) \mathrm{MRC} \text { scores } \\
\text { in the control group varied } \\
\text { from } 2.4 \text { to } 3.6 \text { points }\end{array}$ & $\begin{array}{l}\text { Mean }(m) \text { MRC total score in the inter- } \\
\text { vention group was } 0.83 \text { lower ( } 1.36 \text { to } \\
0.3 \text { lower) }\end{array}$ & $\begin{array}{l}\text { MD - } \mathbf{0 . 8 3}(-1.36 \text { to } \\
-0.30)\end{array}$ & $\begin{array}{l}119 \\
\text { (3 studies) }\end{array}$ & $\begin{array}{l}\oplus \oplus \oplus \ominus \\
\text { low }^{3}\end{array}$ \\
\hline $\begin{array}{l}\text { Courses of oral } \\
\text { steroids: } \\
\text { number of participants } \\
\text { receiving at least one } \\
\text { course of oral steroids }\end{array}$ & 541 per 1000 & $\begin{array}{l}892 \text { per } 1000 \\
\text { (315 to } 983 \text { ) }\end{array}$ & $\begin{array}{l}\text { OR } 4.42 \text { ( } 0.39 \text { to } \\
50.10)\end{array}$ & $\begin{array}{l}901 \\
\text { (3 studies) }\end{array}$ & $\begin{array}{l}\oplus \oplus \ominus \ominus \\
\text { low }^{4}\end{array}$ \\
\hline $\begin{array}{l}\text { Exercise capacity: } \\
6 \text { MWD }\end{array}$ & $\begin{array}{l}\text { Range of mean 6MWD in the } \\
\text { control group varied from } \\
68.6 \text { to } 440.9 \mathrm{~m}\end{array}$ & $\begin{array}{l}\text { Mean } 6 \text { MWD in the intervention group } \\
\text { was } 33.69 \text { higher ( } 9.12 \text { lower to } 76.50 \\
\text { higher) }\end{array}$ & $\begin{array}{l}\text { MD } 33.69 \\
(-9.12 \text { to } 76.50)\end{array}$ & $\begin{array}{l}570 \\
\text { (6 studies) }\end{array}$ & $\begin{array}{l}\oplus \oplus \ominus \ominus \\
\text { low5 } 5\end{array}$ \\
\hline $\begin{array}{l}\text { Mortality: } \\
\text { number of deaths }\end{array}$ & 97 per 1000 & $\begin{array}{l}79 \text { per } 1000 \\
\text { (59 to } 103)\end{array}$ & $\begin{array}{l}\text { OR } 0.79 \text { (0.58 to } \\
1.07 \text { ) }\end{array}$ & $\begin{array}{l}2134 \\
\text { (8 studies) }\end{array}$ & $\begin{array}{l}\oplus \ominus \ominus \ominus \\
\text { very low } 6\end{array}$ \\
\hline
\end{tabular}

*The basis for the assumed risk (e.g. the median control group risk across studies) is provided in footnotes. The corresponding risk (and its $95 \%$ confidence interval) is based on the assumed risk in the comparison group and the relative effect of the intervention (and its $95 \% \mathrm{Cl}$ ).

Cl: Confidence interval; HRQoL: Health-related quality of life; 6MWD: Six-minute walking distance.

GRADE Working Group grades of evidence.

High quality: Further research is very unlikely to change our confidence in the estimate of effect.

Moderate quality: Further research is likely to have an important impact on our confidence in the estimate of effect and may change the estimate.

Low quality: Further research is very likely to have an important impact on our confidence in the estimate of effect and is likely to change the estimate.

Very low quality: We are very uncertain about the estimate.

1Sensitivity analysis with CCTs shows that the outcome is still sensitive to inclusion of new studies.

${ }^{2}$ Confidence intervals of several included studies were wide, and several studies showed low event rates (-1 imprecision).

${ }^{3}$ Heterogeneity was substantial $(12=58 \%)$. Only three small studies were included in this meta-analysis (inconsistency -1 , imprecision -1 ).

4 Heterogeneity was high $\left(I^{2}=96 \%\right)$. Only three studies were included in this meta-analysis, and the study of Rice et al heavily influenced the OR. The $95 \% \mathrm{Cl}$ was wide (inconsistency

-1 , imprecision -1$)$.

${ }^{5}$ Heterogeneity was high $\left(1^{2}=89 \%\right)$ and sensitivity analysis with CCTs shows that the outcome is sensitive to inclusion of new studies (inconsistency -1 , imprecision -1 ).

${ }^{6}$ This meta-analysis was explorative and the number of events is relatively low. Numerous studies had no events and were not included in this analysis. 


\section{B A C K G R O U N D}

\section{Description of the condition}

Chronic obstructive pulmonary disease (COPD) is characterised by persistent airflow limitation. The course of COPD is usually progressive, and it is associated with an enhanced inflammatory response in the airways and lungs to noxious particles or gasses (GOLD 2010). COPD is a serious public health problem and a major cause of chronic morbidity and mortality worldwide. In 2010, COPD was the third leading cause of death worldwide (Lozano 2012). Furthermore, COPD imparts a great economic burden on society, with exacerbations accounting for most of the costs (Toy 2010).

\section{Description of the intervention}

Mortality data do not provide a complete picture of the burden of the disease because many patients with COPD exhibit progressive disability rather than immediate death. In 2010, COPD was the number five cause of years of life lived in less than ideal health (Vos 2012). This is not surprising in that many patients with COPD experience slow development of functional impairment over many years and progressive loss of health-related quality of life (Garrido 2006; Heyworth 2009). In light of this, self management training is considered increasingly important as treatment for patients with COPD. However, debate on the definition and the most effective content of self management interventions is ongoing (Effing 2012). In general, self management training aims to help patients acquire and practise the skills they need to carry out disease-specific medical regimens, to guide changes in health behaviour and to provide emotional support to enable patients to adjust their roles for optimal function and control of their disease (Bourbeau 2009; Effing 2012). Essential patient skills for successful self management include problem solving, decision making, resource utilisation, forming a partnership between patient and healthcare provider, taking action and self tailoring (Lorig 2003b). Ideally, self management training should be aimed at sustained behavioural change. Self efficacy is seen as patients' confidence that they can effectively manage their health and has been recognised as a powerful factor in inducing new behaviours (Bandura 1977; Bourbeau 2004; Lorig 2003b). Skills mastery, modelling, interpretation of symptoms and social persuasion are believed to contribute to enhanced self efficacy (Lorig 2003b).

\section{Why it is important to do this review}

The original Cochrane review regarding COPD self management was published in 2003. In the first update of the review, published in 2007, it was concluded that self management is associated with improved quality of life and reduced hospital admissions with no indication of detrimental effects on the other outcome measures. However, because of heterogeneity in study designs. it was not possible to make recommendations regarding the form and content of self management interventions (Effing 2012). Since the first update, several studies have been published and new opinions have been formed regarding the contents of self management interventions for patients with COPD. Therefore we report the results of the second update of the review. In this update of the review, we have chosen to exclude studies with education as the only active intervention. Although patient education is an indispensable component of self management, education alone is insufficient to achieve the goal of behavioural change (Bandura 1977; Bourbeau 2004; Bourbeau 2009; Effing 2012). To avoid ambiguity, we have removed the term 'education' from the title of the review.

\section{OB JECTIVES}

1. To evaluate whether self management interventions in COPD lead to improved health outcomes.

2. To evaluate whether self management interventions in COPD lead to reduced healthcare utilisation.

\section{METHODS}

\section{Criteria for considering studies for this review Types of studies}

We included randomised controlled trials (RCTs) and nonrandomised controlled clinical trials assessing the efficacy of self management interventions for individuals with COPD. Studies published before 1995 were excluded because we strongly believe that the primary focus of self management programmes before 1995 consisted of improving knowledge through education rather than initiating and enabling sustained behavioural change.

\section{Types of participants}

Patients with a clinical diagnosis of COPD with symptoms and meeting agreed spirometry criteria (i.e. forced expiratory volume in one second $\left(\mathrm{FEV}_{1}\right) /$ forced vital capacity $(\mathrm{FVC})<70 \%$ ) were included (GOLD 2010). Patients with asthma as a primary diagnosis were excluded.

\section{Types of interventions}

Self management interventions were defined as structured interventions for individuals with COPD aimed at improvement of self health behaviours and self management skills. These interventions required at least an iterative process of interaction between participant and healthcare provider, and ideally also included formulation of goals and provision of feedback. Interventions with fewer than two contact moments were therefore excluded. Furthermore, at least two of the following components had to be part of the intervention: smoking cessation, self recognition and self treatment of exacerbations, an exercise or physical activity component, advice about diet, advice about medication or coping with breathlessness. Content could be delivered to study participants verbally, as written material (hardcopy or digital) or via audiovisual media. An action plan was defined as a guideline for participants describing when and how to change medication in case of worsening COPD-related symptoms, indicating (the start of) an exacerbation. Explicitly, interventions involving solely participant education were excluded. Disease management programmes classified as pulmonary rehabilitation offered in a hospital or rehabilitation centre, as well as communityor home-based pulmonary rehabilitation programmes solely directed towards exercise, were also excluded.

Studies with usual care as a control group and those with an active intervention as a control group were included in this review.

\section{Types of outcome measures}

\section{Primary outcomes}

1. Health-related quality of life (HRQoL) scores. 
2. Number of hospital admissions.

\section{Secondary outcomes}

1. Hospitalisation days.

2. Number of exacerbations requiring emergency department visits.

3. Use of (other) healthcare facilities.

4. Number of exacerbations requiring a course of oral corticosteroids or antibiotics.

5. Use of rescue medication.

6. Symptom scores.

7. Anxiety and depression.

8. Self efficacy.

9. Days lost from work.

10.Lung function.

11. Exercise capacity.

\section{Search methods for identification of studies}

\section{Electronic searches}

We identified trials from the Cochrane Airways Group Specialised Register (CAGR), which is maintained by the Trials Search Coordinator (TSC) for the Group. The Register contains trial reports identified through systematic searches of bibliographic databases, including the Cochrane Central Register of Controlled Trials (CENTRAL), MEDLINE, EMBASE, CINAHL, AMED and PsycINFO, and through handsearching of respiratory journals and meeting abstracts (please see Appendix 1 for further details). The TSC searched all records in the CAGR using the search strategy presented in Appendix 2.

The most recent search was conducted in August 2011, with no restriction on language of publication.

\section{Searching other resources}

Additional trials were searched using the database of clinicaltrials.gov and the World Health Organization (WHO) trials database. Also, reference tracking of eligible studies was performed.

\section{Data collection and analysis}

\section{Selection of studies}

Two review authors (MZ and TE) independently assessed titles and abstracts of all references retrieved. Two review authors (MZ and TE or JP or MB-K or PV) independently reviewed full-text versions of potentially relevant reports, and assessed these on definite eligibility for inclusion based on the criteria stated above. Disagreement was resolved by discussion between the two review authors. If consensus was not reached, a third review author was consulted.

\section{Data extraction and management}

Two review authors (MZ and TE or MB-K) independently extracted the following data from included studies: relevant outcome measures, sample size, demographics of included participants, disease severity, setting, duration and contents of the intervention.

\section{Assessment of risk of bias in included studies}

We assessed the risk of bias according to recommendations outlined in the Cochrane Handbook for Systematic Reviews of Interventions (Cochrane Handbook) for the following items.

1. Random sequence generation.

2. Allocation concealment.

3. Blinding of participants and personnel.

4. Blinding of outcome assessment.

5. Incomplete outcome data.

6. Selective outcome reporting.

7. Other bias.

For each included study, two review authors (MZ and TE or MB$\mathrm{K}$ ) independently assessed for all items above whether a high, low or unclear risk of bias was present. Unclear risk indicated that insufficient detail of what happened in the study was reported; that what happened in the study was known but the risk of bias was unknown; or that an entry was not relevant to the study at hand. Each judgement was supported by a short description of what was reported to have happened in the specific study.

\section{Measures of treatment effect}

For continuous outcomes, the mean difference (MD) or the standardised mean difference (SMD) with 95\% confidence intervals $(95 \% \mathrm{Cl})$ was calculated as appropriate. For dichotomous outcomes, a pooled odds ratio (OR) was calculated. Numbers needed to treat for an additional beneficial outcome (NNTB) were calculated for hospital admission using the pooled OR and control group data from individual studies to obtain study-specific NNTB, with Visual Rx.

\section{Unit of analysis issues}

Most studies included in this review were RCTs; therefore the unit of analysis in these trials is the participant. One study was clusterrandomised (Rea 2004). The cluster, and thus the unit of analysis, in this study was the general practice. We decided to include unadjusted values of this study in the meta-analysis because (1) we had no information from which to estimate a suitable intracluster correlation coefficient; and (2) excluding this trial from metaanalyses did not lead to clear changes in effect sizes.

\section{Dealing with missing data}

In cases of missing or incomplete data, we contacted the authors of the report. When the study authors did not respond, a second attempt was made. Trial authors who have contributed to this version or to previous versions of the review have been listed under the heading 'Acknowledgements'.

\section{Assessment of heterogeneity}

We explored variability among studies using the 12 statistic (Higgins 2011). When substantial heterogeneity $\left(1^{2}>50 \%\right)$ was detected, we discussed possible explanations and critically reconsidered the appropriateness of a meta-analysis. Furthermore, in metaanalyses, we used a random-effects model, rather than a fixedeffect model, to account for heterogeneity. 


\section{Assessment of reporting biases}

We explored possible reporting bias by assessing asymmetry in funnel plots.

\section{Data synthesis}

When appropriate, we performed a meta-analysis using Review Manager (RevMan). A meta-analysis was considered when at least three studies reported sufficient data for the outcome. Because of the nature of the intervention analysed in this review, we expected heterogeneity between the studies. Therefore, we performed metaanalyses using a random-effects model rather than a fixed-effect model. Inclusion of controlled clinical trials (CCTs) in this review, resulted in higher risk of bias because of their non-randomised design, and may have introduced heterogeneity into the metaanalysis when data were pooled with findings of RCTs. Therefore meta-analyses were primarily performed without inclusion of CCTs. Sensitivity analyses with inclusion of CCTs were also performed.

Using the criteria outlined in the Cochrane Handbook for Systematic Reviews of Interventions (Higgins 2011), we created a 'Summary of findings' table on the following outcomes: HRQoL measured with the St George's Respiratory Questionnaire (SGRQ), hospital admissions (respiratory-related and all-cause), courses of oral steroids, dyspnoea measured with the (modified) Medical Research Council Scale ((m)MRC), exercise capacity measured with the sixminute walking test and mortality.

\section{Subgroup analysis and investigation of heterogeneity}

Subgroup analyses of interest were defined a priori and were performed according to duration of follow-up (< or $\geq 12$ months), as well as use of an action plan, a standardised exercise programme, and behavioural components in the intervention.

\section{Sensitivity analysis}

We conducted sensitivity analyses to investigate robustness of effect sizes found in this review under different assumptions.

\section{RE S U L T S \\ Description of studies}

See Characteristics of included studies.

\section{Results of the search}

Searches identified 1300 titles and abstracts, which were screened by two review authors ( $M Z$ and TE) independently to identify 205 potentially eligible articles about self management in COPD (Figure 1). Full-text versions of these papers were obtained and independently assessed by two review authors (MZ and TE or JP or MB-K or PV). Twenty-nine studies were included in this review. Eight studies that were included in earlier versions of this review were excluded in this update: four because they were published before 1995, two because they used only one component, one because it did not include participants with COPD as defined by the Global initiative for Obstructive Lung Disease (GOLD) (in the previous two reviews, spirometry data were not required) and one because its intervention could not be classified as self management. 
Figure 1. Study flow diagram.

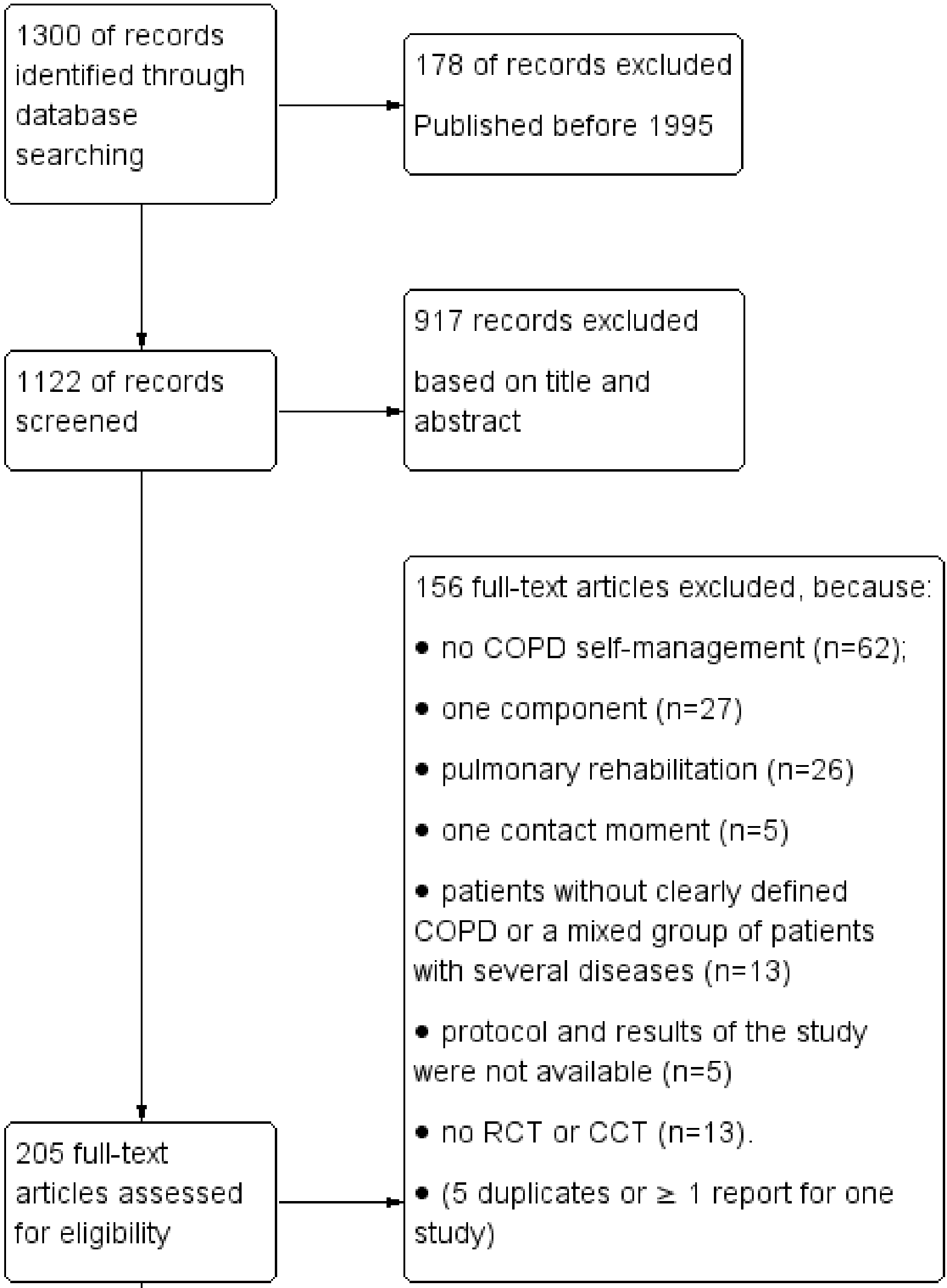


Figure 1. (Continued)

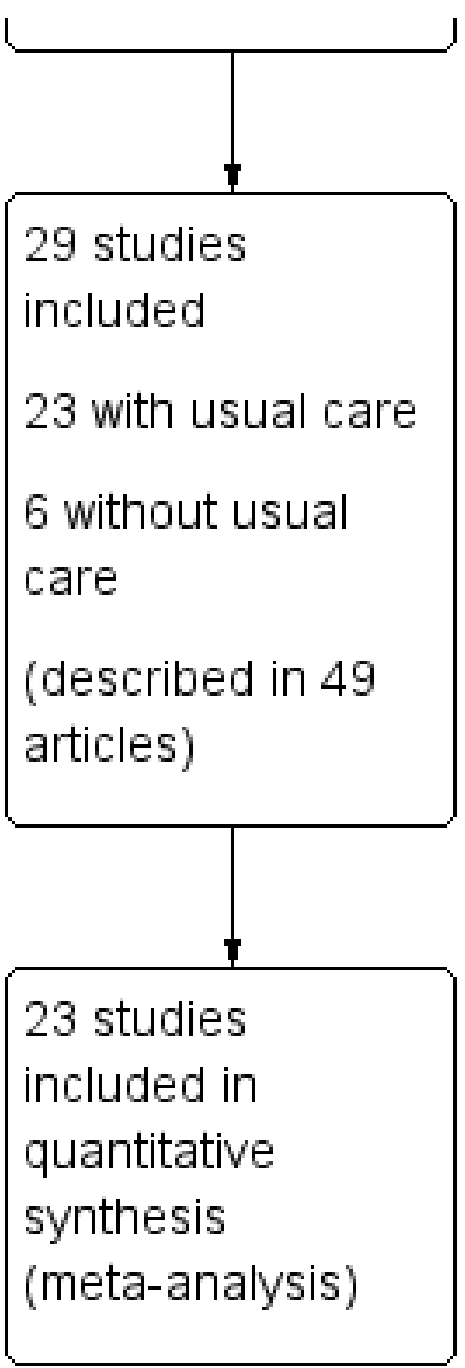

\section{Included studies}

Of the 29 included studies, 23 compared self management versus a usual care control group (Akinci 2011; Bösch 2007; Bourbeau 2003; Casas 2006; Chavannes 2009; Chuang 2011; Coultas 2005a; Coultas 2005b; Emery 1998; Faulkner 2010; Gallefoss 1999; Ghanem 2010; Hill 2010; Khdour 2009; Kheirabadi 2008; Koff 2009; Monninkhof 2003; Moullec 2008; Ninot 2011; Osterlund Efraimsson 2006; Rea 2004; Rice 2010; van Wetering 2009; Wakabayashi 2011). Twentyfive of the included studies were parallel RCTs, one study was a cluster-randomised trial and three studies were CCTs. The clusterrandomised trial and the CCTs all included a usual care control group. Six RCTs, including seven group comparisons, compared different components of self management on a head-to-head basis (Effing 2009; Effing 2011; Kara 2004; Nguyen 2008; Nguyen 2009; Sassi-Dambron 1995; Stulbarg 2002). Details of participant characteristics (Table 1 ) and characteristics of the interventions are tabulated (Table 2).

\section{Trials with a usual care control}

\section{Participants and recruitment}

Twenty-three studies on 3189 participants compared self management versus usual care (Table 1 ). Dropout rates ranged from $0 \%$ to $39 \%$, and $2751(86 \%)$ participants completed the studies. Only eight $(35 \%)$ studies reported details regarding adherence to the intervention. Four studies reported adherence as the number or percentage of sessions attended by participants. Participants in the intervention group in the study of Moullec et al attended $68.6 \%$ of the scheduled sessions (Moullec 2008). Emery et al reported adherence of $88 \%$ in the intervention group (Emery 1998). All participants in the study of Hill et al attended the two scheduled education sessions (Hill 2010). Mean attendance frequency in the study of Monninkhof et al was $0.77 \pm 0.22$ sessions per week (Monninkhof 2003). The other four studies reported the numbers of participants who were not adherent (according to different definitions); these numbers ranged from $5 \%$ to $40 \%$.

Fourteen studies recruited participants from a hospital ( 11 from the outpatient clinic and three from inpatient population). Six studies recruited participants from general practice or primary healthcare clinics; one study recruited participants from a rehabilitation centre, one from a health maintenance registration and one through advertisement in the community, combined with physician referral. 


\section{Interventions}

Contents of the interventions assessed in the 23 included studies were diverse (Table 2). The duration of follow-up was two months or less in three $(13 \%)$ studies and three months in five $(22 \%)$, six months in one (4\%), 12 months in 12 (52\%) and 24 months in two (9\%) studies. Self management interventions were offered individually in $12(52 \%)$ studies and in small groups in six (26\%) studies, and included both individual and group sessions in five (22\%) studies. In 17 (74\%) studies, an action plan was part of the intervention, and a standardised exercise programme was part of the intervention in $11(48 \%)$ studies. Smoking cessation was discussed in $17(74 \%)$ studies, advice about diet and medication was given in $13(57 \%)$ and $20(87 \%)$ studies, respectively, and coping with breathlessness was discussed in $13(57 \%)$ studies. In four $(17 \%)$ studies, the use of cognitive-behavioural therapy was mentioned, in six (26\%) motivational interviewing was used, and in $11(48 \%)$ and $18(78 \%)$ studies, respectively, goal setting or providing feedback to participants was used.

\section{Comparisons}

Self management was compared with usual care in 23 studies. In one of these studies (Coultas 2005a; Coultas 2005b), two intervention groups and one usual care group were used. In metaanalyses, both intervention groups were compared with the same usual care group, resulting in one extra comparison (Coultas 2005a; Coultas 2005b).

\section{Head-to-head studies}

\section{Participants and recruitment}

The six head-to-head studies included 115 (Stulbarg 2002), 17 (Nguyen 2009), 50 (Nguyen 2008), 98 (Sassi-Dambron 1995), 159 (Effing 2009; Effing 2011) and 60 (Kara 2004) participants (Table 1). Percentages of dropouts in these studies ranged from $0 \%$ to $26 \%$. Two studies recruited participants in the outpatient clinic of a hospital, one study recruited at a pulmonary rehabilitation site and three studies recruited in the community (e.g. via advertisements).

\section{Interventions}

Follow-up in the head-to-head studies was two months in one study $(17 \%)$, six months in three (50\%) studies and 12 months in two (33\%) studies. In three (50\%) studies, the intervention was offered in small groups, whereas in the other three $(50 \%)$ studies, the intervention was offered individually. An exercise programme was part of the intervention in five (83\%) studies, and an action plan was part of the intervention in two (33\%) studies. Further details on the contents of separate interventions in the studies without a usual care control group are provided in the characteristics of included studies tables (Included studies).

\section{Comparisons}

Six studies on 499 participants were head-to-head trials (i.e. they had no usual care control group; Table 2). One study assessed the mode of delivery by comparing a face-to-face self management intervention with an Internet-based self management intervention after six months of follow-up (Nguyen 2008). One study had three intervention groups, all of which included dyspnoea self management training combined with different levels of exercise (Stulbarg 2002). One study compared an exercise persistence intervention in which a mobile phone was used to coach the participant versus an exercise persistence intervention in which a mobile phone was used for self monitoring (Nguyen 2009). One study compared a dyspnoea management intervention versus general health education (Sassi-Dambron 1995), and another study compared a structured participant education intervention versus giving educational advice only (Kara 2004). Finally, one study used a $2 \times 2$ factorial design, meaning that two independent interventions were evaluated using one design. This study compared self management only versus self management including an action plan for self treatment (Effing 2009), and self management only versus self management including a community-based exercise programme (Effing 2011).

\section{Outcomes}

See Table 3 for details on the number of studies reporting outcomes of interest.

\section{Missing data}

We received replies from all study authors listed in the 'Acknowledgements' section. However, not all of these authors could provide the additional requested information.

\section{Excluded studies}

One hundred fifty-one studies were excluded on the basis of full-text review (Figure 1). The main reasons for exclusion were as follows: interventions were not related to COPD self management $(n=62)$; interventions contained only one of the components (e.g. only exercise, only smoking cessation) ( $\mathrm{n}=$ $27)$; the studied intervention was classified as hospital-based pulmonary rehabilitation $(n=26)$; the interventions contained only one contact moment between participant and healthcare provider $(n=5)$; the study included participants without clearly defined COPD or a mixed group of participants with several diseases $(n=13)$; the article was a protocol and results of the study were not available $(n=5)$; or the study was neither an RCT nor a CCT $(n=13)$. Further details can be found in the Characteristics of excluded studies.

\section{Risk of bias in included studies}

An overview of our risk of bias judgements is presented in Figure 2. 
Figure 2. Methodological quality summary: review authors' judgements about each methodological quality item for each included study.

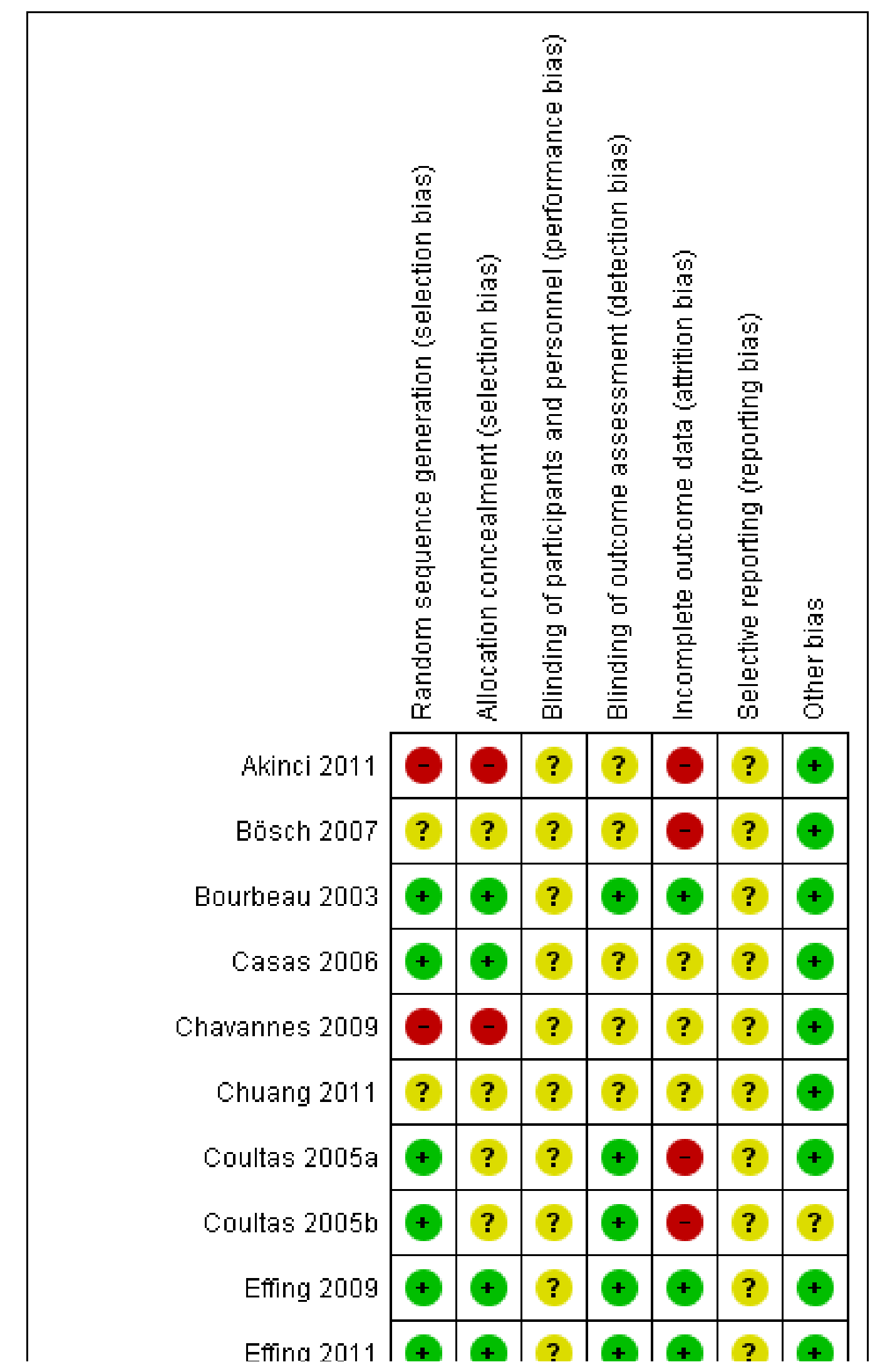


Figure 2. (Continued)

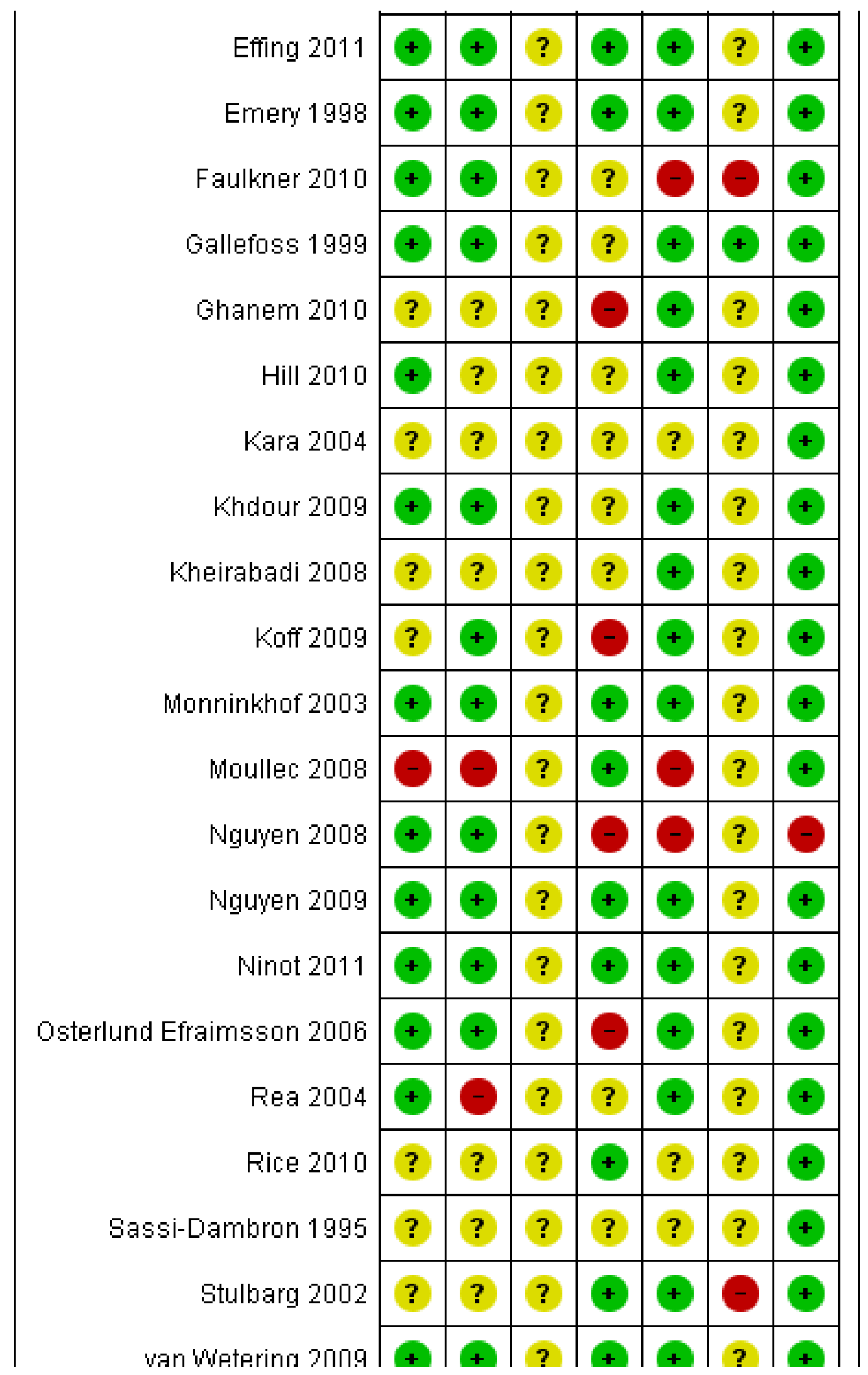


Figure 2. (Continued)

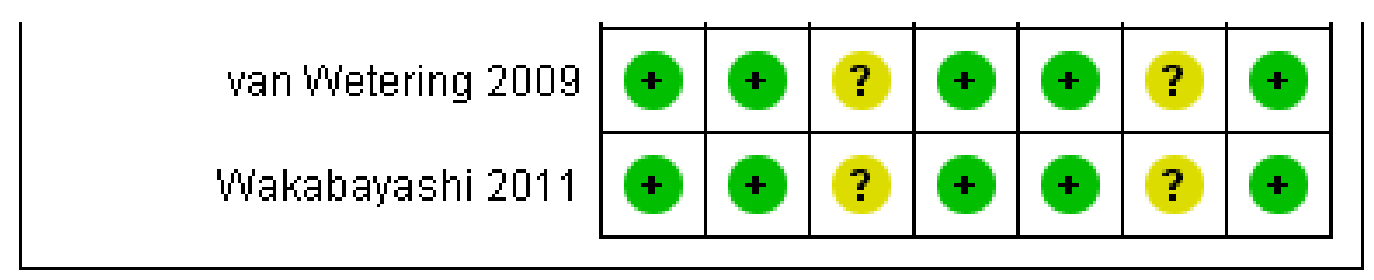

\section{Allocation}

In most studies, computer-generated random number lists or other computerised methods were used to generate allocation sequences, some with stratification for potential confounders leading to a low risk of bias in these studies $(n=17)$. Two studies were controlled clinical trials, and in one study group, assignment was based on place of residence; we judged that all would lead to a high risk of bias. In nine studies, information provided on generation of allocation sequences was not sufficient to allow judgement of the method.

In most studies, the allocation sequence was not known by investigators or staff, or randomisation was performed by an independent person not involved in the study, and the risk of bias was considered to be low $(n=15)$. In 10 studies, it was not reported who performed the randomisation or which method was used; in these studies, the risk of bias was unclear. In three studies, group allocation was based on place of residence, and risk of bias due to allocation concealment was considered to be high. Risk of bias was also considered to be high in another study, which was a clusterrandomised trial.

\section{Blinding}

Blinding of participants and personnel was not reported in any of the studies. Because of the nature of the intervention, it is difficult to blind participants and personnel to group assignment. Therefore, we assumed that in studies in which blinding was not reported, it was not performed. We evaluated as unclear the amount of bias that this would have caused.

When blinding of outcome assessment was not reported and we did not receive additional information from the study authors, we assumed that it was not done. In contrast to blinding of participants and personnel, seven studies reported blinding of outcome assessment and therefore were judged to have a low risk of bias. In five studies, outcome assessments were performed by independent research personnel who were not involved in the intervention, and so risk of bias was evaluated to be low. In four studies, outcome assessments were performed by study personnel who also provided the intervention or who were principal investigators, and the risk of bias was evaluated to be high.

\section{Incomplete outcome data}

In 17 studies, outcome data were complete or some outcome data were missing, but the quantities of missing data were equal in the intervention and control groups, and the reasons for missing data were comparable. In both situations, risk of bias was considered to be low. In one study, the quantities of missing outcome data were not equal in the intervention and control groups, and the reasons for this were not clear, leading to a high risk of bias. In five studies, the quantities of missing outcome data were $>25 \%$, and risk of bias was considered to be high. In six studies, information was insufficient to allow assessment of the risk of bias, and the risk of bias was therefore considered to be unclear.

\section{Selective reporting}

In most of the studies, it was difficult to determine whether outcomes were selectively reported because detailed study protocols often were not available. One paper reported an aim different from that reported in the original trial, and not all outcome measures were reported completely. The risk of bias in this study was therefore considered to be high. Other detected signs of selective reporting included missing domain scores on $\mathrm{HRQ}$ questionnaires and outcome measures that were reported for the short term but not for the longer term. Risk of bias for selective outcome reporting in these studies was considered to be unclear.

\section{Other potential sources of bias}

We additionally assessed the study of Rea et al (Rea 2004) on biases which are important in cluster-randomised trials. In Rea's study, general practices were randomly assigned to the interventions before the participants were included. For reasons unknown, the number of participants screened and included was lower in the intervention group than in the control group. The study authors state that baseline characteristics were not significantly different between groups. Therefore, risk of recruitment bias is unclear and risk of bias for baseline imbalance is low. The risk of bias due to loss of clusters is low because no clusters were lost after participant enrolment. Rea et al did not correct for clustering in their analyses, so risk of bias due to incorrect analysis is high.

No other potential sources of bias within studies were observed. Additionally, we explored reporting bias using funnel plots. We have created plots for our primary outcomes: HRQoL (Figure 3) and respiratory-related hospital admissions (Figure 4). The funnel plot of the MD in SGRQ total score per study plotted against the standard error of the MD seems to show a gap on the left side of the graph. This could indicate that smaller studies with effects in favour of the intervention group are less frequently published. The same could be suggested by the funnel plot of respiratory-related hospital admissions. Publication bias is just one reason for funnel plot asymmetry, so other study factors may have contributed to this. 
Figure 3. Funnel plot of comparison: 1 Self management versus control, outcome: $1.1 \mathrm{HRQOL}$ : SGRQ.

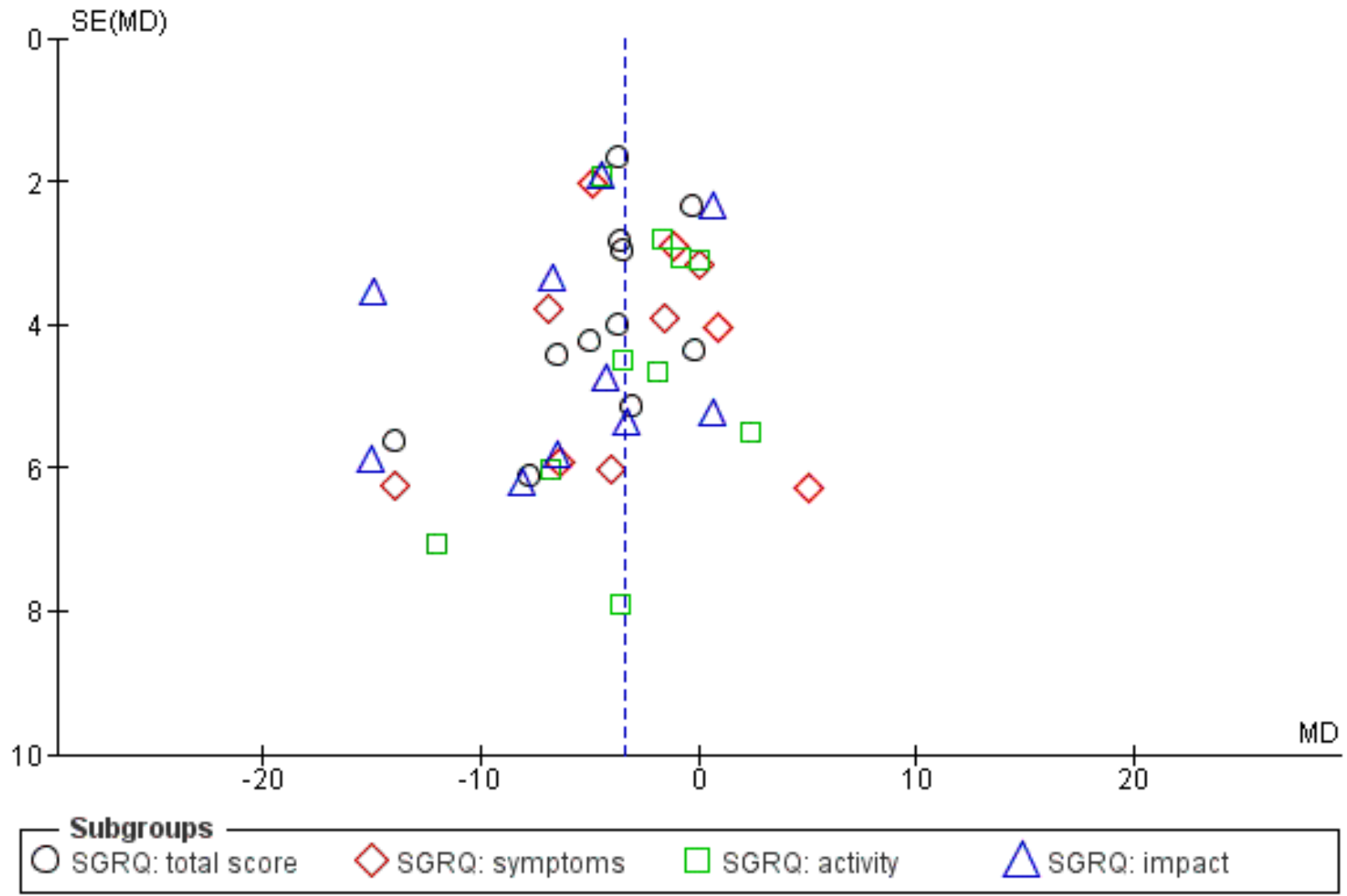


Figure 4. Funnel plot of comparison: 1 Self management versus control, outcome: 1.7 Respiratory-related hospital admissions.

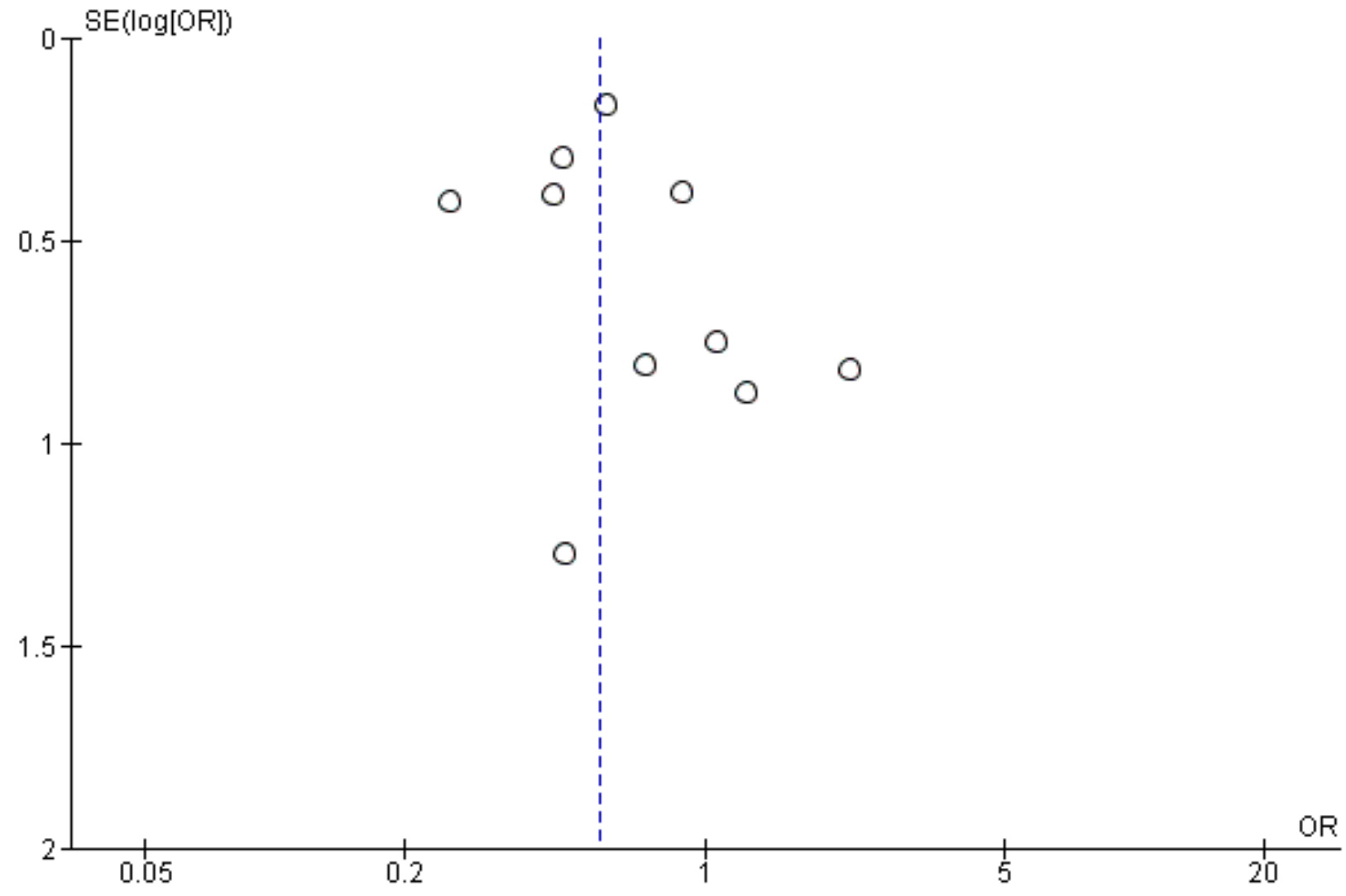

\section{Effects of interventions}

See: Summary of findings for the main comparison Self management compared with control for participants with chronic obstructive pulmonary disease

This review has been augmented with a 'Summary of findings' table, reflecting endpoints related to quality of life, healthcare use, exacerbations, dyspnoea, exercise capacity and mortality (Summary of findings for the main comparison). The table was generated with GRADEpro software. As stated earlier, 23 studies compared self management versus usual care, and six studies (with seven group comparisons) compared different components of self management head-to-head. The latter studies are referred to as "studies without usual care" in the section below. Because of heterogeneity in the interventions, we were not able to pool studies without a usual care control group in the meta-analyses; therefore the results of these studies are described only qualitatively. Also, in the primary meta-analysis, CCTs were excluded. Sensitivity analyses with inclusion of CCTs were performed.

\section{Health-related quality of life-studies with usual care}

COPD-specific HRQoL was measured by the SGRQ in 15 studies (Akinci 2011; Bourbeau 2003; Casas 2006; Chavannes 2009; Coultas 2005a; Coultas 2005b; Gallefoss 1999; Khdour 2009; Koff 2009; Monninkhof 2003; Moullec 2008; Ninot 2011; Osterlund Efraimsson 2006; Rice 2010; van Wetering 2009; Wakabayashi 2011). The studies of van Wetering et al (van Wetering 2009) and Österlund-Efraimsson et al (Osterlund Efraimsson 2006) used the SGRQ but provided insufficient data for inclusion in the meta-analysis. The studies of Akinci et al (Akinci 2011), Chavannes et al (Chavannes 2009) and Moullec et al (Moullec 2008) were CCTs and therefore were not included in the meta-analyses. Mean total scores of 10 studies could be included in the meta-analysis. All of these studies showed lower (meaning better quality of life) total scores in the intervention group compared with the control group. The MD of $-3.51(95 \% \mathrm{Cl}$ -5.37 to-1.65) was statistically significant at the $5 \%$ level (Analysis 1.1). Because Wakabayashi et al (Wakabayashi 2011) reported no domain scores, only mean domain scores of nine of the 10 studies could be included in the meta-analysis. MDs in domain scores of the SGRQ were statistically significant, with MDs of $-3.09(95 \% \mathrm{Cl}$ -5.42 to -0.77$),-2.75(95 \% \mathrm{Cl}-4.93$ to -0.56$)$ and $-5.71(95 \% \mathrm{Cl}-9.17$ to -2.25 ) for symptoms, activity and impact, respectively. The MD on the domain score of impact is considered to be clinically relevant because it reaches the minimal clinically important difference (MCID) of four points (Jones 2005). Meta-analyses of total scores and domain scores of symptoms and activity revealed only minimal heterogeneity, with 12 statistics ranging from $0 \%$ to $4 \%$. Moderate heterogeneity was detected in the meta-analysis of domain score impact $\left(I^{2}=51 \%\right)$. For SGRQ total score, we also performed a metaanalysis on the change from baseline (Analysis 1.2). This analysis showed a statistically significant difference between intervention and control groups, with a somewhat smaller MD of $-2.68(95 \% \mathrm{Cl}$ -4.16 to -1.20 ), indicating that the total score on the SGRQ of the intervention group decreased by 2.68 points more from baseline compared with the score of the control group. 
When we included the CCTs (Akinci 2011; Chavannes 2009; Moullec 2008) in secondary meta-analyses, effect sizes for both total and domain scores increased, and all reached the MCID of four points (Analysis 2.1). However, heterogeneity was high, with $\mathrm{I}^{2}$ statistics ranging from $60 \%$ to $79 \%$. In particular, the study of Moullec et al showed highly positive MDs in comparison with the other studies.

Van Wetering et al (van Wetering 2009) and Österlund-Efraimsson et al (Osterlund Efraimsson 2006) found statistically significantly lower total scores, so better HRQoL, in the intervention group compared with the control group. In the study of ÖsterlundEfraimsson (Osterlund Efraimsson 2006), all domain scores also favoured the intervention group, whereas van Wetering et al found no statistically significant differences in the symptom domain.

In two studies (Chavannes 2009; Kheirabadi 2008), COPD-specific HRQoL was measured by the Clinical COPD Questionnaire (CCQ), on which a lower score again indicates better HRQoL. On total score, Kheirabadi et al (Kheirabadi 2008) found no difference, and Chavannes et al (Chavannes 2009) reported a lower score in the intervention group $(0.92 \pm 0.72)$ than in the control group (1.74

$\pm 0.95)$. Domain scores were reported only by Kheirabadi et al (Kheirabadi 2008) and were comparable between groups after three months of follow-up.

Three studies measured HRQoL by means of the Chronic Respiratory Disease Questionnaire (CRQ) (Faulkner 2010; Ghanem 2010; Rea 2004). Rea et al (Rea 2004) did not report standard deviations (SDs) and therefore could not be included in a metaanalysis, leaving an insufficient number of studies to perform a meta-analysis. In the study of Rea et al (Rea 2004), the dimensions of fatigue and mastery showed statistically significantly higher scores, meaning better $\mathrm{HRQ}$ oL, in the intervention group (17.7 and 21.4, respectively) than in the control group (15.7 and 20.7, respectively) after 12 months of follow-up. The study of Ghanem et al (Ghanem 2010) found statistically significantly higher scores in the intervention group than in the control group on all four domains (dyspnoea $19.6 \pm 5.2$ vs $13.5 \pm 4.3$, fatigue $17.4 \pm 5.4$ vs $13.2 \pm 5.1$, emotion $33.5 \pm 7.2$ vs $29.7 \pm 11.4$, mastery values not reported). However, Faulkner et al (Faulkner 2010) found no significant differences between intervention and control groups on the CRQ.

Three studies measured generic HRQoL using the Short Form-36 (SF-36) (Coultas 2005a; Coultas 2005b; Ghanem 2010; Rea 2004). Mean values and SDs were available only for the studies of Coultas et al (Coultas 2005a; Coultas 2005b) and Ghanem et al (Ghanem 2010); therefore, it was not considered appropriate to perform a meta-analysis. No differences were noted between intervention and control groups at the end of follow-up in the studies of Rea et al (Rea 2004) and Coultas et al (Coultas 2005a; Coultas 2005b). In the study of Ghanem et al (Ghanem 2010), differences between intervention and control groups were reported, but these were already present at baseline. Therefore, the study authors mentioned significant improvement in the scales of physical functioning, role-physical, pain, vitality and role of emotions only in the intervention group. In the control group, no improvements were observed.

Generic HRQoL and health status were further measured using the short version of the questionnaire validated by the WHO (WHOQOL-BREF) in the study of Moullec et al (Moullec 2008), the Illness Intrusiveness Rating Scale (IIRS) in the study of
Coultas et al (Coultas 2005a; Coultas 2005b), the Nottingham Health Profile (NHP) in the study of Ninot et al (Ninot 2011) and the Sickness Impact Profile (SIP) in the study of Emery et al (Emery 1998). Moullec et al (Moullec 2008) found statistically significantly higher scores on the physical domain of the WHOQOLBREF in the intervention group compared with the control group after 12 months of follow-up (13.4 \pm 1.9 vs $9.4 \pm 2.2$ ). No statistically significant differences were noted in the other domains. Coultas et al (Coultas 2005a; Coultas 2005b) found statistically significant improvement in IIRS following nurseassisted collaborative management compared with the usual care group. Ninot et al (Ninot 2011) found significant differences in NHP between the groups, in favour of the intervention group, on the energy and emotional reaction dimensions of the NHP, after adjustment for baseline values. Finally, Emery et al (Emery 1998) found significant improvement in total function in the control group as measured by the SIP, whereas the intervention group showed no change.

\section{Health-related quality of life-head-to-head studies}

Only the study of Nguyen et al(Nguyen 2009) measured HRQoL using the SGRQ and found no between-group differences in SGRQ total score. Three studies measured HRQoL using the diseasespecific CRQ. Nguyen et al (Nguyen 2008) observed statistically significant improvement after six months of follow-up in both study groups in total score, dyspnoea, fatigue and mastery score. Stulbarg et al (Stulbarg 2002) found statistically significantly greater improvement in mastery and dyspnoea in the group that received the most intensive exercise training compared with the groups that received less intense or no training, in addition to dyspnoea self management. Effing et al (Effing 2011) found a significantly higher CRQ dyspnoea score among individuals who participated in a community-based exercise programme in addition to self management compared with those who participated only in self management. No between-group differences were observed in other CRQ components. In the study of Effing et al (Effing 2009) evaluating self treatment of exacerbation, no between-group differences in CRQ components were found. In the studies of Effing et al (Effing 2009; Effing 2011), HRQoL was also measured with the CCQ, but no between-group differences were reported.

The SF-36 was used in three studies. Stulbarg et al (Stulbarg 2002) found no statistically significant differences between groups in mental and physical component scores after 12 months of followup. The study of Nguyen et al (Nguyen 2008) reported statistically significant improvement in both study groups on the SF-36 physical component scale but not on the mental component scale. In contrast, Nguyen et al (Nguyen 2009) found no between-group differences in either physical or mental component scores of the SF-36.

Sassi-Dambron et al (Sassi-Dambron 1995) measured quality of life using the quality of well-being scale and found no differences among the three intervention groups.

\section{Hospital admissions-studies with usual care}

Respiratory-related hospital admissions were reported in 12 studies. Data on nine of these studies were suitable for inclusion in a meta-analysis (Bourbeau 2003; Coultas 2005a; Coultas 2005b; Gallefoss 1999; Khdour 2009; Koff 2009; Monninkhof 2003; Ninot 2011; Rea 2004; Rice 2010). A clinically relevant and statistically significant reduction in the probability of at least one respiratory- 
related hospital admission was noted among participants receiving self management compared with those receiving usual care, with an OR of $0.57(95 \% \mathrm{Cl} 0.43$ to 0.75$)$. Heterogeneity was low, with an $\mathrm{I}^{2}$ of $13 \%$ (Analysis 1.7). Study-specific numbers needed to treat for a beneficial outcome (NNTBs) ranged from eight ( $95 \% \mathrm{Cl}$ five to 14$)$ to 26 (95\% Cl 19 to 45$)$. Differences between studies might be explained by differences in baseline risk, severity of disease and duration of follow-up (Table 4). Over one year of follow-up, eight $(95 \% \mathrm{Cl}$ five to 14$)$ participants with a high baseline risk of respiratory-related hospital admission needed to be treated to prevent one participant with at least one hospital admission (Figure 5), and 20 (95\% Cl 15 to 35) participants with a low baseline risk of hospitalisation needed to be treated to prevent one participant with at least one respiratory-related hospital admission (Figure 6). The studies of van Wetering et al (van Wetering 2009) and Bösch et al (Bösch 2007) could not be included in the meta-analysis because the trialists could not provide the numbers of participants with at least one hospital admission. Van Wetering et al (van Wetering 2009) found a mean number of hospital admissions for COPD of $0.36 \pm$ 1.00 in the intervention group and $0.40 \pm 0.78$ in the control group. The mean number of COPD-related hospitalisations significantly decreased during follow-up in the intervention group in the study of Bösch et al to $0.3 \pm 0.6$, and was constant in the control group at $0.6 \pm 0.7$.

Figure 5. High-risk participants: In the usual care group, $\mathbf{5 1}$ of 100 people had at least one respiratory-related hospital admission over 52 weeks, compared with 37 (95\% CI 31 to 44) of 100 for the self management group.

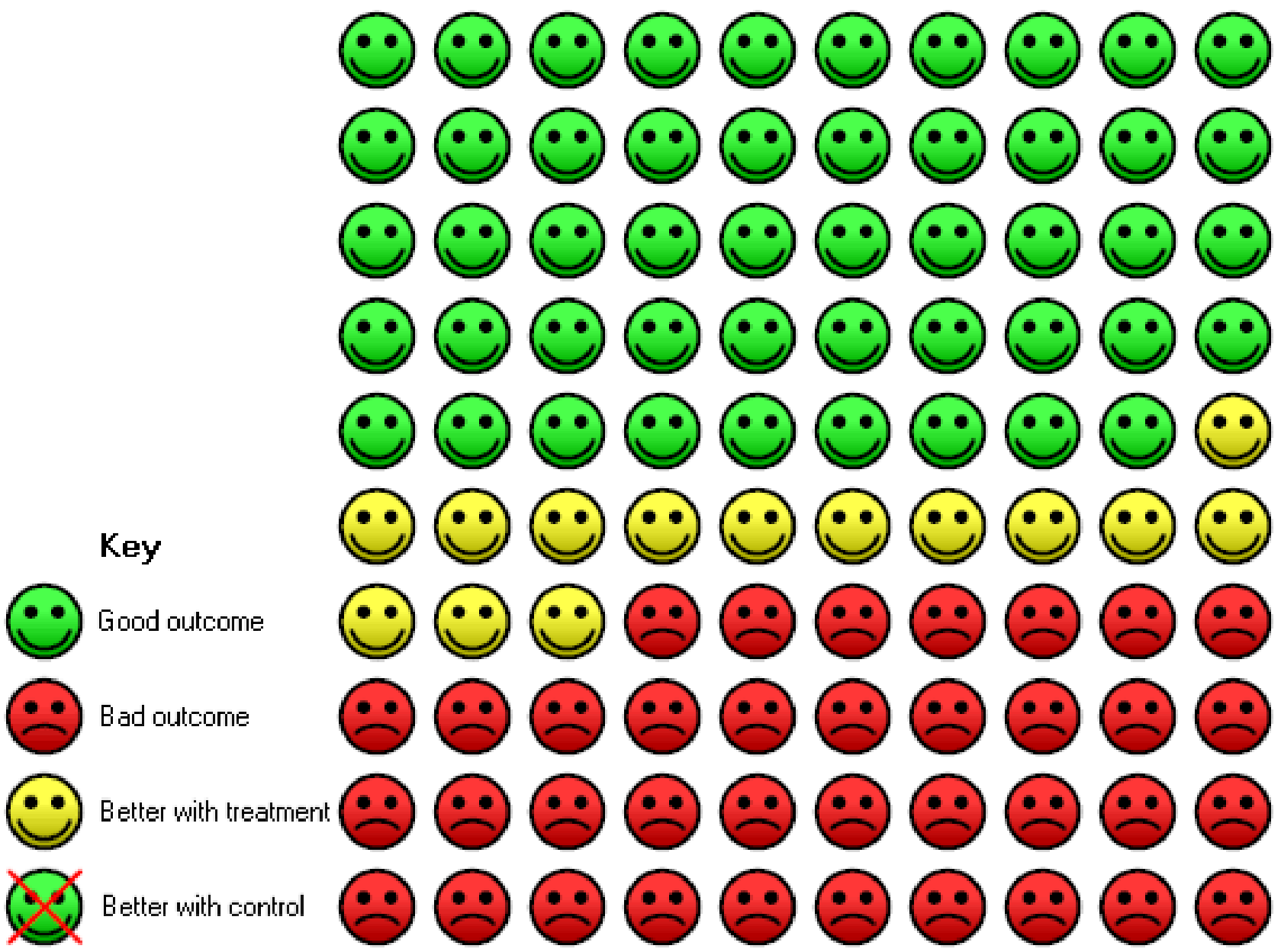


Figure 6. Low-risk participants: In the usual care group, 13 of 100 people had at least one respiratory-related hospital admission over 52 weeks, compared with 8 (95\% Cl 6 to 10) of 100 for the self management group.

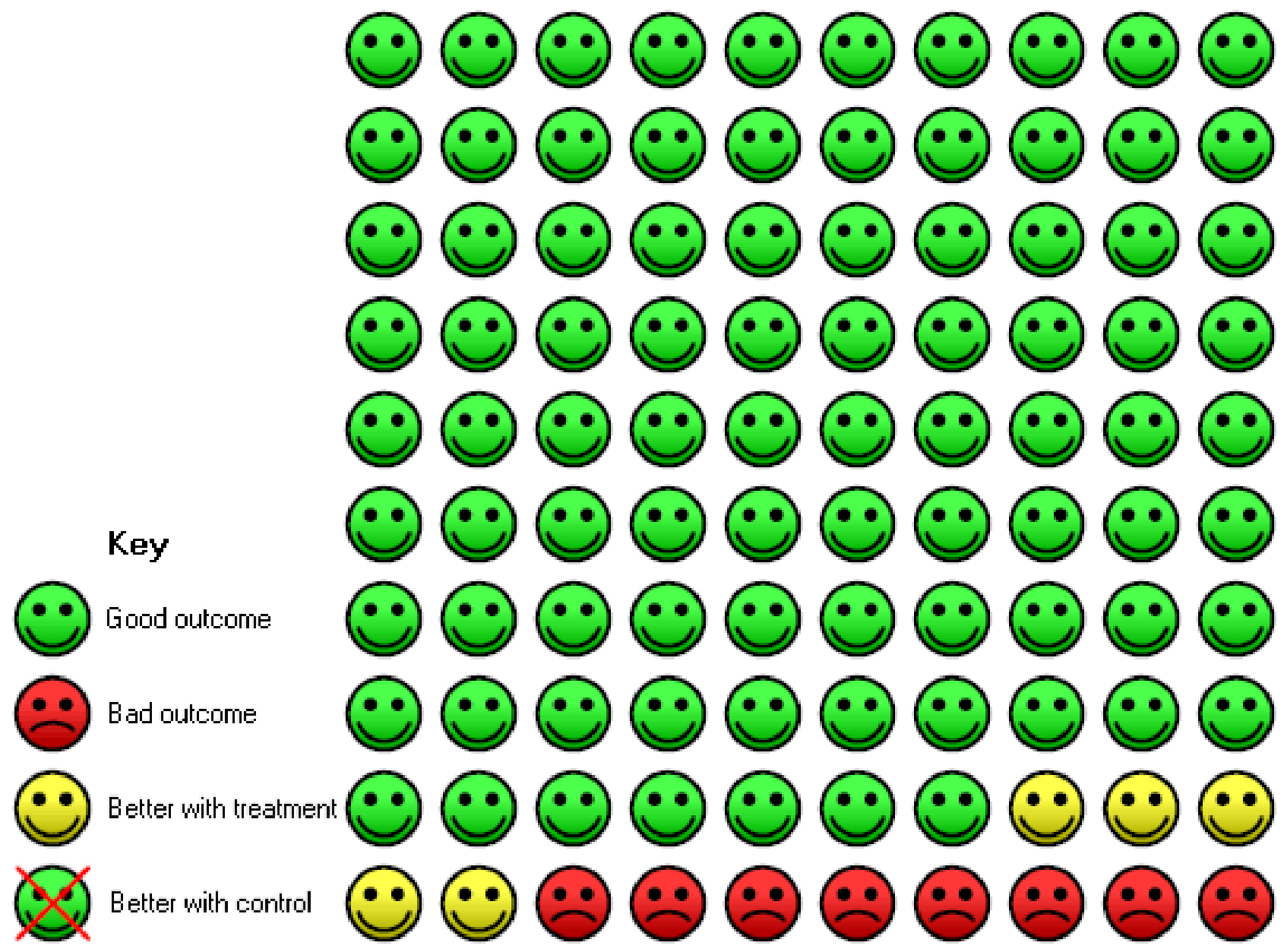

The CCT of Moullec et al reported zero respiratory-related hospital admissions among 11 participants in the intervention group and in two of 16 participants in the control group. We performed a sensitivity analysis by including this study in the meta-analysis on respiratory-related hospital admissions, and OR and heterogeneity were comparable with the primary analysis $(0.57,95 \% \mathrm{Cl} 0.44$ to $0.73 ;\left.\right|^{2}=6 \%$ ) (Analysis 2.3).

Six studies were included in the meta-analysis on all-cause hospital admissions (Casas 2006; Coultas 2005a; Coultas 2005b; Khdour 2009; Ninot 2011; Rea 2004; Rice 2010). The OR of having at least one all-cause hospital admission of $0.60(95 \% \mathrm{Cl} 0.40$ to 0.89$)$ was statistically significant in favour of the self-management group (Analysis 1.8). The studies of van Wetering et al (van Wetering 2009), Wakabayashi et al (Wakabayashi 2011) and Chuang et al (Chuang 2011) could not be included in the meta-analysis for the reason stated in the paragraph above. Van Wetering et al (van Wetering 2009) found a mean number of hospitalisations of $0.75 \pm 1.29$ in the intervention group and $0.96 \pm 1.35$ in the control group after 24 months of follow-up. Wakabayashi et al (Wakabayashi 2011) found $0.07 \pm 0.3$ in the intervention group and $0.19 \pm 0.8$ in the control group after 12 months of follow-up. Chuang et al (Chuang 2011) reported fewer all-cause hospital admissions in the intervention group than in the control group ( $40 \pm 27$ vs $57 \pm 27$ ); however, this difference was not statistically significant.

The CCT of Moullec et al reported three all-cause hospital admissions among 11 participants in the intervention group and four among 16 participants in the control group. We performed a sensitivity analysis by including this CCT in the meta-analysis, and the OR was comparable with that of the primary analysis: 0.61 (95\% $\mathrm{Cl} 0.42$ to 0.89 ), with an $\mathrm{I}^{2}$ of $41 \%$ (Analysis 2.4 ).

\section{Hospital admissions-head-to-head studies}

Effing et al (Effing 2009) observed 14 all-cause hospital admissions in the self treatment intervention group and 24 hospital admissions in the self management group, but this difference was not statistically significant. Effing et al (Effing 2011) observed 15 hospital admissions in the exercise intervention group and 17 hospital admissions among participants who received solely self management. Stulbarg et al (Stulbarg 2002) reported no differences between groups in the number of respiratory-related hospitalisations after one year of follow-up.

\section{Hospitalisation days-studies with usual care}

The number of respiratory-related hospitalisation days was reported in five studies. The studies of Gallefoss et al (Gallefoss 1999), Ninot et al (Ninot 2011) and van Wetering et al (van Wetering 2009) were included in a meta-analysis. No difference in mean number of hospital days was found (MD $0.33,95 \% \mathrm{Cl}-1.01$ to 1.66 ) 
(Analysis 1.9). Moullec et al (Moullec 2008) reported zero hospital days in the intervention group; therefore, these data could not be included in a sensitivity analysis with CCTs. However, these investigators reported a statistically significantly lower number of hospital days in the intervention group compared with the control group (zero vs $6.4 \pm 14.5$ ). Rea et al (Rea 2004) did not report SDs and therefore could not be included in the meta-analysis. Whereas Rea et al (Rea 2004) reported no significant differences between groups in the number of bed days per participant per year, a statistically significant decrease in days per participant per year from 12 months before the trial to 12 months during the trial was noted in the intervention group; in contrast, a statistically significant increase was evident in the control group.

The number of all-cause hospitalisation days was assessed in eight studies (Bourbeau 2003; Chuang 2011; Khdour 2009; Moullec 2008; Ninot 2011; Rea 2004; Rice 2010; van Wetering 2009). Five studies (Bourbeau 2003; Khdour 2009; Ninot 2011; Rice 2010; van Wetering 2009) were included in the meta-analysis, and we found no statistically significant difference between intervention and control group (MD -1.39, 95\% Cl -3.19 to 0.41) (Analysis 1.10). The study of Rea et al (Rea 2004) could not be included in the metaanalysis because of the lack of SDs. The mean number of bed days in the study of Rea et al (Rea 2004) was lower in the intervention group than in the control group (3.2 vs 6.8); however, this difference did not reach statistical significance. Chuang et al (Chuang 2011) reported a lower number of hospitalisation days in the intervention group compared with the control group ( $115 \pm 105$ vs $190 \pm 110$ ), but this difference was not statistically significant.

The CCT of Moullec et al reported a lower number of all-cause hospital days in the intervention group $(1.5 \pm 3.4)$ than in the control group $(7.9 \pm 16.1)$. We performed a sensitivity analysis by including this CCT in the meta-analysis, and the MD was -1.62 (95\% Cl -3.42 to 0.18 ), with heterogeneity comparable with that of the primary analysis (Analysis 2.5).

\section{Hospital days-head-to-head studies}

None of the studies without usual care reported the number of hospital days.

\section{Emergency department visits-studies with usual care}

Four studies (Coultas 2005a; Coultas 2005b; Khdour 2009; Koff 2009; Rice 2010) reported respiratory-related emergency department (ED) visits, but data could not be combined in a meta-analysis because different methods were used to report the outcome. Koff et al (Koff 2009) reported one (5.3\%) visit in the intervention group and three (15.8\%) in the control group after three months of followup. Khdour et al (Khdour 2009) reported the total number of COPDrelated visits and found a statistically significantly lower number in the intervention group than in the control group (40 vs 80 ) after 12 months of follow-up. Rice at al (Rice 2010) found a significant difference between intervention and control groups $(20.8,95 \% \mathrm{Cl}$ 14.5 to 27.1 vs $42.4,95 \% \mathrm{Cl} 31.4$ to 53.4 , per 100 person-years) after 12 months of follow-up. In contrast, Coultas et al (Coultas 2005a; Coultas 2005b) reported no differences between groups in COPDrelated visits after six months of follow-up.

ED visits for all causes were assessed in five studies (Bourbeau 2003; Chuang 2011; Rea 2004; Rice 2010; Wakabayashi 2011), which also could not be included in a meta-analysis because different methods were used to report the outcomes. Rea et al (Rea 2004) observed five $(6 \%)$ visits in the intervention group and seven (13.5\%) visits in the control group after 12 months of follow-up. Bourbeau et al (Bourbeau 2003) reported a significant treatment effect in favour of the intervention group (2.5 vs 3.2 per person per year) after 24 months. Rice et al (Rice 2010) found significantly fewer visits in the intervention group than in the control group (67.0 vs 91.2 per 100 person-years). In the study of Wakabayashi et al (Wakabayashi 2011), no significant changes in the frequency of ED visits were found during follow-up. Chuang et al (Chuang 2011) reported fewer ED visits in the intervention group than in the control group $(92 \pm 42$ vs $71 \pm 29$ ), but this difference was not statistically significant.

\section{Emergency department visits-head-to-head studies}

Effing et al (Effing 2009) reported a mean number of all-cause ED visits of $0.26 \pm 0.61$ per person per year in the self treatment group, and $0.53 \pm 1.3$ per person per year in the group receiving only self management. Effing et al (Effing 2011) reported $0.44 \pm 0.92$ $E D$ visits per person per year in the group participating in the self management exercise programme, and $0.41 \pm 1.18$ visits per person per year in the group that received solely self management. These differences were not statistically significant.

\section{Use of other healthcare facilities-studies with usual care}

Doctor and nurse visits were reported in eight studies (Bourbeau 2003; Chuang 2011; Coultas 2005a; Coultas 2005b; Gallefoss 1999; Khdour 2009; Monninkhof 2003; Moullec 2008; van Wetering 2009). Only two of these studies (Coultas 2005a; Coultas 2005b; Gallefoss 1999) (three group comparisons) could be included in a metaanalysis; therefore a meta-analysis was considered to be not appropriate. After one year of follow-up, Gallefoss et al (Gallefoss 1999) found a statistically significantly lower number of general practitioner consultations in the in the intervention group $(0.5 \pm$ $0.9)$ compared with the control group ( $3.4 \pm 5.5)$. Coultas et al (Coultas 2005a; Coultas 2005b) found no statistically significant differences in doctor visits between any of the intervention groups and the control group. Khdour et al (Khdour 2009) reported a total number of 267 visits to the general practitioner in the intervention group and 258 visits in the control group. Whereas the number of scheduled general practice (GP) visits in this study was lower in the intervention group (145 vs 183), the number of unscheduled visits was somewhat higher in the intervention group (119 vs 75 ). Van Wetering et al (van Wetering 2009) reported the mean number of GP visits over two years of follow-up; numbers in both study groups were comparable (intervention 7.2 \pm 7.0 ; control 7.9 \pm 8.1 ). Chuang et al (Chuang 2011) reported statistically significantly more GP visits in the intervention group than in the control group (683 \pm 123 vs $887 \pm 95$ ). The studies of Bourbeau et al (Bourbeau 2003) and Monninkhof et al (Monninkhof 2003) could not be included in the meta-analysis because of the lack of SDs, but both showed a reduction in unscheduled doctor and nurse visits per person per year, with differences of -0.7 and -0.4 , respectively. Moullec et al found a statistically significant difference between intervention and control groups in home visits by the GP $(0.0$ vs $0.9 \pm 3.0)$ but found no between-group differences in consultations with the GP or in consultations with a lung specialist.

\section{Use of other healthcare facilities-head-to-head studies}

Effing et al (Effing 2011) (evaluating the self management exercise component) reported no between-group differences in total healthcare contacts. Effing et al (Effing 2009) reported a nonstatistically significant reduction in healthcare contacts in the self 
treatment group compared with the self management group (5.37 \pm 3.75 vs $6.51 \pm 3.89$ contacts per participant per year). Total healthcare contacts included consults with the GP, outpatient visits and ED visits.

\section{Number and severity of exacerbations-studies with usual care}

In three studies (Bourbeau 2003; Monninkhof 2003; van Wetering 2009), the numbers of exacerbations were reported. Van Wetering et al observed 3.02 exacerbations per participant in the intervention group and 2.18 in the control group after 24 months of follow-up. This difference was not statistically significant. Reported follow-up in the studies of Bourbeau et al (Bourbeau 2003) and Monninkhof et al (Monninkhof 2003) was 12 months. Whereas Bourbeau et al (Bourbeau 2003) found 299 exacerbations in the intervention group and 362 exacerbations in the control group, Monninkhof et al (Monninkhof 2003) found 360 exacerbations in the intervention group and 177 exacerbations in the control group.

\section{Number and severity of exacerbations-head-to-head studies}

Nguyen et al (Nguyen 2009) reported that four participants experienced an exacerbation that required treatment with antibiotics or oral prednisone. In an earlier study, Nguyen et al (Nguyen 2008) reported that they registered 11 exacerbations in 10 participants; however, they also stated that this number was too small to allow group comparisons. In the study of Effing et al (Effing 2009), frequency, severity and number of exacerbations were assessed. Investigators found no between-group differences in the mean number of exacerbations $(3.5 \pm 2.7$ in both study groups), nor in the mean severity of an exacerbation, over one year. However, participants in the self treatment group did report fewer exacerbation days (median 31, interquartile range (IQR) 8.9 to 67.5) compared with the control group (median 40, IQR 13.3 to 88.2). This difference was statistically significant in participants with a relatively high number of exacerbation days. In the study of Effing et al (Effing 2011), again no statistically significant betweengroup differences were found in mean numbers of exacerbations (3.3 \pm 2.5 vs $3.8 \pm 2.8$ ). Stulbarg et al (Stulbarg 2002) reported no differences between groups in numbers of exacerbations after one year of follow-up.

\section{Courses of oral steroids-studies with usual care}

Three studies reported the use of oral corticosteroids for respiratory problems (Gallefoss 1999; Rea 2004; Rice 2010) and could be included in a meta-analysis. Based on these three studies, the probability of having at least one course of oral steroids was higher in the self management group compared with the control group, with an OR of $4.42(95 \% \mathrm{Cl} 0.39$ to 50.10$)$. However, this OR was not statistically significant ( $P$ value 0.23 ), and heterogeneity was high $\left(1^{2}=96 \%\right)$ (Analysis 1.13). The outlier in this meta-analysis was the study by Rice et al (Rice 2010), which included many more participants than were included in the studies of Gallefoss et al (Gallefoss 1999) and Rea et al (Rea 2004). In addition, the proportion of participants with at least one course of oral steroids in the self management group of the study of Rice et al is relatively high (97.6\%) compared with the studies of Gallefoss et al (69.2\%) and Rea et al (47.6\%). In the case that an event is common, the OR is an overestimation of the risk ratio and should be interpreted with caution. The latter is the case in the study of Rice et al, in which an OR of 32.7 was found. This meta-analysis therefore should be interpreted with caution.

\section{Courses of antibiotics-studies with usual care}

The use of antibiotics for respiratory problems was reported by three studies (Gallefoss 1999; Rea 2004; Rice 2010); however, the number of people with at least one course of antibiotics was available for only two studies (Rea 2004; Rice 2010); therefore a meta-analysis was not justified. Rea et al (Rea 2004) reported fewer participants receiving at least one course of antibiotics in the intervention group than in the control group (59\% vs $69 \%$ ), whereas Rice et al (Rice 2010) reported the opposite (92\% vs 56\%). Bösch et al (Bösch 2007) reported a significant reduction in the mean number of exacerbation-related antibiotic courses in the intervention group, with no changes observed in the control group. Khdour et al (Khdour 2009) reported mean number of oral steroids and antibiotic courses combined and found a significant difference, with less use in the intervention group compared with the control group (3.08, $95 \% \mathrm{Cl} 2.57$ to 3.59 vs $4.03,95 \% \mathrm{Cl} 3.37$ to 4.69 ).

\section{Courses of oral steroids or antibiotics-head-to-head studies}

Nguyen et al (Nguyen 2009) reported that four (23.5\%) participants experienced an exacerbation that required treatment with antibiotics or oral prednisone. In the study of Effing et al (Effing 2009), the median number of prednisolone (2.6, IQR 1.0 to 5.0 vs 1.7, IQR 1.0 to 3.2 ) and antibiotic courses (2.0, IQR 0.8 to 4.0 vs 1.1 , IQR 0.0 to 2.9 ) was higher in the self treatment group than in the group that received only self management. The difference in prednisolone courses was borderline nonstatistically significant, whereas the difference in antibiotic courses was borderline statistically significant.

\section{Use of rescue medication-studies with usual care}

Gallefoss et al (Gallefoss 1999) reported the use of short-acting $\beta_{2}$-agonists as rescue medication. Use of rescue medication was coded as defined daily dosages (DDDs) for comparison of medications within the same chemical therapeutic group. In this study, participants receiving self management used statistically significantly less rescue medication (median DDD 125, IQR 100 to 344) than the control group (median DDD 209, IQR 150 to 550). Rice et al (Rice 2010) reported the use of short-acting $\beta_{2}$-agonists as the mean number of metered-dose inhalers and found no statistically significant differences between intervention and control groups $(6.4 \pm 8.3$ vs $5.6 \pm 8.0)$.

\section{Use of rescue medication-head-to-head studies}

None of the studies without usual care reported the use of rescue medication.

\section{Symptoms-studies with usual care}

The effect of self management education on dyspnoea as measured by the (m)MRC was examined in six studies (Bösch 2007; Casas 2006; Chavannes 2009; Faulkner 2010; van Wetering 2009; Wakabayashi 2011). Three studies assessed dyspnoea using the MRC (Casas 2006; Chavannes 2009; Faulkner 2010), and three studies assessed dyspnoea using the modified version of the MRC (mMRC) (Bösch 2007; van Wetering 2009; Wakabayashi 2011). The outcomes of three studies were combined in a meta-analysis (Analysis 1.15). A statistically significant difference in favour of the intervention group was found, with an MD of -0.83 ( $95 \% \mathrm{Cl}-1.36$, to -0.30$)$. It is unclear whether this difference is also clinically relevant. 
When we included the CCT of Chavannes et al in the meta-analysis, the MD decreased to $-0.67(95 \% \mathrm{Cl}-1.19$ to -0.16$)$ and heterogeneity was comparable with the primary analysis (Analysis 2.6).

The study of Wakabayashi et al could not be included in the metaanalysis because of irregularities in the SD; however, investigators reported an improvement in $\mathrm{mMRC}$ score in the intervention group and a worsening in the usual care group after 12 months of followup. Between-group differences were not statistically significant. Van Wetering et al (van Wetering 2009) reported only changes from baseline and therefore could not be included in the meta-analysis. In this study, a statistically significant between-group difference in change from baseline MRC dyspnoea score of $0.21 \pm 0.10$ units in favour of the intervention group was found. Akinci et al (Akinci 2011) and Moullec et al (Moullec 2008) assessed dyspnoea using the Baseline Dyspnea Index (BDI) and a visual analogue scale (VAS) score for dyspnoea, respectively. In the study of Akinci et al (Akinci 2011), dyspnoea increased significantly in the intervention group, whereas it did not change in the control group after three months of follow-up. Moullec et al (Moullec 2008) observed a lower mean VAS score after 12 months of follow-up in the intervention group (1.3 \pm 1.2) compared with the control group $(4.0 \pm 3.0)$ but did not report statistical significance for between-group differences.

In the study of Monninkhof et al (Monninkhof 2003), no significant between-group differences were seen in mean symptom scores for breathlessness and sputum production over two-week periods. However, small differences in mean cough and sputum colour scores favoured the intervention group. Although these differences reached borderline significance, the study authors stated that differences probably were not clinically relevant. Finally, in the study by Bourbeau et al (Bourbeau 2003), symptoms during exacerbations were scored (breathlessness, sputum volume and sputum colour), but no significant differences were found between intervention and control groups.

\section{Symptoms-head-to-head studies}

Effing et al (Effing 2011) measured dyspnoea with the MRC and found no differences in mean values between groups $(2.2 \pm 1.1$ vs $2.5 \pm 1.2$ ). Stulbarg et al (Stulbarg 2002) assessed dyspnoea using the University of California San Diego (UCSD) Shortness of Breath Questionnaire (SOBQ) and the Transitional Dyspnea Index (TDI). For the total group, dyspnoea as measured with the SOBQ significantly improved after two months of follow-up. No statistically significant differences were observed on the TDI, in spite of improvements of 1.5 to 2.0 units in the three groups. SassiDambron et al (Sassi-Dambron 1995) measured dyspnoea using the TDI, the SOBQ, the American Thoracic Society Dyspnea Scale (ATS-DS), the Oxygen Cost Diagram (OCD), a VAS scale and the Borg Scale of Perceived Dyspnea. On the SOBQ, dyspnoea in both groups improved significantly over time. Furthermore, the group receiving dyspnoea management improved significantly over time on the TDI compared with the group that received solely education. The other measures did not change.

\section{Anxiety and depression-studies with usual care}

Faulkner et al (Faulkner 2010) measured anxiety and depression using the Hospital Anxiety and Depression Scale (HADS). They found no significant differences in anxiety $(3.8 \pm 3.6$ vs $3.3 \pm 2.1)$ or depression ( $2.6 \pm 2.4$ vs $2.9 \pm 2.6)$ between intervention and control groups. Emery et al (Emery 1998) extensively assessed anxiety and depression. Depression was assessed by the Center for Epidemiological Studies-Depression inventory (CES-D), the depression subscale of the Hopkins Symptom Checklist and the Bradburn Affect-Balance Scale. Anxiety was assessed by the anxiety subscales of the State-Trait Anxiety Inventory (STAI) and the Hopkins Symptom Checklist. No statistically significant differences were found between education and stress management and waiting list groups after 10 weeks of follow-up (Emery 1998).

\section{Anxiety and depression-head-to-head studies}

Effing et al (Effing 2009; Effing 2011) assessed anxiety and depression using the HADS. In both group comparisons, no statistically significant between-group differences were found. Sassi-Dambron et al (Sassi-Dambron 1995) assessed anxiety using the STAI-Anxiety and Depression along with the CES-D and found no statistically significant between-group differences after six months of follow-up.

\section{Self-efficacy-studies with usual care}

Faulkner et al (Faulkner 2010) measured self efficacy using the Depression Coping Self-Efficacy Scale, but the results of the assessment were not reported.

\section{Self-efficacy-head-to-head studies}

Kara et al (Kara 2004) assessed disease-specific self efficacy using the COPD Self-Efficacy Scale (CSES). In the intervention group, statistically significant improvements in total score and in all domains of the CSES were noted in the intervention group. Differences varied from 0.95 to 1.46 points after two months of follow-up. In the intervention group, only total scores and scores on the domains of weather/environment and behavioural risk factors were statistically significantly improved. Stulbarg et al (Stulbarg 2002) measured two types of self efficacy after two months of follow-up. Self-efficacy for walking was measured with the SelfEfficacy for Walking Questionnaire (SEWQ), and self efficacy for managing shortness of breath was measured using the CSES and the Self-Efficacy for Managing Shortness of Breath instrument (SEMSOB). Self-efficacy for walking improved over time for all intervention groups, but no between-group differences were noted. No improvements were observed for self efficacy for managing shortness of breath as measured by the CSES. In contrast, the SEMSOB showed statistically significant improvement in all groups. The SEMSOB showed no between-group differences in changes over time.

Nguyen et al (Nguyen 2009) measured self efficacy for overcoming barriers to exercise with the Exercise Barriers Efficacy Scale. No significant between-group differences were observed. Nguyen et al (Nguyen 2008) assessed self efficacy for managing dyspnoea with a single question ("How confident are you that you can keep your shortness of breath from interfering with what you want to do?") using a 0 to 10-point response scale. In both intervention groups, self efficacy improved over six months of follow-up, but no between-group differences were found.

\section{Days lost from work-studies with usual care}

Three studies reported days lost from work (Gallefoss 1999; Monninkhof 2003; van Wetering 2009). Gallefoss et al reported no significant differences between groups. Almost $50 \%$ of participants with COPD in this study were employed. Only three of 14 participants in the intervention group and two of 13 in the control group reported absence from work. Monninkhof et al (Monninkhof 
2003) used the term 'restrictive activity days', defined as days on which work was missed or days on which activities were significantly reduced because of health problems. A reduction in the average number of restricted activity days was seen in the education group compared with the control group ( $4.1 \pm 4.2$ vs 5.3 \pm 5.3 ), but no significant between-group differences were detected. Van Wetering et al (van Wetering 2009) provided self reported hours unable to work and found a mean time of $22 \pm 89$ hours in the intervention group and a mean time of $6.8 \pm 40$ hours in the control group during 24 months of follow-up.

\section{Days lost from work-head-to-head studies}

None of the studies without usual care reported days lost from work.

\section{Lung function-studies with usual care}

Lung function was assessed as forced expiratory volume in one second $\left(\mathrm{FEV}_{1}\right)$ in litres in eight studies (Akinci 2011; Bösch 2007; Emery 1998; Faulkner 2010; Khdour 2009; Moullec 2008; Ninot 2011; Wakabayashi 2011) and as percentage predicted for age, gender and height (FEV1\%) in eight studies (Akinci 2011; Bourbeau 2003; Casas 2006; Emery 1998; Faulkner 2010; Gallefoss 1999; Rea 2004; Wakabayashi 2011). Six and seven studies, respectively, could be included in the meta-analyses. The MD of $\mathrm{FEV}_{1}$ was $0.08(95 \% \mathrm{Cl}$ -0.03 to 0.19 ) (Analysis 1.17). No heterogeneity was observed, with an $\mathrm{I}^{2}$ of $0 \%$. In accordance with this, the MD of FEV $1 \%$ was 1.78 (95\% $\mathrm{Cl}-1.44$ to 5.01 ), with an 12 of $15 \%$ (Analysis 1.18). $\mathrm{FEV}_{1} / \mathrm{FVC}$ was measured in five studies (Akinci 2011; Casas 2006; Faulkner 2010; Ninot 2011; Wakabayashi 2011), and again no significant difference was found for this outcome (MD $-0.84,95 \% \mathrm{Cl}-5.04$ to 3.36) (Analysis 1.20).

The CCTs of Moullec et al (Moullec 2008) and Akinci et al (Akinci 2011) reported no between-group differences for any of the lung function outcomes. Adding these two studies to the meta-analyses led to MDs of $\mathrm{FEV}_{1}$ and $\mathrm{FEV}_{1} / \mathrm{FVC}$ comparable with those of the primary analysis (Analysis 2.7; Analysis 2.8; Analysis 2.9).

\section{Lung function-head-to-head studies}

In both studies of Effing et al (Effing 2009; Effing 2011), no betweengroup differences were found in $\mathrm{FEV}_{1}$ and FEV $1 \%$. This corresponds with the results of Stulbarg et al (Stulbarg 2002), who found no significant changes in lung function after 12 months of follow-up.

\section{Exercise capacity and physical activity-studies with usual care}

Exercise capacity was measured in eight studies using the sixminute walking test (6MWT) (Akinci 2011; Bösch 2007; Bourbeau 2003; Ghanem 2010; Monninkhof 2003; Moullec 2008; Ninot 2011; Wakabayashi 2011). Six studies were included in the meta-analysis. A between-group difference with an MD of 33.69 m (95\% Cl -9.12 to 76.50) was found (Analysis 1.20). Heterogeneity between the studies was high, with an 12 of $89 \%$. The studies of Bourbeau et al and Monninkhof et al found a lower mean distance walked in the intervention group compared with the control group, which seems to be the main contributor to the heterogeneity in this analysis.

The studies of Moullec et al (Moullec 2008) and Akinci et al (Akinci 2011) were excluded from the primary analysis because they were CCTs. Moullec et al (Moullec 2008) found a statistically significantly higher walking distance in the intervention group (510.6 \pm 80.2$)$ compared with the control group $(436.3 \pm 82.1)$ after one year of follow-up. Akinci et al (Akinci 2011) also found higher values in the intervention group $(190.3 \pm 65)$ than in the control group (170.6 \pm 55.4). We performed a sensitivity analysis by including these two studies in the meta-analysis; the MD increased to $35.90(95 \% \mathrm{Cl}$ 1.35 to 70.44 ) and became statistically significant, with comparable heterogeneity.

Activity level was measured using the Voorrips Questionnaire in the studies of Ninot et al (Ninot 2011) and Moullec et al (Moullec 2008). Both groups in the study of Ninot et al (Ninot 2011) showed a significant increase in total Voorrips scores (meaning a higher activity level) after one year of follow-up, but participants in the intervention group had a significantly higher activity level compared with the control group (absolute values not reported). Ninot et al (Ninot 2011) also measured physical activity using a daily diary, but these data were not analysed because of non-compliance. Moullec et al (Moullec 2008) found statistically significant improvement in total Voorrips score from low to moderate activity levels in the intervention group, whereas the score in the control group did not significantly change after six months of follow-up. Also, the intervention group was statistically significantly more active than the control group after 12 months of follow-up $(12.0 \pm 5.8$ vs $5.1 \pm 4.9)$. Faulkner et al (Faulkner 2010) assessed physical activity using the seven-day physical activity recall questionnaire and observed no statistically significant differences between intervention and control groups.

\section{Exercise capacity and physical activity-head-to-head studies}

Four studies without a usual care control group assessed exercise capacity using the 6MWT (Nguyen 2008; Nguyen 2009; SassiDambron 1995; Stulbarg 2002). Nguyen et al (Nguyen 2008) after six months of follow-up observed a decline in walking distance in the group that participated in a face-to-face dyspnoea self management programme and an increase in walking distance among individuals who participated in an Internet-based self management programme. Nguyen et al (Nguyen 2009) showed an increase in the self monitored intervention group and a decrease in the coached intervention group. This finding did not reach statistical significance. In the studies of Stulbarg et al (Stulbarg 2002) and Sassi-Dambron et al (Sassi-Dambron 1995), no significant differences in changes in walking distance were reported between intervention groups after follow-up.

Effing et al (Effing 2011) measured exercise capacity using the incremental shuttle walking test (ISWT) and the endurance shuttle walk test (ESWT). On the ISWT, they found a statistically significant between-group difference of $35.1 \mathrm{~m}$ in favour of the group participating in an exercise programme in addition to a self management programme after 12 months of follow-up. The between-group difference of $145.8 \mathrm{~m}$ on the ESWT did not reach statistical or clinical significance. Stulbarg et al also assessed exercise capacity using both incremental and endurance walk tests, although these tests were performed on a treadmill. On both tests, the group that received exercise training in addition to dyspnoea self management performed better than groups that received less exercise training, or no supervised exercise training at all. Nguyen et al (Nguyen 2009) assessed exercise capacity using the incremental cycle ergometer test and found no significant differences between groups after six months of follow-up. 
Effing et al (Effing 2011) measured daily physical activity using pedometers. The mean between-group difference over 12 months of follow-up of 877 steps/d was statistically significant in favour of the group that participated in an exercise programme in addition to a self management programme. Nguyen et al (Nguyen 2009) assessed daily physical activity using a dual-axis accelerometer incorporated into an activity monitor. They found a decrease in the mean number of steps/d with the coached intervention and a lesser increase with the self monitored intervention.

\section{Mortality-studies with usual care}

Mortality was reported as an outcome measure in only two studies (Casas 2006; Rice 2010). Therefore we extracted data on mortality mainly from sections describing the participant flow and reasons for loss to follow-up. Ten studies (Akinci 2011; Chavannes 2009; Emery 1998; Faulkner 2010; Gallefoss 1999; Hill 2010; Kheirabadi 2008; Koff 2009; Ninot 2011; Wakabayashi 2011) reported zero deaths in the self management and control groups; three studies provided no information on dropouts (Chuang 2011; Ghanem 2010; Osterlund Efraimsson 2006) and therefore could not be included in the meta-analysis. Eight studies (Bourbeau 2003; Casas 2006; Coultas 2005a; Coultas 2005b; Khdour 2009; Monninkhof 2003; Rea 2004; Rice 2010; van Wetering 2009) were included in a metaanalysis. No statistically significant differences in mortality were found between intervention and control groups, with an OR of 0.79 (95\% $\mathrm{Cl} 0.58$ to 1.07 ) (Analysis 1.21).

Performing a sensitivity analysis with the CCT of Moullec et al, who reported zero deaths in the intervention group and one death in the control group, resulted in no change in the OR (Analysis 2.11).

\section{Subgroup analyses}

We planned to perform subgroup analyses on the duration of follow-up (less than 12 months vs 12 months or longer) and the contents of the intervention. Contents of particular interest were the use of an action plan, the use of a standardised exercise programme and the use of behavioural components. Subgroup analyses were considered possible when at least three studies could be included in each subgroup. Subgroup analyses were performed on our primary outcome measures HRQoL as measured with the SGRQ and respiratory-related hospital admissions.

Because of the relatively small number of studies with follow-up longer than 12 months, no subgroup analysis for duration of followup that met the criterion of at least three studies in a subgroup could be performed.

Action plans were used in most of the studies (17 of 23). HRQoL and respiratory-related hospital admissions were considered to be relevant outcome measures in subgroup analyses on the use of an action plan. However, because of the general use of action plans in the studies included in these meta-analyses, it was not possible to create subgroups of at least three studies that did not use an action plan in their intervention; therefore, subgroup analyses on studies with versus without an action plan could not be performed.

Subgroup analyses on the use of exercise programmes were performed on the outcomes of HRQOL and respiratory-related hospital admissions. In this specific subgroup analysis it would also be relevant to analyse exercise capacity as measured by the 6MWT, this was however not possible because the study of Wakabayashi 2011 was the only study in that meta-analysis that did not include a standardised exercise programme. The subgroup difference in HRQoL between studies with and without exercise programmes was substantial but was not statistically significant. The MD of SGRQ total scores for studies with an exercise programme was $-2.13(95 \% \mathrm{Cl}-5.52$ to 1.25$)$, and the MD for studies without an exercise programme was $-4.10(95 \% \mathrm{Cl}-6.33$ to -1.88$)$ (Analysis 3.3). Subgroup differences in respiratory-related hospital admissions between studies with and without exercise programmes were not statistically significant. The OR for having at least one respiratoryrelated hospital admission was $0.75(95 \% \mathrm{Cl} 0.37$ to 1.53$)$ for studies with an exercise programme and $0.54(95 \% \mathrm{Cl} 0.41$ to 0.71$)$ for studies without an exercise programme (Analysis 3.4).

Studies with and without behavioural components showed no statistically significant subgroup differences in respiratory-related hospital admissions and HRQoL. The MD of SGRQ total score for studies with behavioural components was $-3.61(95 \% \mathrm{Cl}-7.65$ to 0.44 ), and the MD of studies without behavioural components was $-3.88(95 \% \mathrm{Cl}-6.31$ to -1.46$)$ (Analysis 3.6). The OR for respiratory-related hospital admissions in studies with behavioural components was 0.47 ( $95 \% \mathrm{Cl} 0.30$ to 0.74 ), and the OR in studies without behavioural components was 0.65 ( $95 \% \mathrm{Cl} 0.48$ to 0.89$)-$ both in favour of the intervention group (Analysis 3.7).

\section{DISCUSSION}

\section{Summary of main results}

This review is an update of a review published in 2007 (Effing 2007). We have systematically evaluated 23 studies with a usual care control group and six studies comparing different components of self management head-to-head. A statistically significant effect of self management on quality of life as measured by the SGRQ was found, with the score on the impact domain reaching the MCID of four points. Also, individuals who participated in a self management intervention were at lower risk for both one or more respiratory-related and all cause hospitalisations, compared with individuals who received usual care. No effects of self management on lung function were found, but dyspnoea as measured by the $(m) M R C$ was significantly reduced in participants assigned to self management. The mean difference between intervention and control groups in the distance walked on the 6MWT was not statistically significant.

Physiological and functional impairments in patients with COPD often go together with a reduced health-related quality of life (Garrido 2006; Heyworth 2009). In the included studies, healthrelated quality of life was the most frequently assessed outcome measure, with the SGRQ the most frequently used questionnaire. In the previous update of the review, total and impact scores on the SGRQ were statistically significant lower (meaning better $\mathrm{HRQ}$ oL) in the intervention group than in the control group. In the current update, the positive effect of self management on HRQoL of participants with COPD was even more distinct, with total and domain scores all significantly lower in the intervention group than in the control group. Only the score on the impact domain, which covers social, emotional and psychological impact of the disease, reached the MCID of four points and therefore can be considered as clinically relevant (Jones 2005). Whereas the MD of the SGRQ total score did not reach the MCID, we need to consider this more carefully. First, in the subgroup analysis, we found a clinically relevant MD of $-4.10(95 \% \mathrm{Cl}-6.33$ to -1.88$)$ in the interventions without an exercise programme. Second, in another Cochrane 
review on the use of tiotropium versus placebo, an MD of -2.89 (95\% $\mathrm{Cl}-3.35$ to -2.44 ) in the SGRQ total score was found (Karner 2012). Secondary analysis revealed that statistically significantly more participants receiving tiotropium experienced a clinically relevant improvement of four points in SGRQ total score than participants given placebo. Based on this analysis, the study authors considered the effects of tiotropium on SGRQ total score to be clinically relevant. The mean effect on SGRQ total score in our meta-analysis was substantially greater than that in the review on tiotropium. We were not able to perform the same secondary analysis, but based on the reasoning above, we expect that significantly more individuals participating in self management experienced clinically relevant improvement compared with participants receiving usual care.

The number of hospitalisations was analysed using the number of participants with at least one hospital admission. The odds ratio for having one or more respiratory-related hospital admissions favoured the intervention group. It is debatable whether this is clinically relevant because there is no such thing as an MCID for hospitalisations. However, the OR of 0.57 indicates that individuals with COPD who participate in self management are at substantially lower risk for one or more respiratory-related hospitalisations, meaning a reduction in the risk for a worse health outcome (Soler-Cataluña 2005) and a reduction in costs (Toy 2010). It was expected that self management interventions for participants with COPD would principally lead to a reduction in respiratory-related hospitalisations because the programmes focus on COPD-related self management skills that aim to stimulate proper patient behaviours and actions, thereby preventing severe exacerbations and hospitalisations. However, our review data show that self management interventions do also lead to a reduction in the odds ratio for having at least one all-cause hospital admission. This was less expected since all programmes were COPD-specific and not directed towards co-morbidities. Comorbidities are more the rule than the exception in patients with COPD, with more than $90 \%$ of patients with COPD suffering from at least one co-morbidity (e.g. cardiovascular disease, diabetes, mental health issues) (Schnell 2012; Vanfleteren 2013). Co-morbidities in patients with COPD are associated with increased risk for any hospitalisation (Mannino 2008). Future COPD self management interventions should probably be more directed towards the individual patient's co-morbidities to further increase the benefit on all-cause hospitalisations among patients. The latter would most likely also further increase the safety of COPD self management interventions. More generally, self management should be tailored to the individual needs of each patient.

Exacerbations of COPD are negatively associated with disease progression and health-related quality of life and are positively associated with mortality (Donaldson 2002; Jones 2011; Seemungal 1998; Suissa 2012). Only three of the included studies assessed the effect of self management on exacerbations (Bourbeau 2003; Monninkhof 2003; van Wetering 2009). Two of these three studies (Monninkhof 2003; van Wetering 2009) reported a higher number of exacerbations in the intervention group than in the control group. Although this might seem remarkable, a plausible explanation can be found in the underreporting of COPD exacerbations in general. Earlier studies showed that approximately $50 \%$ to $70 \%$ of exacerbations of COPD are not reported to a physician (Langsetmo 2008; Seemungal 1998; Wilkinson 2004; Xu 2010). Most self management interventions include approaches to improve recognition of symptoms of a worsening of COPD. This might have led to improved recognition and improved reporting of exacerbations in the intervention group compared with the control group. Seventy-five percent of the studies in this review incorporated the use of an action plan into their self management intervention. The primary goal of an action plan is to teach patients to recognise an exacerbation at an early stage and to act promptly to the worsening of symptoms. Because an action plan is used after the start of an exacerbation, it is not intended to prevent exacerbations. However, it could lead to less-severe exacerbations, which in turn lead to a reduced number of hospitalisations. The decrease in respiratory-related hospitalisations found in this review might be a reflection of this. Another point of attention is the diversity of definitions of 'exacerbation' used in clinical trials. Roughly, the definitions used can be classified as symptom-based or event-based (Pauwels 2004; Trappenburg 2011). This is reflected in the three studies discussed above, all of which used different definitions. No consensus has been reached on which definition is most accurate, but the chosen definition can seriously influence outcomes and even the statistical significance of effect sizes (Effing 2009b; Trappenburg 2011). Outcome measures such as courses of oral steroids and/ or antibiotics or the use of rescue medication can serve as proxy variables for exacerbations of COPD because these variables indicate worsening of COPD. Two of the three studies (Gallefoss 1999; Rea 2004; Rice 2010) in the meta-analysis on this outcome reported that more participants had at least one course of oral corticosteroids in the intervention group than in the control group, with similar reversed causation, as discussed above.

In this update, we found an MD in distance walked on the 6MWT of $33.7 \mathrm{~m}$. Although this difference exceeds the recently reported MCID of $25 \mathrm{~m}$ of Holland et al (Holland 2010), it is not statistically significant. Because all but one study in this metaanalysis included some sort of standardised physical exercise programme, it is likely that these exercise programmes account for most of the improvement in walking distance. Heterogeneity in this analysis was high $\left(1^{2}=86 \%\right)$. Major contributors to this high level of heterogeneity seem to be the studies of Moninnkhof et al (Monninkhof 2003) and Bourbeau et al (Bourbeau 2003), both of which show lower values in the intervention group compared with the control group. This contrasts with the findings of other studies included in this meta-analysis. Monninkhof and colleagues concluded at the end of their study that the frequency and intensity of the incorporated exercise intervention were too low to permit an increase in exercise capacity (Monninkhof 2003). In the study of Bourbeau et al, the exercise programme was home-based, unsupervised and voluntary; this may have led to an intensity of the programme that was not sufficient to achieve an increase in exercise capacity (Bourbeau 2003).

As expected, no effect of self management on lung function was found. A statistically significant effect on shortness of breath was found with the $(m) M R C$, but whether this difference is clinically relevant is not clear because studies on this topic are lacking. A reasonable explanation for the reduction in breathlessness score might be that patients learn strategies to cope with breathlessness during self management education (Norweg 2013). As a result, the anxiety that patients might have for becoming short of breath during activities of daily life is reduced; therefore patients may experience less dyspnoea during activities. 
Subgroup analyses on the use of exercise programmes, the use of action plans and the use of behavioural components were performed to gain greater insight into the "black box" of self management. Unfortunately, because most studies included an action plan for exacerbations, we were not able to create a subgroup of sufficient size to permit meta-analyses on the use of an action plan. Subgroup analyses on the use of an exercise programme revealed no statistically significant differences between studies with and without exercise programmes in $\mathrm{HRQ}$ oL and respiratory-related hospital admissions. This indicates that improved $\mathrm{HRQOL}$ and reduced respiratory-related hospital admissions can thus be achieved solely with self management training, and that a standardised exercise programme is not essential in this aspect.

In addition to the subgroup analyses, and in contrast to previous versions of the review, we did include studies comparing different components of self management head-to-head. This gave us an extra opportunity to gain a better understanding of the effectiveness of the separate self management components. One study compared two methods of delivery of self management to the participant, and the other studies assessed which combination of components was most effective. Unfortunately, whereas betweengroup differences were found, studies were too unique to allow general conclusions or recommendations on effective components.

The additional value of behavioural components, defined as cognitive-behavioural therapy, motivational interviewing, goalsetting and providing feedback to the participant, was difficult to determine because of lack of detailed information. We have created subgroups regarding the use of behavioural components based on global information received from authors about the use of these behavioural components. Whereas the literature provides a theoretical background for incorporating behavioural components into self management interventions (Bourbeau 2004; Lorig 2003b), we found no differences in HRQoL and respiratoryrelated hospital admissions between studies with and without behavioural components. This is probably a result of our definition of 'behavioural components', lack of information regarding these components and the limited number of studies in the subgroup analyses. Future studies should provide detailed information regarding the behavioural techniques. For example, this can be done by using an established taxonomy for behavioural change techniques (Michie 2013).

Nowadays, studies focus predominantly on ultimate outcomes such as health status and physiological functioning. Intermediate outcomes linked to behaviour change, such as self efficacy (Bourbeau 2004; Lorig 2003b), are only incidentally measured. In this review, only one of 24 studies without a usual care control group reported the results of a questionnaire that assesses self efficacy. The limited availability of valid and patient-friendly instruments to measure self efficacy might explain in part the minimal use of these instruments (Frei 2009). Furthermore, in research on self management, it is recommended that one select outcome measures that are in line with the goals and contents of the intervention. For example, effects on anxiety and depression most likely can be expected only when parts of the self management intervention are targeted towards anxiety and/or depression.

When the effectiveness of self management interventions is considered, it is appropriate to take into account adherence of patients to the intervention. Adherence was discussed in eight studies and was reported as the percentage of participants attending or not attending a certain percentage of sessions, or as the percentage of sessions attended by participants. In one study, participants were excluded from the analysis when they did not meet a prespecified attendance rate, with the consequence that a per-protocol analysis was performed. An intention-to-treat analysis including all randomly assigned participants is preferred because it will give a more realistic view of the intervention effect in real life, where there will always be poorly adhering patients. However, information about patient attendance should always be reported, so that some idea about the dose-response relationship can be obtained. Sohanpal et al studied reasons for low attendance in a self management intervention for participants with COPD (Sohanpal 2012). The main reasons for low attendance were that participants considered themselves not ill enough, or, conversely, participants were too physically or psychologically disabled, or they had competing obligations. According to the tutors, low adherence was also caused by participants blaming others for their condition, having fear of making a change in their lives or lacking support from family or friends. Close to the concept of adherence is patient engagement to the programme (i.e. active involvement in tasks and processes); this is another requirement for achieving behavioural change in self management (Willis 2011).

\section{Overall completeness and applicability of evidence}

Our searches were current up until August 2011. Since then, several new studies on the effectiveness of self management have been published. The studies of Bucknall et al (Bucknall 2012), Fan et al (Fan 2012) and Bischoff et al (Bischoff 2012) would have undoubtedly fitted our inclusion criteria; all had a reasonable follow-up of at least one year and were sufficiently powered to detect differences. The primary outcomes of two of these studies were related to hospital admissions for COPD (Bucknall 2012; Fan 2012), and one study primarily focused on HRQoL (Bischoff 2012). In the latter study, HRQoL was measured with the CRQ, and no differences were found between self management and usual care groups (Bischoff 2012). Bucknall et al (Bucknall 2012) found no differences between self management and control groups in COPD-related hospital admissions and deaths. However, only $42 \%$ of participants in the intervention group could be classified as successful self managers, which might clarify the lack of difference (Bucknall 2012). It is disturbing to note that the study of Fan et al (Fan 2012) was stopped prematurely because of a higher number of deaths in the intervention group compared with the control group that could not be explained satisfactorily by the study authors. When we add the mortality data of Fan et al exploratively to our meta-analysis on mortality, the OR becomes 0.98 (95\% $\mathrm{Cl} 0.62$ to 1.54). This indicates that the results of Fan et al influence the effect size, but little meaningful difference in mortality is evident between self management and control groups. However, these results need to be interpreted with caution because the analyses were just exploratory. Differences in study design and characteristics of included participants were not taken into account in these analyses; an analysis of individual participant data could contribute to the knowledge of factors influencing proper self management. The additional results of these recently published studies do not automatically fit with the results reported in this review;therefore future updates should demonstrate how this recently gained knowledge influences the results of current meta-analyses. 


\section{Potential biases in the review process}

As we did in previous versions of this review, we included CCTs in this update. After due deliberation, we decided to exclude these CCTs from the primary meta-analyses because our data confirm the fact that their inclusion in meta-analyses led to a substantial increase in heterogeneity and therefore decreased the quality level of evidence. The main explanation for this can be found in differences in study design between CCTs and RCTs. The non-randomised character of CCTs makes them more prone to biases such as selection bias, which, in turn, may lead to biased effect sizes. For this reason, we have chosen to include CCTs only in secondary sensitivity analyses. Although the exclusion of CCTs from the primary analysis led to reduced effect sizes in, for example, health-related quality of life as measured with the SGRQ, heterogeneity is also reduced, and we believe that this has contributed to the robustness of the results of this review. These observations on our data show that one should be very cautious about including CCTs in meta-analyses; for this reason, we will include only RCTs in future updates of this review.

In line with recent ideas regarding self management training (Bourbeau 2009; Effing 2012), we have made changes to the definition of self management training before updating this review. The main objective of this change was to capture studies that do not focus purely on education but also have the potential to initiate behaviour change. Because the protocols of these interventions and the reasoning behind them are in general only globally described in the articles, we have chosen to exclude studies with only one contact moment between participants and healthcare providers (having only one contact moment makes it impossible to set goals and provide feedback, let alone change behaviour). For the same reason, we have chosen a priori to exclude studies published before 1995. We believe that evolving ideas about the goals and contents of self management interventions over the years have resulted in substantially different interventions that are focused on more than just education. Moreover, health care in general has clearly changed over the past 25 years, leading to usual care groups and patient populations that are not comparable. Knowing this, we think that it would not be appropriate to pool the results of a study conducted in 1987 with results of a study conducted 24 years later, in 2011.

Although we have tried in this update to define more clearly criteria for self management interventions, the included interventions are still diverse, both in name and in content. The simplest interventions that we have included in this review consisted of an educational session plus reinforcement by telephone or during routine outpatient visits. The most complex interventions consisted of several educational sessions combined with an exercise programme plus an optimisation of care plan. Furthermore, a large variety of topics were discussed during educational sessions. With this heterogeneity in interventions, it is difficult to determine the most effective parts of them. As Wagg (Wagg 2012) clearly presented in a diagram, disease management in patients with COPD requires a continuum of care in which self management is part of both pulmonary rehabilitation and integrated disease management. Because it is a continuum of care, no clear borders can be seen between the disciplines, and some overlap is inevitable. Nevertheless, we decided to exclude hospital- and rehabilitation centre-based rehabilitation programmes because self management often is only a minor part of these very intensive programmes. This will make it difficult or even impossible to filter the effects of self management from other effects. We did, however, choose to include studies on home-based pulmonary rehabilitation that did not focus solely on exercise. In these programmes, training often is not supervised and action planning is frequently included. Therefore, in our opinion, these programmes resemble self management.

Topics that were discussed in the previous update are still relevant in this version of the review. The included studies used a broad spectrum of outcome measures. Meta-analyses often could not be performed because included studies used different methods to assess the outcome measure (e.g. different questionnaires) or calculated the same outcome in different ways (e.g. mean number of visits vs percentage of participants with ED visits). Lack of availability of data, even after contact was made with the study authors, hampered statistical combinations of data. The latter may have biased the effect estimates in the review. Furthermore, variation in follow-up was seen, the COPD population differed across studies and, as already stated, considerable variation was evident in the interventions provided. In future studies, it will be important to ensure greater homogeneity to allow comparisons with other studies and to permit the possibility of stronger recommendations.

\section{AUTHORS' CONCLUSIONS}

\section{Implications for practice}

Self management interventions in patients with COPD are associated with improvement in health-related quality of life as measured by the SGRQ, reduction in both respiratory-related and all cause hospital admissions and improvement in dyspnoea as measured by the (m)MRC. No statistically significant differences were found in other outcome parameters. Action plans were part of most of the studies included in the meta-analysis, and so are already considered to be an essential component of self management. However, because of the low number of studies without an action plan, subgroup analyses could not be performed to confirm this. Also, the data indicate that self management without exercise and self management with exercise are equally effective in improving HRQoL. However, because of heterogeneity among interventions, study populations, follow-up times and outcome measures, and consequent limited possibilities to perform subanalyses, data remain insufficient to permit clear recommendations about the optimal form and content of self management training for COPD.

\section{Implications for research}

Future studies should focus on the following.

- Consensus on an operational definition for 'self management'.

- Self management training with the goal of acquisition of self management skills and behavioural change.

- Comparison of self management interventions and their different components to contribute to the definition of effective components in self management interventions (e.g. programmes with and without self treatment of exacerbations, programmes with and without exercise).

- Homogeneity in outcome measures, with greater attention on standardised behavioural outcome measures. 
- Integration of the handling of co-morbidities in self management training for patients with COPD.

- Assessment of outcomes over the long term (> 12 months).

\section{ACKNOWLEDGEMENTS}

We are grateful to Nancy Santesso for generating the 'Summary of findings' table in the original version of the review; however, this has been revised. We would like to thank the following authors for their assistance:
F. Gallefoss (Gallefoss 1999), A. Cockcroft, I. Town, D. Gourley, F. Emery (Emery 1998), D. Sassi-Dambron, P. Littlejohns, J. Howland, R. Blake, J. Bourbeau (Bourbeau 2003), H. Worth, D. Coultas (Coultas 2005a), D. Taylor, H. Rea (Rea 2004), J. Rich (Chuang 2011), K. Rice (Rice 2010), G. Ninot (Ninot 2011), G. Moullec (Moullec 2008), J. Garcia-Aymerich (Casas 2006), B. Vandivier (Koff 2009), J. McElnay and M. Khdour (Khdour 2009), D. Bösch (Bösch 2007), R. WoodBaker (Wood-Baker 2006), J. Faulkner (Faulkner 2010), G. Caplan (Boxall 2005) and K. Kida (Wakabayashi 2011).

E. Haydn Walters was the Editor for this review and commented critically on it. 


\section{R E F E R E N C E S}

\section{References to studies included in this review}

Akinci 2011 \{published data only\}

Akinci A, Olgun N. The effectiveness of nurse-led, home-based pulmonary rehabilitation in patients with COPD in Turkey. Rehabilitation Nursing 2011;36(4):159-65.

\section{Bösch 2007 \{published and unpublished data\}}

Bösch D, Feierabend M, Becker A. COPD outpatient education programme (ATEM) and BODE index [Ambulante COPDpatientenschulung (ATEM) und BODE-index]. Pneumologie 2007;61(10):629-35

\section{Bourbeau 2003 \{published and unpublished data\}}

Bourbeau J, Collet JP, Schwartzman K, Ducruet T, Nault D, Bradley C. Economic benefits of self-management education in COPD. Chest 2006;130(6):1704-11.

* Bourbeau J, Julien M, Maltais F, Rouleau M, Beaupré A, Bégin $\mathrm{R}$, et al. Reduction of hospital utilization in patients with chronic obstructive pulmonary disease: a disease-specific self-management intervention. Archives of Internal Medicine 2003;163(5):585-91.

Gadoury MA, Schwartzman K, Rouleau M, Maltais F, Julien M, Beaupre A, et al. Self-management reduces both short- and long-term hospitalisation in COPD. European Respiratory Journal 2005;26(5):853-7.

Sedeno MF, Nault D, Hamd DH, Bourbeau J. A self-management education program including an action plan for acute COPD exacerbations. Journal of Chronic Obstructive Pulmonary Disease 2009;6(5):352-8.

\section{Casas 2006 \{published and unpublished data\}}

Casas A, Troosters T, Garcia-Aymerich, Roca J, Hernández, del Pozo F, et al. Integrated care prevents hospitalisations for exacerbations in COPD. European Respiratory Journal 2006;28(1):123-30.

Garcia-Aymerich J, Hernandez C, Alonso A, Casas A, RodriguezRoisin R, Anto J, et al. Effects of an integrated care intervention on risk factors of COPD readmission. Respiratory Medicine 2007;101:1462-69.

\section{Chavannes 2009 \{published and unpublished data\}}

Chavannes NH, Grijsen M, van den Akker M, Schepers H, Nijdam M, Tiep B, et al. Integrated disease management improves one-year quality of life in primary care COPD patients: a controlled clinical trial. Primary Care Respiratory Journal 2009;18(3):171-6.

\section{Chuang 2011 \{published and unpublished data\}}

Chuang C, Levine SH, Rich J. Enhancing cost-effective care with a patient-centric chronic obstructive pulmonary disease program. Population Health Management 2011;14(3):133-6.
Coultas 2005a \{published and unpublished data\}

Coultas D, Frederick J, Barnett B, Singh G, Wludyka P. A randomized trial of two types of nurse-assisted home care for patients with COPD. Chest 2005;128(4):2017-24.

Coultas 2005b \{published and unpublished data\}

Coultas D, Frederick J, Barnett B, Singh G, Wludyka P. A randomized trial of two types of nurse-assisted home care for patients with COPD. Chest 2005;128(4):2017-24.

Effing 2009 \{published and unpublished data\}

Effing T, Kerstjens $\mathrm{H}$, van der Valk $P$, Zielhuis $\mathrm{G}$, van der Palen J. (Cost)-effectiveness of self-treatment of exacerbations on the severity of exacerbations in patients with COPD: the COPE II study. Thorax 2009;64(11):956-62.

\section{Effing 2011 \{published and unpublished data\}}

Effing T, Zielhuis $G$, Kerstjens $H$, van der Valk $P$, van der Palen $P$. Community-based physiotherapeutic exercise in COPD selfmanagement: a randomised controlled trial. Respiratory Medicine 2011;105(3):418-26.

\section{Emery 1998 \{published and unpublished data\}}

Emery CF, Schein RL, Hauck ER, MacIntyre NR. Psychological and cognitive outcomes of a randomized trial of exercise among patients with chronic obstructive pulmonary disease. Health Psychology 1998;17(3):232-40.

\section{Faulkner 2010 \{published and unpublished data\}}

Faulkner J, Walshaw E, Campbell J, Jones R, Taylor R, Price $\mathrm{D}$, et al. The feasibility of recruiting patients with early COPD to a pilot trial assessing the effects of a physical activity intervention. Primary Care Respiratory Journal 2010;19(2):124-30.

Gallefoss 1999 \{published data only\}

Gallefoss F, Bakke PS. How does patient education and self-management among asthmatics and patients with chronic obstructive pulmonary disease affect medication?. American Journal of Respiratory and Critical Care Medicine 1999;160(6):2000-5.

Gallefoss F, Bakke PS. Impact of patient education and selfmanagement on morbidity in asthmatics and patients with chronic obstructive pulmonary disease. Respiratory Medicine 2000;94(3):279-87.

* Gallefoss F, Bakke PS, Rsgaard PK. Quality of life assessment after patient education in a randomized controlled study on asthma and chronic obstructive pulmonary disease. American Journal of Respiratory and Critical Care Medicine 1999;159(3):812-7.

\section{Ghanem 2010 \{published data only\}}

Ghanem M, Abd ELaal E, Mehany M, Tolba K. Home-based pulmonary rehabilitation program: effect on exercise tolerance and quality of life in chronic obstructive pulmonary disease patients. Annals of Thoracic Medicine 2010;5(1):18-25. 


\section{Hill 2010 \{published data only\}}

Hill K, Mangovski-Alzamora S, Blouin M, Guyat G, HeelsAndell D, Bragaglia P, et al. Disease-specific education in the primary care setting increases the knowledge of people with chronic obstructive pulmonary disease: a randomized controlled trial. Patient Education and Counseling 2010;81(1):14-8.

\section{Kara 2004 \{published data only\}}

Kara M, Asti T. Effects of education on self-efficacy of Turkish patients with chronic obstructive pulmonary disease. Patient Education and Counseling 2004;55(1):114-20.

\section{Khdour 2009 \{published and unpublished data\}}

Khdour MR, Kidney JC, Smyth BM, McElnay JC. Clinical pharmacy-led disease and medicine management programme for patients with COPD. British Journal of Clinical Pharmacology 2009;68(4):588-99.

\section{Kheirabadi 2008 \{published data only\}}

Kheirabadi GR, Keypour M, Attaran N, Bagherian R, Maracy MR. Effect of add-on "self-management and behaviour modification" education on severity of COPD. Tanaffos 2008;7(3):23-30.

\section{Koff 2009 \{published and unpublished data\}}

Koff PB, Jones RH, Cashman JM, Voelkel NF, Vandivier RW. Proactive integrated care improves quality of life in patients with COPD. European Respiratory Journal 2009;33(5):1031-8.

\section{Monninkhof 2003 \{published and unpublished data\}}

Monninkhof E, van der Valk P, Schermer T, van der Palen J, van Herwaarden C, Zielhuis G. Economic evaluation of a comprehensive self-management programme in patients with moderate to severe chronic obstructive pulmonary disease. Chronic Respiratory Disease 2004;1(1):7-16.

* Monninkhof E, van der Valk P, van der Palen J, van Herwaarden C, Zielhuis $\mathrm{G}$. Effects of a comprehensive self-management programme in patients with chronic obstructive pulmonary disease. European Respiratory Journal 2003;22(5):815-20.

\section{Moullec 2008 \{published and unpublished data\}}

Moullec G, Ninot G. An integrated programme after pulmonary rehabilitation in patients with chronic obstructive pulmonary disease: effect on emotional and functional dimensions of quality of life. Clinical Rehabilitation 2010;24(2):122-36.

* Moullec G, Ninot G, Varray A, Desplan J, Hayot M, Prefaut C. An innovative maintenance follow-up program after a first inpatient pulmonary rehabilitation. Respiratory Medicine 2008;102(4):556-66

\section{Nguyen 2008 \{published data only\}}

Nguyen HQ, Donesky-Cuenco D, Wolpin S, Reinke LF, Benditt JO, Paul SM, et al. Randomized controlled trial of an internet-based versus face-to-face dyspnea self-management program for patients with chronic obstructive pulmonary disease: pilot study. Journal of Medical Internet Research 2008;10(2):e9.
Nguyen 2009 \{published data only\}

Nguyen HQ, Gill DP, Wolpin S, Steele BG, Benditt JO. Pilot study of a cell phone-based exercise persistence intervention post-rehabilitation for COPD. International Journal of COPD 2009;4:301-13.

\section{Ninot 2011 \{published and unpublished data\}}

Ninot G, Moullec G, Picot MC, Jaussent A, Hayot M, Desplan M, et al. Cost-saving effect of supervised exercise associated to COPD self-management education program. Respiratory Medicine 2011;105(3):377-85.

\section{Osterlund Efraimsson 2006 \{published and unpublished data\}}

Osterlund Efraimsson E, Hillervik C, Ehrenberg A. Effects of COPD self-care management education at a nurse-led primary health care clinic. Scandinavian Journal of Caring Sciences 2008;22(2):178-85

\section{Rea 2004 \{published and unpublished data\}}

Rea H, McAuley S, Stewart A, Lamont C, Roseman P, Didsbury P. A chronic disease management programme can reduce days in hospital for patients with chronic obstructive pulmonary disease. Internal Medicine Journal 2004;34(11):608-14.

Rice 2010 \{published and unpublished data\}

Rice KL, Dewan N, Bloomfield HE, Grill J, Schult TM, Nelson DB, et al. Disease management program for chronic obstructive pulmonary disease: a randomized controlled trial. American Journal of Respiratory and Critical Care Medicine 2010;182(7):890-6.

Sassi-Dambron 1995 \{published data only\} Sassi-Dambron DE, Eakin EG, Ries AL, Kaplan RM. Treatment of dyspnea in COPD. A controlled clinical trial of dyspnea management strategies. Chest 1995;107(3):724-9.

Stulbarg 2002 \{published data only\}

Carrieri-Kohlman V, Nguyen HQ, Donesky-Cuenco D, DemirDeviren S, Neuhaus J, Stulbarg MS. Impact of brief or extended exercise training on the benefit of a dyspnea self-management program in COPD. Journal of Cardiopulmonary Rehabilitation 2005;25(5):275-84.

Davis AHT, Carrieri-Kohlman V, Janson SL, Gold WM, Stulbarg MS. Effects of treatment on two types of self-efficacy in people with chronic obstructive pulmonary disease. Journal of Pain and Symptom Management 2006;32(1):60-70.

Donesky-Cuenco DA, Janson S, Neuhaus J, Neilands TB, Carrieri-Kohlman V. Adherence to a home-walking prescription in patients with chronic obstructive pulmonary disease. Heart and Lung 2007;36(5):348-63.

Nguyen HQ, Carrieri-Kohlman V. Dyspnea self-management in patients with chronic obstructive pulmonary disease: moderating effects of depressed mood. Psychosomatics 2005;46(5):402-10.

Stulbarg MS, Carrieri-Kohlman V, Demir-Deviren S, Nguyen HQ, Adams L, Tsang AH, et al. Exercise training improves outcomes of a dyspnea self-management program. Journal of Cardiopulmonary Rehabilitation 2002;22(2):109-21. 
van Wetering 2009 \{published data only\}

Hoogendoorn M, van Wetering CR, Schols AM, Rutten-van Mölken MP. Is INTERdisciplinary COMmunity-based COPD management (INTERCOM) cost-effective?. European Respiratory Journal 2010;35(1):79-87.

* van Wetering CR, Hoogendoorn M, Mol SJM, Rutten-van Mölken MPMH, Schols AM. Short- and long-term efficacy of a community-based COPD management programme in less advanced COPD: a randomised controlled trial. Thorax 2010;65(1):7-13.

Wakabayashi 2011 \{published and unpublished data\}

Wakabayashi R, Motegi T, Yamada K, Ishii T, Jones RCM, Hyland $\mathrm{M}$, et al. Efficient integrated education for older patients with chronic obstructive pulmonary disease using the Lung Information Questionnaire. Geriatrics and Gerontology International 2011;11(4):422-30.

\section{References to studies excluded from this review}

\section{Blake 1990 \{published data only\}}

Blake RL Jr, Vandiver TA, Braun S, Bertuso DD, Straub V. A randomized controlled evaluation of a psychosocial intervention in adults with chronic lung disease. Family Medicine 1990;22:365-70.

\section{Boxall 2005 \{published data only\}}

Boxall AM, Barclay L, Sayers A, Caplan GA. Managing chronic obstructive pulmonary disease in the community. A randomized controlled trial of home-based pulmonary rehabilitation for elderly housebound patients. Journal of Cardiopulmonary Rehabilitation 2005;25(6):378-85.

\section{Carone 2002 \{published data only\}}

Carone M, Bertolotti G, Cerveri I, De Benedetto F, Fogliani V, Nardini S, et al. EDU-CARE, a randomised, multicentre, parallel group study on education and quality of life in COPD. Monaldi Archives for Chest Disease 2002;57(1):25-9.

\section{Cockcroft 1987 \{published data only\}}

Cockcroft A, Bagnall P, Heslop A, Andersson N, Heaton R, Batstone J, et al. Controlled trial of respiratory health worker visiting patients with chronic respiratory disability. British Medical Journal (Clin Res Ed) 1987;294(6566):225-8.

\section{de Toledo 2006 \{published data only\}}

de Toledo P, Jiménez S, del Pozo F, Roca J, Alonso A, Hernandez $C$. Telemedicine experience for chronic care in COPD. IEEE Transactions on Information Technology in Biomedicine 2006;10(3):567-73.

\section{Gourley 1998 \{published data only\}}

Gourley GA, Portner TS, Gourley DR, Rigolosi EL, Holt JM, Solomon DK, et al. Humanistic outcomes in the hypertension and COPD arms of a multicenter outcomes study. Journal of the American Pharmaceutical Association 1998;38(5):586-97.

Hesselink 2004 \{published data only\}

Hesselink AE, Penninx BW, van der Windt DA, van Duin BJ, de Vries P, Twisk JW, et al. Effectiveness of an education programme by a general practice assistant for asthma and COPD patients: results from a randomised controlled trial. Patient Education and Counseling 2004;55(1):121-8.

\section{Jerant 2009 \{published data only\}}

Jerant A, Moore-Hill M, Franks P. Home-based, peer-led chronic illness self-management training: findings from a 1year randomized controlled trial. Annals of Family Medicine 2009;7(4):319-27.

\section{Kunik 2008 \{published data only\}}

Kunik ME, Veazey C, Cully JA, Souchek J, Graham DP, Hopko D, et al. COPD education and cognitive behavioral therapy group treatment for clinically significant symptoms of depression and anxiety in COPD patients: a randomized controlled trial. Psychological Medicine 2008;38(3):385-96.

\section{Lamers 2010 \{published data only\}}

Lamers F, Jonkers CC, Bosma H, Chavannes NH, Knottnerus JA, van Eijk JT. Improving quality of life in depressed COPD patients: effectiveness of a minimal psychological intervention. COPD 2010;7(5):315-22.

\section{Littlejohns 1991 \{published data only\}}

Littlejohns P, Baveystock CM, Parnell H, Jones P. Randomised controlled trial of the effectiveness of a respiratory health worker in reducing impairment, disability, and handicap due to chronic airflow imitation. Thorax 1991;46:559-64.

Lorig 1999 \{published data only\}

Lorig KR, Sobel DS, Stewart AL, Brown BW Jr, Bandura A, Ritter $P$, et al. Evidence suggesting that a chronic disease self-management program can improve health status while reducing hospitalization: a randomized trial. Medical Care 1999;37(1):5-14.

\section{Lorig 2003a \{published data only\}}

Lorig KR, Ritter PL, González VM. Hispanic chronic disease selfmanagement: a randomized community-based outcome trial. Nursing Research 2003;52(6):361-9.

\section{Martin 2004 \{published data only\}}

Martin IR, McNamara D, Sutherland FR, Tilyard MW, Taylor DR. Care plans for acutely deteriorating COPD: a randomized controlled trial. Chronic Respiratory Disease 2004;1(4):191-5.

\section{Martin 2008 \{published data only\}}

Maltais F, Bourbeau J, Shapiro S, Lacasse Y, Perrault H, Baltzan M, et al. Effects of home-based pulmonary rehabilitation in patients with chronic obstructive pulmonary disease: a randomized trial. Annals of Internal Medicine 2008;149(12):869-78.

\section{McGeoch 2006 \{published data only\}}

McGeoch GR, Willsman KJ, Dowson CA, Town GI, Frampton CM, McCartin FJ, et al. Self-management plans in the primary care of patients with chronic obstructive pulmonary disease. Respirology 2006;11(5):611-8. 
Rootmensen 2008 \{published data only\}

Rootmensen GN, van Keimpema AR, Looysen EE, van der Schaaf L, de Haan RJ, Jansen HM. The effects of additional care by a pulmonary nurse for asthma and COPD patients at a respiratory outpatient clinic: results from a double blind, randomized clinical trial. Patient Education and Counseling 2008;70(2):179-86

\section{Sridhar 2008 \{published data only\}}

Sridhar M, Taylor R, Dawson S, Roberts NJ, Partridge MR. A nurse led intermediate care package in patients who have been hospitalised with an acute exacerbation of chronic obstructive pulmonary disease. Thorax 2008;63(3):194-200.

Watson 1997 \{published data only\}

Watson PB, Town GI, Holbrook N, Dwan C, Toop LJ, Drennan CJ. Evaluation of a self-management plan for chronic obstructive pulmonary disease. European Respiratory Journal 1997;10(6):1267-71.

\section{Wood-Baker 2006 \{published data only\}}

Wood-Baker R, McGlone S, Venn A, Walters EH. Written action plans in chronic obstructive pulmonary disease increase appropriate treatment for acute exacerbations. Respirology 2006;11(5):619-26.

\section{Additional references}

\section{Bandura 1977}

Bandura A. Self-efficacy: toward a unifying theory of behavioral change. Psychological Review 1977;84(2):191-215.

\section{Bischoff 2012}

Bischoff EW, Akkermans R, Bourbeau J, van Weel C, Vercoulen JH, Schermer TR. Comprehensive self management and routine monitoring in chronic obstructive pulmonary disease patients in general practice: randomised controlled trial. BMJ 2012;345:e7642. [http: http://dx.doi.org/10.1136/ bmj.e7642]

\section{Bourbeau 2004}

Bourbeau J, Nault D, Dang-Tan T. Self-management and behaviour modification in COPD. Patient Education and Counseling 2004;52(3):271-7.

\section{Bourbeau 2009}

Bourbeau J, van der Palen J. Promoting effective selfmanagement programmes to improve COPD. European Respiratory Journal 2009;33(3):461-3.

\section{Bucknall 2012}

Bucknall CE, Miller G, Lloyd SM, Cleland J, McCluskey S, Cotton M, et al. Glasgow supported self-management trial (GSUST) for patients with moderate to severe COPD: randomised controlled trial. BMJ 2012;344:e1060. [http: http:// dx.doi.org/10.1136/bmj.e1060 ] function decline in chronic obstructive pulmonary disease. Thorax 2002;57(10):847-52.

\section{Effing 2009b}

Effing TW, Kerstjens HA, Monninkhof EM, van der Valk PD, Wouters EF, Postma DS, et al. Definitions of exacerbations: does it really matter in clinical trials on COPD?. Chest 2009;136(3):918-23.

\section{Effing 2012}

Effing TW, Bourbeau J, Vercoulen J, Apter AJ, Coultas D, Meek P, et al. Self-management programmes for COPD: moving forward. Chronic Respiratory Disease 2012;9(1):27-35.

\section{Fan 2012}

Fan VS, Gaziano JM, Lew R, Bourbeau J, Adams SG, Leatherman $\mathrm{S}$, et al. A comprehensive care management program to prevent chronic obstructive pulmonary disease hospitalizations: a randomized, controlled trial. Annals of Internal Medicine 2012;156(10):673-83.

\section{Frei 2009}

Frei A, Svarin A, Steurer-Stey C, Puhan MA. Self-efficacy instruments for patients with chronic diseases suffer from methodological limitations-a systematic review. Health and Quality of Life Outcomes 2009;7(86):--. [DOI: 10.1186/1477-7525-7-86]

\section{Garrido 2006}

Carrasco Garrido P, de Miguel Díez J, Rejas Gutiérrez J, Centeno AM, Gobartt Vázquez E, Gil de Miguel A, et al. Negative impact of chronic obstructive pulmonary disease on the healthrelated quality of life of patients. Results of the EPIDEPOC study. Health and Quality of Life Outcomes 2006;4:31.

\section{GOLD 2010}

Global strategy for the diagnosis, management and prevention of COPD 2010. http://www.goldcopd.org (accessed August 2011).

\section{Heyworth 2009}

Heyworth ITM, Hazell ML, Linehan ML, Frank TL. How do common chronic conditions affect health-related quality of life?. British Journal of General Practice 2009;59(568):833-8.

\section{Higgins 2011}

Higgins JPT, Green S (editors). Cochrane Handbook for Systematic Reviews of Interventions Version 5.1 [updated March 2011]. The Cochrane Collaboration, 2011. www.cochranehandbook.org.

\section{Holland 2010}

Holland AE, Hill CJ, Rasekaba T, Lee A, Naughton MT, MCDonald CF. Updating the minimal important difference for six-minute walk distance in patients with chronic obstructive pulmonary disease. Archives of Physical Medicine and Rehabilitation 2010;91(2):221-5.

\section{Donaldson 2002}

Donaldson GC, Seemungal TA, Bhowmik A, Wedzicha JA. Relationship between exacerbation frequency and lung 


\section{Jones 2005}

Jones PW. St. George's Respiratory Questionnaire: MCID. COPD: Journal of Chronic Obstructive Pulmonary Disease 2005;2(1):75-9.

\section{Jones 2011}

Jones PW, Brusselle G, Dal Negro RW, Ferrer M, Kardos P, Levy ML, et al. Health-related quality of life in patients by COPD severity within primary care in Europe. Respiratory Medicine 2011;105(1):57-66.

\section{Karner 2012}

Karner C, Chong J, Poole P. Tiotropium versus placebo for chronic obstructive pulmonary disease. Cochrane Database of Systematic Reviews 2012, Issue 7. [DOI: 10.1002/14651858.CD009285.pub2]

\section{Langsetmo 2008}

Langsetmo L, Platt RW, Ernst P, Bourbeau J. Underreporting exacerbation of chronic obstructive pulmonary disease in a longitudinal cohort. American Journal of Respiratory and Critical Care Medicine 2008;177(4):396-401.

\section{Lorig 2003b}

Lorig KR, Holman HR. Self-management education: history, definition, outcomes, and mechanisms. Annals of Behavioral Medicine 2003;26(1):1-7.

\section{Lozano 2012}

Lozano R, Naghavi M, Foreman K, Lim S, Shibuya K, Aboyans V. Global and regional mortality from 235 causes of death for 20 age groups in 1990 and 2010: a systematic analysis for the Global Burden of Disease Study 2010. Lancet 2012;380(9859):2095-128.

\section{Mannino 2008}

Mannino DM, Thorn D, Swensen A, Holguin F. Prevalence and outcomes of diabetes, hypertension and cardiovascular disease in COPD. European Respiratory Journal 2008;32(4):962-9.

\section{Michie 2013}

Michie S, Richardson M, Johnston M, Abraham C, Francis J, Hardeman W, et al. The behavior change technique taxonomy (v1) of 93 hierarchically clustered techniques: building an international consensus for the reporting of behavior change interventions. Annals of Behavioral Medicine 2013 [Epub ahead of print].

\section{Norweg 2013}

Norweg A, Collins EG. Evidence for cognitive-behavioral strategies improving dyspnea and related distress in COPD. International Journal of Chronic Obstructive Pulmonary Disease 2013;8:439-51.

\section{Pauwels 2004}

Pauwels R, Calverley P, Buist AS, Rennard S, Fukuchi Y, Stahl E, et al. COPD exacerbations: the importance of a standard definition. Respiratory Medicine 2004;98(2):99-107.

\section{Review Manager (RevMan) [Computer program]}

The Nordic Cochrane Centre, The Cochrane Collaboration. Review Manager (RevMan). Version 5.2. Copenhagen: The Nordic Cochrane Centre, The Cochrane Collaboration, 2012.

\section{Schnell 2012}

Schnell K, Weiss CO, Lee T, Krishnan JA, Leff B, Wolff JL, et al. The prevalence of clinically-relevant comorbid conditions in patients with physician-diagnosed COPD: a cross-sectional study using data from NHANES 1999-2008. BMC Pulmonary Medicine 2012;12:26. [DOI: 10.1186/1471-2466-12-26]

\section{Seemungal 1998}

Seemungal TA, Donaldson GC, Paul EA, Bestall JC, Jeffries DJ, Wedzicha JA. Effect of exacerbation on quality of life in patients with chronic obstructive pulmonary disease. American Journal of Respiratory and Critical Care Medicine 1998;157(5):1418-22.

\section{Sohanpal 2012}

Sohanpal R, Seale C, Taylor SJ. Learning to manage COPD: a qualitative study of reasons for attending and not attending a COPD-specific self-management programme. Chronic Respiratory Disease 2012;9(3):163-74.

\section{Soler-Cataluña 2005}

Soler-Cataluña JJ, Martínez-García MA, Román Sánchez P, Salcedo E, Navarro M, Ochando R. Severe acute exacerbations and mortality in patients with chronic obstructive pulmonary disease. Thorax 2005;60(11):925-31.

\section{Suissa 2012}

Suissa S, Dell'Aniello S, Ernst P. Long-term natural history of chronic obstructive pulmonary disease: severe exacerbations and mortality. Thorax 2012;67(11):957-63.

\section{Toy 2010}

Toy EL, Gallagher KF, Stanley EL, Swensen AR, Duh MS. The economic impact of exacerbations of chronic obstructive pulmonary disease and exacerbation definition: a review. COPD: Journal of Chronic Obstructive Pulmonary Disease 2010;7(3):214-28.

\section{Trappenburg 2011}

Trappenburg JC, van Deventer AC, Troosters T, Verheij TJ, Schrijvers AJ, Lammers JW, et al. The impact of using different symptom-based exacerbation algorithms in patients with COPD. European Respiratory Journal 2011;37(5):1260-8.

\section{Vanfleteren 2013}

Vanfleteren LE, Spruit MA, Groenen M, Gaffron S, van Empel VP, Bruijnzeel PL, et al. Clusters of comorbidities based on validated objective measurements and systemic inflammation in patients with chronic obstructive pulmonary disease. American Journal of Respiratory and Critical Care Medicine 2013;187(7):728-35.

\section{Vos 2012}

Vos T, Flaxman AD, Naghavi M, Lozano R, Michaud C, Ezzati M. Years lived with disability (YLDs) for 1160 sequelae of 289 diseases and injuries 1990-2010: a systematic analysis for the Global Burden of Disease Study 2010. Lancet 2012;380(9859):2163-96. 


\section{Wagg 2012}

Wagg K. Unravelling self-management for COPD: what next?. Chronic Respiratory Disease 2012;9(1):5-7.

\section{Wilkinson 2004}

Wilkinson TM, Donaldson GC, Hurst JR, Seemungal TA, Wedzicha JA. Early therapy improves outcomes of exacerbations of chronic obstructive pulmonary disease. American Journal of Respiratory and Critical Care Medicine 2004;169(12):1298-303.

\section{Willis 2011}

Willis KF, Robinson A, Wood-Baker R, Turner P, Walters EH. Participating in research: exploring participation and engagement in a study of self-management for people with chronic obstructive pulmonary disease. Qualitative Health Research 2011;21(9):1273-82.

\section{Xu 2010}

Xu W, Collet JP, Shapiro S, Lin Y, Yang T, Wang C, et al. Negative impacts of unreported COPD exacerbations on healthrelated quality of life at 1 year. European Respiratory Journal 2010;35(5):1022-30.

\section{CHARACTERISTICS OF STUDIES}

Characteristics of included studies [ordered by study ID]

\section{References to other published versions of this review}

\section{Effing 2007}

Effing TW, Monninkhof EM, van der Valk PDLPM, Zielhuis GA, van Herwaarden CLA, Partridge MR, et al. Self-management education for patients with chronic obstructive pulmonary disease. Cochrane Database of Systematic Reviews 2007, Issue 4. [DOI: 10.1002/14651858.CD002990.pub2]

\section{Monninkhof 2002c}

Monninkhof EM, van der Valk PDLPM, van der Palen J, van Herwaarden CLA, Partidge MR, Walters EH, et al. Selfmanagement education for chronic obstructive pulmonary disease. Cochrane Database of Systematic Reviews 2002, Issue 4. [DOI: 10.1002/14651858.CD002990]

\section{Monninkhof 2003b}

Monninkhof E, van der Valk P, van der Palen J, van Herwaarden C, Partridge MR, Zielhuis G. Self-management education for patients with chronic obstructive pulmonary disease: a systematic review. Thorax 2003;58(5):394-8.

* Indicates the major publication for the study

Akinci 2011

\begin{tabular}{ll}
\hline Methods & Design: CCT. Follow-up: three months. Control group: usual care \\
\hline Participants & Recruitment: university hospital (outpatient clinic) \\
& Eligible: 68 \\
Randomly assigned: 52 & Completed: 32 \\
Mean age: I: 71.8 (7.8) years; C: 65.1 (10.2) years \\
Sex (\% male): not reported \\
COPD: clinically stable COPD stage three or four according to GOLD \\
Major inclusion criteria: clinically stable condition with no history of infection or exacerbation of res- \\
piratory symptoms and with no observable change in medication during the two months preceding the \\
study \\
Major exclusion criteria: myocardial infarction within the preceding four months; unstable angina; \\
severe congestive heart disease; severe hypertension; DM with complications; muscle and joint prob- \\
lems; cancer and asthma
\end{tabular}

Interventions

Mode: home-based, individual, face-to-face, educational booklet

Professional: nurse specialising in pulmonary rehabilitation

Topics: education regarding the disease, methods for smoking cessation, use of medication, coping with breathlessness, advice about exercise and activities

Duration: participant education: two to three sessions of two to three hours, four phone calls; exercise: daily, 30 to 60 minutes

Action plan: no

\section{Exercise programme: yes}

Behavioural components: providing feedback to the participant 
Akinci 2011 (Continued)

Outcomes
2. Bare
3. FEV $1 \%$ of predicted
4. FEV $1 /$ FVC
5. $6 \mathrm{MWT}$

Notes Sources of funding: not reported

\section{Risk of bias}

\begin{tabular}{lll}
\hline Bias & Authors' judgement & Support for judgement \\
\hline $\begin{array}{l}\text { Random sequence genera- } \\
\text { tion (selection bias) }\end{array}$ & High risk & $\begin{array}{l}\text { "These patients were divided into a rehabilitation group ( } \mathrm{n}=27) \text { and a control } \\
\text { group }(\mathrm{n}=25) . " \text { page } 160\end{array}$ \\
& Comment: The study is a CCT, so no random sequence was generated \\
\hline $\begin{array}{l}\text { Allocation concealment } \\
\text { (selection bias) }\end{array}$ & High risk & $\begin{array}{l}\text { "These patients were divided into a rehabilitation group ( } \mathrm{n}=27) \text { and a control } \\
\text { group ( } \mathrm{n}=25) . " \text { page } 160\end{array}$ \\
& Comment: The study is a CCT, so no allocation concealment was provided
\end{tabular}

$\begin{array}{ll}\begin{array}{l}\text { Blinding of participants } \\ \text { and personnel (perfor- }\end{array} & \text { Unclear risk } \\ \text { bias of this is unclear }\end{array}$
bias of this is unclear mance bias)

All outcomes

\begin{tabular}{|c|c|c|}
\hline $\begin{array}{l}\text { Blinding of outcome as- } \\
\text { sessment (detection bias) }\end{array}$ & Unclear risk & $\begin{array}{l}\text { Comment: Blinding of outcome assessment was not reported; the risk of bias } \\
\text { of this is unclear }\end{array}$ \\
\hline
\end{tabular}

sessment (detection bias)

Comment: Blinding of outcome assessment was not reported; the risk of bias

All outcomes

Incomplete outcome data High risk

(attrition bias)
"In the pulmonary rehabilitation group, five patents did not perform the as- signed exercise, five patients had acute exacerbations of COPD, and one pa- tient died. In the control group, five patients did not attend the second evalu- ation and four patients had exacerbation. Thus the study was conducted with 16 rehabilitation patients and 16 control patients." page 160
Comment: The number of dropouts was comparable in both groups but quite high (>30\%). Not clear why five participants did not perform the exercises and why five participants did not attend the second meeting. A per-protocol analy- sis was performed

\begin{tabular}{|c|c|c|}
\hline $\begin{array}{l}\text { Selective reporting (re- } \\
\text { porting bias) }\end{array}$ & Unclear risk & Comment: no signs of selective reporting; however, no protocol available \\
\hline Other bias & Low risk & \\
\hline
\end{tabular}

Bourbeau 2003

\begin{tabular}{ll}
\hline Methods & Design: RCT. Follow-up: $12 / 24$ months. Control group: usual care \\
\hline Participants & Recruitment: hospital (outpatients) \\
& Eligible: 469 \\
& Randomly assigned: 191 \\
& Completed: 175 \\
\hline
\end{tabular}


Bourbeau 2003 (Continued)

Mean age: I: $69.4(6.5)$ years; C: $69.6(7.4)$ years

Sex (\% male): I: $52 \%$; C: $59 \%$

COPD: stable COPD with at least one hospitalisation for an exacerbation in preceding year

Major inclusion criteria: age >= 50 years; >= 10 pack-years; FEV1\% (post): $25 \%$ to $70 \%$; FEV 1 /VC $<70$

Major exclusion criteria: no previous diagnosis of asthma or left congestive heart failure, terminal disease, dementia, uncontrolled psychiatric disease, no pulmonary rehab < one year ago, no long-term facility stays

Interventions

Mode: individual sessions by an experienced health professional at the participant's home

Professional: nurse, respiratory therapist or respiratory physiotherapist

Topics: COPD knowledge, breathing and coughing techniques, energy conservation during day-by-day activities, relaxation exercises, preventing and controlling symptoms through inhalation techniques, understanding and using plan of action for acute exacerbations, adopting a healthy lifestyle, leisure activities and travelling, a simple home exercise programme, long-term oxygen therapy when appropriate

Duration: seven to eight weeks * one hour; first two months weekly telephone calls, from then, oncea-month telephone call. Exercise evaluation (not mandatory) and exercise teaching three times a week for 30 to 45 minutes

Action plan: yes

Exercise programme: yes (not mandatory)

Behavioural components: goal setting, motivational interviewing, providing feedback

\begin{tabular}{ll}
\hline Outcomes & 1. SGRQ \\
2. Exacerbations \\
3. Spirometry \\
4. FEV 1 (L) \\
5. Forced vital capacity \\
6. Hospital admissions \\
7. Symptoms \\
8. Emergency department visits \\
9. Outpatient visits \\
10.6MWT
\end{tabular}

Notes

Risk of bias

\begin{tabular}{lll}
\hline Bias & Authors' judgement & Support for judgement \\
\hline $\begin{array}{l}\text { Random sequence genera- } \\
\text { tion (selection bias) }\end{array}$ & Low risk & $\begin{array}{l}\text { "...central computer-generated list of random numbers. Randomization was } \\
\text { stratified per center and in blocks of 6, and patients were assigned to the self } \\
\text { management program (intervention group) or to usual care." Bourbeau 2003, } \\
\text { page 586 }\end{array}$
\end{tabular}

Comment: Random sequence generation was adequately performed

\begin{tabular}{lll}
\hline $\begin{array}{l}\text { Allocation concealment } \\
\text { (selection bias) }\end{array}$ & Low risk & $\begin{array}{l}\text { "The blocking factor was not known by the investigators or their staff in each } \\
\text { participating center." Bourbeau 2003, page } 586\end{array}$ \\
& Comment: Allocation was adequately concealed \\
\hline $\begin{array}{l}\text { Blinding of participants } \\
\begin{array}{l}\text { and personnel (perfor- } \\
\text { mance bias) }\end{array}\end{array}$ & Unclear risk & "Since a double-blind design was impossible..." Bourbeau 2003, page 586 \\
& Comment: Participants and personnel were not blinded
\end{tabular}


Bourbeau 2003 (Continued)

All outcomes

\section{Blinding of outcome as- Low risk} sessment (detection bias)

All outcomes "...an independent evaluator unaware of the patient assignment was responsible for the evaluation process in each center. The evaluator was cautioned not to ask about the workbook modules and types of contact." Bourbeau 2003, page 586

Comment: Outcome assessment was blinded
Incomplete outcome data Low risk

(attrition bias)

All outcomes
"At the end of the 2 nd yr of follow-up, data were available for 75 patients in the standard-care group (two subjects were lost to follow-up, nine patients died in the 1st yr and nine in the 2nd yr) and 83

patients following the self-management programme (five patients died in the 1 st yr and eight in the 2nd yr)." Gadoury 2005, page 855

Comment: Dropout in the usual care group was somewhat higher than in the self management group; however, an intention-to-treat analysis was used

Selective reporting (re- Unclear risk

Comment: no signs of selective reporting; however, no protocol available porting bias)

Other bias Low risk

Bösch 2007

Methods Design: RCT. Follow-up: 12 months. Control group: usual care

Participants Recruitment: hospital (outpatient clinic)

Eligible: not reported

Randomly assigned: 50

Completed: 41

Mean age: I: 63.8 (8.4) years; C: 64.6 (6.8) years

Sex ( $\%$ male): $63 \%$ of 41 participants who completed the study were male; the distribution in the groups is not reported

COPD: COPD with obstruction confirmed by spirometry and $\mathrm{FEV}_{1} / \mathrm{FVC}<70 \%$

Major exclusion criteria: co-morbidities that significantly influence symptoms, capacity or spirometry (symptomatic cardiopulmonary disease)

Interventions Mode: group-based (six to eight participants), face-to-face, outpatient clinic

Professional: respiratory nurse under supervision of a respiratory specialist

Topics: education regarding the disease, smoking cessation, action plan with self treatment of exacerbations, advice about exercise, advice about nutrition, advice about medication, coping with breathlessness, travelling

Duration: four sessions of two hours

Action plan: yes

\section{Exercise programme: no}

Behavioural components: cognitive-behavioural therapy, motivational interviewing, goal setting, providing feedback to the participant

$\begin{array}{ll}\text { Outcomes } & \text { 1. } \mathrm{mMRC} \\ \text { 2. Courses of antibiotics } \\ \text { 3. } \mathrm{FEV}_{1}(\mathrm{~L}) \\ \text { 4. Hospital admissions }\end{array}$


Bösch 2007 (Continued)

5. $6 \mathrm{MWT}$

Notes Sources of funding: not reported

\section{Risk of bias}

\begin{tabular}{|c|c|c|}
\hline Bias & Authors' judgement & Support for judgement \\
\hline $\begin{array}{l}\text { Random sequence genera- } \\
\text { tion (selection bias) }\end{array}$ & Unclear risk & $\begin{array}{l}\text { Comment: The method of random sequence generation was not clearly re- } \\
\text { ported }\end{array}$ \\
\hline \multirow{2}{*}{$\begin{array}{l}\text { Allocation concealment } \\
\text { (selection bias) }\end{array}$} & \multirow[t]{2}{*}{ Unclear risk } & Information from the author: "Pick of envelope" \\
\hline & & Comment: This information is too concise to assess risk of bias \\
\hline $\begin{array}{l}\text { Blinding of participants } \\
\text { and personnel (perfor- } \\
\text { mance bias) } \\
\text { All outcomes }\end{array}$ & Unclear risk & Comment: Blinding of participants and personnel was not reported \\
\hline $\begin{array}{l}\text { Blinding of outcome as- } \\
\text { sessment (detection bias) } \\
\text { All outcomes }\end{array}$ & Unclear risk & Comment: Blinding of outcome assessment was not reported \\
\hline $\begin{array}{l}\text { Incomplete outcome data } \\
\text { (attrition bias) } \\
\text { All outcomes }\end{array}$ & High risk & $\begin{array}{l}\text { Comment: Eight participants in the intervention group and one participant in } \\
\text { the control group dropped out. Reasons for dropout were not clearly reported, } \\
\text { and only participants who completed follow-up were included in the analysis }\end{array}$ \\
\hline $\begin{array}{l}\text { Selective reporting (re- } \\
\text { porting bias) }\end{array}$ & Unclear risk & Comment: no signs of selective reporting; however, no protocol available \\
\hline Other bias & Low risk & \\
\hline
\end{tabular}

Casas 2006

Methods Design: RCT. Follow-up: 12 months. Control group: usual care

\begin{tabular}{ll}
\hline Participants & Recruitment: hospital (inpatient clinic) \\
& Eligible: 160 \\
Randomly assigned: 155 \\
Completed: 120 \\
Mean age: I: 70 (9) years; C: 72 (9) years \\
Sex (\% male): I: $77 \% ;$ C: $88 \%$ \\
COPD: admitted because of an episode of exacerbation requiring hospitalisation $>48$ hours \\
Major exclusion criteria: not living in the healthcare area or in a nursing home; severe co-morbid con- \\
ditions; logistical limitations due to extremely poor social conditions
\end{tabular}


Duration: one group session of two hours, three individual sessions of 40 minutes, and one to 10 sessions of 20 minutes at home

Action plan: yes

\section{Exercise programme: no}

Behavioural components: cognitive-behavioural therapy, motivational interviewing, goal setting, providing feedback to the participant

$\begin{array}{ll}\text { Outcomes } & \text { 1. SGRQ } \\ \text { 2. EQ-5D } \\ \text { 3. MRC } \\ \text { 4. } \mathrm{FEV}_{1}(\mathrm{~L}) \\ \text { 5. FEV } / \mathrm{FVC} \\ \text { 6. Hospital admissions } \\ \text { 7. Doctor and nurse visits } \\ \text { 8. Courses of antibiotics }\end{array}$

Notes

Sources of funding: The present study was supported by: the CHRONIC project (IST-1999/12158) from the European Union; Marato de TV3; Comissionat per a Universitats I Recerca de la Generalitat de Catalunya (SGR-00386); Red Respira Instituto de Salud Carlos III (ISCIII)-Redes Tematicas de Investigacion Cooperativa (RTIC)-03/11; and Red Telemedicina ISCIII-RTIC-03/117. A. Casas and T. Troosters were research fellows supported by CHRONIC (IST-1999/12158). T. Troosters is currently a postdoctoral research fellow of the Fonds voor Wetenschappelijk Onderzoek (Vlaanderen, Belgium). J. Garcia-Aymerich was supported by Red Respira (RTIC C03/11) and ICS III

\section{Risk of bias}

Bias Authors' judgement Support for judgement

Random sequence genera- Low risk tion (selection bias)
"All 155 patients included in the study were blindly assigned (1:1 ratio) using computer generated random numbers to either IC or usual care (UC)". page 124

Comment: Random sequence generation was adequately performed

Allocation concealment Low risk
(selection bias)

\begin{abstract}
"Adequacy of the assignment process to either IC or UC was ensured by both the generation of the allocation sequence by a random process and preventing foreknowledge of the treatment assignments in the specialised team that implemented the allocation sequence". page 128
\end{abstract}

Comment: Allocation was adequately concealed

\begin{tabular}{|c|c|c|}
\hline $\begin{array}{l}\text { Blinding of participants } \\
\text { and personnel (perfor- } \\
\text { mance bias) } \\
\text { All outcomes }\end{array}$ & Unclear risk & Comment: Blinding of participants and personnel was not reported \\
\hline $\begin{array}{l}\text { Blinding of outcome as- } \\
\text { sessment (detection bias) } \\
\text { All outcomes }\end{array}$ & Unclear risk & $\begin{array}{l}\text { "Early assessment of patients at study admission was identical for both } \\
\text { groups. Assessment included a blind administration of a questionnaire, de- } \\
\text { scribed in detail elsewhere." } \\
\text { Comment: Only part of the baseline assessment was blinded; the other assess- } \\
\text { ments were not blinded, and it is not clear who performed the measurements }\end{array}$ \\
\hline $\begin{array}{l}\text { Incomplete outcome data } \\
\text { (attrition bias) } \\
\text { All outcomes }\end{array}$ & Unclear risk & $\begin{array}{l}\text { "A strength of the present analysis was that there were no subjects lost to fol- } \\
\text { low-up, since all drop-outs were due to appearance of exclusion criteria or } \\
\text { death and, in any case, valid information about re-hospitalisations was avail- } \\
\text { able from the national health services." Casas 2006, page XX }\end{array}$ \\
\hline
\end{tabular}


"During follow-up, a priori defined exclusion criteria, such as lung cancer, appeared in 9 subjects. Twenty-one subjects died, and 16 were lost to follow-up. Only $57 \%$ of subjects finished the study at 12 months". .... "Since data about outcome variables was not available in the lost subjects (whether due to exclusion, loss to follow-up or death), an intention-to-treat principle was not possible". Garcia-Aymerich 2007, page 1464

Comment: Data on healthcare utilisation reported in Casas et al 2006 were presented for all included participants, leading to a low risk of bias. However, $>40 \%$ of the data on functional status and HRQoL reported in Garcia-Aymerich et al 2006 was missing, leading to a high risk of bias

\section{Selective reporting (reporting bias)

Methods Design: CCT. Follow-up: 12 months. Control group: usual care

\section{Participants}

Recruitment: general practise

Eligible: not reported

Randomly assigned: 162

Completed: 152

Mean age: I: 64 (11) years; C: 63 (11) years

Sex (\% male): I: $59 \%$; C: $67 \%$

COPD: existing diagnosis, with chronic respiratory complaints in the absence of prior history of asthma or atopy, and had to fulfil former national guideline lung function criteria with a postbronchodilator $\mathrm{FEV}_{1}<80 \%$ predicted and/or a postbronchodilator $\mathrm{FEV}_{1} / \mathrm{FVC}$ ratio $<0.7$

Major exclusion criteria: rapidly progressing or terminal disease, immobility, substance abuse or inability to fill in questionnaires

\section{Interventions \\ Mode: group sessions and individual sessions, face-to-face, telephone, general practise \\ Professional: specialised physiotherapist, respiratory nurse, physician assistant, dietician, respiratory} specialist, general practitioner

Topics: education regarding the disease, smoking cessation, action plan with self treatment of exacerbations, exercise programme, advice about nutrition, advice about medication

Duration: 10 group sessions, eight individual sessions, duration unknown Action plan: yes

\section{Exercise programme: yes}

Behavioural components: goal setting, providing feedback to the participant

\begin{tabular}{ll}
\hline Outcomes & 1. SGRQ \\
& 2. CCQ \\
3. MRC
\end{tabular}

Notes

Souces of funding: PICASSO for COPD, an initiative of Boehringer Ingelheim, Pfizer and Caphri Research Institute, Maastricht University

Note: 106 (70\%) of the participants had an $\mathrm{FEV}_{1} / \mathrm{FVC}>70 \%$ 
Chavannes 2009 (Continued)

Risk of bias

\begin{tabular}{lll}
\hline Bias & Authors' judgement & Support for judgement \\
\hline $\begin{array}{l}\text { Random sequence genera- } \\
\text { tion (selection bias) }\end{array}$ & High risk & $\begin{array}{l}\text { "Two primary health care centres serving two separate villages in the southern } \\
\text { part of the Netherlands were recruited for epidemiological reasons: both had } \\
\text { very similar patient populations with comparable regional living conditions, } \\
\text { but these were traditionally self-sufficient communities with little risk of inter- } \\
\text { vention contamination." page } 172\end{array}$ \\
Comment: The study is a CCT, so no random sequence was generated
\end{tabular}

Allocation concealment High risk (selection bias)
"Two primary health care centres serving two separate villages in the southern part of the Netherlands were recruited for epidemiological reasons: both had very similar patient

populations with comparable regional living conditions, but these were traditionally self-sufficient communities with little risk of intervention contamination." page 172

Comment: The study is a CCT, so no allocation concealment was provided

Blinding of participants Unclear risk Comment: Blinding of participants and personnel was not reported
and personnel (performance bias)

All outcomes

\begin{tabular}{|c|c|c|}
\hline $\begin{array}{l}\text { Blinding of outcome as- } \\
\text { sessment (detection bias) } \\
\text { All outcomes }\end{array}$ & Unclear risk & Comment: Blinding of outcome assessment was not reported \\
\hline $\begin{array}{l}\text { Incomplete outcome data } \\
\text { (attrition bias) } \\
\text { All outcomes }\end{array}$ & Unclear risk & $\begin{array}{l}\text { "We recruited } 162 \text { primary care COPD patients, of whom } 152 \text { had analysable } \\
\text { data." page } 173 \\
\text { Comment: It is not clear in which group participants dropped out and for what } \\
\text { reason }\end{array}$ \\
\hline $\begin{array}{l}\text { Selective reporting (re- } \\
\text { porting bias) }\end{array}$ & Unclear risk & $\begin{array}{l}\text { Domains of the SGRQ and the CCQ were not reported; further no signs of selec- } \\
\text { tive reporting }\end{array}$ \\
\hline
\end{tabular}

Other bias Low risk

Chuang 2011

Methods Design: RCT. Follow-up: 12 months. Control group: usual care

Participants

Recruitment: health maintenance registration

Eligible: 424

Randomly assigned: 282

Completed: not reported

Mean age: I: males: 76.8 (1.3) years, females: 75.4 (1.1) years

C: males: 76.9 (1.2) years, females: 75.6 (1.15) years

Sex (\% male): I: $35 \%$; C: $35 \%$

COPD: clinical diagnosis 
Major exclusion criteria: The participant or the primary care physician (PCP) declined or opted out, was no longer an active participant in the HCP health maintenance organisation; enrolled in hospice or institutionalised in custodial nursing facilities; was unable to participate because of severe dementia or organic brain disorder; was on long-term haemodialysis because of end-stage renal disease; or was undergoing chemotherapy for active malignancies

Interventions

Mode: individual sessions, face-to-face, telephone, written educational material, outpatient clinic Professional: registered nurse/case manager

Topics: education regarding the disease, smoking cessation, action plan with self treatment of exacerbations, exercise programme, advice about exercise, advice about nutrition, advice about medication, coping with breathlessness

Duration: at least 10 educational calls 10 to 15 minutes each, at least one face-to-face 45 minutes Action plan: yes

\section{Exercise programme: yes}

Behavioural components: motivational interviewing, providing feedback to the participant

\begin{tabular}{ll}
\hline Outcomes & 1. Hospital admissions \\
2. Hospital days \\
3. General practitioner visits \\
4. Emergency department visits \\
5. Costs
\end{tabular}

Notes Souces of funding: not reported

\section{Risk of bias}

Bias Authors' judgement Support for judgement

Random sequence genera- Unclear risk "A risk stratification tool (developed at SCAN Health Plan) helped prioritize pation (selection bias) tients for inclusion in the program with prospective designation of matched intervention and control groups. Nurse case managers then telephonically contacted the patients on the list in a 1-to-1 alternating fashion, to enroll patients into the intervention group until the end of the 6-month enrolment period". page 134

Additional information from the authors: "Stratified randomisation, with one to one assignment of patient to control vs intervention, stratified based on age, sex, risk/cost modelling and whether patient belongs to a group vs IPA practice"

Comment: unclear how the random sequence was generated

Allocation concealment Unclear risk
(selection bias)

Information from the authors: "See above and Patient selected sequentially from list, with stratification above, by project manager without influence from physicians or case managers"

Comment: unclear whether allocation was really concealed

\begin{tabular}{lll}
\hline $\begin{array}{l}\text { Blinding of participants } \\
\text { and personnel (perfor- } \\
\text { mance bias) }\end{array}$ & Unclear risk & \\
$\begin{array}{l}\text { All outcomes } \\
\text { Blinding of outcome as- } \\
\begin{array}{l}\text { sessment (detection bias) } \\
\text { All outcomes }\end{array}\end{array}$ & Unclear risk & $\begin{array}{l}\text { Comment: Blinding of outcome assessment was not reported, and it was not } \\
\text { clear who performed the outcome assessment }\end{array}$ \\
\hline
\end{tabular}


Chuang 2011 (Continued)

Incomplete outcome data Unclear risk Comment: No information was given regarding the completeness of outcome (attrition bias) data

All outcomes

Selective reporting (re- Unclear risk Comment: no signs of selective reporting; however, no protocol available porting bias)

Other bias Low risk

Coultas 2005a

Methods Design: RCT. Follow-up: six months. Intervention one: nurse-assisted medical management (MM). Intervention two: nurse-assisted collaborative management (CM). Control group: usual care (UC)

Participants Recruitment: primary care clinics

Eligible: 217

Randomly assigned: 217

Completed: 151

Mean age: MM: 68.3 (6.6) years; CM: 70.1 (7.0) years; UC 68.8 (10.4) years

Sex (\% male): MM: 42.9\%; CM: 32.7\%; UC: $53.8 \%$

COPD: COPD-related diagnosis code (International Classification of Diseases, Ninth Revision: codes 491, 492, 496); current or former smoker (at least 20 pack-years); at least one respiratory symptom (cough, shortness of breath, wheeze) during the past 12 months; FEV $1 \%<80 \%$; FEV $1 / \mathrm{VC}<70 \%$

Major exclusion criteria: not reported

Interventions

Mode: $M$ M: nurse-assisted medical management = enhance patient knowledge; $\mathrm{CM}$ : nurse-assisted collaborative management = goals of $\mathrm{MM}+$ facilitating the adoption of healthy behaviour including lifestyle and self management skills

Professional: nurse

Topics: MM: COPD, symptoms, optimal medical management, smoking cessation, action plan for worsening symptoms. Finally, a letter was written to the participant's GP, describing the participant's status and providing suggestions of modifying management consistent with GOLD guidelines

Duration (mean): MM: 124 minutes (seven sessions); CM: 207 minutes (eight sessions)

Action plan: yes

Exercise programme: no

Behavioural components: providing feedback to the participant

\begin{tabular}{ll}
\hline Outcomes & 1. Health status \\
2. SGRQ \\
3. SF-36 \\
4. Perceived illness intrusiveness \\
5. Doctor visits \\
6. ER visits \\
7. Hospital admissions
\end{tabular}

Note 1: Baseline characteristics are given only for the group of participants who completed the sixmonth follow-up period

Note 2: Dropout percentages are high: MM: 32.0\%; CM: 29.2\%; UC: $30.1 \%$

Note 3: Participants who dropped out of the study had more severe airflow obstruction, higher levels of distress and lower quality of life compared with participants who completed the study 
Note 4: Content of the interventions is not described properly, whereas the training of the nurses providing the intervention was described in detail

Note 5: Outcome measures of self efficacy and social support and BSI-18 and CES-D scores were measured but not reported in the article

\section{Risk of bias}

Bias Authors' judgement Support for judgement

Random sequence genera- Low risk tion (selection bias)
"Patients were randomly assigned (...) using a computer-generated random list". page 2018

Comment: Random sequence generation was adequately performed

Allocation concealment Unclear risk Comment: It is unclear how allocation concealment was guaranteed
(selection bias)

(selection bias)

Blinding of participants Unclear risk Comment: Blinding of participants and personnel was not reported
and personnel (perfor-
mance bias)
All outcomes

Blinding of outcome as- Low risk sessment (detection bias)

All outcomes

\begin{abstract}
"Health outcomes in the intervention groups were assessed at baseline and after the 6-month intervention by two different trained interviewers who were not involved in the interventions and were blinded to group assignments". page 2019

"To limit interviewer bias, each interviewer who obtained the baseline and 6month outcome data was blinded to the patient's treatment group". page 2023

Comment: The interviewers who performed the assessments were not involved in the intervention and were blinded to participants' treatment groups
\end{abstract}

Incomplete outcome data High risk (attrition bias)

"Of the 217 patients enrolled in the study, 151 (69.6\%) completed the 6-month intervention and follow-up data collection. The reasons for the failure to complete the study were patient was unavailable for follow-up (26.7\%) and death (3.7\%) [Fig 1]. The frequency of patients being unavailable for follow-up was equally distributed among the three intervention groups (Fig 1). Overall, the demographic characteristics of the patients who dropped out of the study were similar to those who completed the study (data not shown). However, patients who dropped out of the study had more severe airflow obstruction, higher levels of distress, and lower quality of life, as measured with the SGRQ, compared with the patients who had completed the study (data not shown)". page 2020

Comment: Approximately the same number of participants dropped out from each group, but the total number of dropouts was high (>30\%). Participants who dropped out were more severely diseased than those who did not drop out

\begin{tabular}{lll}
\hline $\begin{array}{l}\text { Selective reporting (re- } \\
\text { porting bias) }\end{array}$ & Unclear risk & Comment: no signs of selective reporting; however, no protocol available \\
\hline Other bias & Low risk \\
\hline
\end{tabular}


Coultas 2005b

\begin{tabular}{ll}
\hline Methods & See Coultas 2005a \\
\hline Participants & See Coultas 2005a \\
\hline Interventions & See Coultas 2005a \\
\hline Outcomes & See Coultas 2005a \\
\hline Notes & See Coultas 2005a \\
\hline
\end{tabular}

\section{Risk of bias}

\begin{tabular}{lll}
\hline Bias & Authors' judgement & Support for judgement \\
\hline $\begin{array}{l}\text { Random sequence genera- } \\
\text { tion (selection bias) }\end{array}$ & Low risk & See Coultas 2005a \\
\hline $\begin{array}{l}\text { Allocation concealment } \\
\text { (selection bias) }\end{array}$ & Unclear risk & See Coultas 2005a \\
\hline $\begin{array}{l}\text { Blinding of participants } \\
\text { and personnel (perfor- } \\
\text { mance bias) } \\
\text { All outcomes }\end{array}$ & Unclear risk & See Coultas 2005a \\
\hline $\begin{array}{l}\text { Blinding of outcome as- } \\
\text { sessment (detection bias) } \\
\text { All outcomes }\end{array}$ & Low risk & See Coultas 2005a \\
\hline $\begin{array}{l}\text { Incomplete outcome data } \\
\text { (attrition bias) } \\
\text { All outcomes }\end{array}$ & High risk & See Coultas 2005a \\
\hline $\begin{array}{l}\text { Selective reporting (re- } \\
\text { porting bias) }\end{array}$ & Unclear risk & See Coultas 2005a \\
\hline \begin{tabular}{l} 
Other bias \\
\hline
\end{tabular} & Unclear risk & See Coultas 2005a \\
\hline
\end{tabular}

Effing 2009

Methods Design: RCT. Follow-up: 12 months. Intervention one: self management programme and self treatment of exacerbations. Intervention two: self management programme

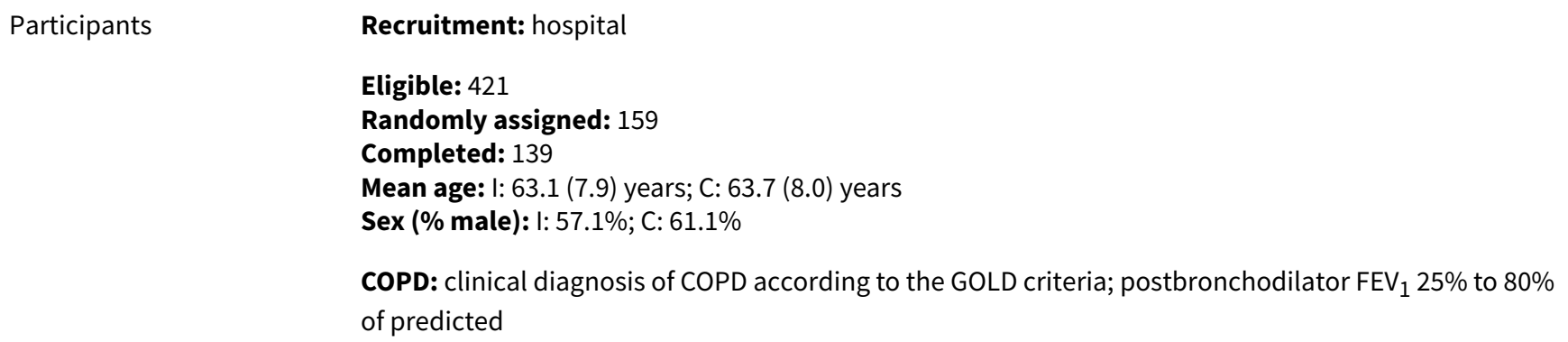

COPD: clinical diagnosis of COPD according to the GOLD criteria; postbronchodilator $\mathrm{FEV}_{1} 25 \%$ to $80 \%$ of predicted

Major inclusion criteria: no exacerbation in the month before enrolment; >= three exacerbations, defined as respiratory problems that required a course of oral corticosteroids and/or antibiotics, or one 
Effing 2009 (Continued)

hospitalisation for respiratory problems in the two years preceding study entry; (ex)smoker; age 40 to 75 years

Major exclusion criteria: other serious disease with a low survival rate; other diseases influencing bronchial symptoms and/or lung function (e.g. cardiac insufficiency, sarcoidosis); severe psychiatric illness; uncontrolled diabetes mellitus during COPD exacerbation in the past or hospitalisation for diabetes mellitus in the two years preceding the study; need for regular oxygen therapy (> 16 hours/d or $\mathrm{pO}_{2}<7.2 \mathrm{kPa}$ ); maintenance therapy with antibiotics; known $a_{1}$-antitrypsin deficiency; disorders or progressive disease seriously influencing walking ability (e.g. amputation, paralysis, progressive muscle disease)

Interventions

Mode: group and individual sessions, face-to-face, telephone, booklet, outpatient clinic Professional: respiratory nurse, respiratory physiotherapist

Topics: education regarding COPD, action plan, advice about exercise, advice about nutrition, advice about medication, coping with breathlessness

Duration: Four weekly group sessions of two hours and three recall telephone calls Action plan: yes

\title{
Exercise programme: yes
}

Behavioural components: goal setting, providing feedback to the participant

Outcomes
2. CRQ
3. HADS
4. Exacerbations (frequency, days, symptom score)
5. Courses of oral steroids
6. Courses of antibiotics
7. FEV1\% of predicted
8. FEV $1 /$ FVC
9. Hospital admissions
10.Hospital days
11.ED visits
12.Outpatient visits
13.GP visits

Notes Sources of funding: a grant from the Dutch Asthma Foundation

\section{Risk of bias}

Bias Authors' judgement Support for judgement

Random sequence genera- Low risk tion (selection bias)

\begin{abstract}
"Patients were randomised into two study groups, using a minimisation programme, minimising differences between groups in gender, current smoking, FEV1 predicted ( $<=$ or $>50 \%$ ), use of inhaled corticosteroid, and current participation in a regular physiotherapy programme". page 957

Comment: Random sequence generation was adequately performed
\end{abstract}

\begin{tabular}{ll}
\hline $\begin{array}{l}\text { Allocation concealment } \\
\text { (selection bias) }\end{array}$ & Low risk \\
& "Patients were randomised into two study groups, using a minimisation pro- \\
& FEV1 predicted (<= or $>50 \%)$, use of inhaled corticosteroid, and current partici- \\
& pation in a regular physiotherapy programme". page 957 \\
& Comment: Allocation was adequately concealed
\end{tabular}




\section{Effing 2009 (Continued)}

Blinding of participants and personnel (perforComment: Participants and personnel were not blinded mance bias)

All outcomes

\begin{tabular}{|c|c|c|}
\hline $\begin{array}{l}\text { Blinding of outcome as- } \\
\text { sessment (detection bias) }\end{array}$ & Low risk & $\begin{array}{l}\text { Comment: Outcome assessment was not blinded; however, measurements } \\
\text { were performed by an assessor who was independent of the study }\end{array}$ \\
\hline
\end{tabular}

All outcomes

Incomplete outcome data Low risk (attrition bias)

All outcomes

\begin{abstract}
"Between inclusion and the baseline measurements, three patients dropped out in each group and insufficient diary data were delivered by 11 patients. The baseline characteristics of the remaining 142 patients are shown in table 2 , and were similar in both groups with respect to all measured prognostic factors. The 11 dropouts did not differ from the remaining group in any factors except the Medical Research Council dyspnoea scale (mean (SD) 2.3 (1.1) vs 3.0 (1.1) in dropouts versus remaining patients; $P=0.041$ ). During the 1-year follow-up period, three patients in the self-treatment group dropped out, of whom one died of an intracerebral haemorrhage. Thus, 67 patients in the selftreatment group and 72 patients in the control group completed the 1-year follow-up"
\end{abstract}

Comment: The number of dropouts and insufficient data were somewhat greater in the intervention group than in the control group. Reasons for dropout were comparable in the two groups, and overall dropout is low

\begin{tabular}{lll}
\hline $\begin{array}{l}\text { Selective reporting (re- } \\
\text { porting bias) }\end{array}$ & Unclear risk & Comment: no signs of selective reporting; however, no protocol available \\
\hline Other bias & Low risk \\
\hline
\end{tabular}

Effing 2011

Methods

Design: RCT. Follow-up: 12 months. Intervention one: self management programme and community-based physiotherapeutic exercise programme.Intervention two: self management programme

\section{Participants}

\section{Recruitment: hospital}

Eligible: 421

Randomly assigned: 159

Completed: 142

Mean age: I: 62.9 (8.1) years; C: 63.9 (7.8) years

Sex (\% male): I: $58.4 \%$; C: $57.9 \%$

COPD: clinical diagnosis of COPD according to GOLD criteria, postbronchodilator $\mathrm{FEV}_{1} 25 \%$ to $80 \%$ of predicted

Major inclusion criteria: no exacerbation in the month before enrolment; >= three exacerbations, defined as respiratory problems that required a course of oral corticosteroids and/or antibiotics, or one hospitalisation for respiratory problems in the two years preceding study entry; (ex)smoker; age 40 to 75 years

Major exclusion criteria: other serious disease with a low survival rate; other diseases influencing bronchial symptoms and/or lung function (e.g. cardiac insufficiency, sarcoidosis); severe psychiatric illness; uncontrolled diabetes mellitus during COPD exacerbation in the past or hospitalisation for diabetes mellitus in the two years preceding the study; need for regular oxygen therapy ( $>16$ hours/d or $\mathrm{pO}_{2}<7.2 \mathrm{kPa}$ ); maintenance therapy with antibiotics; known $\alpha_{1}$-antitrypsin deficiency; disorders or 
Effing 2011 (Continued)

progressive disease seriously influencing walking ability (e.g. amputation, paralysis, progressive muscle disease)

Interventions

Mode: group and individual sessions, face-to-face, telephone, booklet, outpatient clinic, private physiotherapy practice

Professional: respiratory nurse, (respiratory) physiotherapist

Topics: education regarding COPD, action plan, advice about exercise, advice about nutrition, advice about medication, coping with breathlessness

Duration: Four weekly group sessions of two hours and three recall telephone calls

Six months: three times/wk training sessions $=72$ sessions

Five months: two times/wk training sessions $=40$ sessions

During the whole period, one training session of a half hour was provided at home

Action plan: yes

\section{Exercise programme: yes}

Behavioural components: goal setting, providing feedback to the participant

\begin{tabular}{|c|c|}
\hline Outcomes & $\begin{array}{l}\text { - } \text { CRQ } \\
\text { - } \text { CCQ } \\
\text { - } \text { HADS } \\
\text { - Exacerbations (frequency, days, symptom score) } \\
\text { - Courses of oral steroids } \\
\text { - Courses of antibiotics } \\
\text { - } \text { FEV } 1 \% \text { of predicted } \\
\text { - } \text { FEV } 1 / F V C \\
\text { - Hospital admissions } \\
\text { - Hospital days } \\
\text { - ED visits } \\
\text { - Outpatient visits } \\
\text { - } \text { GP visits }\end{array}$ \\
\hline
\end{tabular}

\section{Risk of bias}

\begin{tabular}{lll}
\hline Bias & Authors' judgement & Support for judgement \\
\hline $\begin{array}{l}\text { Random sequence genera- } \\
\text { tion (selection bias) }\end{array}$ & Low risk & $\begin{array}{l}\text { "Patients were randomised into two study groups, using a minimisation pro- } \\
\text { gramme, minimising differences between groups in gender, current smoking, }\end{array}$ \\
& $\begin{array}{l}\text { FEV1 predicted }(<=\text { or }>50 \%) \text {, use of inhaled corticosteroid, and current partici- } \\
\text { pation in a regular physiotherapy programme". page } 419\end{array}$ \\
& Comment: Random sequence generation was adequately performed \\
\hline $\begin{array}{l}\text { Allocation concealment } \\
\text { (selection bias) }\end{array}$ & Low risk & "Patients were randomised into two study groups, using a minimisation pro- \\
& & $\begin{array}{l}\text { gramme, minimising differences between groups in gender, current smoking, } \\
\text { FEV predicted (<= or }>50 \%), \text { use of inhaled corticosteroid, and current partici- } \\
\text { pation in a regular physiotherapy programme". page 419 }\end{array}$ \\
& Comment: Allocation was adequately concealed \\
\hline
\end{tabular}


Effing 2011 (Continued)
Blinding of participants
Unclear risk
Comment: Participants and personnel were not blinded and personnel (performance bias)

All outcomes

Blinding of outcome as-
sessment (detection bias)

All outcomes

Comment: Outcome assessment was not blinded; however, the measurements were performed by an assessor who was independent of the study

Incomplete outcome data Low risk
(attrition bias)

All outcomes

\begin{abstract}
"Between the inclusion and the baseline measurements three patients dropped out in each study group (Fig. 1).....During the year after the baseline measurements, three patients dropped out in the intervention group, as did eight patients in the control group (see Fig. 1).

The three patients who dropped out of the intervention group during the oneyear follow-up all dropped out directly after the baseline measurements before the start of COPE-active". page 421

Comment: The number of dropouts was somewhat higher in the control group than in the intervention group. Reasons for dropout were comparable in the two groups, and overall dropout was low. An intention-to-treat analysis was performed
\end{abstract}

\begin{tabular}{lll}
\hline $\begin{array}{l}\text { Selective reporting (re- } \\
\text { porting bias) }\end{array}$ & Unclear risk & Coment: no signs of selective reporting; however, no protocol available \\
\hline Other bias & Low risk \\
\hline
\end{tabular}

\title{
Emery 1998
}

Methods Design: RCT. Follow-up: two months. Control group: usual care

Participants

Recruitment: announcements, word of mouth, advertisements in weekly newspapers for older adults and physician referral

Eligible: 92

Randomly assigned: 50

Completed: 49

Mean age: I: 67.4 (5.9) years C: $67.4(7.1)$ years

Sex (\% male): I: $40 \%$ C: $48 \%$

COPD: stable COPD; > 50 years; $\mathrm{FEV}_{1} / \mathrm{VC}<70$; > six months of clinical symptoms of COPD

Major exclusion criteria: significant cardiac disease; other diseases affecting exercise tolerance or learning skills last three months; asthma without fixed obstruction

Profession: clinical psychologist

Topics: COPD knowledge, therapy, coping, interpreting pulmonary function tests, understanding arterial blood gases, stress management

Duration: 26 hours

Action plan: no

\section{Exercise programme: no}

Behavioural components: cognitive-behavioural therapy

\begin{tabular}{ll}
\hline Outcomes & 1. Health status \\
& 2. SIP
\end{tabular}


Emery 1998 (Continued)
3. HRQOL-MHLC
4. Health knowledge test
5. FEV1\%pred

Notes

Sources of funding: grants from the National Heart Lung and Blood Institute (HL45290) and the National Institute on Aging (AG00029)

Note 1: The third arm was disregarded because it was focused on pulmonary rehabilitation

\section{Risk of bias}

\begin{tabular}{lll}
\hline Bias & Authors' judgement & Support for judgement \\
\hline $\begin{array}{l}\text { Random sequence genera- } \\
\text { tion (selection bias) }\end{array}$ & Low risk & "Group assignments were taken from a random number schedule..." page 233 \\
& & Comment: Random sequence generation was adequately performed \\
\hline $\begin{array}{l}\text { Allocation concealment } \\
\text { (selection bias) }\end{array}$ & Low risk & $\begin{array}{l}\text { "...printed on a piece of paper, and placed in a sealed envelope. Participants } \\
\text { were not given the envelope containing their group assignment until after } \\
\text { completing the baseline assessment, and technical staff conducting the as- } \\
\text { sessments were not aware of group assignments" }\end{array}$ \\
& Comment: Allocation was adequately concealed
\end{tabular}

Blinding of participants Unclear risk Comment: Blinding of participants and personnel was not reported
and personnel (perfor-
mance bias)
All outcomes

\begin{tabular}{|c|c|c|}
\hline $\begin{array}{l}\text { Blinding of outcome as- } \\
\text { sessment (detection bias) } \\
\text { All outcomes }\end{array}$ & Low risk & $\begin{array}{l}\text { "...technical staff conducting the assessments were not aware of group assign- } \\
\text { ments". page } 233 \\
\text { Comment: Blinding of outcome assessment was performed }\end{array}$ \\
\hline $\begin{array}{l}\text { Incomplete outcome data } \\
\text { (attrition bias) } \\
\text { All outcomes }\end{array}$ & Low risk & $\begin{array}{l}\text { "..and } 2 \text { dropped out of the ESM condition because of transportation prob- } \\
\text { lems". page } 235 \\
\text { Comment: Dropout was low, two participants dropped out in the intervention } \\
\text { group and zero participants dropped out in the control group. A per-protocol } \\
\text { analysis was performed }\end{array}$ \\
\hline $\begin{array}{l}\text { Selective reporting (re- } \\
\text { porting bias) }\end{array}$ & Unclear risk & Comment: no signs of selective reporting; however, no protocol available \\
\hline Other bias & Low risk & \\
\hline
\end{tabular}

Faulkner 2010

\begin{tabular}{ll}
\hline Methods & Design: RCT. Follow-up: 10 weeks. Control group: usual care \\
\hline Participants & Recruitment: general practise \\
& Eligible: 215 \\
& Randomly assigned: 20 \\
& Completed: 14 \\
& Mean age: I: 70.8 (10.5) years; C: $71.3(4.5)$ years \\
& Sex (\% male): I: $90 \% ;$ C: $70 \%$
\end{tabular}


Faulkner 2010 (Continued)

COPD: clinical diagnosis of COPD GOLD stage II; FEV $150 \%$ to $80 \%$ expected postbronchodilator and $\mathrm{FEV}_{1} / \mathrm{FVC} \leq 70 \%$

Major exclusion criteria: $\mathrm{BMI}>35 \mathrm{~kg} \cdot \mathrm{m}^{2} \mathrm{or}<18 \mathrm{~kg} \cdot \mathrm{m}^{2}$; history of asthma; recent respiratory tract infection; oxygen desaturation $\left(\mathrm{SaO}_{2}\right)$ at rest $<90 \%$; prior participation in a PR programme; serious comorbid condition that would interfere with regular exercise training

Interventions

Mode: group sessions, face-to-face, booklet, University exercise facility Professional: exercise practitioner

Topics: education regarding the disease, exercise programme, advice about exercise, coping with breathlessness

Duration: eight sessions of 90 minutes

Action plan: no

Exercise programme: yes

Behavioural components: cognitive-behavioural therapy, goal setting, providing feedback to the participant

\begin{tabular}{ll}
\hline Outcomes & 1. CRQ \\
2. HADS \\
3. Self-efficacy questionnaire \\
4. MRC \\
5. FEV 1 (L and \% of predicted) \\
6. FEV $1 / F V C$ \\
7. ISWT \\
8. Seven-day physical activity recall questionnaire \\
9. Physical self perception profile
\end{tabular}

Notes Sources of funding: $£ 137,256$ from the International Primary Care Respiratory Group

\section{Risk of bias}

Bias Authors' judgement Support for judgement

Random sequence genera- Low risk tion (selection bias)
"The randomisation sequence, stratified for smoking status, was computer generated by a statistician who was independent of the trial". page 126

Comment: Random sequence generation was adequately performed

\begin{tabular}{|c|c|c|}
\hline $\begin{array}{l}\text { Allocation concealment } \\
\text { (selection bias) }\end{array}$ & Low risk & $\begin{array}{l}\text { "Group allocation was kept concealed by means of sealed envelopes which } \\
\text { were only opened in sequence by the trial researcher following baseline as- } \\
\text { sessment". page } 126 \\
\text { Comment: Allocation was adequately concealed }\end{array}$ \\
\hline $\begin{array}{l}\text { Blinding of participants } \\
\text { and personnel (perfor- } \\
\text { mance bias) } \\
\text { All outcomes }\end{array}$ & Unclear risk & $\begin{array}{l}\text { "It was not possible to blind patients or GPs to group allocation". page } 126 \\
\text { Comment: Blinding of participants and personnel was not performed }\end{array}$ \\
\hline $\begin{array}{l}\text { Blinding of outcome as- } \\
\text { sessment (detection bias) } \\
\text { All outcomes }\end{array}$ & Unclear risk & $\begin{array}{l}\text { "Given the nature of the intervention it was also difficult to blind researchers } \\
\text { from group allocation". page } 126 \\
\text { Comment: Outcome assessment was not blinded; it is unclear who performed } \\
\text { the outcome assessment }\end{array}$ \\
\hline
\end{tabular}

Self management for patients with chronic obstructive pulmonary disease (Review)

Copyright $\odot 2014$ The Cochrane Collaboration. Published by John Wiley \& Sons, Ltd. 
Faulkner 2010 (Continued)

Incomplete outcome data High risk (attrition bias)

All outcomes
"Following participant withdrawals post-randomisation - adverse event $(n=4)$; personal commitments $(n=2)-14$ participants attended the post-intervention follow-up assessment". page 127

Comment: Dropout was high (30\%); reasons not clear

\section{Selective reporting (re- High risk} porting bias)

Comment: Selective reporting is possible; the report has a different aim than the original study. Of the HADS, only the anxiety part is reported, and other domain scores of the questionnaire are not reported. On page 126, the investigators name the self efficacy questionnaire (SEE) as an outcome measure; however, this is not reported in the results section

Other bias Low risk

Gallefoss 1999

\begin{tabular}{ll}
\hline Methods & Design: RCT. Follow-up: 12 months. Control group: usual care \\
\hline Participants & Recruitment: hospital (outpatient clinic) \\
& Eligible: 68 \\
& Randomly assigned: 62 \\
& Completed: 53 \\
& Mean age: I: 57 (nine) years C: 58 (10) years \\
& Sex (\% male): I: $48 \% ;$ C: $52 \%$ \\
& COPD: FEV1\% $>=40 \%$ and $<80 \%$ \\
& Major exclusion criteria: any serious disease
\end{tabular}

Interventions

Mode: group sessions and patient brochure

Professional:

Topics: COPD knowledge, medication, symptoms, action plan, exacerbations, inhalation technique, smoking cessation, relaxation, coping

Duration: max 6.5 hours

Action plan: yes

Exercise programme: no

Behavioural components: providing feedback

\begin{tabular}{ll}
\hline Outcomes & 1. SGRQ \\
2. Other HRQoL instruments & 3. Hospital admissions \\
4. Days lost from work \\
5. GP-consultation \\
6. FEV1\%pred
\end{tabular}

Notes

Sources of funding: Norwegian Medical Association's Fund for Quality Improvement

\section{Risk of bias}

\begin{tabular}{lll}
\hline Bias & Authors' judgement & Support for judgement \\
\hline $\begin{array}{l}\text { Random sequence genera- } \\
\text { tion (selection bias) }\end{array}$ & Low risk & $\begin{array}{l}\text { "The patients signed a written consent and were then randomly assigned us- } \\
\text { ing random number tables supplied by an external statistician in sealed en- } \\
\text { velopes". Gallefoss 2002, page } 425\end{array}$
\end{tabular}




$\begin{array}{ll}\begin{array}{l}\text { Allocation concealment } \\ \text { (selection bias) }\end{array} & \begin{array}{l}\text { "The patients signed a written consent and were then randomly assigned us- } \\ \text { ing random number tables supplied by an external statistician in sealed en- } \\ \text { velopes". Gallefoss 2002, page } 425\end{array}\end{array}$

Blinding of participants Unclear risk Comment: Blinding of participants and personnel was not reported
and personnel (perfor-
mance bias)
All outcomes

\begin{tabular}{|c|c|c|}
\hline $\begin{array}{l}\text { Blinding of outcome as- } \\
\text { sessment (detection bias) }\end{array}$ & Unclear risk & $\begin{array}{l}\text { Comment: Blinding of outcome assessment was not reported; not clear who } \\
\text { performed the measurements }\end{array}$ \\
\hline
\end{tabular}

All outcomes

\section{Incomplete outcome data Low risk} (attrition bias)
All outcomes
Comment: Allocation was adequately concealed

ing random number tables supplied by an external statistician in sealed en-
velopes". Gallefoss 2002 , page 425

\begin{abstract}
"In the control group four patients were withdrawn (lack of co-operation ( $\mathrm{n}=$ 2 ), diagnosis of rectal cancer $(n=1)$ and emigration $(n=1)$ ). Two of the withdrawn control group patients were hospitalised for exacerbations of their COPD. This left us with 27 patients (84\%) for the 1-year follow-up. In the intervention group, four patients failed to complete the educational program (social problems $(n=1)$, unannounced emigration $(n=1)$, failure to meet at educational group sessions for unknown reasons $(n=1)$ and serious myocardial infarction $(n=1)$ ). Another patient was withdrawn from the study during the follow-up due to lymphoma $(n=1)$. This left us with 26 patients $(81 \%)$ for a 1-year follow-up. The patients who were withdrawn from the intervention group did not, to our knowledge, have any serious deterioration in their obstructive lung disease, and none were hospitalised"
\end{abstract}

Comment: The number of dropouts was relatively low, and reasons for dropout were comparable over groups
Selective reporting (re- Low risk Comment: no signs of selective outcome reporting; study extensively deporting bias) scribed in various articles

Other bias Low risk

Ghanem 2010

Methods Design: RCT. Follow-up: two months. Control group: usual care

$\begin{array}{ll}\text { Participants } & \text { Recruitment: hospital (inpatient clinic) } \\ & \text { Eligible: not reported } \\ & \text { Randomly assigned: } 39 \\ \text { Completed: } 39 \\ \text { Mean age: I: } 56.96 \text { (11.59) years; C: } 56.43 \text { (9.03) years } \\ \text { Sex (\% male): not reported } \\ \text { COPD: moderate to severe COPD according to GOLD }\end{array}$

Major exclusion criteria: unable to read or write, locomotor problems, cognitive impairment, ischaemic heart disease, aortic valve disease, cancer or lung disease other than COPD

Interventions

Mode: individual sessions, face-to-face, booklet, home-based

Professional: respiratory nurse, respiratory specialist 
Topics: education regarding the disease, exercise programme, advice about nutrition, advice about medication

Duration: four individual sessions of one hour, every other day exercise for two months

Action plan: no

Exercise programme: yes

Behavioural components: goal setting

\begin{tabular}{ll}
\hline Outcomes & 1. $\mathrm{CRQ}$ \\
2. SF-36 \\
3. $\mathrm{FEV}_{1}$ (L and \% of predicted) \\
4. $\mathrm{FEV}_{1} / \mathrm{FVC}$ \\
5. $6 \mathrm{MWT}$
\end{tabular}

Notes Sources of funding: none

\section{Risk of bias}

\begin{tabular}{|c|c|c|}
\hline Bias & Authors' judgement & Support for judgement \\
\hline $\begin{array}{l}\text { Random sequence genera- } \\
\text { tion (selection bias) }\end{array}$ & Unclear risk & $\begin{array}{l}\text { Comment: The method of random sequence generation was not reported; nei- } \\
\text { ther was the decision for the different group sizes }\end{array}$ \\
\hline $\begin{array}{l}\text { Allocation concealment } \\
\text { (selection bias) }\end{array}$ & Unclear risk & Comment: The method of allocation concealment was not reported \\
\hline $\begin{array}{l}\text { Blinding of participants } \\
\text { and personnel (perfor- } \\
\text { mance bias) }\end{array}$ & Unclear risk & $\begin{array}{l}\text { "Owing to the nature of the intervention, it was not possible to blind patients } \\
\text { or assessors". page } 20\end{array}$ \\
\hline All outcomes & & Comment: Participants and personnel were not blinded \\
\hline \multirow[t]{2}{*}{$\begin{array}{l}\text { Blinding of outcome as- } \\
\text { sessment (detection bias) } \\
\text { All outcomes }\end{array}$} & High risk & $\begin{array}{l}\text { "Owing to the nature of the intervention, it was not possible to blind patients } \\
\text { or assessors. The assessors were either the investigator responsible for assign- } \\
\text { ment or members of the pulmonary rehabilitation team including the pul- } \\
\text { monary specialist and the specialized nurses who were involved in the delivery } \\
\text { of the intervention". page } 20\end{array}$ \\
\hline & & $\begin{array}{l}\text { Comment: Outcome assessment was not blinded; outcome assessors were in- } \\
\text { volved in the intervention }\end{array}$ \\
\hline $\begin{array}{l}\text { Incomplete outcome data } \\
\text { (attrition bias) }\end{array}$ & Low risk & "We analyzed data on an intention to treat basis". page 20 \\
\hline All outcomes & & $\begin{array}{l}\text { Comment: No information on dropouts was reported, but an intention-to-treat } \\
\text { analysis was performed }\end{array}$ \\
\hline $\begin{array}{l}\text { Selective reporting (re- } \\
\text { porting bias) }\end{array}$ & Unclear risk & Comment: no signs of selective reporting; however, no protocol available \\
\hline Other bias & Low risk & \\
\hline
\end{tabular}

\section{Hill 2010}

Methods Design: RCT. Follow-up: three months. Control group: usual care

Participants Recruitment: primary care setting


Hill 2010 (Continued)

Eligible: 131

Randomly assigned: 110

Completed: 93

Mean age: I: 63.4 (9.6) years; C: 65.7 (9.9) years

Sex (\% male): I: 44\%; C: $46.5 \%$

COPD: postbronchodilator ratio of forced expiratory volume in one second $\left(\mathrm{FEV}_{1}\right)$ to forced vital capacity $(\mathrm{FVC})<0.7$ and $\mathrm{FEV}_{1}<80 \%$ predicted

Major exclusion criteria: unable to perform spirometry for a medical reason; unable to communicate in written or spoken English

Mode: individual sessions, face-to-face, written teaching manual, primary care practise
Professional: certified COPD educator

Topics: education regarding the disease, (strategies for) smoking cessation, recognition of an exacerbation, advice about exercise, advice about medication

Duration: two individual sessions of one hour

Action plan: no

Exercise programme: no

Behavioural components: none reported

\begin{tabular}{ll}
\hline Outcomes & Bristol COPD Knowledge Questionnaire \\
\hline Notes & Sources of funding: Government of Ontario, Ontario Lung Association
\end{tabular}

\section{Risk of bias}

\begin{tabular}{lll}
\hline Bias & Authors' judgement & Support for judgement \\
\hline $\begin{array}{ll}\text { Random sequence genera- } \\
\text { tion (selection bias) }\end{array}$ & Low risk & $\begin{array}{l}\text { "Individuals were randomised to the experimental and control groups us- } \\
\text { ing a computer-generated random number sequence. The randomisation se- } \\
\text { quence was stratified according to the Medical Research Council (MRC) dysp- } \\
\text { noea scale". page } 15\end{array}$ \\
& Comment: Random sequence generation was adequately performed \\
\hline
\end{tabular}

\begin{tabular}{|c|c|c|}
\hline $\begin{array}{l}\text { Allocation concealment } \\
\text { (selection bias) }\end{array}$ & Unclear risk & Comment: The method used to conceal allocation was not reported \\
\hline $\begin{array}{l}\text { Blinding of participants } \\
\text { and personnel (perfor- } \\
\text { mance bias) }\end{array}$ & Unclear risk & $\begin{array}{l}\text { "Physicians at the three recruitment sites were unaware as to the group alloca- } \\
\text { tion of their patients" page } 15\end{array}$ \\
\hline All outcomes & & $\begin{array}{l}\text { Comment: Personnel were blinded, and blinding of participants was not re- } \\
\text { ported }\end{array}$ \\
\hline
\end{tabular}

Blinding of outcome as- Unclear risk sessment (detection bias) All outcomes
Comment: Blinding of outcome assessment was not reported; the questionnaire was self administered
Incomplete outcome data Low risk (attrition bias)

All outcomes

\begin{abstract}
"Analyses were performed according to the intention-to-treat principle using data from all participants for whom baseline and follow-up administrations of the BCKQ were available, irrespective of the time between the administrations"......"Of the 55 people allocated to the experimental group, 5 withdrew before completing the study and of the 45 allocated to the control group, 2 withdrew before completing the study. Reasons for withdrawal included: moved away from the area $(n=2)$, medical problems precluding further partic-
\end{abstract}


Hill 2010 (Continued)

ipation ( $n=2)$, language barrier $(n=1)$, lack of interest $(n=1)$, and deceased ( $n$ $=1)^{\prime \prime}$

Comment: Study dropout was somewhat higher in the intervention group than in the control group, but overall it was quite low; an intention-to-treat analysis was performed

Selective reporting (re- Unclear risk
porting bias)

"Given that the study selectively recruited individuals in the primary care setting, many of whom had only been recently diagnosed with COPD and were unlikely to be using inhaled steroids, they excluded the BCKQ questions in the domain that pertained to knowledge about this medication" page 15

Comment: further, no signs of selective reporting

\begin{tabular}{ll}
\hline Other bias Low risk \\
\hline
\end{tabular}

Kara 2004

\begin{tabular}{|c|c|}
\hline Methods & Design: RCT. Follow-up: two months. Control group: educational advice \\
\hline \multirow[t]{8}{*}{ Participants } & Recruitment: hospital (outpatient clinic) \\
\hline & Eligible: not reported \\
\hline & Randomly assigned: 60 \\
\hline & Completed: 60 \\
\hline & Mean age: I: 61.06 (11.33) years; C: 61.36 (11.06) years \\
\hline & Sex (\% male): $78.3 \%$ in total group, distribution in groups was not reported \\
\hline & COPD: mild and moderate $\mathrm{FEV}_{1}<85 \%, \mathrm{FEV}_{1} / \mathrm{FVC}<70 \%$ \\
\hline & $\begin{array}{l}\text { Major inclusion criteria: at least two weeks after recovery from acute exacerbation of COPD; no evi- } \\
\text { dence of ischaemic heart disease, musculoskeletal disorders or other disabling disease that could re- } \\
\text { strict the exercise; } 45 \text { or more years of age; literate, volunteer and coherent }\end{array}$ \\
\hline
\end{tabular}

Major exclusion criteria: none reported

Mode: group and individual sessions, face-to-face, written teaching manual, hospital (outpatient clinic) Professional: clinic nurse, respiratory physiotherapist

Topics: education regarding the disease, smoking cessation, exercise programme, advice about exercise, advice about nutrition, advice about medication, coping with breathlessness

Duration: 60 to 70 minutes, later 35 to 40 minutes three or four times per week in small groups Action plan: no

Exercise programme: yes

Behavioural components: none reported

\begin{tabular}{|c|c|c|}
\hline Outcomes & \multicolumn{2}{|l|}{ COPD self efficacy scale } \\
\hline Notes & \multicolumn{2}{|c|}{ Sources of funding: not reported } \\
\hline \multicolumn{3}{|l|}{ Risk of bias } \\
\hline Bias & Authors' judgement & Support for judgement \\
\hline $\begin{array}{l}\text { Random sequence genera- } \\
\text { tion (selection bias) }\end{array}$ & Unclear risk & $\begin{array}{l}\text { "The patients were randomly assigned to the experimental and control group } \\
\text { in order of referral up to } 60 \text { patients". page } 116\end{array}$ \\
\hline
\end{tabular}


Kara 2004 (Continued)

Comment: The method of random sequence generation was not reported

\begin{tabular}{|c|c|c|}
\hline $\begin{array}{l}\text { Allocation concealment } \\
\text { (selection bias) }\end{array}$ & Unclear risk & $\begin{array}{l}\text { "The patients were randomly assigned to the experimental and control group } \\
\text { in order of referral up to } 60 \text { patients". page } 116\end{array}$ \\
\hline & & Comment: The method of allocation concealment was not reported \\
\hline
\end{tabular}

Blinding of participants Unclear risk Comment: Blinding of participants and personnel was not reported
and personnel (perfor-
mance bias)
All outcomes

Blinding of outcome as- Unclear risk

Comment: Blinding of outcome assessment was not reported. Questionnaires sessment (detection bias) were self administered

All outcomes

Incomplete outcome data Unclear risk Comment: No information on dropouts was reported
(attrition bias)

All outcomes

\begin{tabular}{|c|c|c|}
\hline $\begin{array}{l}\text { Selective reporting (re- } \\
\text { porting bias) }\end{array}$ & Unclear risk & $\begin{array}{l}\text { Comment: no signs of selective reporting, although only one outcome mea- } \\
\text { sure was reported }\end{array}$ \\
\hline
\end{tabular}

Other bias Low risk

Khdour 2009

\begin{tabular}{ll}
\hline Methods & Design: RCT. Follow-up: 12 months. Control group: usual care \\
\hline Participants & Recruitment: hospital (outpatient clinic) \\
Eligible: not reported \\
Randomly assigned: 173 \\
Completed: 143 \\
Mean age: I: $65.6(10.1)$ years; C: 67.3 (9.2) years \\
Sex (\% male): I: $43.7 \%$; $44.2 \%$ \\
COPD: confirmed diagnosis of COPD (by the hospital consultant) for at least one year, having FEV $130 \%$ \\
to $80 \%$ of predicted and > 45 years old \\
Major exclusion criteria: congestive heart failure; moderate to severe learning difficulties (as judged \\
by hospital consultant); attended a pulmonary rehabilitation programme in the last six months; severe \\
mobility problems or terminal illness
\end{tabular}

Interventions

Mode: individual sessions, face-to-face, telephone, hospital (outpatient clinic)

Professional: clinical pharmacist

Topics: education regarding the disease, smoking cessation, action plan with self treatment of exacerbations, advice about exercise, advice about nutrition, advice about medication, coping with breathlessness

Duration: one session of one hour, reinforcement at each outpatient visit every six months, two telephone calls at three and nine months

Action plan: yes

\section{Exercise programme: no}

Behavioural components: motivational interviewing, feedback to the participant 
Khdour 2009 (Continued)
Outcomes
1. SGRQ
2. $\mathrm{FEV}_{1}$
3. Hospital admissions for acute exacerbations
4. ED visits for acute exacerbations
5. GP visits, scheduled and unscheduled
6. COPD knowledge questionnaire
7. Adherence to prescribed medication

Notes

Sources of funding: Chest Heart and Stroke (N. Ireland)

\section{Risk of bias}

\begin{tabular}{lll}
\hline Bias & Authors' judgement & Support for judgement \\
\hline $\begin{array}{l}\text { Random sequence genera- } \\
\text { tion (selection bias) }\end{array}$ & Low risk & $\begin{array}{l}\text { "Recruited patients were randomly assigned to one of two groups: the inter- } \\
\text { vention group and the usual care (control group). Both groups were matched } \\
\text { as closely as possible for the following parameters: severity of COPD (mea- } \\
\text { sured by FEV1), age, gender and other concomitant illness. The randomisation } \\
\text { was carried out using the minimization method described by Gore". page 589 }\end{array}$ \\
& \\
& Comment: Random sequence generation was performed adequately
\end{tabular}

$\begin{array}{ll}\begin{array}{l}\text { Allocation concealment } \\ \text { (selection bias) }\end{array} & \text { "Recruited patients were randomly assigned to one of two groups: the inter- } \\ & \text { vention group and the usual care (control group). Both groups were matched } \\ & \text { as closely as possible for the following parameters: severity of COPD (mea- } \\ & \text { sured by FEV1), age, gender and other concomitant illness. The randomisation } \\ & \text { was carried out using the minimization method described by Gore". page 589 } \\ & \text { Comment: Allocation was adequately concealed }\end{array}$

Blinding of participants Unclear risk Comment: Blinding of participants and personnel was not reported
and personnel (performance bias)

All outcomes

\begin{tabular}{|c|c|c|}
\hline $\begin{array}{l}\text { Blinding of outcome as- } \\
\text { sessment (detection bias) } \\
\text { All outcomes }\end{array}$ & Unclear risk & $\begin{array}{l}\text { "Baseline measurements were performed by the research pharmacist".... "for } \\
\text { operational reasons, the researcher could not be blinded to the group to which } \\
\text { the patient belonged". page } 590\end{array}$ \\
\hline & & $\begin{array}{l}\text { Comment: Outcome assessment was not blinded; it was not clearly reported } \\
\text { how the research pharmacist was related to the study }\end{array}$ \\
\hline
\end{tabular}

Incomplete outcome data Low risk
(attrition bias) "A per-protocol analysis was used". page 590 "During the study period, three
patients from the intervention group and five from the control group died and
a total of 22 patients withdrew from the study; 12 patients from the interven-
tion group and 10 from the control group". page 590
Comment: In both groups, 15 participants (17\%) dropped out during the 12 -
month follow-up. Reasons for dropout were comparable across groups

All outcomes

Comment: no signs of selective reporting; however, no protocol available

Selective reporting (re- Unclear risk Comment: no signs of selective reporting; however, no protocol available
porting bias)

Other bias Low risk


Kheirabadi 2008

\begin{tabular}{ll}
\hline Methods & Design: RCT. Follow-up: three months. Control group: usual care \\
\hline Participants & Recruitment: hospital (outpatient clinic) \\
& Eligible: not reported \\
& Randomly assigned: 42 \\
& Completed: 42 \\
& Mean age: I: $56.6(5.7)$ years; C: $56.2(4.1)$ years \\
& Sex (\% male): I: $61.9 \% ;$ C: $76.2 \%$ \\
& COPD: diagnosed by a pulmonologist according to ATS \\
& Major exclusion criteria: primary diagnosis of asthma; hospitalisation during the intervention; main \\
treatment with oxygen; occurrence of serious unexpected stresses during the study
\end{tabular}

Interventions

Mode: group sessions, face-to-face, telephone, hospital (outpatient clinic)

Professional: psychologist, trained psychiatric residents

Topics: education regarding the disease, smoking cessation, exercise programme, action plan, advice about exercise, advice about nutrition, advice about medication

Duration: eight group sessions of 60 to 90 minutes; participants were followed up by phone Action plan: yes

Exercise programme: no

Behavioural components: providing feedback to the participant

\begin{tabular}{ll}
\hline Outcomes & CCQ \\
\hline Notes & Sources of funding: not reported
\end{tabular}

\section{Risk of bias}

\begin{tabular}{lll}
\hline Bias & Authors' judgement & Support for judgement \\
\hline $\begin{array}{l}\text { Random sequence genera- } \\
\text { tion (selection bias) }\end{array}$ & Unclear risk & Comment: The method of random sequence generation was not reported \\
\hline $\begin{array}{l}\text { Allocation concealment } \\
\text { (selection bias) }\end{array}$ & Unclear risk & Comment: The method of allocation concealment was not reported \\
\hline $\begin{array}{l}\text { Blinding of participants } \\
\text { and personnel (perfor- } \\
\text { mance bias) } \\
\text { All outcomes }\end{array}$ & Unclear risk & Comment: Blinding of participants and personnel was not reported \\
\hline
\end{tabular}

\begin{tabular}{lll}
\hline $\begin{array}{l}\text { Blinding of outcome as- } \\
\text { sessment (detection bias) }\end{array}$ & Unclear risk & $\begin{array}{l}\text { Comment: Blinding of outcome assessment was not reported. Not clear who } \\
\text { performed the measurements }\end{array}$
\end{tabular}

All outcomes

$\begin{array}{ll}\begin{array}{l}\text { Incomplete outcome data } \\ \text { (attrition bias) }\end{array} & \begin{array}{l}\text { "We also encouraged and followed up the patients by phone and even when } \\ \text { someone was absent, we teached him/her over the phone. In this way, all pa- } \\ \text { tients accompanied us till the end of the course and no patient was excluded } \\ \text { from the study". page } 28\end{array} \\ \text { Comment: All participants completed follow-up }\end{array}$

\begin{tabular}{|c|c|c|}
\hline $\begin{array}{l}\text { Selective reporting (re- } \\
\text { porting bias) }\end{array}$ & Unclear risk & $\begin{array}{l}\text { Comment: no signs of selective reporting, although only one outcome mea- } \\
\text { sure was reported }\end{array}$ \\
\hline
\end{tabular}


Kheirabadi 2008 (Continued)
Other bias
Low risk

Koff 2009

\begin{tabular}{ll}
\hline Methods & Design: RCT. Follow-up: three months. Control group: usual care \\
\hline Participants & Recruitment: hospital (outpatient clinic) \\
& Eligible: not reported \\
Randomly assigned: 40 \\
Completed: 38 \\
Mean age: I: $66.6(9.1)$ years; C: $65.0(8.2)$ years \\
Sex (\% male): I: $45 \% ;$ C: $50 \%$ \\
COPD: GOLD stage three or four \\
Major exclusion criteria: active treatment for lung cancer; illiteracy; non-English speaking; inability to \\
Complete a six-minute walk test
\end{tabular}

Mode: individual sessions, face-to-face, telecommunication device, home-based
Professional: respiratory physiotherapist

Topics: education regarding the disease, exercise programme, action plan, advice about exercise, advice about medication

Duration: one individual session at enrolment; each weekday morning, a telehealth session with COPD-specific education of 20 minutes

Action plan: yes

\section{Exercise programme: no}

Behavioural components: goal setting, providing feedback to the participant

\begin{tabular}{|c|c|c|}
\hline Outcomes & \multicolumn{2}{|c|}{$\begin{array}{l}\text { 1. SGRQ } \\
\text { 2. COPD hospitalisations } \\
\text { 3. COPD ER visits } \\
\text { 4. Healthcare costs }\end{array}$} \\
\hline Notes & \multicolumn{2}{|c|}{ Sources of funding: University of Colorado Hospital } \\
\hline \multicolumn{3}{|l|}{ Risk of bias } \\
\hline Bias & Authors' judgement & Support for judgement \\
\hline $\begin{array}{l}\text { Random sequence genera- } \\
\text { tion (selection bias) }\end{array}$ & Unclear risk & $\begin{array}{l}\text { "Following informed consent, patients randomly selected their group assign- } \\
\text { ment by choosing a blinded envelope that contained a group indicator". page } \\
1032 \\
\text { Comment: The method of random sequence generation was not reported }\end{array}$ \\
\hline $\begin{array}{l}\text { Allocation concealment } \\
\text { (selection bias) }\end{array}$ & Low risk & $\begin{array}{l}\text { "Following informed consent, patients randomly selected their group assign- } \\
\text { ment by choosing a blinded envelope that contained a group indicator". page } \\
1032 \\
\text { Comment: Allocation was adequately concealed }\end{array}$ \\
\hline
\end{tabular}




\section{Koff 2009 (Continued)}

Blinding of participants and personnel (performance bias)

All outcomes
Unclear risk "Because of the type of intervention, it was not possible to blind the subjects or investigators as to whether they were randomised to the treatment or control arms of the trial". page 1032

Comment: Blinding of participants and personnel was not performed

\section{Blinding of outcome as- High risk sessment (detection bias) All outcomes

\begin{abstract}
"Because of the type of intervention, it was not possible to blind the subjects or investigators as to whether they were randomised to the treatment or control arms of the trial". page 1032

"This end-point (SGRQ) was collected by the coordinator...." page 1034

Comment: Blinding of outcome assessment was not performed; the assessor of the primary outcome was involved in the intervention
\end{abstract}

"A total of 40 patients were randomised; 20 to the PIC group and 20 to the UC control group, and one patient withdrew from each group". page 1034

Comment: The number of dropouts was low

$\begin{array}{ll}\text { (attrition bias) } & \text { control group, and one patient withdrew from } \\ \text { All outcomes } & \text { Comment: The number of dropouts was low }\end{array}$

Selective reporting (re- Unclear risk Comment: no signs of selective reporting; however, no protocol available
porting bias)
porting bias)

Other bias Low risk

\section{Monninkhof 2003}

\begin{tabular}{ll}
\hline Methods & Design: RCT. Follow-up: 12 months. Control group: usual care \\
\hline Participants & Recruitment: hospital (outpatients) \\
& Eligible: 615 \\
& Randomly assigned: 248 \\
& Completed: 236 \\
& Mean age: I: 65 (seven) years C: 65 (seven) years \\
& Sex (\% male): I: $85 \%$ C: $84 \%$ \\
& COPD: diagnosis of stable COPD (ATS); FEV $1 \%$ pred (pre): $25 \%$ to $80 \%$ FEV $\mathrm{F}_{1} / \mathrm{VC}$ (pre): $<60$ \\
& Major exclusion criteria: no previous diagnosis of asthma; exacerbation in the months before inclu- \\
& Sion; medical condition with low survival or serious psychiatric morbidity; any other lung disease; \\
& maintenance treatment of oral steroids or antibiotics
\end{tabular}

Professional: respiratory nurse

Topics: COPD knowledge; inhalation technique; importance of exercise; relaxation; nutrition; coping with breathlessness; ergonomic posture and energy conservation during daily activities or work; communication and social relationships; guidelines for self treatment for exacerbations (action plans). A fitness program was aimed at coping with disease, recognising participants' individual capacity, social interactions and behavioural changes

Duration: education: five * two hours. Exercise: duration one to two a week for 30 to 45 minutes Action plan: yes

Exercise programme: yes

Behavioural components: goal setting, providing feedback

Outcomes 1. SGRQ


Monninkhof 2003 (Continued)
2. EuroQol
3. Self confidence
4. Walking distance
5. 6MWT
6. Exacerbations
7. Symptoms
8. Doctor consultations
9. Hospital admissions
10.Symptoms
11.Days lost from work

Notes

Sources of funding: the Netherlands Asthma Foundation, Boehringer Ingelheim, Amicon Health Care Insurance Company and GlaxoSmithKline BV

\section{Risk of bias}

\begin{tabular}{lll}
\hline Bias & Authors' judgement & Support for judgement \\
\hline $\begin{array}{ll}\text { Random sequence genera- } \\
\text { tion (selection bias) }\end{array}$ & Low risk & "Randomisation was performed in blocks of four, stratified by sex and smoking \\
& & status, using sealed envelopes". page 816 \\
& Comment: Random sequence generation was adequately performed
\end{tabular}

\begin{tabular}{ll}
\hline $\begin{array}{l}\text { Allocation concealment } \\
\text { (selection bias) }\end{array}$ & Low risk \\
& $\begin{array}{l}\text { "Randomisation was performed in blocks of four, stratified by sex and smoking } \\
\text { status, using sealed envelopes". page } 816\end{array}$ \\
& Comment: Allocation was adequately concealed \\
\hline
\end{tabular}

Blinding of participants Unclear risk Comment: Participants and personnel were not blinded

and personnel (perfor-

mance bias)

All outcomes

\begin{tabular}{|c|c|c|}
\hline $\begin{array}{l}\text { Blinding of outcome as- } \\
\text { sessment (detection bias) }\end{array}$ & Low risk & $\begin{array}{l}\text { Comment: Outcome assessment was not blinded; however, measurements } \\
\text { were performed by an assessor who was independent of the study }\end{array}$ \\
\hline
\end{tabular}

\begin{tabular}{ll}
\hline $\begin{array}{l}\text { Incomplete outcome data Low risk } \\
\text { (attrition bias) }\end{array}$ & $\begin{array}{l}\text { "In the intervention group five patients (three deaths, two other) dropped out, } \\
\text { all outcomes did seven patients (three deaths, two carcinoma, two other) in the control } \\
\text { group". page } 818\end{array}$ \\
& $\begin{array}{l}\text { Comment: The number of dropouts and reasons for dropout in both groups } \\
\text { were comparable. Moreover, an intention-to-treat analysis was used and } \\
\text { dropout was low }\end{array}$
\end{tabular}

Selective reporting (re- Unclear risk $\quad$ Comment: no signs of selective reporting; however, no protocol available
porting bias)

Other bias Low risk

Moullec 2008

Methods Design: CCT. Follow-up: 12 months. Control group: usual care


Moullec 2008 (Continued)

Eligible: 50

Randomly assigned: 40

Completed: 27

Mean age: I: 62.9 (7.4) years; C: $59.7(9.6)$ years

Sex (\% male): I: $71 \%$; C: $81 \%$

COPD: moderate or severe COPD according to GOLD; postbronchodilator FEV $1 / F V C<0.7$ and FEV1\% $30 \%$ to $79 \%$ predicted

Major inclusion criteria: no indication for home oxygen therapy; no exacerbation or hospitalisation in the previous two months; participation in the 20 sessions of the four-week inpatient PR

Major exclusion criteria: significant medical or psychiatric disturbances that would interfere with full participation in the programme; previous diagnosis of asthma

Interventions

Mode: group sessions, face-to-face, community-based

Professional: respiratory physiotherapist, respiratory specialist, psychologist, peer-led, dietician, adapted physical activity professional (Faculty of Exercise Sciences)

Topics: education regarding the disease, smoking cessation, exercise programme, action plan, advice about exercise, advice about nutrition, advice about medication, coping with breathlessness

Duration: total 96 group sessions; individualised exercise training ( 3.5 hours/wk; 72 sessions), health education provided alternatively by all professionals of the healthcare network (two hours/mo; 12 sessions), psychosocial support (one hour/mo; 12 sessions)

Action plan: yes

Exercise programme: yes

Behavioural components: providing feedback to the participant

\begin{tabular}{ll}
\hline Outcomes & 1. SGRQ \\
2. WHQOL-BREF \\
3. FEV 1 \\
4. Hospital days \\
5. Consultations with GP \\
6. Consultations with lung specialist \\
7. 6MWT \\
8. Voorrips questionnaire
\end{tabular}

Notes

Sources of funding: the Fond d'Aide a' la Qualite des Soins de Ville (FAQSV) of the Union Regionale des Caisses d'Assurance Maladie (URCAM) and the Agence Regionale de l'Hospitalisation (ARH) of the region Languedoc-Roussillon in France

\section{Risk of bias}

Bias Authors' judgement Support for judgement

Random sequence genera- High risk tion (selection bias)

\begin{abstract}
"The consecutive assignment of eligible patients to the follow-up groups was based on the unpredictable occurrence of their place of residence. The subjects assigned to the usual aftercare were those who lived in towns without an existing self help association". Moullec 2010, page 124

Comment: The method of random sequence generation was not adequate
\end{abstract}




Blinding of participants Unclear risk Comment: Blinding of participants and personnel was not reported
and personnel (perfor-
mance bias)
All outcomes

\begin{tabular}{|c|c|c|}
\hline \multirow[t]{2}{*}{$\begin{array}{l}\text { Blinding of outcome as- } \\
\text { sessment (detection bias) } \\
\text { All outcomes }\end{array}$} & Low risk & $\begin{array}{l}\text { "...the same trained research assistant visited the patients at home to super- } \\
\text { vise the completion of all quality of life questionnaires"...."The research as- } \\
\text { sistant had no contact with participants other than during the evaluations". } \\
\text { Moullec } 2010 \text {, page } 124\end{array}$ \\
\hline & & $\begin{array}{l}\text { Comment: Blinding of outcome assessment was not reported. However, the } \\
\text { measurements were performed by someone not directly involved in the inter- } \\
\text { vention }\end{array}$ \\
\hline
\end{tabular}

\begin{tabular}{|c|c|c|}
\hline $\begin{array}{l}\text { Incomplete outcome data } \\
\text { (attrition bias) } \\
\text { All outcomes }\end{array}$ & High risk & $\begin{array}{l}\text { "At } 1 \text { year of individual follow-up, } 13 \text { subjects had not completed the sched- } \\
\text { uled sessions of assessment. In the SG, six patients had dropped out at the 6- } \\
\text { month point for the following reasons: three exacerbation crises, one inpatient } \\
\text { psychiatry admission, one death due to cardiac failure and one infectious arm. } \\
\text { At 1-year, further four control subjects had dropped out because of acute exac- } \\
\text { erbation. In the MG, three patients were lost to follow-up evaluation (two be- } \\
\text { cause of acute chest exacerbation crises at } 6 \text {-month, and one with myocardial } \\
\text { aneurysm at } 1 \text { year)" }\end{array}$ \\
\hline
\end{tabular}

Comment: high number of dropouts compared with the number of participants included $(>30 \%)$ and a per-protocol analysis was performed

\begin{tabular}{|c|c|c|}
\hline $\begin{array}{l}\text { Selective reporting (re- } \\
\text { porting bias) }\end{array}$ & Unclear risk & Comment: no signs of selective reporting; however, no protocol available \\
\hline Other bias & Low risk & \\
\hline
\end{tabular}

\section{Nguyen 2008}

\section{Methods}

Design: RCT. Follow-up: six months. Intervention one: Internet-based dyspnoea self management programme. Intervention two: face-to-face dyspnoea self management programme

\section{Participants}

Recruitment: community and clinic

Eligible: 84

Randomly assigned: 50

Completed: 38

Mean age: I: $68.0(8.3)$ years; C: 70.9 (8.6) years

Sex (\% male): I: $61 \%$; C: $55 \%$

COPD: diagnosis of COPD with spirometry showing at least mild obstructive disease defined as postbronchodilator $\mathrm{FEV}_{1} / \mathrm{FVC}<0.70$ with $\mathrm{FEV}_{1}<80 \%$ predicted, or $\mathrm{FEV}_{1} / \mathrm{FVC}<0.60$ with $\mathrm{FEV}_{1}>80 \%$ predicted

Major inclusion criteria: clinically stable for at least one month; ADL limited by dyspnoea; using the Internet and/or checking email at least once per week with a Windows operating

system; oxygen saturation $>85 \%$ on room air or $\leq 6 \mathrm{~L} / \mathrm{min}$ of nasal oxygen at the end of a six-minute walk test

Major exclusion criteria: active symptomatic illness (i.e. cancer, heart failure, ischaemic heart disease with known coronary artery or valvular heart disease, psychiatric illness or neuromuscular disease); 
Nguyen 2008 (Continued)

participation in a pulmonary rehabilitation programme in the last 12 months; participation in > two days of supervised maintenance exercise

Interventions

Mode: group and individual sessions, face-to-face, telephone or Internet, outpatient clinic and homebased

Professional: (respiratory) nurse

Topics: exercise programme, action plan, advice about exercise, advice about medication, coping with breathlessness

\section{Duration:}

1.5- to two-hour face-to-face consultation

Six one-hour weekly group sessions of structured education of dyspnoea management strategies via chat or face-to-face

Four times/wk 30-minute endurance, three times/wk arm strengthening

Reinforcement: via email or telephone weekly in month one, biweekly in months two through six Action plan: yes

\section{Exercise programme: yes}

Behavioural components: motivational interviewing, goal setting, providing feedback to the participant

\begin{tabular}{ll}
\hline Outcomes & 1. SGRQ \\
2. WHQOL-BREF \\
3. FEV 1 \\
4. Hospital days \\
5. Consultations with GP \\
6. Consultations with lung specialist \\
7. 6MWT \\
8. Voorrips questionnaire
\end{tabular}

Notes

Sources of funding: This study was supported in part by Robert Wood Johnson Health e-Technologies Initiative grant RWJ49153 to Dr Carrieri-Kohlman, General Clinical Research Centers at the University of Washington (MO1-RR-000037) and UC San Francisco (MO1-RR-00079), and Grant Number 1KL2RR025015-01 from the National Center for Research Resources (NCRR), a component of the National Institutes of Health (NIH) and the NIH Roadmap for Medical Research

Note: "Both programs were designed to provide similar content and 'contact' time for ongoing reinforcement and support and differed only in the mode of delivery"

\section{Risk of bias}

\begin{tabular}{lll}
\hline Bias & Authors' judgement & Support for judgement \\
\hline $\begin{array}{l}\text { Random sequence genera- } \\
\text { tion (selection bias) }\end{array}$ & Low risk & $\begin{array}{l}\text { "An investigator who was not involved in the day-to-day study operations gen- } \\
\text { erated the randomisation sequence using the SPSS version } 14.0 \text { random se- } \\
\text { quence generator feature and placed the randomisation in separate sealed } \\
\text { opaque envelopes" }\end{array}$ \\
& $\begin{array}{l}\text { Comment: Random sequence generation was adequately performed. } \\
\text { Allocation concealment } \\
\text { (selection bias) }\end{array}$ & Low risk \\
& $\begin{array}{l}\text { "An investigator who was not involved in the day-to-day study operations gen- } \\
\text { erated the randomisation sequence using the SPSS version 14.0 random se- } \\
\text { quence generator feature and placed the randomisation in separate sealed } \\
\text { opaque envelopes" }\end{array}$
\end{tabular}




Blinding of participants Unclear risk
and personnel (perfor-
mance bias)
All outcomes

"Since registration and access to the Web questionnaires on the vendor-supported website required designation of a treatment group early in the baseline visit, the study nurse opened the randomisation envelope during the first half of the visit. While the study nurse was privy to the treatment assignment, participants were not informed of their assignment until the visit was complete"

Comment: Participants were blinded until the end of the baseline visit, and personnel were not blinded

$\begin{array}{lll}\begin{array}{l}\text { Blinding of outcome as- } \\ \text { sessment (detection bias) }\end{array} & \text { High risk } & \begin{array}{l}\text { "They returned to the medical center at } 3 \text { and } 6 \text { months for testing by study } \\ \text { stl outcomes }\end{array} \\ & \begin{array}{l}\text { terviews were conducted either in person or via telephone at the final visit by } \\ \text { the evaluation staff or investigators (HQN and VCK) who were not directly in- } \\ \text { volved in the intervention" }\end{array} \\ & \begin{array}{l}\text { Comment: Blinding of outcome assessment was not reported, and measure- } \\ \text { ments were performed by study staff not directly involved in the intervention; } \\ \text { however, staff members were investigators and therefore were involved in the } \\ \text { study }\end{array}\end{array}$

Incomplete outcome data High risk (attrition bias)

All outcomes

\begin{tabular}{lll}
\hline $\begin{array}{l}\text { Selective reporting (re- } \\
\text { porting bias) }\end{array}$ & Unclear risk & Comment: no signs of selective reporting; however, no protocol available \\
\hline Other bias & High risk & $\begin{array}{l}\text { "The investigators stopped the study early due to the cumulative technical } \\
\text { and usability challenges that peaked when three consecutive eDSMP partici- } \\
\text { pants had multiple difficulties accessing the Web application and subsequent- } \\
\text { ly withdrew. All enrolled participants were followed through } 6 \text { months accord- } \\
\text { ing to the study protocol" }\end{array}$
\end{tabular}

Comment: A high percentage dropped out ( $>20 \%)$, and not all randomly assigned participants were included in the intention-to-treat analysis

\section{Nguyen 2009}

$\begin{array}{ll}\text { Methods } & \text { Design: RCT. Follow-up: six months. Intervention one: mobile coached cell phone-based exercise } \\ \text { persistence intervention; Intervention two: self monitored cell phone-based exercise persistence in- } \\ \text { tervention }\end{array}$

\section{Participants}

Recruitment: pulmonary rehabilitation site

Eligible: 34

Randomly assigned: 17

Completed: 15

Mean age: I: 72 (nine) years; C: 64 (12) years

Sex (\% male): I: 33\%; C: $37 \%$

COPD: stable moderate to severe COPD according to GOLD criteria

Major exclusion criteria: active symptomatic illness (e.g. cancer, heart failure, ischaemic heart disease, neuromuscular disease, psychiatric illness); inability (e.g. severe arthritis) or unwillingness to use the study issued cell phone; residence outside of the wireless coverage area

Interventions

Mode: individual sessions, face-to-face, booklet, telephone, outpatient clinic and home-based Professional: respiratory nurse

Topics: exercise programme, action plan, advice about exercise 
Duration: one individual session of 30 to 45 minutes, at least one or two phone calls of 10 minutes with participants in the coached group, and 24 weekly personalised (coached) or standard (self monitored) text message. 150 minutes of moderate-intensity endurance exercise per week in three to five sessions Action plan: yes

\section{Exercise programme: yes}

Behavioural components: providing feedback to the participant

\begin{tabular}{ll}
\hline Outcomes & 1. SGRQ \\
2. Exercise barriers efficacy scale \\
3. $6 \mathrm{MWT}$ \\
4. Free-living ambulatory physical activity
\end{tabular}

$\begin{array}{ll}\text { Notes } & \text { Sources of funding: This study was supported in part by R03NR009361 and 1KL2RR025015-01; Omron } \\ \text { Healthcare donated the pedometers }\end{array}$

\section{Risk of bias}

\begin{tabular}{lll}
\hline Bias & Authors' judgement & Support for judgement \\
\hline $\begin{array}{l}\text { Random sequence genera- } \\
\text { tion (selection bias) }\end{array}$ & Low risk & $\begin{array}{l}\text { "A biostatistician who was not involved in the day-to-day study operations } \\
\text { generated the randomisation sequence and placed the randomisation in sep- } \\
\text { arate sealed opaque envelopes. The randomisation scheme was stratified by } \\
\text { gender to ensure balanced allocation" page } 303\end{array}$ \\
& $\begin{array}{l}\text { Comment: Random sequence generation was adequately performed } \\
\text { Allocation concealment } \\
\text { (selection bias) }\end{array}$ & Low risk \\
& $\begin{array}{l}\text { "A biostatistician who was not involved in the day-to-day study operations } \\
\text { generated the randomisation sequence and placed the randomisation in sep- } \\
\text { arate sealed opaque envelopes. The randomisation scheme was stratified by } \\
\text { gender to ensure balanced allocation". page 303 }\end{array}$ \\
& \begin{tabular}{l} 
Comment: Allocation was adequately concealed \\
\hline
\end{tabular}
\end{tabular}

\begin{tabular}{|c|c|c|}
\hline $\begin{array}{l}\text { Blinding of participants } \\
\text { and personnel (perfor- } \\
\text { mance bias) } \\
\text { All outcomes }\end{array}$ & Unclear risk & $\begin{array}{l}\text { "The interventionist was not blind to group assignment..." page } 303 \\
\text { Comment: Personnel was not blinded; blinding of participants was not report- } \\
\text { ed }\end{array}$ \\
\hline
\end{tabular}

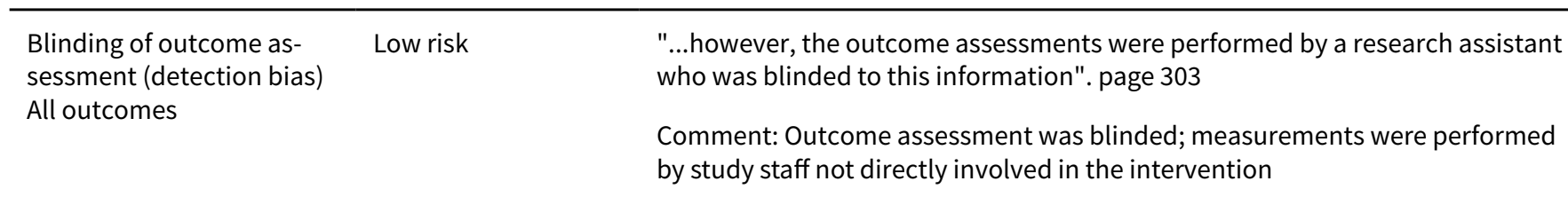

\begin{tabular}{lll}
\hline $\begin{array}{l}\text { Incomplete outcome data } \\
\text { (attrition bias) } \\
\text { All outcomes }\end{array}$ & Low risk & $\begin{array}{l}\text { Comment: Loss to follow-up was low, and an intention-to-treat analysis was } \\
\text { used }\end{array}$ \\
\hline $\begin{array}{l}\text { Selective reporting (re- } \\
\text { porting bias) }\end{array}$ & Unclear risk & $\begin{array}{l}\text { Comment: The domain scores of HRQoL questionnaires were not reported; fur- } \\
\text { ther no signs of selective reporting were noted }\end{array}$ \\
\hline Other bias & Low risk & \\
\hline
\end{tabular}


Ninot 2011

\begin{tabular}{ll}
\hline Methods & Design: RCT. Follow-up: 12 months. Control group: usual care \\
\hline Participants & Recruitment: hospital (university-based centre by flyers advertising the study) \\
& Eligible: 61 \\
& Randomly assigned: 45 \\
Completed: 38 & \\
Mean age: I: 65 (59 to 74$)$ years; C: 61 (56 to 65$)$ years \\
Sex (\% male): I: $78 \% ;$ : $64 \%$ \\
COPD: stable COPD; FEV 1 FVC ratio < 0.70 \\
Major exclusion criteria: previous diagnosis of asthma; oxygen dependence; unstable and/or uncon- \\
trolled cardiac disease; musculoskeletal problems precluding exercise training; terminal disease, de- \\
mentia or an uncontrolled psychiatric illness
\end{tabular}

Interventions

Mode: group and Individual sessions, face-to-face, telephone, hospital on outpatient basis

Professional: health professional and qualified exercise trainer

Topics: smoking cessation, exercise programme, action plan, advice about exercise, advice about nutrition, advice about medication

Duration: eight group sessions of two hours, three phone calls

Action plan: yes

Exercise programme: yes

Behavioural components: goal setting, providing feedback to the participant

\begin{tabular}{|c|c|c|}
\hline Outcomes & \multicolumn{2}{|c|}{$\begin{array}{l}\text { 1. CRQ } \\
\text { 2. SF-36 } \\
\text { 3. Self efficacy for managing dyspnoea } \\
\text { 4. } 6 \mathrm{MWT} \\
\text { 5. Dyspnoea knowledge } \\
\text { 6. Excercise stage of change }\end{array}$} \\
\hline Notes & \multicolumn{2}{|c|}{ Sources of funding: a grant from the Hospital of Montpellier CHRU, PHRC (grant number UF7608) } \\
\hline \multicolumn{3}{|l|}{ Risk of bias } \\
\hline Bias & Authors' judgement & Support for judgement \\
\hline $\begin{array}{l}\text { Random sequence genera- } \\
\text { tion (selection bias) }\end{array}$ & Low risk & $\begin{array}{l}\text { "Participants were randomly assigned either to the self-management program } \\
\text { or usual care group. The trial statistician, MCP, generated the random alloca- } \\
\text { tion sequence using the random procedure in SAS (SAS v.9.1 e SAS Institute, } \\
\text { Cary NC), with a 1:1 allocation using block size of } 4 . . . " \text { page } 379 \text {. } \\
\text { Comment: Random sequence generation was adequately performed }\end{array}$ \\
\hline $\begin{array}{l}\text { Allocation concealment } \\
\text { (selection bias) }\end{array}$ & Low risk & $\begin{array}{l}\text { "....After the physician had obtained the patient's consent, he sent by fax the } \\
\text { randomisation form to the Clinical Research Unit (AJ) for allocation consign- } \\
\text { ment re-addressed by fax". page } 379 \\
\text { Comment: Allocation was adequately concealed }\end{array}$ \\
\hline $\begin{array}{l}\text { Blinding of participants } \\
\text { and personnel (perfor- } \\
\text { mance bias) } \\
\text { All outcomes }\end{array}$ & Unclear risk & $\begin{array}{l}\text { "Due to the nature of the intervention conditions, it is not possible to blind re- } \\
\text { search participants or assessors. Several stratagems were adopted in an ef- } \\
\text { fort to ensure that objectivity was maintained as rigorously as possible. Partic- } \\
\text { ipants were unaware of their group allocation until they had completed all of } \\
\text { their pre-intervention assessment". page } 379\end{array}$ \\
\hline
\end{tabular}


Blinding of outcome as- Low risk sessment (detection bias) All outcomes
"... The individuals carrying out the assessments were not part of the intervention team. Research participants were asked not to divulge information regarding their group allocation in conversation during assessments at 12 month"

Comment: Outcome assessment was not blinded; however, assessors were not part of the intervention team

Incomplete outcome data Low risk (attrition bias)

"One patient from the intervention group did not fulfil our adherence criteria to the 4-week program, and also did not complete the 1-year evaluation. Six more patients were not available for follow-up evaluation: four in the usual care group, and two in the intervention group. The withdrawals were due to miscellaneous medical conditions $(n=3)$, and COPD exacerbation $(n=3)$. Due to the missing data, we did not retain these patients in our 1-year analyses"

Comment: The number of dropouts was relatively low and equally distributed over groups. Also, reasons for dropout in the two groups were comparable

Selective reporting (re- Unclear risk Comment: no signs of selective reporting; however, no protocol available
porting bias)

Methods Design: RCT. Follow-up: three to five months. Control group: usual care

Participants Recruitment: primary healthcare clinic

Eligible: 62

Randomly assigned: 52

Completed: 38

Mean age: I: 66 (9.4) years; C: 67 (10.4) years

Sex (\% male): I: $50 \%$; C: $50 \%$

COPD: mild, moderate, severe or very severe COPD based on spirometry, lung capacity after bronchodilator use, based on GOLD criteria

Major exclusion criteria: Severe mental disorders such as schizophrenia, dementia and alcohol or drug abuse were excluded

Interventions Mode: individual sessions, face-to-face, outpatient clinic

Professional: respiratory nurse

Topics: education regarding COPD, smoking cessation, action plan, advice about exercise, advice about nutrition, advice about medication, coping with breathlessness

Duration: two individual sessions of one hour

\section{Action plan: yes}

\section{Exercise programme: no}

Behavioural components: motivational interviewing, providing feedback to the participant

$\begin{array}{ll}\text { Outcomes } & \text { 1. SGRQ } \\ & \text { 2. COPD knowledge }\end{array}$


Osterlund Efraimsson 2006 (Continued)

Notes Sources of funding: County of Council of Dalarna, Sweden

\section{Risk of bias}

Bias Authors' judgement Support for judgement

Random sequence genera- Low risk

"The randomisation was performed when two patients with the same variables agreed to participate in the study by assigning each individual an identity number. An independent person drew lots for allocation to either intervention or control group". pages 2 to 3

Comment: The random sequence generation was performed adequately

Allocation concealment Low risk
(selection bias)
"The randomisation was performed when two patients with the same variables agreed to participate in the study by assigning each individual an identity number. An independent person drew lots for allocation to either intervention or control group". pages 2 to 3

Comment: Allocation was adequately concealed
Blinding of participants Unclear risk Comment: Blinding of participants and personnel was not reported and personnel (perfor-

mance bias)

All outcomes
Blinding of outcome as- High risk sessment (detection bias) All outcomes

\begin{abstract}
"Each visit lasted for about 1 hour and the same nurse (Eva Österlund Efraimsson) was responsible for all consultations. At the first and last visits, all patients responded to the two questionnaires, which were completed by each participant in an undisturbed area. The nurse in charge was available to answer questions and to check that the patients responded to all the items". page 180
\end{abstract}

Comment: Outcome assessment was not blinded, and measurements were performed/supervised by the same person who provided the intervention (who was also the principal investigator)

Incomplete outcome data Low risk No participants were lost to follow-up

(attrition bias)

All outcomes

\begin{tabular}{lll}
\hline $\begin{array}{l}\text { Selective reporting (re- } \\
\text { porting bias) }\end{array}$ & Unclear risk & $\begin{array}{l}\text { Comment: All subscales of the two questionnaires used were reported; no } \\
\text { signs of selective reporting were noted }\end{array}$ \\
\hline Other bias & Low risk & \\
\hline
\end{tabular}

\section{Rea 2004}

Methods Design: RCT (cluster). Follow-up: 12 months. Control group: usual care

Participants Recruitment: general practise

Eligible: 158

Randomly assigned: 135

Completed: 117

Mean age of both groups: 68 years (range 44 to 84 )

Sex ( $\%$ male) of the whole study populations: $41.5 \%$ 
Rea 2004 (Continued)

COPD: diagnosis of COPD by ICD-9-CM codes and GP records for a clinical diagnosis of moderate to severe COPD

Major exclusion criteria: chronic asthma; bronchiectasis; co-morbidity more significant than COPD; unable to give informed consent; prognosis < 12 months; long-term oxygen therapy or too unwell; deceased; no longer enrolled with GP practise or moved out; unable to contact participant; insufficient practise nurse

Interventions Mode: timetable for regular maintenance checks; set achievable goals for lifestyle changes

Professional: general practitioner, practise nurse, respiratory physician, respiratory nurse specialist Topics: an action plan detailing advice on how to manage worsening symptoms, when to call the GP and self medication options decided by the GP. Information about smoking cessation and the use of inhalers was given. Annual influenza vaccination and attendance at a pulmonary rehabilitation programme were recommended. Monthly visits with practise nurse, and three-monthly with the GP. More visits were demanded if worsening of symptoms occurred

Duration: 12 monthly visits to practise nurse, four three-monthly visits to GP, at least one home visit of respiratory nurse specialist and one following hospital admissions

Action plans: yes

Exercise programme: no

Behavioural components: goal setting, providing feedback

\begin{tabular}{ll}
\hline Outcomes & 1. SF-36 \\
2. CRQ \\
3. ISWT \\
4. Hospital admissions \\
5. Spirometry \\
6. FEV 1 \\
7. Medication \\
8. Courses of oral steroids \\
9. Courses of antibiotics \\
10.Smoking cessation
\end{tabular}

Sources of funding: provided by the Health Funding Authority, South Auckland Health, South-Med Ltd, ProCare Health Ltd and First Health Ltd

Note: Randomisation is done at the level of GP practise; analysis is performed at the level of participants

\section{Risk of bias}

\section{Bias Authors' judgement Support for judgement}

Random sequence genera- Low risk tion (selection bias)

"Fifty-one eligible practices with 116 GPs were randomised, using a set of computer-generated random numbers..." page 609

Comment: Random sequence generation was adequately performed

\begin{tabular}{|c|c|c|}
\hline $\begin{array}{l}\text { Allocation concealment } \\
\text { (selection bias) }\end{array}$ & High risk & $\begin{array}{l}\text { Comment: The study was cluster-randomised, so no allocation concealment } \\
\text { was provided }\end{array}$ \\
\hline $\begin{array}{l}\text { Blinding of participants } \\
\text { and personnel (perfor- } \\
\text { mance bias) } \\
\text { All outcomes }\end{array}$ & Unclear risk & Comment: Blinding of participants and personnel was not reported \\
\hline $\begin{array}{l}\text { Blinding of outcome as- } \\
\text { sessment (detection bias) }\end{array}$ & Unclear risk & $\begin{array}{l}\text { "For all patients, an initial assessment with the GP and practice nurse included } \\
\text { clinical history and the Short Form (SF)-36. Spirometry, the Shuttle Walk Test }\end{array}$ \\
\hline
\end{tabular}

Self management for patients with chronic obstructive pulmonary disease (Review)

Copyright $\odot 2014$ The Cochrane Collaboration. Published by John Wiley \& Sons, Ltd. 
Rea 2004 (Continued)

All outcomes

and the Chronic Respiratory Questionnaire (CRQ) were administered at the hospital outpatient clinic by a respiratory physician, respiratory nurses and experienced interviewers, respectively. At the completion of a 12-month trial period, an identical reassessment was undertaken". page 609

Comment: Blinding of outcome assessment was not reported; measurements were predominantly performed by study personnel at the outpatient clinic

Incomplete outcome data Low risk

(attrition bias)

All outcomes
"During the trial period, six patients died, six patients withdrew from the study, four patients developed cancer and two patients moved from the area. The 12 month follow-up assessment was completed by 117 patients (71 INT, 46 CON), although hospital admission data were available for all 135 patients". page 609

Comment: 12 participants dropped out in the intervention group (14\%), six in the control group (12\%). Reasons were comparable. Intention-to-treat analysis was performed on the primary outcome
Selective reporting (re-
Unclear risk
Comment: no signs of selective reporting; however, no protocol available porting bias)

\begin{tabular}{ll}
\hline Other bias & We additionally assessed this study on bias specifically important in clus- \\
& ter-randomised trials. In Rea's study, the general practises were randomly as- \\
signed before the participants were included. For reasons unknown, the num- & ber of participants screened and included was lower in the intervention group \\
than in the control group. The study authors state that baseline characteristics & were not significantly different between groups. Therefore, risk of recruitment \\
bias is unclear, and risk of bias for baseline imbalance is low. The risk of bias & due to loss of clusters is low because no clusters were lost after participant en- \\
rolment. Rea et al did not correct for clustering in their analyses, so risk of bias \\
due to incorrect analysis is high
\end{tabular}

Rice 2010

Methods Design: RCT. Follow-up: 12 months. Control group: usual care

Participants

Recruitment: hospital

Eligible: 1739

Randomly assigned: 743

Completed: 659

Mean age: I: 69.1 (9.4) years; C: 70.7 (9.7) years

Sex (\% male): I: $97.6 \%$; : $98.4 \%$

COPD: clinical diagnosis of COPD with postbronchodilator spirometry showing an $\mathrm{FEV}_{1}<70 \%$ predicted and an $\mathrm{FEV}_{1} / \mathrm{FVC}<0.70$

Major exclusion criteria: inability to have access to a home telephone line or to sign a consent form; any condition that would preclude effective participation in the study or likely to reduce life expectancy to less than a year

Interventions

Mode: group and individual sessions, face-to-face, outpatient clinic Professional: respiratory therapist case manager

Topics: education regarding COPD, smoking cessation, action plan with self treatment, advice about exercise, advice about medication, coping with breathlessness

Duration: one group session of one to 1.5 hours, 12 monthly phone calls of 10 to 15 minutes Action plan: yes 
Rice 2010 (Continued)

\section{Exercise programme: no}

Behavioural components: providing feedback to the participant

Outcomes
2. SGRQ
2. Use of short-acting beta-agonist, prednisone, antibiotics
3. Hospitalisations
5. Hospital days
6. ED visits
7. ICU days

Notes

Sources of funding: an unrestricted grant from the Veterans Integrated Service Network 23 Primary Care and Research Services and by the Center for Chronic Disease Outcomes Research, a Veterans Affairs Health Services Research and Development Center of Excellence

\section{Risk of bias}

\begin{tabular}{lll}
\hline Bias & Authors' judgement & Support for judgement \\
\hline $\begin{array}{ll}\text { Random sequence genera- } \\
\text { tion (selection bias) }\end{array}$ & Unclear risk & $\begin{array}{l}\text { "We assigned subjects in equal proportions to each of the two treatment arms } \\
\text { by permuted-block randomisation". Appendix 1, page } 3\end{array}$ \\
& $\begin{array}{l}\text { Comment: Information on the method of random sequence generation was } \\
\text { not reported }\end{array}$
\end{tabular}

\begin{tabular}{|c|c|c|}
\hline $\begin{array}{l}\text { Allocation concealment } \\
\text { (selection bias) }\end{array}$ & Unclear risk & $\begin{array}{l}\text { "We assigned subjects in equal proportions to each of the two treatment arms } \\
\text { by permuted-block randomisation". Appendix } 1 \text {, page } 3\end{array}$ \\
\hline & & $\begin{array}{l}\text { Comment: Information on the method of allocation concealment was not re- } \\
\text { ported }\end{array}$ \\
\hline
\end{tabular}

\begin{tabular}{l}
\hline Blinding of participants Unclear risk Comment: Blinding of participants and personnel was not reported \\
and personnel (perfor- \\
mance bias)
\end{tabular}

\begin{tabular}{|c|c|c|}
\hline $\begin{array}{l}\text { Blinding of outcome as- } \\
\text { sessment (detection bias) } \\
\text { All outcomes }\end{array}$ & Low risk & $\begin{array}{l}\text { "Blinded pulmonologists independently reviewed all discharge summaries } \\
\text { and ED reports and assigned a primary cause for each". page } 891 \\
\text { Comment: Outcome assessment was blinded }\end{array}$ \\
\hline \multirow{3}{*}{$\begin{array}{l}\text { Incomplete outcome data } \\
\text { (attrition bias) } \\
\text { All outcomes }\end{array}$} & Unclear risk & $\begin{array}{l}\text { "All patients were followed for } 12 \text { months or until the time of death if it oc- } \\
\text { curred before } 12 \text { months". page } 981\end{array}$ \\
\hline & & $\begin{array}{l}\text { "Fifty-five percent of patients in the usual care group and } 60 \% \text { of patients in } \\
\text { the disease management group returned a completed the Saint George's Res- } \\
\text { piratory Questionnaire in response to a single mailing at the end of the study". } \\
\text { page } 982\end{array}$ \\
\hline & & $\begin{array}{l}\text { Comment: low response rates on SGRQ leading to a high risk of bias. However, } \\
\text { data on healthcare utilisation seem complete with no risk of bias }\end{array}$ \\
\hline $\begin{array}{l}\text { Selective reporting (re- } \\
\text { porting bias) }\end{array}$ & Unclear risk & Comment: no signs of selective reporting; however, no protocol available \\
\hline Other bias & Low risk & \\
\hline
\end{tabular}


Sassi-Dambron 1995

\begin{tabular}{ll}
\hline Methods & Design: RCT. Follow-up: six months. Intervention one: dyspnoea management programme.Interven- \\
tion two: general health education
\end{tabular}

\begin{tabular}{ll}
\hline Participants & Recruitment: community \\
Eligible: not reported, 497 persons were screened \\
Randomly assigned: 98 \\
Completed: 80 \\
Mean age: I: 67.5 (8.0) years; C: 67.3 (8.0) years \\
Sex (\% male): I: $55 \%$; : $41 \%$ \\
COPD: diagnosis of COPD confirmed with medical recor \\
piratory obstruction \\
Major exclusion criteria: none reported \\
Mode: group sessions, face-to-face \\
Professional: one: clinical nurse, graduate student in \\
ing in each subject \\
Topics: one: education regarding the disease, advice \\
topics not directly related to lung disease: exercise, gen \\
nutrition, Alzheimer's disease and medical insurance \\
Duration: six weekly group sessions, duration not re \\
Action plan: no \\
Exercise programme: no \\
Behavioural components: not reported \\
1. Quality of well-being scale \\
2. Spielberger state-trait anxiety inventory \\
3. The Centre of Epidemiologic Studies Depression \\
4. American Thoracic Society Dyspnea Scale \\
5. 6MWT \\
6. Shortness of Breath Questionnaire \\
\hline Outcomes
\end{tabular}

Notes

Sources of funding: grant 2RT0268 from the University of California Tobacco Related Disease Research Program and grant R01 HL34732 from the National Heart Lung \& Blood Institute

\section{Risk of bias}

\begin{tabular}{lll}
\hline Bias & Authors' judgement & Support for judgement \\
\hline $\begin{array}{l}\text { Random sequence genera- } \\
\text { tion (selection bias) }\end{array}$ & Unclear risk & $\begin{array}{l}\text { "Study subjects were randomly assigned into either a treatment or an educa- } \\
\text { tion-control group". page } 725\end{array}$ \\
& $\begin{array}{l}\text { Comment: Information on the method of random sequence generation was } \\
\text { not reported }\end{array}$ \\
\hline $\begin{array}{l}\text { Allocation concealment } \\
\text { (selection bias) }\end{array}$ & Unclear risk & $\begin{array}{l}\text { "Study subjects were randomly assigned into either a treatment or an educa- } \\
\text { tion-control group". page } 725\end{array}$ \\
& $\begin{array}{l}\text { Comment: Information on the method of allocation concealment was not re- } \\
\text { ported }\end{array}$ \\
\hline
\end{tabular}


Sassi-Dambron 1995 (Continued)
Blinding of participants
Unclear risk
Comment: Blinding of participants and personnel was not reported and personnel (performance bias)

All outcomes

\begin{tabular}{|c|c|c|}
\hline $\begin{array}{l}\text { Blinding of outcome as- } \\
\text { sessment (detection bias) }\end{array}$ & Unclear risk & $\begin{array}{l}\text { Comment: Blinding of outcome assessment was not reported. Not clear who } \\
\text { performed the measurement }\end{array}$ \\
\hline
\end{tabular}

\section{Incomplete outcome data Unclear risk (attrition bias)}

All outcomes

\begin{abstract}
"...nine dropped out before treatment, one from the treatment and eight from the control group. Reasons for dropping included illness (treatment $=1$, control =1), time conflict (control =4), and lack of interest (control =3). An additional nine subjects dropped out during treatment, five from the treatment and four from the control group. We attempted to follow up these subjects at the posttreatment and 6-month follow-up periods and included them as part of the study database resulting in 46 subjects in the treatment group and 43 subjects in the control group. However, only one subject returned to complete the 6-month follow-up examination". page 727

Comment: Dropout in the control group was higher than in the intervention group at 12 versus six; overall dropout is relatively low. Reasons for dropout after the start of treatment are not clear. A per-protocol analysis was performed
\end{abstract} Selective reporting (re- Unclear risk Comment: no signs of selective reporting; however, no protocol available
porting bias)

Other bias Low risk

\section{Stulbarg 2002}

$\begin{array}{ll}\text { Methods } & \text { Design: RCT. Follow-up: } 12 \text { months. Intervention one: dyspnoea self management programme and } \\ \text { training. Intervention two: dyspnoea self management programme and exposure. Intervention } \\ \text { three: dyspnoea self management programme }\end{array}$

Participants Recruitment: community and practising physicians

Eligible: 115

Randomly assigned: 115

Completed: 103

Mean age: one: 66.2 (6.4) years; two: 67.2 (7.6) years; three: 65.7 (8.8) years

Sex (\% male): one: $35.2 \%$; two: $42.4 \%$; three: $55.6 \%$

COPD: diagnosis of moderate to severe COPD with clinical stability for at least one month, persistent moderate to severe airflow obstruction after inhalation of two puffs of albuterol (i.e. $\mathrm{FEV}_{1}$ less than $60 \%$ of predicted or $\mathrm{FEV}_{1} / \mathrm{FVC}$ less than $60 \%$

Major exclusion criteria: cardiopulmonary (arrhythmias and desaturation $(<75)$ during incremental treadmill test) or musculoskeletal complications

Topics: exercise programme, advice about exercise, advice about medication, coping with breathlessness

Duration: all: four individual educational sessions over the first eight weeks of one and one half-hour reinforcement sessions at four and eight months and >= four times walking per week for at least 20 minutes for 12 months. Biweekly nurse telephone calls 
Three: 24 supervised exercise sessions three times per week over two months Action plan: no

\section{Exercise programme: yes}

Behavioural components: goal setting, providing feedback to the participant

\begin{tabular}{ll}
\hline Outcomes & 1. CRQ \\
2. SF-36 \\
3. Self-efficacy for walking questionnaire \\
4. CES-D \\
5. Baseline and transitional dyspnoea index \\
6. FEV 1 \\
7. FEV $1 /$ FVC \\
8. $6 M W T$ \\
9. Endurance treadmill test
\end{tabular}

Notes

Sources of funding: funded by National Institutes of Health NINR R01-NR02131-08; Nursing Research Training in Symptom Management National Institutes of Health/NINR 2T32 NR07088. This study was carried out in part in the General Clinical Research Center, Moffitt Hospital, University of California, San Francisco, with funds provided by the National Center for Research Resources, 5 M01 RR-00079, US Public Health Service

\section{Risk of bias}

Bias Authors' judgement Support for judgement

Random sequence genera- Unclear risk "In an attempt to control for disease severity, after baseline testing and betion (selection bias) fore randomisation, subjects were stratified by oxygen saturation ( $\mathrm{SaO} 2)$ less than $85 \%$ or greater than or equal to $85 \%$ during incremental exercise testing and their ability (yes) or inability (no) to achieve anaerobic threshold (AT). Four strata were therefore created... A randomisation plan was created for each of the four strata". Stulbarg 2002, page 110

Comment: Information on the method of random sequence generation was not reported

\begin{tabular}{|c|c|c|}
\hline \multirow[t]{2}{*}{$\begin{array}{l}\text { Allocation concealment } \\
\text { (selection bias) }\end{array}$} & Unclear risk & $\begin{array}{l}\text { "In an attempt to control for disease severity, after baseline testing and be- } \\
\text { fore randomisation, subjects were stratified by oxygen saturation (SaO2) less } \\
\text { than } 85 \% \text { or greater than or equal to } 85 \% \text { during incremental exercise testing } \\
\text { and their ability (yes) or inability (no) to achieve anaerobic threshold (AT). Four } \\
\text { strata were therefore created... A randomisation plan was created for each of } \\
\text { the four strata". Stulbarg 2002, page } 110\end{array}$ \\
\hline & & $\begin{array}{l}\text { Comment: Information on the method of allocation concealment was not re- } \\
\text { ported }\end{array}$ \\
\hline
\end{tabular}

\begin{tabular}{|c|c|c|}
\hline $\begin{array}{l}\text { Blinding of participants } \\
\text { and personnel (perfor- } \\
\text { mance bias) } \\
\text { All outcomes }\end{array}$ & Unclear risk & Comment: Blinding of participants and personnel was not reported \\
\hline $\begin{array}{l}\text { Blinding of outcome as- } \\
\text { sessment (detection bias) } \\
\text { All outcomes }\end{array}$ & Low risk & $\begin{array}{l}\text { "Research personnel who performed these measurements were blinded to pa- } \\
\text { tients' treatment group assignments". Carrieri-Kohlman 2005, page } 275 \\
\text { Comment: Outcome assessment was blinded }\end{array}$ \\
\hline
\end{tabular}


Stulbarg 2002 (Continued) Low risk (attrition bias)

All outcomes
"A total of 115 patients were randomised and 4 patients from each group dropped out before the first evaluation at 2 months.... There were no significant differences between the 3 treatment groups in any of the baseline characteristics". Carrieri-Kohlman 2005, pages 278 to 279

Comment: A per-protocol analysis was performed; however, dropout was relatively low and equally distributed over groups

\begin{tabular}{|c|c|c|}
\hline $\begin{array}{l}\text { Selective reporting (re- } \\
\text { porting bias) }\end{array}$ & High risk & $\begin{array}{l}\text { Comment: Several measures that were reported at two months were not re- } \\
\text { ported at } 12 \text { months (CES-D, self efficacy, USCD shortness of breath question- } \\
\text { naire) }\end{array}$ \\
\hline
\end{tabular}

Other bias Low risk

van Wetering 2009

\begin{tabular}{|c|c|}
\hline Methods & Design: RCT. Follow-up: 24 months. Control group: usual care \\
\hline \multirow[t]{8}{*}{ Participants } & Recruitment: hospital \\
\hline & Eligible: not reported \\
\hline & Randomly assigned: 199 \\
\hline & Completed: 158 \\
\hline & Mean age: I: 65.9 (8.8) years; C: $67.2(8.9)$ years \\
\hline & Sex (\% male): I: $71 \%$; C: $71 \%$ \\
\hline & COPD: COPD GOLD stage two or three \\
\hline & Major exclusion criteria: prior rehabilitation; serious co-morbidity that precluded exercise therapy \\
\hline \multirow[t]{5}{*}{ Interventions } & $\begin{array}{l}\text { Mode: individual sessions, face-to-face, patient education book, community- and home-based } \\
\text { Professional: respiratory nurse, respiratory physiotherapist, dietician }\end{array}$ \\
\hline & $\begin{array}{l}\text { Topics: education regarding COPD, smoking cessation, exercise programme, advice about exercise, ad- } \\
\text { vice about nutrition }\end{array}$ \\
\hline & $\begin{array}{l}\text { Duration: } 52 \text { individual sessions of exercise training of } 30 \text { minutes. Daily home-based exercise sessions } \\
\text { Action plan: no }\end{array}$ \\
\hline & Exercise programme: yes \\
\hline & Behavioural components: providing feedback to the participant \\
\hline \multirow[t]{10}{*}{ Outcomes } & 1. SGRQ \\
\hline & 2. Number of exacerbations \\
\hline & 3. $\mathrm{mMRC}$ \\
\hline & 4. Hospitalisations \\
\hline & 5. Hospital days \\
\hline & 6. Time unable to work \\
\hline & 7. GP visits \\
\hline & 8. Nurse visits \\
\hline & 9. Specialist visits \\
\hline & 10.6MWT \\
\hline
\end{tabular}
jding" (SAB), Nutricia Netherlands, Pfizer and Partners in Care Solutions (PICASSO) for COPD 
van Wetering 2009 (Continued)

\section{Risk of bias}

\begin{tabular}{|c|c|c|}
\hline Bias & Authors' judgement & Support for judgement \\
\hline \multirow[t]{2}{*}{$\begin{array}{l}\text { Random sequence genera- } \\
\text { tion (selection bias) }\end{array}$} & Low risk & $\begin{array}{l}\text { "Patients were randomised to the INTERCOM programme or to usual care us- } \\
\text { ing a computerised procedure with concealed patient allocation". page } 8\end{array}$ \\
\hline & & Comment: Random sequence generation was performed adequately \\
\hline \multirow[t]{2}{*}{$\begin{array}{l}\text { Allocation concealment } \\
\text { (selection bias) }\end{array}$} & Low risk & $\begin{array}{l}\text { "Patients were randomised to the INTERCOM programme or to usual care us- } \\
\text { ing a computerised procedure with concealed patient allocation". page } 8\end{array}$ \\
\hline & & Comment: Allocation was adequately concealed \\
\hline
\end{tabular}

Blinding of participants

Unclear risk

Comment: Participants and personnel were not blinded

and personnel (perfor-

mance bias)

All outcomes

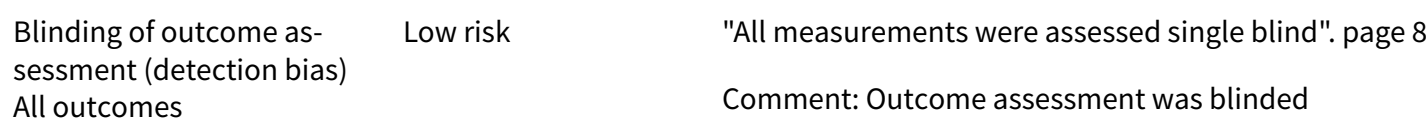

Incomplete outcome data Low risk

(attrition bias)

"The analysis was performed according to an intention-to-treat (ITT) ap-

All outcomes proach. All randomised patients who started the treatment (in the INTERCOM group) and who completed at least one post-randomisation outcome measurement (in both the INTERCOM group and usual care group) were included in the statistical analysis." page 8

"Thirteen of the 199 randomised patients did not start the treatment. The total drop-out rate was $24.5 \%$ (25 patients) in the INTERCOM group and 16.5\% (16 patients) in the usual care group. This difference was not statistically significant $(\mathrm{P}=0.22) "$

Comment: Reasons for dropout were comparable in the intervention and control groups

Selective reporting (re- Unclear risk Comment: no signs of selective reporting; however, no protocol available
porting bias)

Other bias Low risk

Wakabayashi 2011

Methods Design: RCT. Follow-up: 12 months. Control group: usual care

Participants

Recruitment: hospital (outpatient clinic)

Eligible: 118

Randomly assigned: 102

Completed: 85

Mean age: I: 72.9 (6.4) years; C: 70.4 (8.6) years

Sex (\% male): $1: 88.5 \%$; C: $84 \%$

COPD: clinical diagnosis of COPD including airflow obstruction assessed by pulmonary function tests with postbronchodilator inhalation 
Wakabayashi 2011 (Continued)

Major exclusion criteria: history of atopy or any apparent asthmatic features; illiterate or had a cognitive impairment score of less than 26 on the Mini-Mental State Examination (MMSE); lived in a residential care facility or a nursing home; had exacerbations during the preceding three months; had other respiratory diseases such as bronchiectasis, any type of pulmonary fibrosis or congestive heart failure

Interventions Mode: individual sessions, face-to-face, booklet, outpatient clinic

Professional: respiratory nurse, pulmonary physician

Topics: education regarding COPD, smoking cessation, action plan with self treatment, advice about exercise, advice about nutrition, advice about medication, coping with breathlessness

Duration: six monthly individual sessions of at least 30 minutes

Action plan: yes

Exercise programme: no

Behavioural components: providing feedback to the participant

$\begin{array}{ll}\text { Outcomes } & \text { 1. SGRQ } \\ \text { 2. LINQ } \\ \text { 3. } \mathrm{mMRC} \\ \text { 4. FEV1\% of predicted } \\ \text { 5. Hospital admissions } \\ \text { 6. Emergency department visits } \\ \text { 7. GMWT } \\ \text { 8. Instrumental activities of daily living }\end{array}$

Notes Sources of funding: Environmental Restoration and Conservation Agency of Japan (2003 to 2005)

\section{Risk of bias}

Bias Authors' judgement Support for judgement

Random sequence genera- Low risk tion (selection bias) "A case manager independent of the study randomly assigned patients to ei-
ther group I or group U using a computer-generated list". page 423

Comment: Random sequence generation was performed adequately

\begin{tabular}{ll}
\hline $\begin{array}{l}\text { Allocation concealment } \\
\text { (selection bias) }\end{array}$ & "A case manager independent of the study randomly assigned patients to ei- \\
& ther group I or group U using a computer-generated list. Patient allocations \\
were sealed in numbered envelopes by an independent evaluator, not in- & volved in the interventions, who assessed outcomes at the beginning of the \\
study, after initial integrated education ( 6 months) and after the follow-up pe- \\
riod ( 6 months)". page 423 \\
Comment: Allocation was adequately concealed
\end{tabular}

Blinding of participants Unclear risk Comment: Blinding of participants and personnel was not reported and personnel (performance bias)

All outcomes

\begin{tabular}{|c|c|c|}
\hline $\begin{array}{l}\text { Blinding of outcome as- } \\
\text { sessment (detection bias) } \\
\text { All outcomes }\end{array}$ & Low risk & $\begin{array}{l}\text { "Patient allocations were sealed in numbered envelopes by an independent } \\
\text { evaluator, } \\
\text { not involved in the interventions, who assessed outcomes at the beginning of } \\
\text { the study, after initial integrated education ( } 6 \text { months) and after the follow-up } \\
\text { period ( } 6 \text { months)". page } 423\end{array}$ \\
\hline
\end{tabular}


Wakabayashi 2011 (Continued)

Comment: Outcome assessment was not blinded, but outcome assessment was performed by an independent evaluator

Incomplete outcome data Low risk
(attrition bias)
All outcomes

Incomplete outcome data Low risk

All outcomes

\begin{abstract}
"A total of 125 patients fulfilled the inclusion criteria, and 102 were enrolled into the integrated or usual care groups. A total of 42 and 43 patients in group I and group $U$, respectively, completed the study. Withdrawal rates were similar for both groups". page 424

Comment: The number of dropouts was relatively low and equally distributed over groups; also the reasons for withdrawal were comparable
\end{abstract}

\begin{tabular}{lll}
\hline $\begin{array}{l}\text { Selective reporting (re- } \\
\text { porting bias) }\end{array}$ & Unclear risk & $\begin{array}{l}\text { Comment: no signs of selective reporting, although only one outcome mea- } \\
\text { sure was reported }\end{array}$ \\
\hline Other bias & Low risk & \\
\hline
\end{tabular}

Coultas has three study groups: two intervention groups and one control group. To be able to do the analyses, two comparisons are made: UC versus MM (Coultas 2005a) and UC versus CM (Coultas 2005b).

\title{
Characteristics of excluded studies [ordered by study ID]
}

\begin{tabular}{|c|c|}
\hline Study & Reason for exclusion \\
\hline Blake 1990 & In the update of 2007; now excluded because it was published before 1995 \\
\hline Boxall 2005 & In the update of 2007; now excluded because included participants did not have solely COPD \\
\hline Carone 2002 & No results \\
\hline Cockcroft 1987 & In the update of 2007; now excluded because it was published before 1995 \\
\hline de Toledo 2006 & No self management \\
\hline Gourley 1998 & In the update of 2007 ; now excluded because it provided no self management \\
\hline Hesselink 2004 & Participants with COPD and asthma included \\
\hline Jerant 2009 & Participants with several chronic diseases included \\
\hline Kunik 2008 & Self management directed towards depression \\
\hline Lamers 2010 & Self management directed towards depression \\
\hline Littlejohns 1991 & In the update of 2007; now excluded because it was published before 1995 \\
\hline Lorig 1999 & Participants with several chronic diseases included \\
\hline Lorig 2003a & Participants with several chronic diseases included \\
\hline Martin 2004 & $\begin{array}{l}\text { In the update of 2007; now excluded because it incorporated solely an action plan (= only one com- } \\
\text { ponent) }\end{array}$ \\
\hline Martin 2008 & No self management; home- versus hospital-based rehabilitation \\
\hline McGeoch 2006 & Solely action plan (= only one component), with only one contact moment \\
\hline
\end{tabular}




\begin{tabular}{ll}
\hline Study & Reason for exclusion \\
\hline Rootmensen 2008 & Only one contact moment \\
\hline Sridhar 2008 & Hospital-based rehabilitation \\
\hline Watson 1997 & $\begin{array}{l}\text { In the update of } 2007 ; \text { now excluded because it incorporated solely an action plan (= only one com- } \\
\text { ponent), with only one contact moment }\end{array}$ \\
\hline Wood-Baker 2006 & Solely action plan (= only one component), with only one contact moment \\
\hline
\end{tabular}

DATA AND ANALYSES

Comparison 1. Self management versus control

\begin{tabular}{|c|c|c|c|c|}
\hline Outcome or subgroup title & $\begin{array}{l}\text { No. of } \\
\text { studies }\end{array}$ & $\begin{array}{l}\text { No. of } \\
\text { partici- } \\
\text { pants }\end{array}$ & Statistical method & Effect size \\
\hline 1 HRQoL: SGRQ & 11 & & $\begin{array}{l}\text { Mean Difference (IV, Random, } \\
95 \% \mathrm{CI})\end{array}$ & Subtotals only \\
\hline 1.1 SGRQ: total score & 11 & 1413 & $\begin{array}{l}\text { Mean Difference (IV, Random, } \\
95 \% \mathrm{CI})\end{array}$ & $-3.51[-5.37,-1.65]$ \\
\hline 1.2 SGRQ: symptoms & 10 & 1371 & $\begin{array}{l}\text { Mean Difference (IV, Random, } \\
95 \% \mathrm{CI})\end{array}$ & $-3.09[-5.42,-0.77]$ \\
\hline 1.3 SGRQ: activity & 10 & 1356 & $\begin{array}{l}\text { Mean Difference (IV, Random, } \\
95 \% \mathrm{CI})\end{array}$ & $-2.75[-4.93,-0.56]$ \\
\hline 1.4 SGRQ: impact & 10 & 1356 & $\begin{array}{l}\text { Mean Difference (IV, Random, } \\
95 \% \mathrm{CI} \text { ) }\end{array}$ & $-5.71[-9.17,-2.25]$ \\
\hline $\begin{array}{l}2 \mathrm{HRQOL} \text { : SGRQ total score: change from } \\
\text { baseline }\end{array}$ & 10 & 1364 & $\begin{array}{l}\text { Mean Difference (Random, } \\
95 \% \mathrm{Cl} \text { ) }\end{array}$ & $-2.68[-4.16,-1.20]$ \\
\hline 3 HRQoL: CRQ & 2 & & $\begin{array}{l}\text { Mean Difference (IV, Random, } \\
95 \% \mathrm{CI})\end{array}$ & Totals not selected \\
\hline 3.1 CRQ: dyspnoea & 2 & & $\begin{array}{l}\text { Mean Difference (IV, Random, } \\
95 \% \mathrm{CI} \text { ) }\end{array}$ & $0.0[0.0,0.0]$ \\
\hline 3.2 CRQ: mastery & 1 & & $\begin{array}{l}\text { Mean Difference (IV, Random, } \\
95 \% \mathrm{CI} \text { ) }\end{array}$ & $0.0[0.0,0.0]$ \\
\hline 3.3 CRQ: fatigue & 2 & & $\begin{array}{l}\text { Mean Difference (IV, Random, } \\
95 \% \mathrm{CI} \text { ) }\end{array}$ & $0.0[0.0,0.0]$ \\
\hline 3.4 CRQ: emotional function & 2 & & $\begin{array}{l}\text { Mean Difference (IV, Random, } \\
95 \% \mathrm{CI} \text { ) }\end{array}$ & $0.0[0.0,0.0]$ \\
\hline 4 HRQoL: CCQ & 1 & & $\begin{array}{l}\text { Mean Difference (IV, Random, } \\
95 \% \mathrm{CI})\end{array}$ & Totals not selected \\
\hline
\end{tabular}




\begin{tabular}{|c|c|c|c|c|}
\hline Outcome or subgroup title & $\begin{array}{l}\text { No. of } \\
\text { studies }\end{array}$ & $\begin{array}{l}\text { No. of } \\
\text { partici- } \\
\text { pants }\end{array}$ & Statistical method & Effect size \\
\hline 4.1 Total & 1 & & $\begin{array}{l}\text { Mean Difference (IV, Random, } \\
95 \% \mathrm{Cl} \text { ) }\end{array}$ & $0.0[0.0,0.0]$ \\
\hline 4.2 Mental state & 1 & & $\begin{array}{l}\text { Mean Difference (IV, Random, } \\
95 \% \mathrm{CI} \text { ) }\end{array}$ & $0.0[0.0,0.0]$ \\
\hline 4.3 Symptoms & 1 & & $\begin{array}{l}\text { Mean Difference (IV, Random, } \\
95 \% \mathrm{CI})\end{array}$ & $0.0[0.0,0.0]$ \\
\hline 4.4 Functional state & 1 & & $\begin{array}{l}\text { Mean Difference (IV, Random, } \\
95 \% \mathrm{CI})\end{array}$ & $0.0[0.0,0.0]$ \\
\hline $5 \mathrm{HRQ}$ oL: SIP total score & 1 & & $\begin{array}{l}\text { Mean Difference (IV, Random, } \\
95 \% \mathrm{CI})\end{array}$ & Totals not selected \\
\hline 6 HRQoL: SF-36 & 3 & & $\begin{array}{l}\text { Mean Difference (IV, Random, } \\
95 \% \mathrm{CI})\end{array}$ & Totals not selected \\
\hline 6.1 SF-36-total & 0 & & $\begin{array}{l}\text { Mean Difference (IV, Random, } \\
95 \% \mathrm{CI})\end{array}$ & $0.0[0.0,0.0]$ \\
\hline 6.2 SF-36-physical functioning & 3 & & $\begin{array}{l}\text { Mean Difference (IV, Random, } \\
95 \% \mathrm{CI})\end{array}$ & $0.0[0.0,0.0]$ \\
\hline 6.3 SF-36-role limitations-physical & 3 & & $\begin{array}{l}\text { Mean Difference (IV, Random, } \\
95 \% \mathrm{CI})\end{array}$ & $0.0[0.0,0.0]$ \\
\hline 6.4 SF-36-bodily pain & 3 & & $\begin{array}{l}\text { Mean Difference (IV, Random, } \\
95 \% \mathrm{CI})\end{array}$ & $0.0[0.0,0.0]$ \\
\hline 6.5 SF-36-social limitations & 3 & & $\begin{array}{l}\text { Mean Difference (IV, Random, } \\
95 \% \mathrm{CI})\end{array}$ & $0.0[0.0,0.0]$ \\
\hline 6.6 SF-36-mental health & 3 & & $\begin{array}{l}\text { Mean Difference (IV, Random, } \\
95 \% \mathrm{CI})\end{array}$ & $0.0[0.0,0.0]$ \\
\hline 6.7 SF-36-role limitations-emotional & 3 & & $\begin{array}{l}\text { Mean Difference (IV, Random, } \\
95 \% \mathrm{CI})\end{array}$ & $0.0[0.0,0.0]$ \\
\hline 6.8 SF-36-vitality, energy, fatigue & 3 & & $\begin{array}{l}\text { Mean Difference (IV, Random, } \\
95 \% \mathrm{CI})\end{array}$ & $0.0[0.0,0.0]$ \\
\hline 6.9 SF-36-general health & 3 & & $\begin{array}{l}\text { Mean Difference (IV, Random, } \\
95 \% \mathrm{CI} \text { ) }\end{array}$ & $0.0[0.0,0.0]$ \\
\hline 7 Respiratory-related hospital admissions & 10 & 1749 & $\begin{array}{l}\text { Odds Ratio (M-H, Random, } \\
95 \% \mathrm{Cl})\end{array}$ & $0.57[0.43,0.75]$ \\
\hline 8 All-cause hospital admissions & 7 & 1365 & $\begin{array}{l}\text { Odds Ratio (M-H, Random, } \\
95 \% \mathrm{Cl})\end{array}$ & $0.60[0.40,0.89]$ \\
\hline $\begin{array}{l}9 \text { Respiratory-related hospital admissions: } \\
\text { days }\end{array}$ & 3 & 272 & $\begin{array}{l}\text { Mean Difference (IV, Random, } \\
95 \% \mathrm{CI} \text { ) }\end{array}$ & $0.33[-1.01,1.66]$ \\
\hline
\end{tabular}




\begin{tabular}{|c|c|c|c|c|}
\hline Outcome or subgroup title & $\begin{array}{l}\text { No. of } \\
\text { studies }\end{array}$ & $\begin{array}{l}\text { No. of } \\
\text { partici- } \\
\text { pants }\end{array}$ & Statistical method & Effect size \\
\hline 10 All-cause hospital admissions: days & 5 & 1298 & $\begin{array}{l}\text { Mean Difference (IV, Random, } \\
95 \% \mathrm{CI} \text { ) }\end{array}$ & $-1.39[-3.19,0.41]$ \\
\hline $\begin{array}{l}11 \text { Emergency department visits per person } \\
\text { per year }\end{array}$ & 3 & & $\begin{array}{l}\text { Mean Difference (IV, Random, } \\
95 \% \mathrm{CI})\end{array}$ & Totals not selected \\
\hline $\begin{array}{l}\text { 11.1 Emergency department visits per person } \\
\text { per year (all causes) }\end{array}$ & 1 & & $\begin{array}{l}\text { Mean Difference (IV, Random, } \\
95 \% \mathrm{CI})\end{array}$ & $0.0[0.0,0.0]$ \\
\hline $\begin{array}{l}\text { 11.2 Emergency department visits per person } \\
\text { per year (lung diseases) }\end{array}$ & 2 & & $\begin{array}{l}\text { Mean Difference (IV, Random, } \\
95 \% \mathrm{CI})\end{array}$ & $0.0[0.0,0.0]$ \\
\hline $\begin{array}{l}12 \text { Doctor and nurse visits: mean number per } \\
\text { person per year }\end{array}$ & 3 & & $\begin{array}{l}\text { Mean Difference (IV, Random, } \\
95 \% \mathrm{CI})\end{array}$ & Totals not selected \\
\hline $\begin{array}{l}\text { 12.1 Doctor and nurse visits: mean number } \\
\text { per person per year }\end{array}$ & 3 & & $\begin{array}{l}\text { Mean Difference (IV, Random, } \\
95 \% \mathrm{CI})\end{array}$ & $0.0[0.0,0.0]$ \\
\hline $\begin{array}{l}13 \text { Participants using at least one course of } \\
\text { oral steroids }\end{array}$ & 3 & 901 & $\begin{array}{l}\text { Odds Ratio (M-H, Random, } \\
95 \% \mathrm{Cl})\end{array}$ & $4.42[0.39,50.10]$ \\
\hline $\begin{array}{l}14 \text { Participants using at least one course of } \\
\text { antibiotics }\end{array}$ & 2 & & $\begin{array}{l}\text { Odds Ratio (M-H, Random, } \\
95 \% \mathrm{Cl})\end{array}$ & Totals not selected \\
\hline $\begin{array}{l}15 \text { (Modified) Medical Research Council Dysp- } \\
\text { noea Scale ((m)MRC) }\end{array}$ & 3 & 119 & $\begin{array}{l}\text { Mean Difference (IV, Random, } \\
95 \% \mathrm{CI})\end{array}$ & $-0.83[-1.36,-0.30]$ \\
\hline $\begin{array}{l}16 \text { Days lost from work: mean number per } \\
\text { person per year }\end{array}$ & 1 & & $\begin{array}{l}\text { Mean Difference (IV, Random, } \\
95 \% \mathrm{CI})\end{array}$ & Totals not selected \\
\hline 17 Lung function: $\mathrm{FEV}_{1}$ (litres) & 6 & 369 & $\begin{array}{l}\text { Mean Difference (IV, Random, } \\
95 \% \mathrm{CI})\end{array}$ & $0.08[-0.03,0.19]$ \\
\hline 18 Lung function: $\mathrm{FEV}_{1}$ (\% of predicted) & 7 & 506 & $\begin{array}{l}\text { Mean Difference (IV, Random, } \\
95 \% \mathrm{CI} \text { ) }\end{array}$ & $1.78[-1.44,5.01]$ \\
\hline 19 Exercise capacity: 6MWT & 6 & 570 & $\begin{array}{l}\text { Mean Difference (IV, Random, } \\
95 \% \mathrm{CI})\end{array}$ & $33.69[-9.12,76.50]$ \\
\hline 20 Lung function: $\mathrm{FEV}_{1} / \mathrm{FVC}$ & 4 & 192 & $\begin{array}{l}\text { Mean Difference (IV, Random, } \\
95 \% \mathrm{CI})\end{array}$ & $-0.84[-5.04,3.36]$ \\
\hline 21 Mortality & 9 & 2134 & $\begin{array}{l}\text { Odds Ratio (M-H, Random, } \\
95 \% \mathrm{Cl})\end{array}$ & $0.79[0.58,1.07]$ \\
\hline
\end{tabular}

Analysis 1.1. Comparison 1 Self management versus control, Outcome 1 HRQoL: SGRQ.

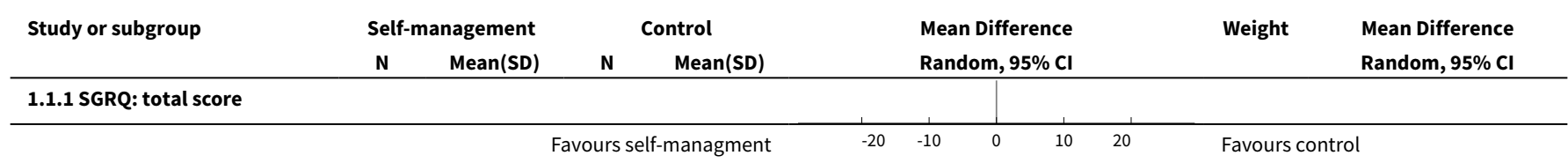




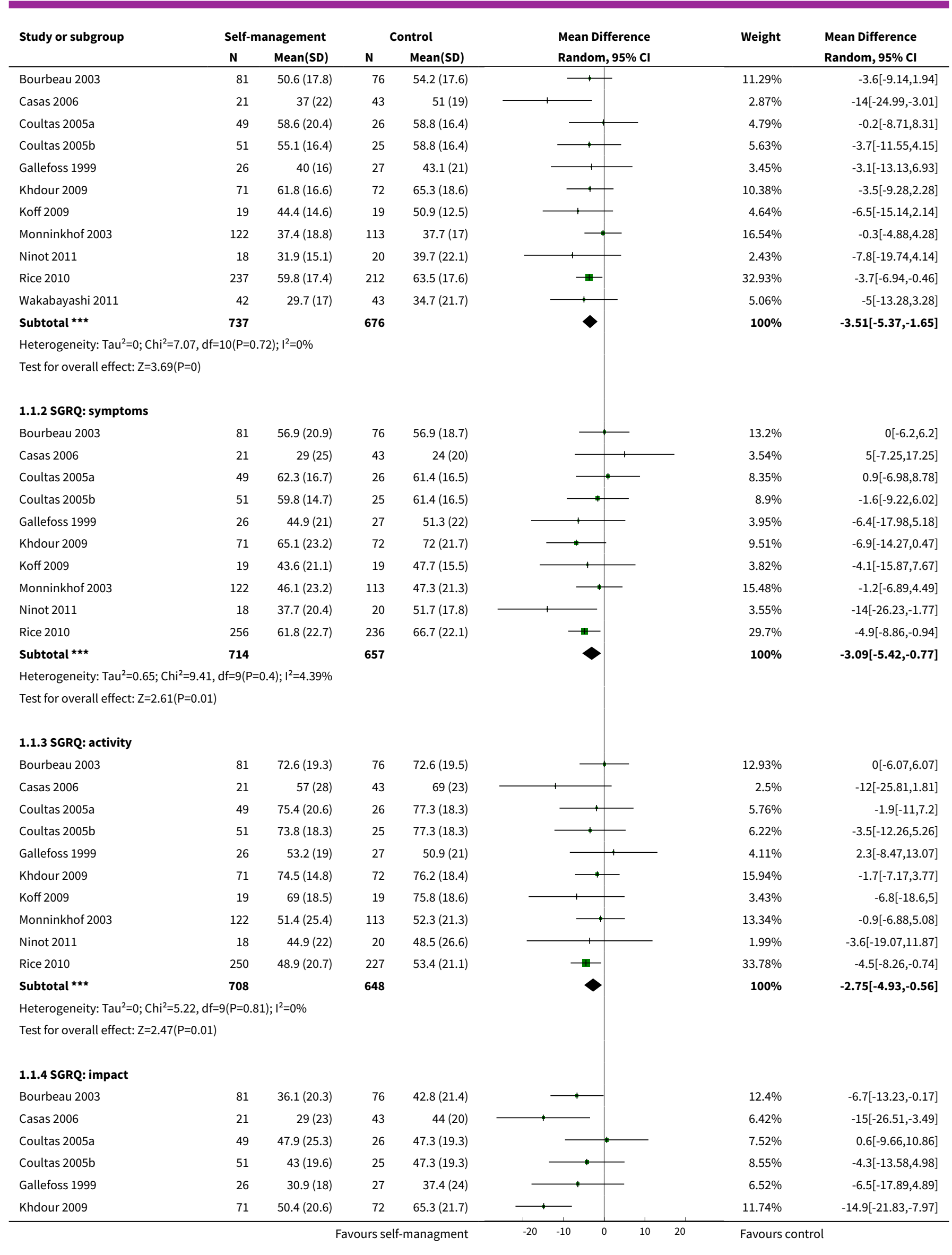




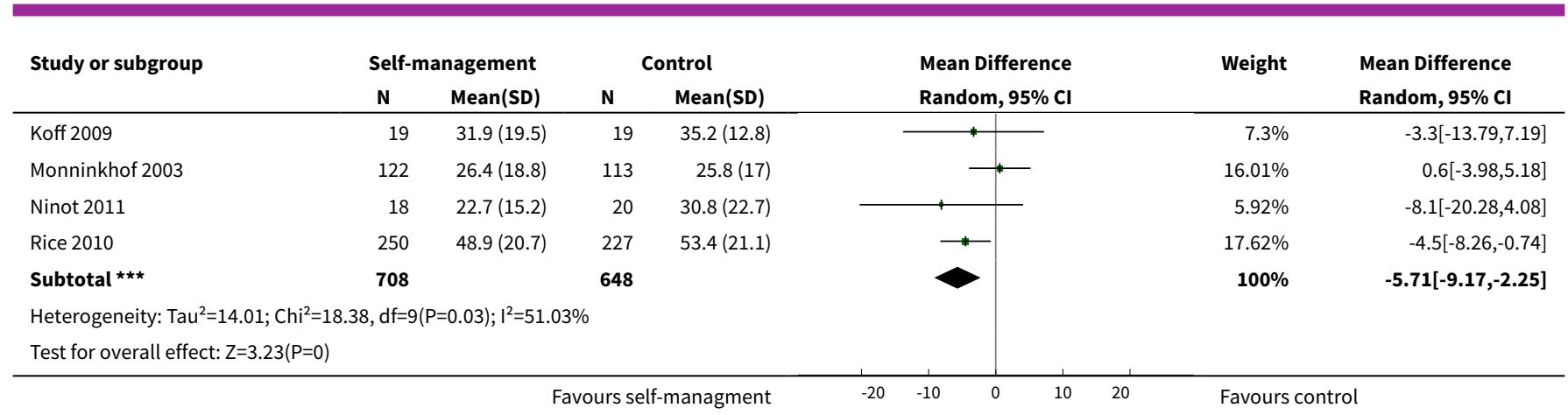

\section{Analysis 1.2. Comparison 1 Self management versus control, Outcome 2 HRQOL: SGRQ total score: change from baseline.}

\begin{tabular}{|c|c|c|c|c|c|c|c|}
\hline Study or subgroup & $\begin{array}{c}\text { Self-man- } \\
\text { agement } \\
\mathrm{N}\end{array}$ & Control & $\begin{array}{l}\text { Mean Dif- } \\
\text { ference } \\
\text { (SE) }\end{array}$ & & $\begin{array}{c}\text { Mean Difference } \\
\text { IV, Random, 95\% CI }\end{array}$ & Weight & $\begin{array}{c}\text { Mean Difference } \\
\text { IV, Random, } 95 \% \mathrm{CI}\end{array}$ \\
\hline Bourbeau 2003 & 81 & 76 & $-2(1.99)$ & & $\rightarrow$ & $12.52 \%$ & $-2[-5.9,1.9]$ \\
\hline Casas 2006 & 21 & 41 & $-2.4(4.168)$ & & \begin{tabular}{l|l}
1 \\
1
\end{tabular} & $3.18 \%$ & $-2.39[-10.56,5.78]$ \\
\hline Coultas 2005a & 49 & 26 & $-2.9(3.521)$ & & $\longrightarrow$ & $4.4 \%$ & $-2.9[-9.8,4]$ \\
\hline Coultas 2005b & 51 & 26 & $-2.6(3.587)$ & & $\longrightarrow$ & $4.24 \%$ & $-2.6[-9.63,4.43]$ \\
\hline Koff 2009 & 19 & 19 & $-9.7(4.428)$ & & $\longrightarrow$ & $2.83 \%$ & $-9.7[-18.38,-1.02]$ \\
\hline Monninkhof 2003 & 122 & 113 & $-0.6(1.123)$ & & $\#$ & $30.66 \%$ & $-0.6[-2.8,1.6]$ \\
\hline Ninot 2011 & 20 & 18 & $-2.9(4.873)$ & & 1 & $2.35 \%$ & $-2.9[-12.45,6.65]$ \\
\hline Rice 2010 & 233 & 204 & $-5.1(1.28)$ & & + & $25.49 \%$ & $-5.1[-7.61,-2.59]$ \\
\hline Wakabayashi 2011 & 52 & 50 & $-0.8(2.97)$ & & $\longrightarrow$ & $6.06 \%$ & $-0.8[-6.62,5.02]$ \\
\hline \multicolumn{8}{|c|}{ Heterogeneity: $\mathrm{Tau}^{2}=0.6 ; \mathrm{Chi}^{2}=10.05, \mathrm{df}=9(\mathrm{P}=0.35) ; \mathrm{I}^{2}=10.42 \%$} \\
\hline \multicolumn{8}{|c|}{ Test for overall effect: $Z=3.54(P=0)$} \\
\hline & & Favours se & nanagement & -40 & -20 & Favours & \\
\hline
\end{tabular}

Analysis 1.3. Comparison 1 Self management versus control, Outcome 3 HRQoL: CRQ.

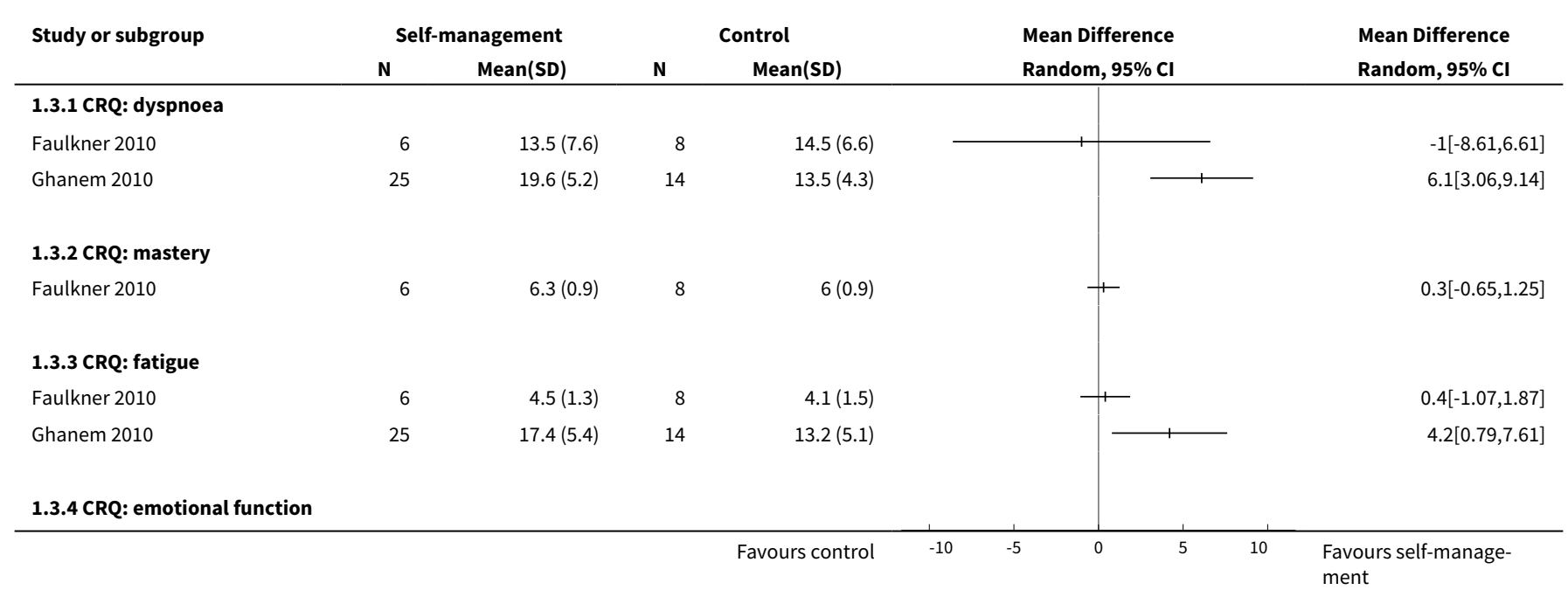




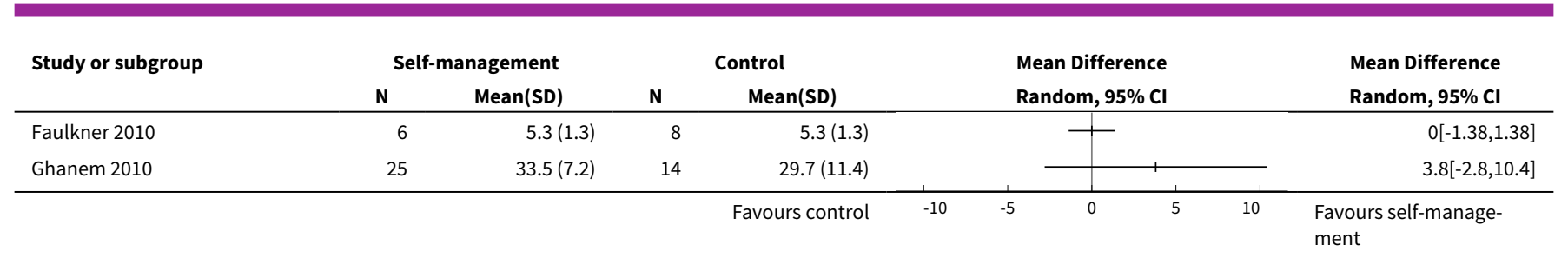

Analysis 1.4. Comparison 1 Self management versus control, Outcome 4 HRQoL: CCQ.

\begin{tabular}{|c|c|c|c|c|c|c|}
\hline \multirow[t]{2}{*}{ Study or subgroup } & \multicolumn{2}{|c|}{ Self-management } & \multicolumn{2}{|c|}{ Control } & \multirow{2}{*}{$\begin{array}{l}\text { Mean Difference } \\
\text { Random, } 95 \% \mathrm{Cl}\end{array}$} & \multirow{2}{*}{$\begin{array}{l}\text { Mean Difference } \\
\text { Random, } 95 \% \mathrm{Cl}\end{array}$} \\
\hline & $\mathrm{N}$ & $\operatorname{Mean}(S D)$ & $\mathbf{N}$ & $\operatorname{Mean}(S D)$ & & \\
\hline \multicolumn{7}{|l|}{ 1.4.1 Total } \\
\hline Kheirabadi 2008 & 21 & $2(0.6)$ & 21 & $2(0.6)$ & + & $0[-0.36,0.36]$ \\
\hline \multicolumn{7}{|l|}{ 1.4.2 Mental state } \\
\hline Kheirabadi 2008 & 21 & $1.9(0.8)$ & 21 & $2.3(0.9)$ & + & $-0.41[-0.91,0.09]$ \\
\hline \multicolumn{7}{|l|}{ 1.4.3 Symptoms } \\
\hline Kheirabadi 2008 & 21 & $2(6.1)$ & 21 & $2.2(0.4)$ & - & $-0.18[-2.79,2.43]$ \\
\hline \multicolumn{7}{|c|}{ 1.4.4 Functional state } \\
\hline Kheirabadi 2008 & 21 & $2(0.7)$ & 21 & $2.2(0.5)$ & + & $-0.16[-0.52,0.2]$ \\
\hline
\end{tabular}

Analysis 1.5. Comparison 1 Self management versus control, Outcome 5 HRQOL: SIP total score.

\begin{tabular}{|c|c|c|c|c|c|c|c|}
\hline \multirow[t]{2}{*}{ Study or subgroup } & \multicolumn{2}{|c|}{ Self-management } & \multicolumn{2}{|c|}{ Control } & \multirow{2}{*}{$\begin{array}{l}\text { Mean Difference } \\
\text { Random, } 95 \% \mathrm{Cl}\end{array}$} & & \multirow{2}{*}{$\begin{array}{l}\text { Mean Difference } \\
\text { Random, } 95 \% \mathrm{Cl}\end{array}$} \\
\hline & $\mathbf{N}$ & $\operatorname{Mean}(S D)$ & $\mathbf{N}$ & Mean(SD) & & & \\
\hline Emery 1998 & 23 & $10.7(7.4)$ & 25 & $10.4(7.8)$ & - & & $0.3[-4,4.6]$ \\
\hline
\end{tabular}

Analysis 1.6. Comparison 1 Self management versus control, Outcome 6 HRQoL: SF-36.

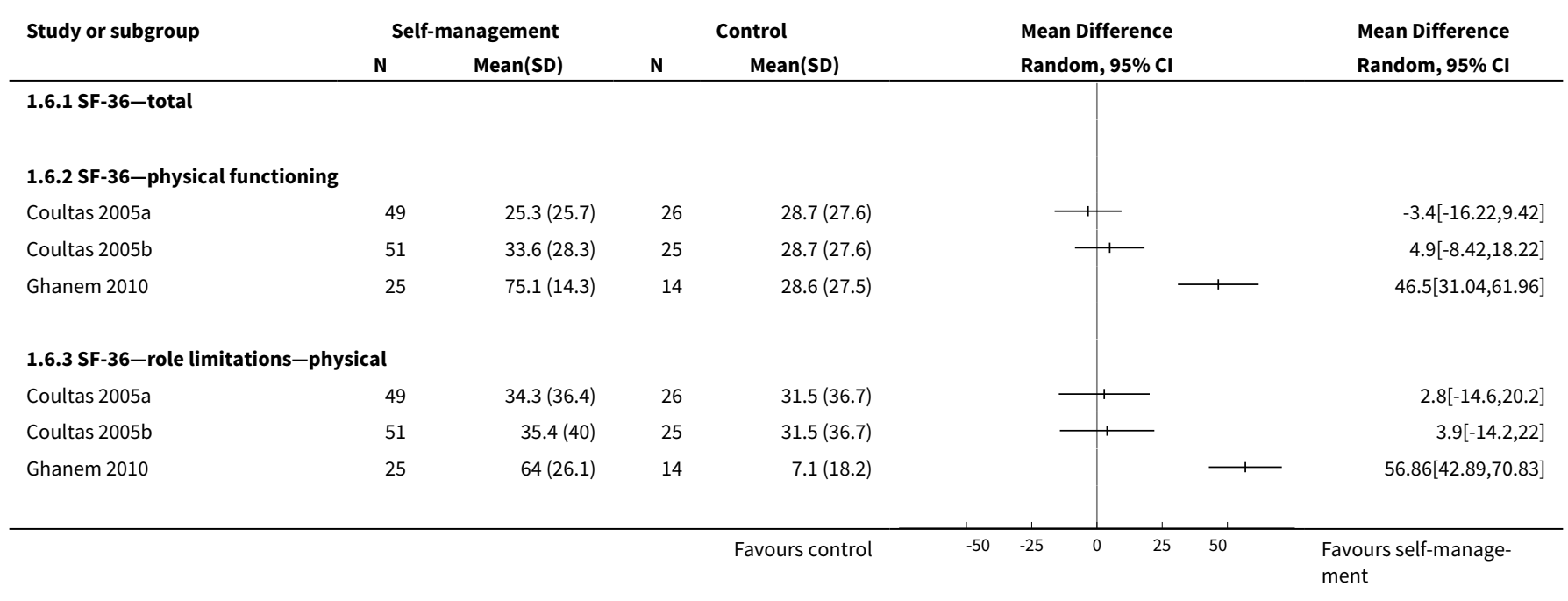




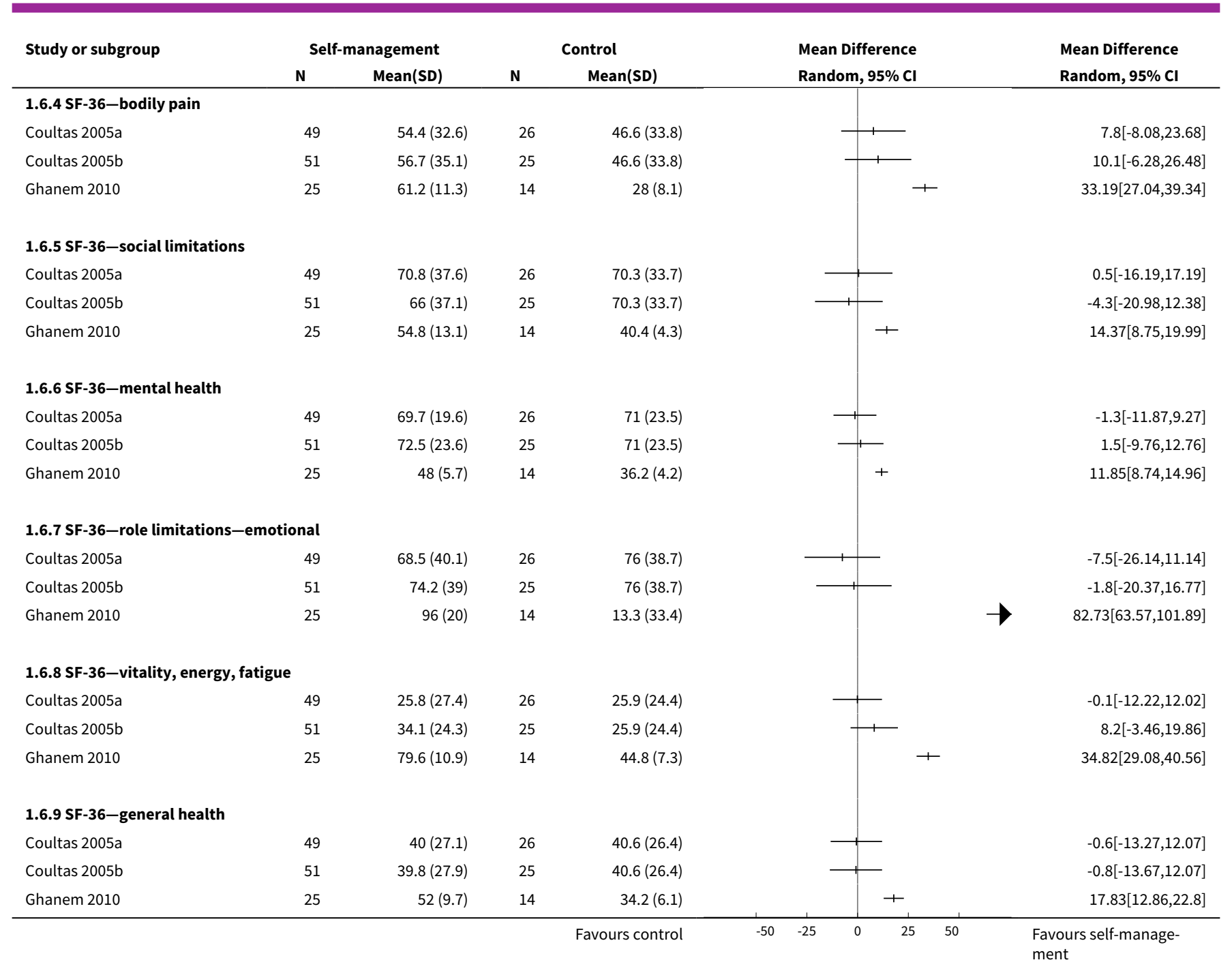

Analysis 1.7. Comparison 1 Self management versus control, Outcome 7 Respiratory-related hospital admissions.

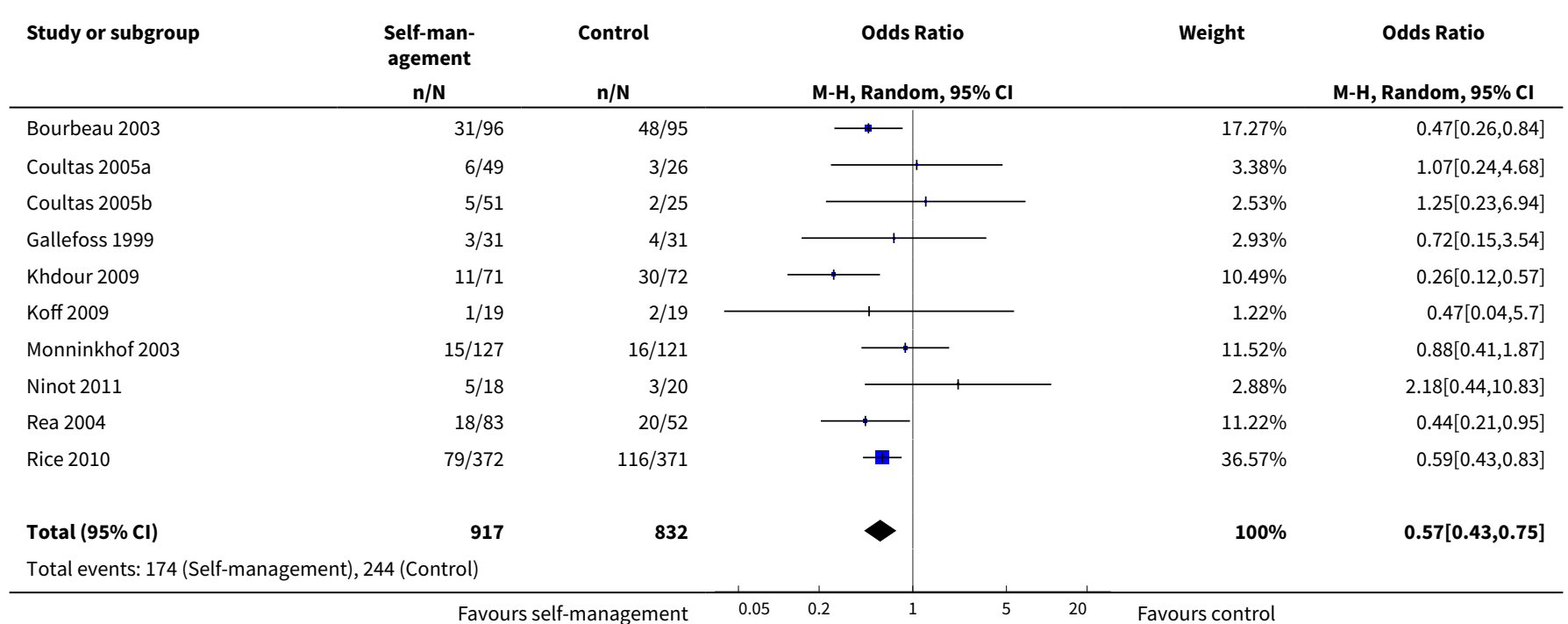




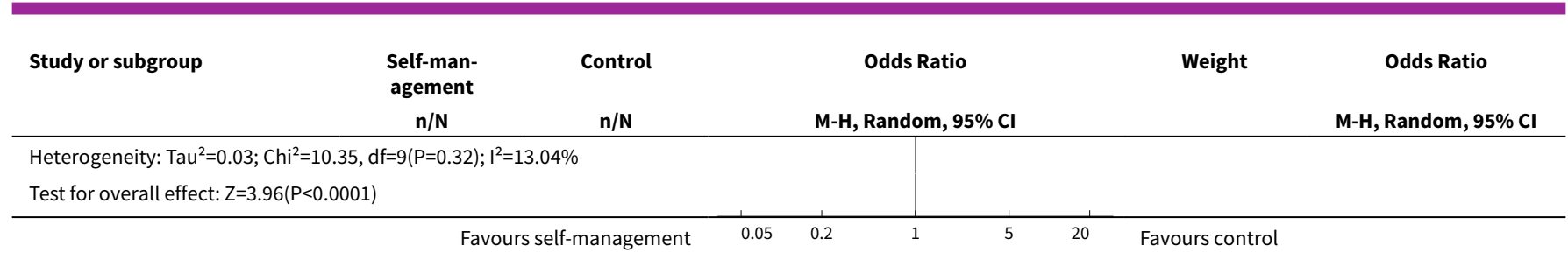

Analysis 1.8. Comparison 1 Self management versus control, Outcome 8 All-cause hospital admissions.

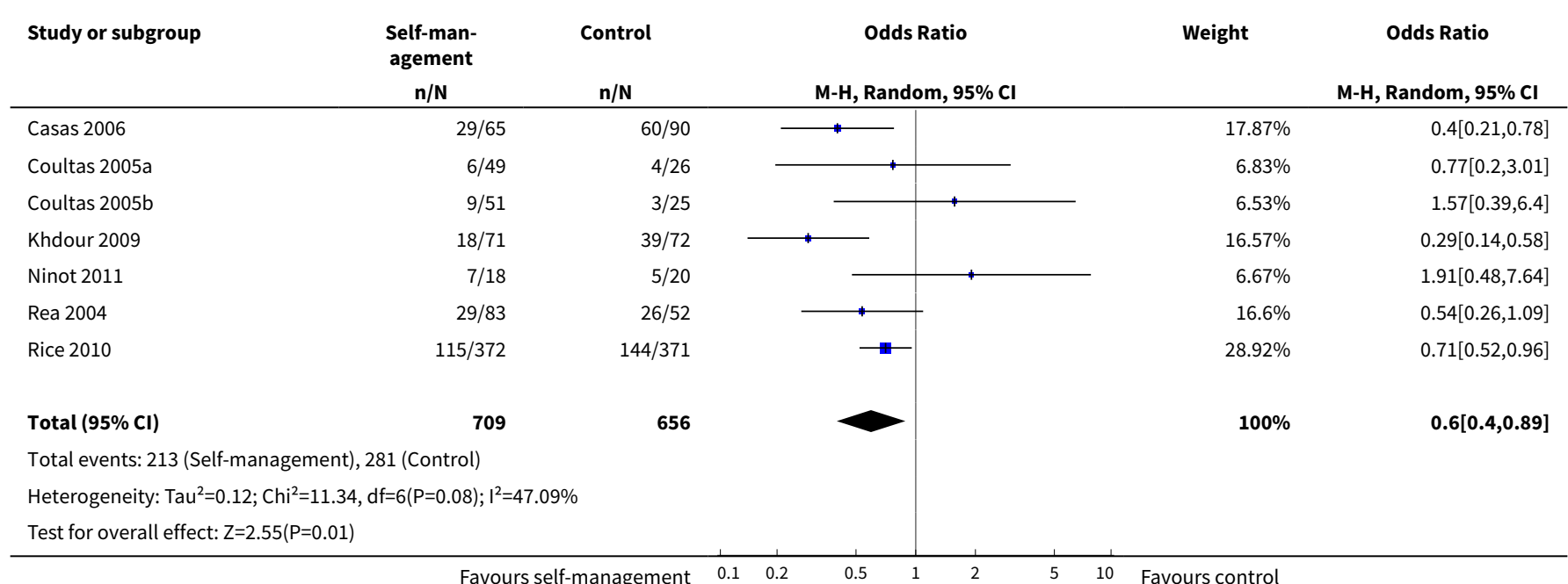

Analysis 1.9. Comparison 1 Self management versus control, Outcome 9 Respiratory-related hospital admissions: days.

\begin{tabular}{|c|c|c|c|c|c|c|c|}
\hline \multirow[t]{2}{*}{ Study or subgroup } & \multicolumn{2}{|c|}{ Self-management } & \multicolumn{2}{|c|}{ Control } & \multirow{2}{*}{$\begin{array}{l}\text { Mean Difference } \\
\text { Random, } 95 \% \mathrm{CI}\end{array}$} & \multirow[t]{2}{*}{ Weight } & \multirow{2}{*}{$\begin{array}{l}\text { Mean Difference } \\
\text { Random, } 95 \% \mathrm{Cl}\end{array}$} \\
\hline & $\mathbf{N}$ & Mean(SD) & $\mathbf{N}$ & Mean(SD) & & & \\
\hline Gallefoss 1999 & 26 & $0.7(2)$ & 27 & $2.5(11)$ & - & $8.57 \%$ & $-1.8[-6.02,2.42]$ \\
\hline Ninot 2011 & 20 & $1.9(3.7)$ & 18 & $0.3(0.7)$ & -1 & $31.53 \%$ & $1.6[-0.05,3.25]$ \\
\hline van Wetering 2009 & 102 & $0.4(1)$ & 79 & $0.4(0.8)$ & & $59.9 \%$ & $-0.04[-0.3,0.22]$ \\
\hline Total $\star \star \star$ & 148 & & 124 & & & $100 \%$ & $0.33[-1.01,1.66]$ \\
\hline Test for overall effect & & & & & & & \\
\hline
\end{tabular}

Analysis 1.10. Comparison 1 Self management versus control, Outcome 10 All-cause hospital admissions: days.

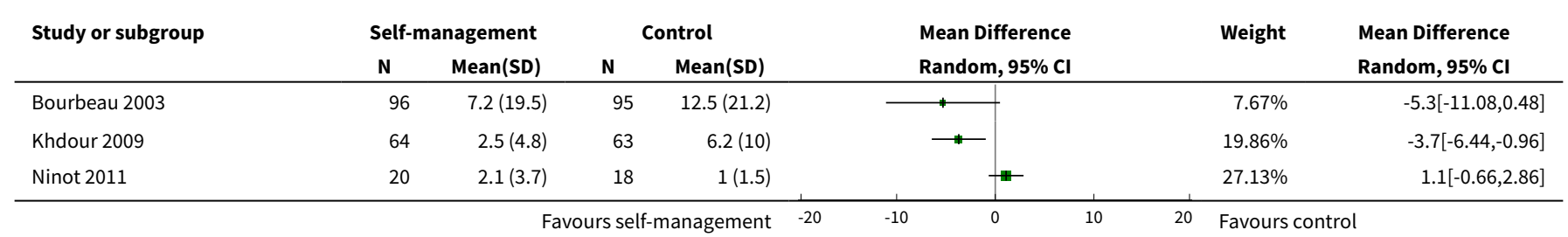




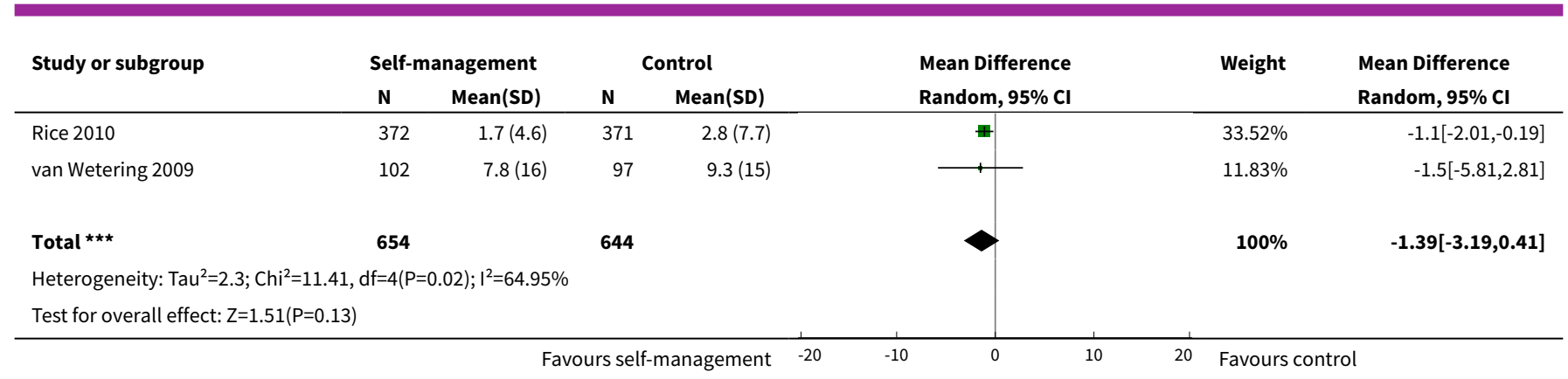

Analysis 1.11. Comparison 1 Self management versus control, Outcome 11 Emergency department visits per person per year.

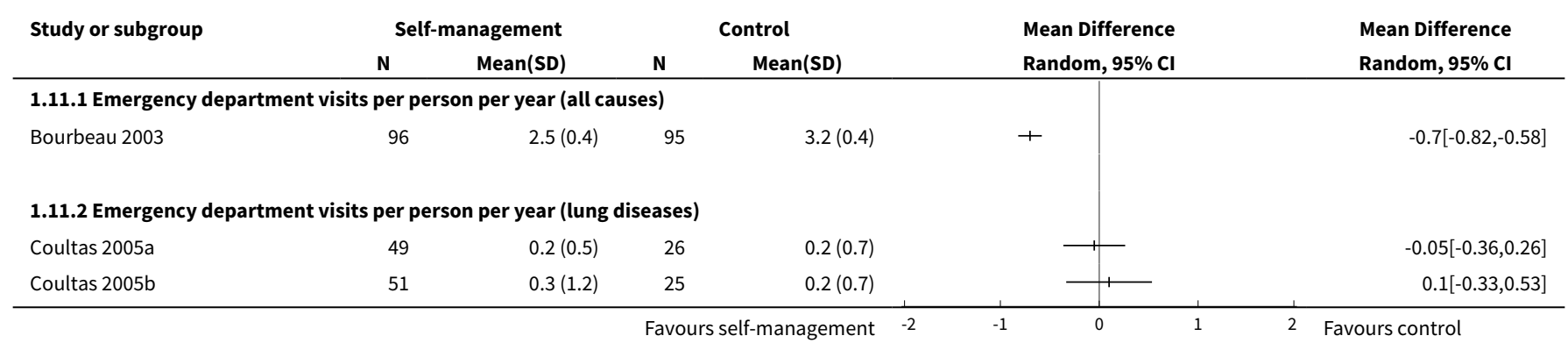

Analysis 1.12. Comparison 1 Self management versus control, Outcome 12 Doctor and nurse visits: mean number per person per year.

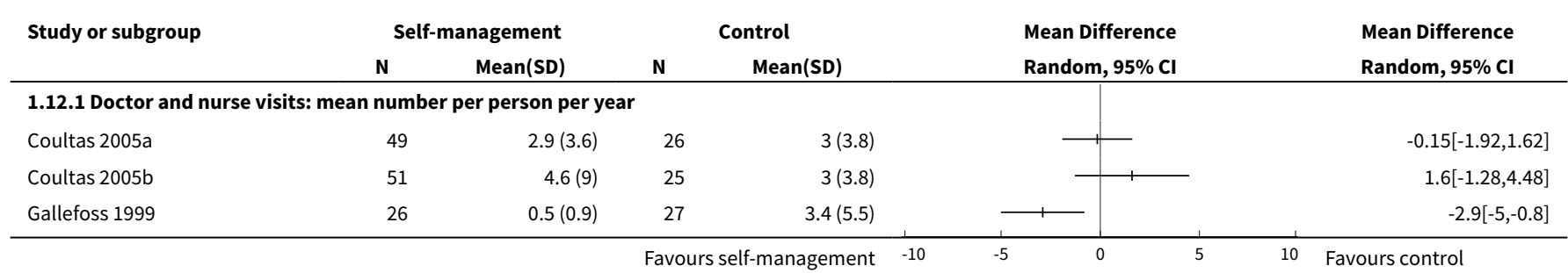

Analysis 1.13. Comparison 1 Self management versus control, Outcome 13 Participants using at least one course of oral steroids.

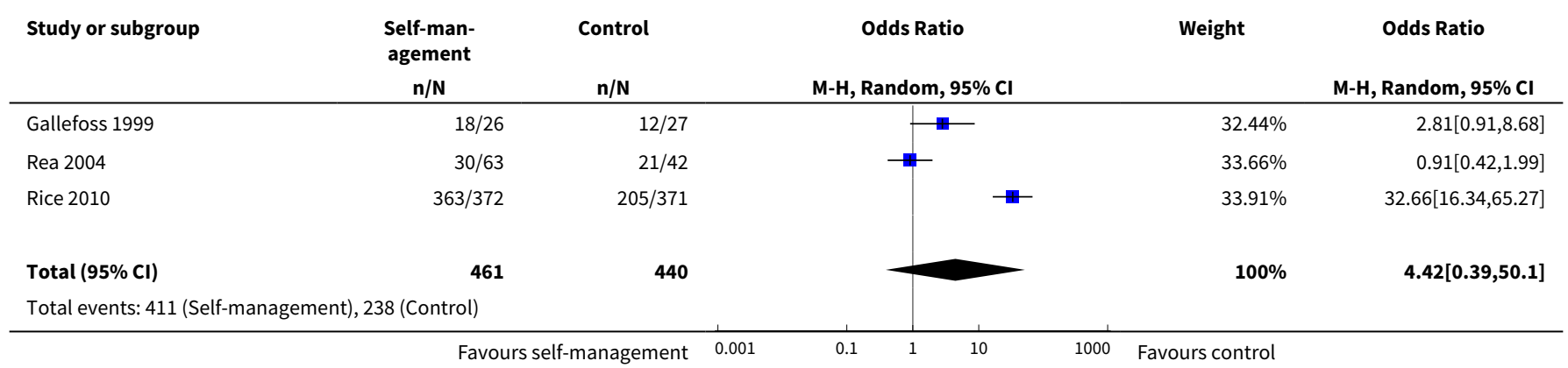




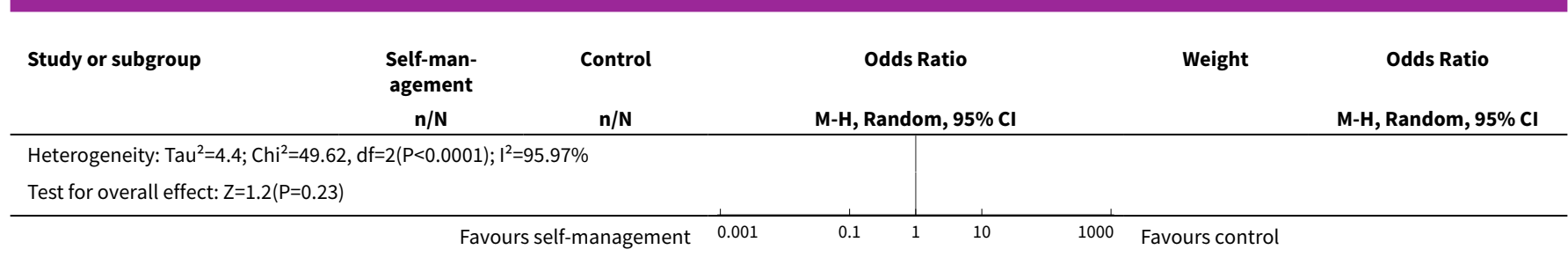

Analysis 1.14. Comparison 1 Self management versus control, Outcome 14 Participants using at least one course of antibiotics.

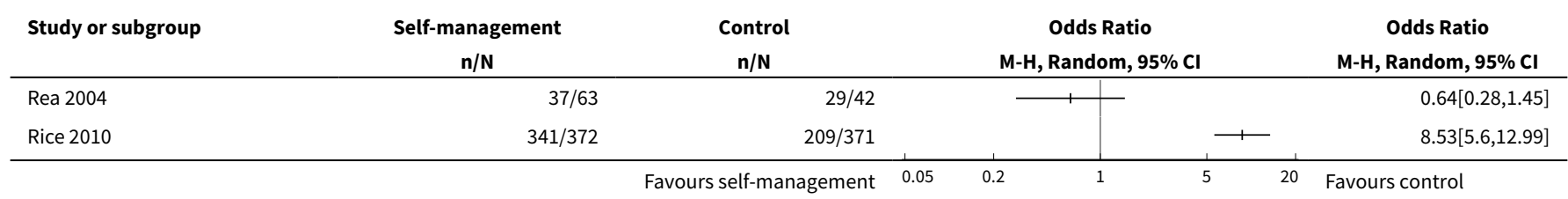

\section{Analysis 1.15. Comparison 1 Self management versus control, Outcome 15 (Modified) Medical Research Council Dyspnoea Scale ((m)MRC).}

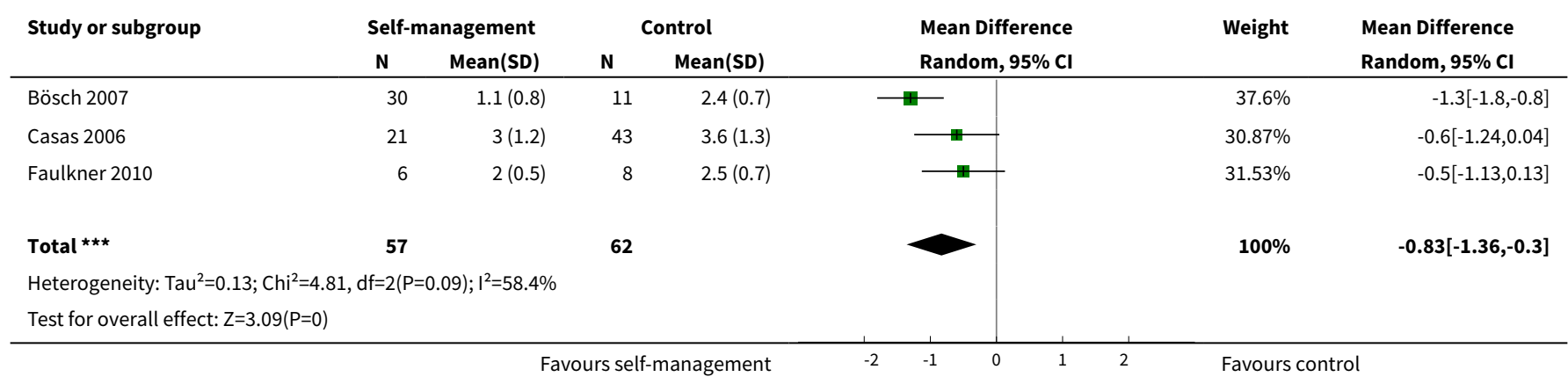

Analysis 1.16. Comparison 1 Self management versus control, Outcome 16 Days lost from work: mean number per person per year.

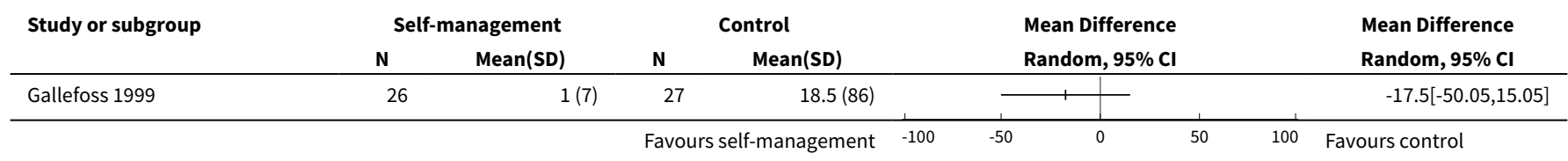

Analysis 1.17. Comparison 1 Self management versus control, Outcome 17 Lung function: FEV $_{1}$ (litres).

\begin{tabular}{|c|c|c|c|c|c|c|c|}
\hline \multirow[t]{2}{*}{ Study or subgroup } & \multicolumn{2}{|c|}{ Self-management } & \multicolumn{2}{|c|}{ Control } & \multirow{2}{*}{$\begin{array}{l}\text { Mean Difference } \\
\text { Random, } 95 \% \mathrm{Cl}\end{array}$} & \multirow[t]{2}{*}{ Weight } & \multirow{2}{*}{$\begin{array}{l}\text { Mean Difference } \\
\text { Random, } 95 \% \mathrm{CI}\end{array}$} \\
\hline & $\mathbf{N}$ & Mean(SD) & $\mathbf{N}$ & Mean(SD) & & & \\
\hline Bösch 2007 & 30 & $1.2(0.5)$ & 11 & $1.3(0.5)$ & $\longrightarrow$ & $10.16 \%$ & $-0.1[-0.45,0.25]$ \\
\hline Emery 1998 & 23 & $1.1(0.5)$ & 25 & $1(0.4)$ & $\rightarrow$ & $20.22 \%$ & $0.03[-0.21,0.27]$ \\
\hline
\end{tabular}




\begin{tabular}{|c|c|c|c|c|c|c|c|}
\hline \multirow{3}{*}{$\begin{array}{l}\text { Study or subgroup } \\
\text { Faulkner } 2010\end{array}$} & \multicolumn{2}{|c|}{ Self-management } & \multicolumn{2}{|c|}{ Control } & \multirow{2}{*}{$\begin{array}{l}\text { Mean Difference } \\
\text { Random, } 95 \% \mathrm{Cl}\end{array}$} & \multirow[t]{2}{*}{ Weight } & \multirow{2}{*}{$\begin{array}{l}\text { Mean Difference } \\
\text { Random, } 95 \% \mathrm{Cl}\end{array}$} \\
\hline & $\mathbf{N}$ & Mean(SD) & $\mathbf{N}$ & Mean(SD) & & & \\
\hline & 6 & $1.9(0.5)$ & 8 & $1.7(0.5)$ & \begin{tabular}{l|l} 
& 1 \\
\end{tabular} & $4.27 \%$ & $0.25[-0.28,0.78]$ \\
\hline Khdour 2009 & 71 & $1.2(0.6)$ & 72 & $1.1(0.5)$ & $\#$ & $40.7 \%$ & $0.14[-0.03,0.31]$ \\
\hline Ninot 2011 & 20 & $1.7(0.6)$ & 18 & $1.5(0.6)$ & $\longrightarrow$ & $8.84 \%$ & $0.25[-0.12,0.62]$ \\
\hline Wakabayashi 2011 & 42 & $1.5(0.6)$ & 43 & $1.6(0.7)$ & $\rightarrow$ & $15.8 \%$ & $-0.04[-0.32,0.24]$ \\
\hline 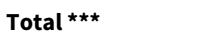 & 192 & & 177 & & 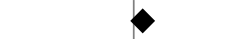 & $100 \%$ & $0.08[-0.03,0.19]$ \\
\hline \multicolumn{8}{|c|}{ Heterogeneity: Tau $^{2}=0 ; \mathrm{Chi}^{2}=3.59, \mathrm{df}=5(\mathrm{P}=0.61) ; \mathrm{I}^{2}=0 \%$} \\
\hline \multicolumn{8}{|c|}{ Test for overall effect: $Z=1.41(P=0.16)$} \\
\hline & & & & urs control -2 & -1 & Favours & anagement \\
\hline
\end{tabular}

\section{Analysis 1.18. Comparison 1 Self management versus control, Outcome 18 Lung function: FEV $_{1}$ (\% of predicted).}

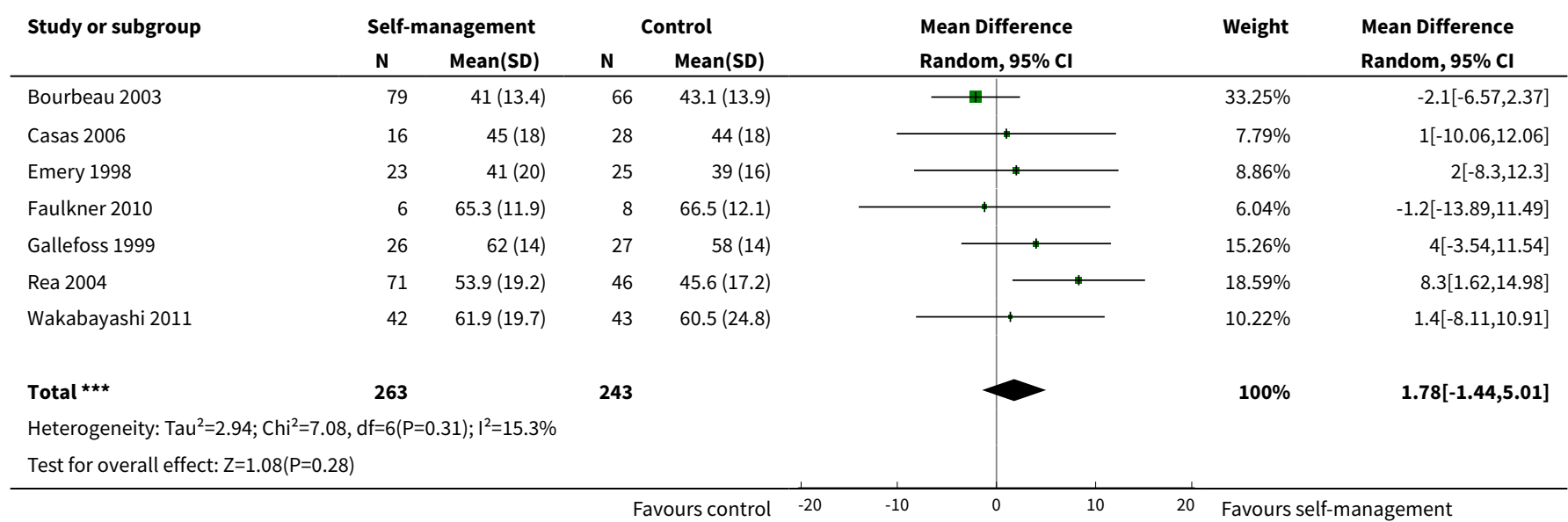

\section{Analysis 1.19. Comparison 1 Self management versus control, Outcome 19 Exercise capacity: 6MWT.}

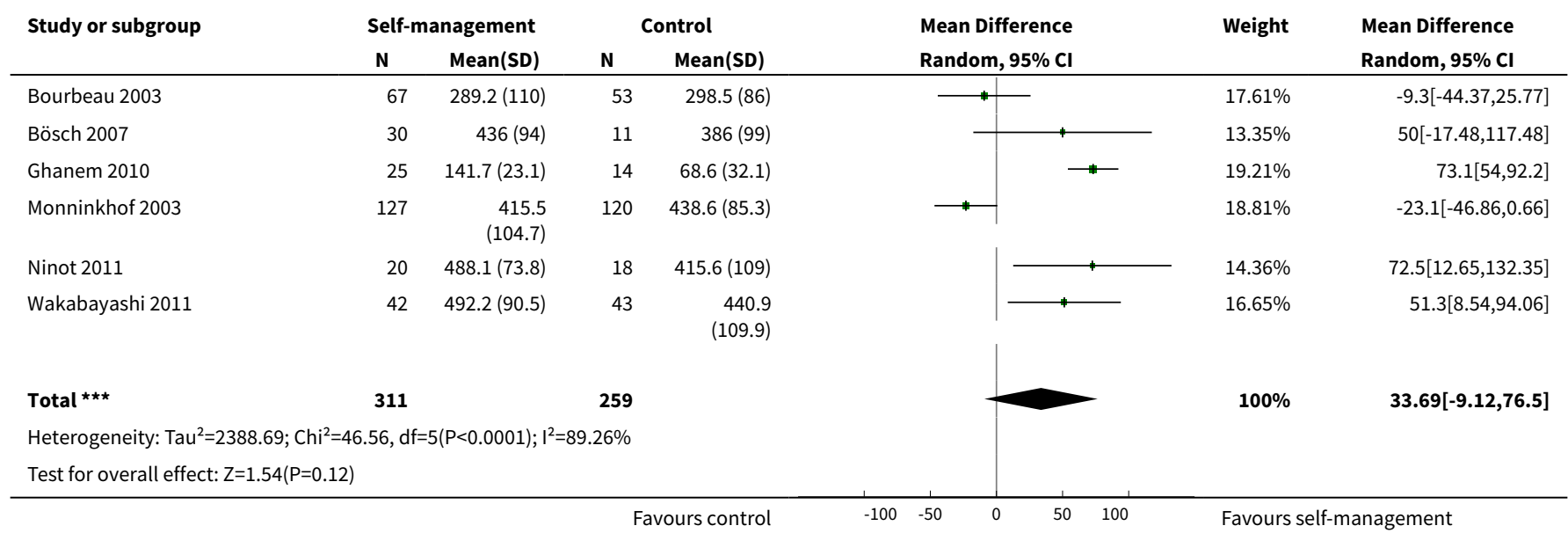


Analysis 1.20. Comparison 1 Self management versus control, Outcome 20 Lung function: FEV 1 FVC.

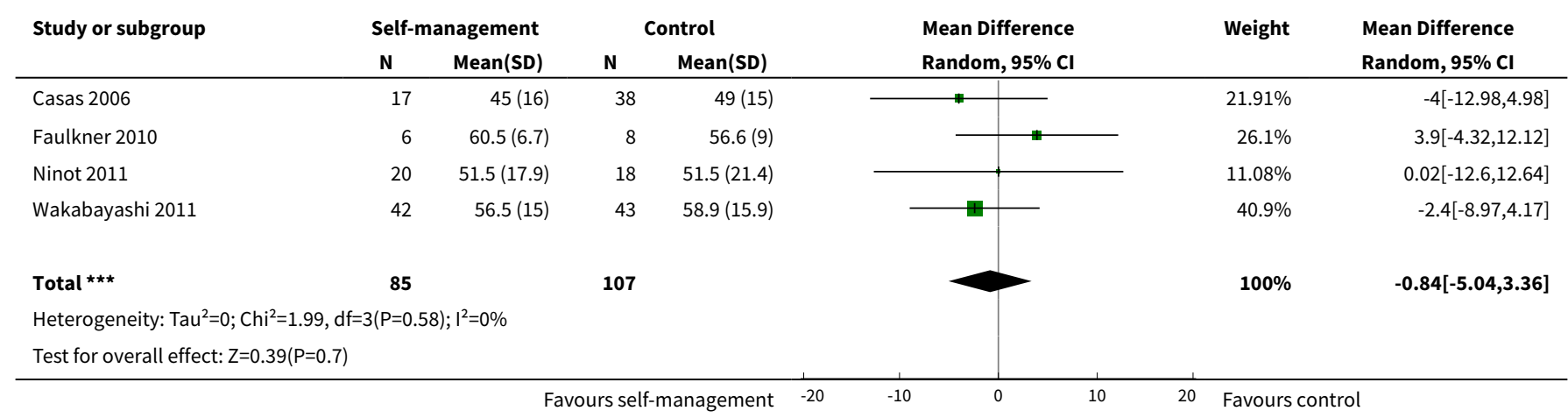

Analysis 1.21. Comparison 1 Self management versus control, Outcome 21 Mortality.

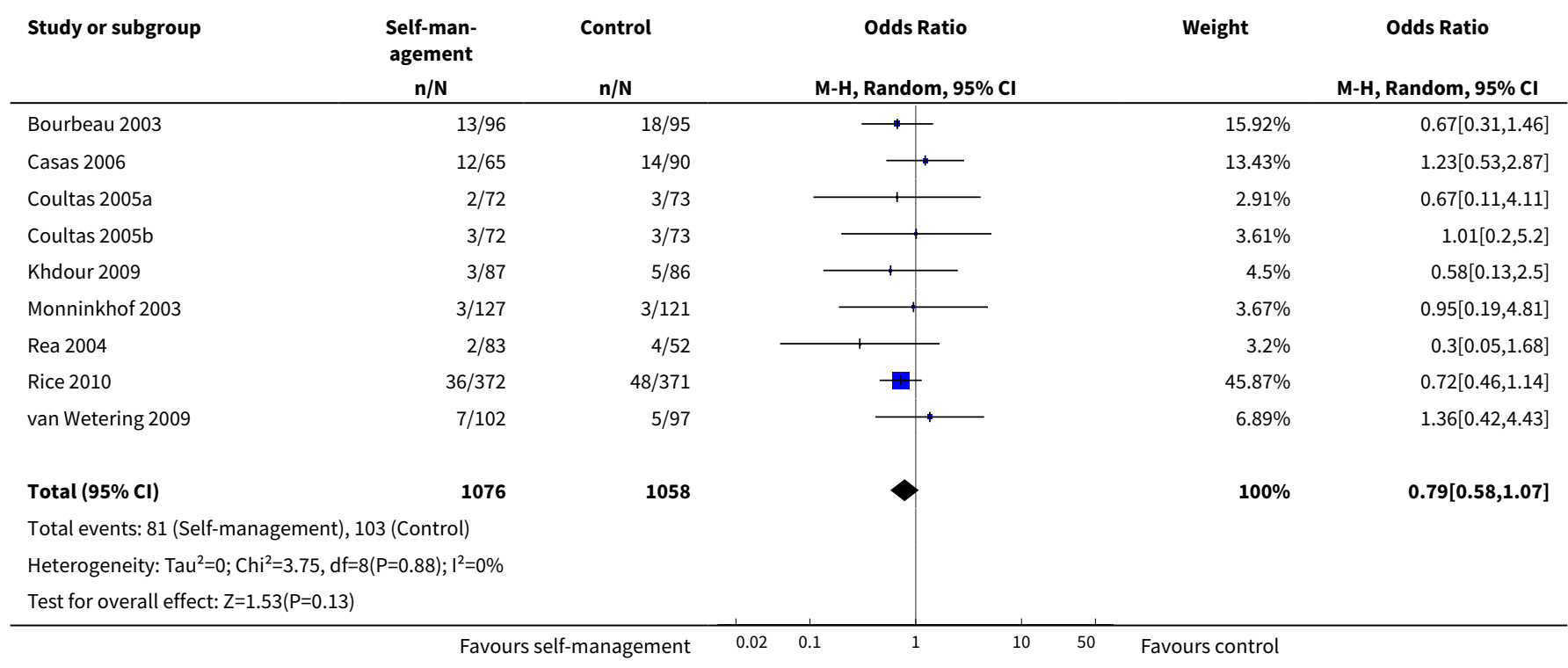

\section{Comparison 2. Sensitivity analyses with inclusion of CCTs}

\begin{tabular}{lllll}
\hline Outcome or subgroup title & $\begin{array}{l}\text { No. of } \\
\text { studies }\end{array}$ & $\begin{array}{l}\text { No. of } \\
\text { partici- } \\
\text { pants }\end{array}$ & Statistical method & Effect size \\
\hline 1 HRQoL: SGRQ (with CCTs) & 14 & & Mean Difference (IV, Random, 95\% CI) & Subtotals only \\
\hline 1.1 SGRQ: total score & 14 & 1605 & Mean Difference (IV, Random, 95\% CI) & $-6.92[-10.42,-3.42]$ \\
\hline 1.2 SGRQ: symptoms & 13 & 1563 & Mean Difference (IV, Random, 95\% CI) & $-5.40[-9.21,-1.58]$ \\
\hline 1.3 SGRQ: activity & 13 & 1548 & Mean Difference (IV, Random, 95\% CI) & $-5.84[-9.50,-2.18]$ \\
\hline 1.4 SGRQ: impact & 13 & 1548 & Mean Difference (IV, Random, 95\% CI) & $-8.88[-13.39,-4.38]$ \\
\hline
\end{tabular}




\begin{tabular}{|c|c|c|c|c|}
\hline Outcome or subgroup title & $\begin{array}{l}\text { No. of } \\
\text { studies }\end{array}$ & $\begin{array}{l}\text { No. of } \\
\text { partici- } \\
\text { pants }\end{array}$ & Statistical method & Effect size \\
\hline $\begin{array}{l}2 \text { HRQOL: SGRQ total score: } \\
\text { change from baseline (with } \\
\text { CCTs) }\end{array}$ & 13 & & Mean Difference (Random, 95\% Cl) & $-5.05[-7.73,-2.37]$ \\
\hline $\begin{array}{l}3 \text { Respiratory-related hospital } \\
\text { admissions (with CCTs) }\end{array}$ & 11 & 1776 & Odds Ratio (M-H, Random, 95\% Cl) & $0.57[0.44,0.73]$ \\
\hline $\begin{array}{l}4 \text { All-cause hospital admis- } \\
\text { sions (with CCTs) }\end{array}$ & 8 & 1392 & Odds Ratio (M-H, Random, 95\% Cl) & $0.61[0.42,0.89]$ \\
\hline $\begin{array}{l}5 \text { All-cause hospital admis- } \\
\text { sions: days (with CCTs) }\end{array}$ & 6 & 1325 & Mean Difference (IV, Random, 95\% CI) & $-1.62[-3.42,0.18]$ \\
\hline $\begin{array}{l}6 \text { (Modified) Medical Re- } \\
\text { search Council Dyspnoea Scale } \\
((\mathrm{m}) \mathrm{MRC}) \text { (with CCTs) }\end{array}$ & 4 & 269 & Mean Difference (IV, Random, 95\% CI) & $-0.67[-1.19,-0.16]$ \\
\hline $\begin{array}{l}7 \text { Lung function: } \text { FEV }_{1} \text { (liters) } \\
\text { (with CCTs) }\end{array}$ & 8 & 428 & Mean Difference (IV, Random, 95\% CI) & $0.08[-0.02,0.18]$ \\
\hline $\begin{array}{l}8 \text { Lung function: } \mathrm{FEV}_{1} \text { (\% of } \\
\text { predicted) (with CCTs) }\end{array}$ & 8 & 538 & Mean Difference (IV, Random, 95\% CI) & $1.51[-1.21,4.23]$ \\
\hline $\begin{array}{l}9 \text { Lung function: } \mathrm{FEV}_{1} / \mathrm{FVC} \\
\text { (with CCTs) }\end{array}$ & 5 & 224 & Mean Difference (IV, Random, 95\% CI) & $0.01[-3.83,3.85]$ \\
\hline $\begin{array}{l}10 \text { Exercise capacity: } 6 \mathrm{MW} \\
\text { (with CCTs) }\end{array}$ & 8 & 629 & Mean Difference (IV, Random, 95\% CI) & $35.90[1.35,70.44]$ \\
\hline 11 Mortality (with CCTs) & 10 & 2174 & Odds Ratio (M-H, Random, 95\% Cl) & $0.78[0.57,1.07]$ \\
\hline
\end{tabular}

Analysis 2.1. Comparison 2 Sensitivity analyses with inclusion of CCTs, Outcome 1 HRQoL: SGRQ (with CCTs).

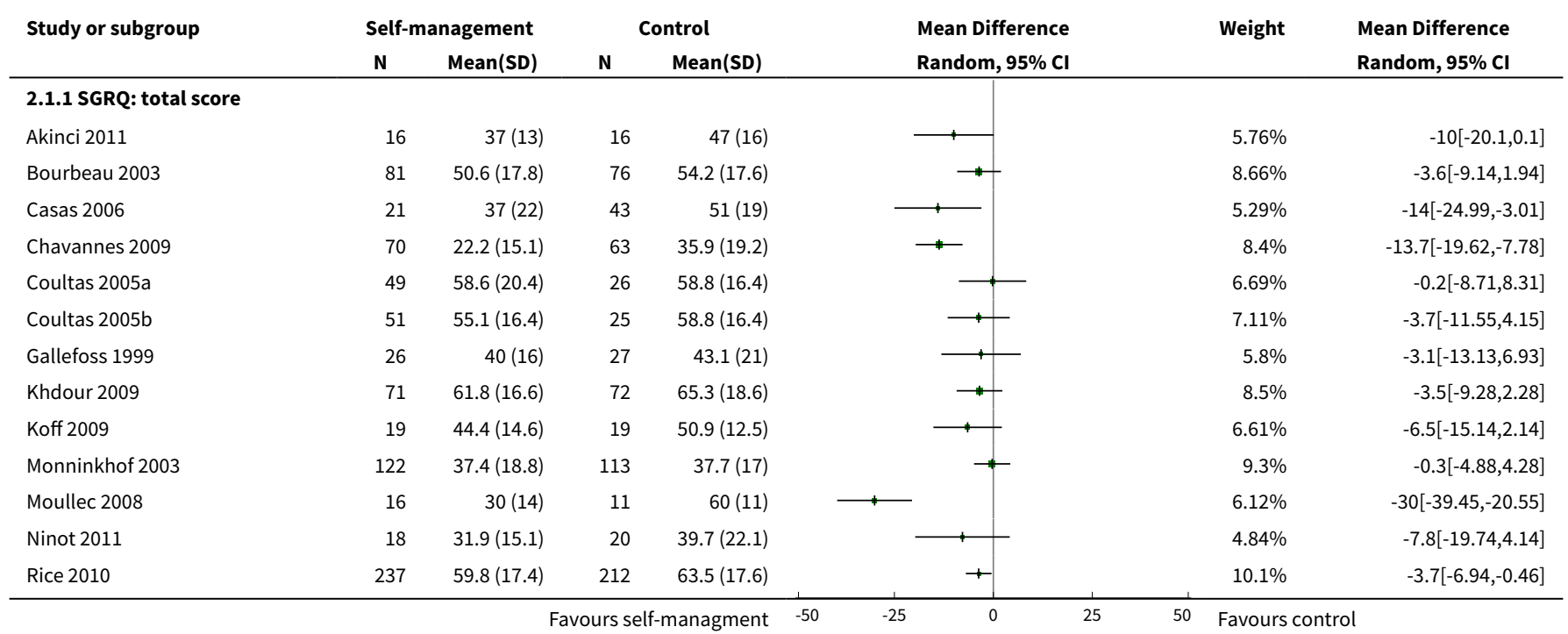




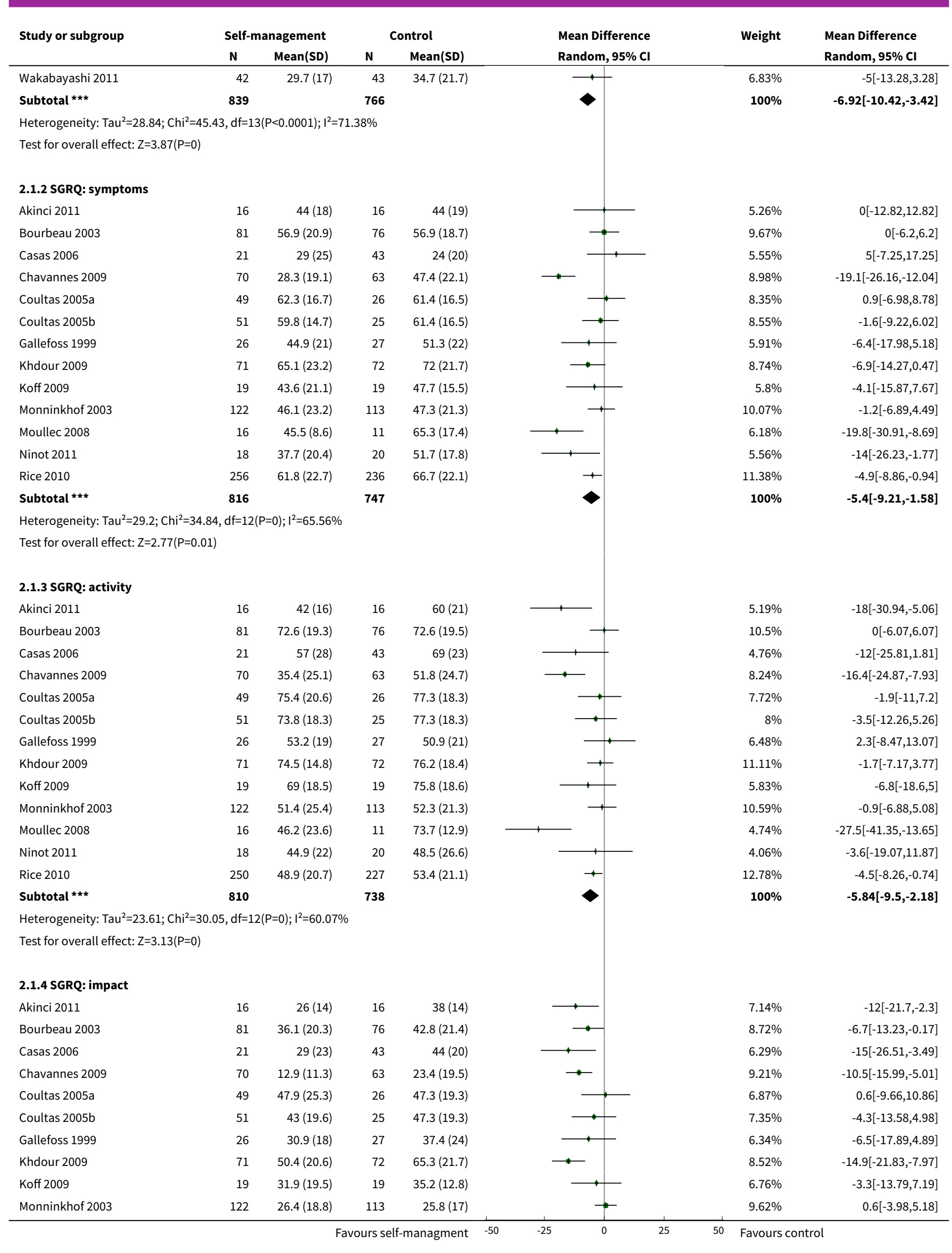




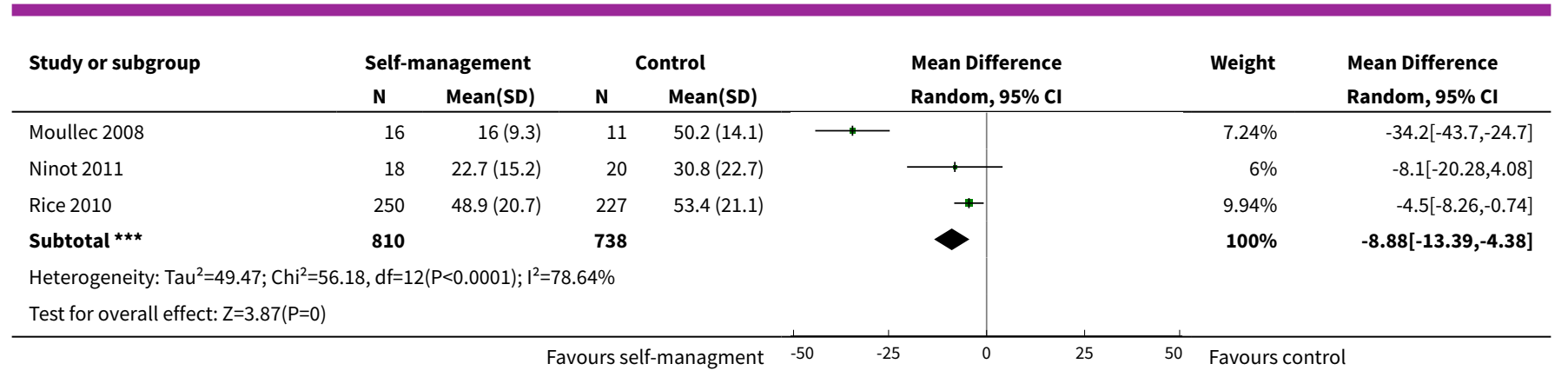

Analysis 2.2. Comparison 2 Sensitivity analyses with inclusion of CCTs, Outcome 2 HRQOL: SGRQ total score: change from baseline (with CCTs).

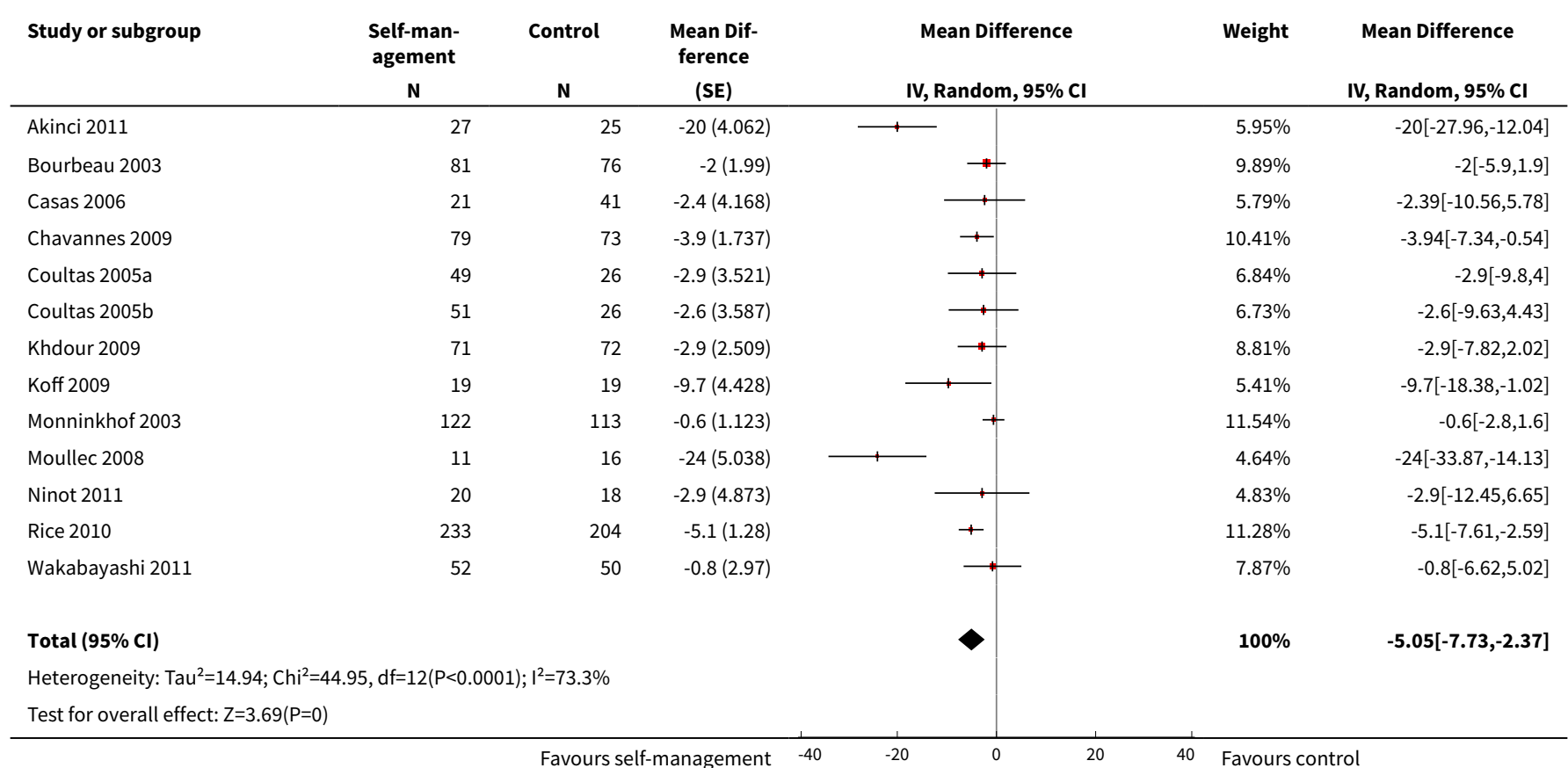

Analysis 2.3. Comparison 2 Sensitivity analyses with inclusion of CCTs, Outcome 3 Respiratory-related hospital admissions (with CCTs).

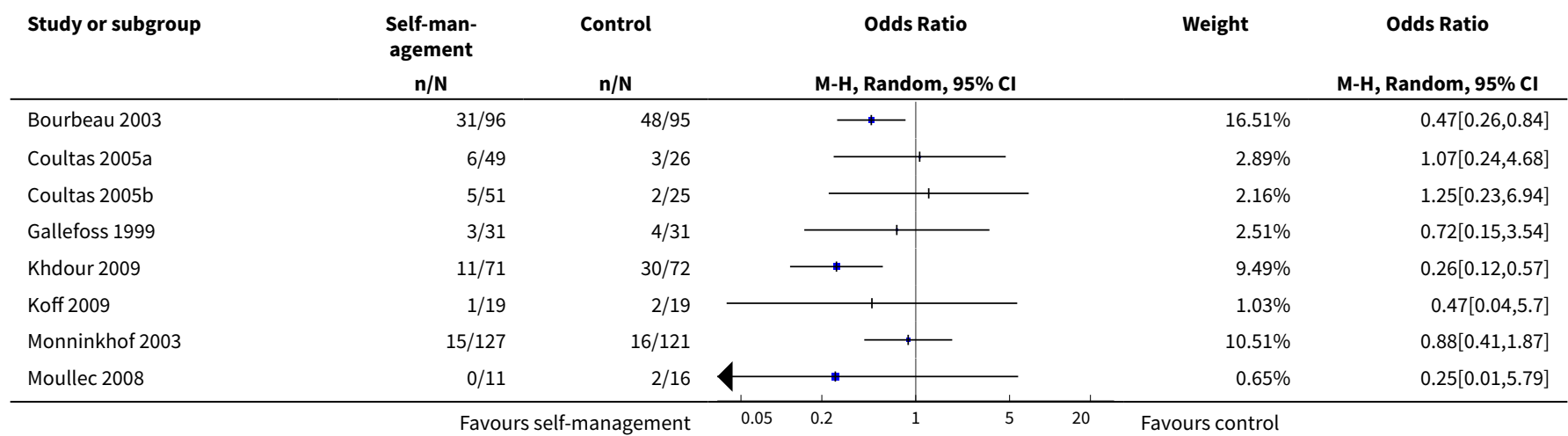




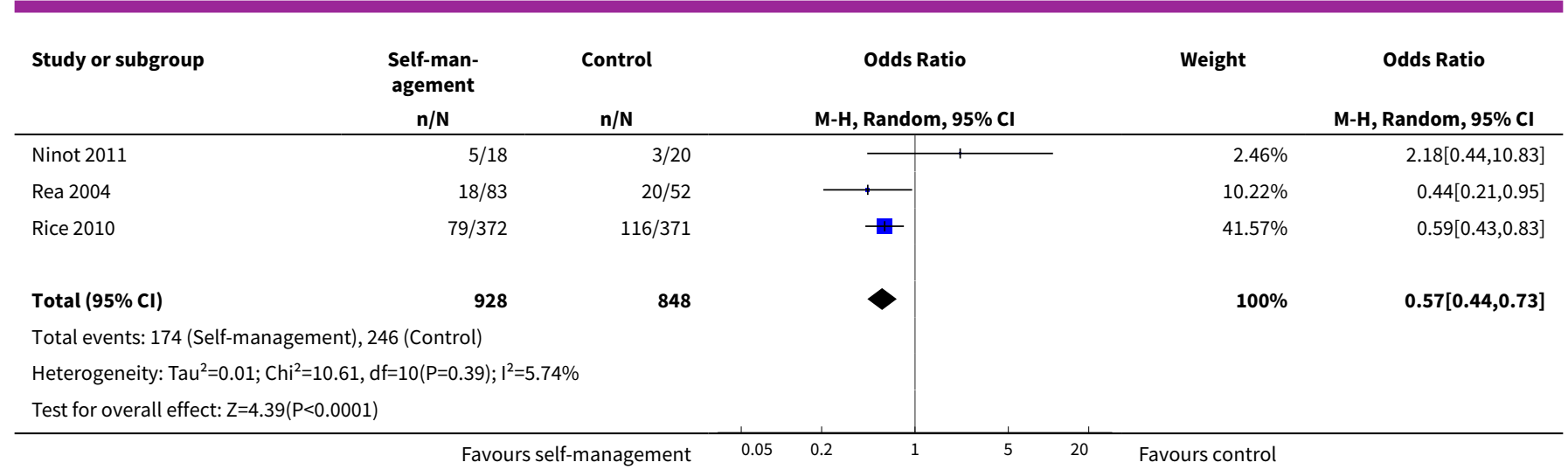

Analysis 2.4. Comparison 2 Sensitivity analyses with inclusion
of CCTs, Outcome 4 All-cause hospital admissions (with CCTs).

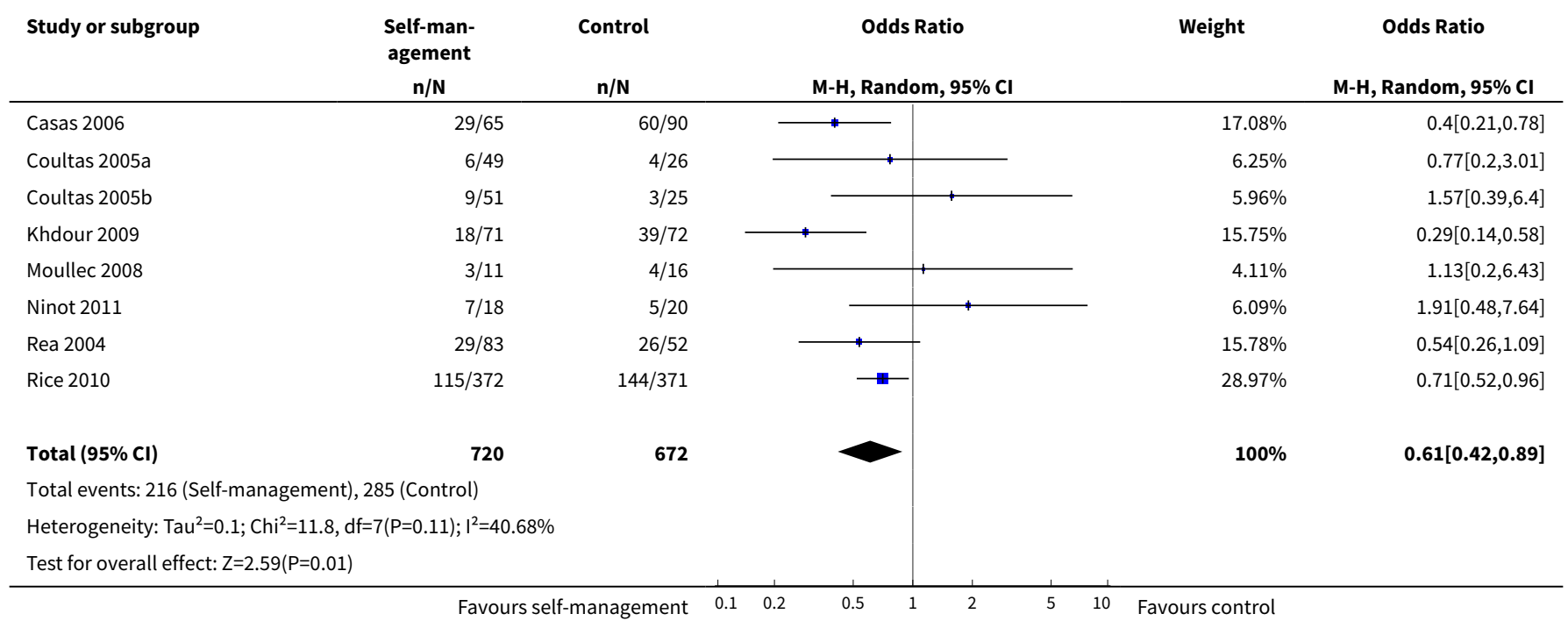

\section{Analysis 2.5. Comparison 2 Sensitivity analyses with inclusion of} CCTs, Outcome 5 All-cause hospital admissions: days (with CCTs).

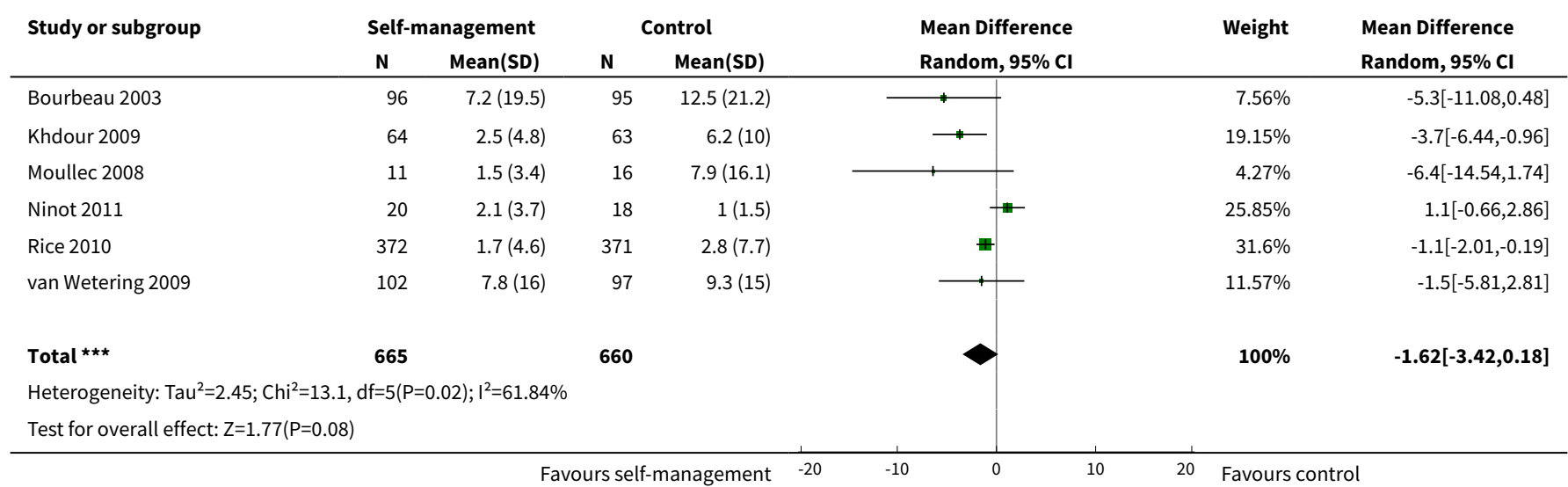


Analysis 2.6. Comparison 2 Sensitivity analyses with inclusion of CCTs, Outcome 6 (Modified) Medical Research Council Dyspnoea Scale ((m)MRC) (with CCTs).

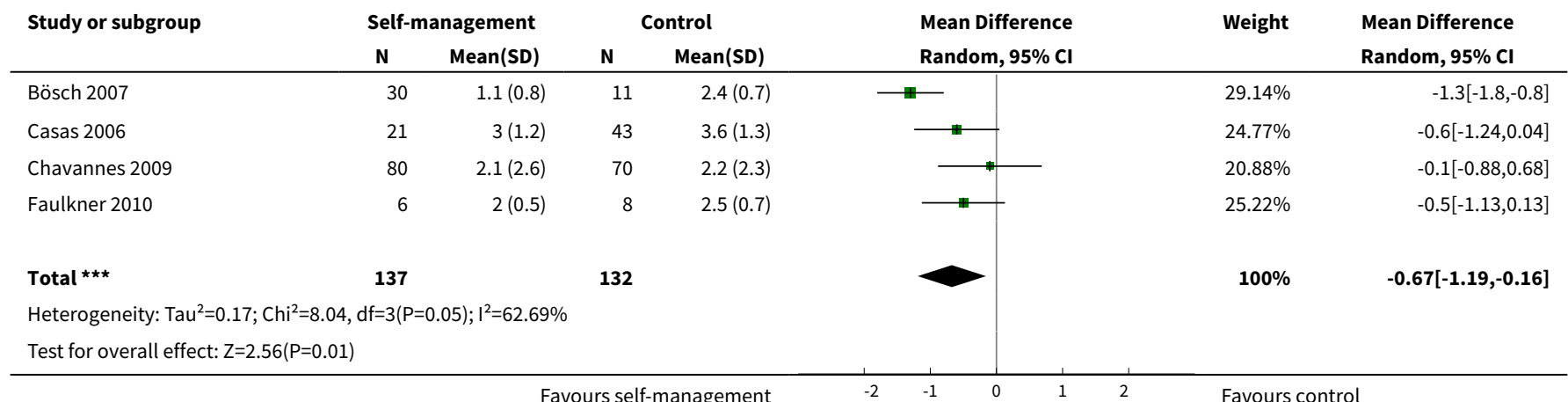

\section{Analysis 2.7. Comparison 2 Sensitivity analyses with inclusion of CCTs, Outcome 7 Lung function: FEV $_{1}$ (liters) (with CCTs).}

\begin{tabular}{|c|c|c|c|c|c|c|c|}
\hline \multirow[t]{2}{*}{ Study or subgroup } & \multicolumn{2}{|c|}{ Self-management } & \multicolumn{2}{|c|}{ Control } & \multirow{2}{*}{$\begin{array}{l}\text { Mean Difference } \\
\text { Random, } 95 \% \mathrm{CI}\end{array}$} & \multirow[t]{2}{*}{ Weight } & \multirow{2}{*}{$\begin{array}{l}\text { Mean Difference } \\
\text { Random, } 95 \% \mathrm{Cl}\end{array}$} \\
\hline & $\mathbf{N}$ & $\operatorname{Mean}(S D)$ & $\mathbf{N}$ & $\operatorname{Mean}(S D)$ & & & \\
\hline Akinci 2011 & 16 & $1.1(0.6)$ & 16 & $1.1(0.6)$ & + & $5.9 \%$ & $0.08[-0.33,0.49]$ \\
\hline Bösch 2007 & 30 & $1.2(0.5)$ & 11 & $1.3(0.5)$ & $\longrightarrow$ & $8.41 \%$ & $-0.1[-0.45,0.25]$ \\
\hline Emery 1998 & 23 & $1.1(0.5)$ & 25 & $1(0.4)$ & $\longrightarrow$ & $16.75 \%$ & $0.03[-0.21,0.27]$ \\
\hline Faulkner 2010 & 6 & $1.9(0.5)$ & 8 & $1.7(0.5)$ & 1 & $3.54 \%$ & $0.25[-0.28,0.78]$ \\
\hline Khdour 2009 & 71 & $1.2(0.6)$ & 72 & $1.1(0.5)$ & \pm & $33.7 \%$ & $0.14[-0.03,0.31]$ \\
\hline Ninot 2011 & 20 & $1.7(0.6)$ & 18 & $1.5(0.6)$ & 4 & $7.32 \%$ & $0.25[-0.12,0.62]$ \\
\hline Wakabayashi 2011 & 42 & $1.5(0.6)$ & 43 & $1.6(0.7)$ & $\longrightarrow$ & $13.08 \%$ & $-0.04[-0.32,0.24]$ \\
\hline 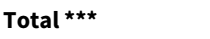 & 224 & & 204 & & 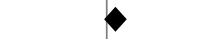 & $100 \%$ & $0.08[-0.02,0.18]$ \\
\hline \multicolumn{8}{|c|}{ Heterogeneity: $\mathrm{Tau}^{2}=0 ; \mathrm{Chi}^{2}=3.6, \mathrm{df}=7(\mathrm{P}=0.82) ; \mathrm{I}^{2}=0 \%$} \\
\hline \multicolumn{3}{|c|}{ Test for overall effect: $Z=1.51(P=0.13)$} & & & & & \\
\hline
\end{tabular}

Analysis 2.8. Comparison 2 Sensitivity analyses with inclusion of CCTs, Outcome 8 Lung function: FEV $_{1}$ (\% of predicted) (with CCTs).

\begin{tabular}{|c|c|c|c|c|c|c|c|c|}
\hline \multirow{3}{*}{$\begin{array}{l}\text { Study or subgroup } \\
\text { Akinci } 2011\end{array}$} & \multicolumn{2}{|c|}{ Self-management } & \multicolumn{2}{|c|}{ Control } & \multirow{2}{*}{\multicolumn{2}{|c|}{$\begin{array}{l}\text { Mean Difference } \\
\text { Random, 95\% CI }\end{array}$}} & \multirow[t]{2}{*}{ Weight } & \multirow{2}{*}{$\begin{array}{l}\text { Mean Difference } \\
\text { Random, } 95 \% \mathrm{CI}\end{array}$} \\
\hline & $\mathbf{N}$ & Mean(SD) & $\mathbf{N}$ & Mean(SD) & & & & \\
\hline & 16 & $40.7(13.2)$ & 16 & $39.3(12.1)$ & & & $9.52 \%$ & $1.4[-7.37,10.17]$ \\
\hline Bourbeau 2003 & 79 & $41(13.4)$ & 66 & $43.1(13.9)$ & $\mp$ & - & $35.69 \%$ & $-2.1[-6.57,2.37]$ \\
\hline Casas 2006 & 16 & $45(18)$ & 28 & $44(18)$ & & & $6.02 \%$ & $1[-10.06,12.06]$ \\
\hline Emery 1998 & 23 & $41(20)$ & 25 & $39(16)$ & & $\rightarrow$ & $6.92 \%$ & $2[-8.3,12.3]$ \\
\hline Faulkner 2010 & 6 & $65.3(11.9)$ & 8 & $66.5(12.1)$ & 1 & & $4.58 \%$ & $-1.2[-13.89,11.49]$ \\
\hline Rea 2004 & 71 & $53.9(19.2)$ & 46 & $45.6(17.2)$ & & & $16.3 \%$ & $8.3[1.62,14.98]$ \\
\hline Wakabayashi 2011 & 42 & $61.9(19.7)$ & 43 & $60.5(24.8)$ & & 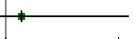 & $8.12 \%$ & $1.4[-8.11,10.91]$ \\
\hline
\end{tabular}




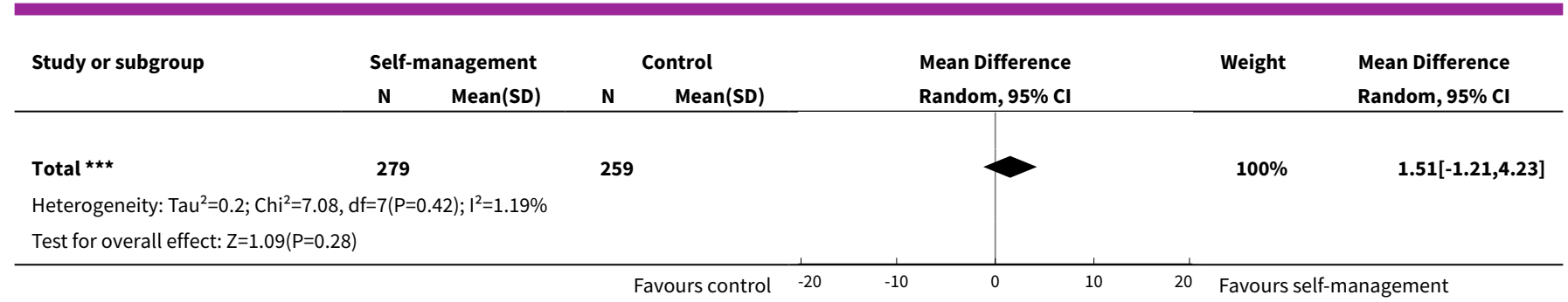

\section{Analysis 2.9. Comparison 2 Sensitivity analyses with inclusion of CCTs, Outcome 9 Lung function: FEV $_{1} /$ FVC (with CCTs).}

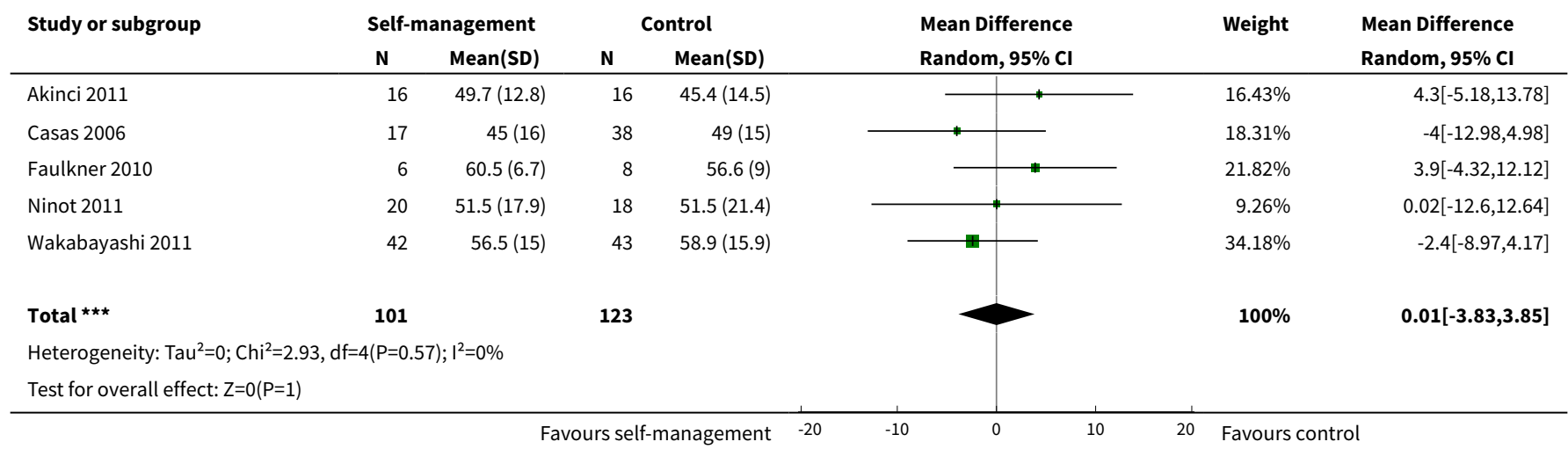

\section{Analysis 2.10. Comparison 2 Sensitivity analyses with inclusion of CCTs, Outcome 10 Exercise capacity: 6MW (with CCTs).}

\begin{tabular}{|c|c|c|c|c|c|c|c|c|}
\hline \multirow{3}{*}{$\begin{array}{l}\text { Study or subgroup } \\
\text { Akinci } 2011\end{array}$} & \multicolumn{2}{|c|}{ Self-management } & \multicolumn{2}{|c|}{ Control } & \multirow{2}{*}{\multicolumn{2}{|c|}{$\begin{array}{l}\text { Mean Difference } \\
\text { Random, } 95 \% \mathrm{Cl}\end{array}$}} & \multirow{3}{*}{$\begin{array}{l}\text { Weight } \\
12.83 \%\end{array}$} & \multirow{3}{*}{$\begin{array}{l}\begin{array}{l}\text { Mean Difference } \\
\text { Random, 95\% Cl }\end{array} \\
19.7[-22.15,61.55]\end{array}$} \\
\hline & \multirow{2}{*}{$\frac{\mathbf{N}}{16}$} & \multirow{2}{*}{$\frac{\text { Mean(SD) }}{190.3(65)}$} & \multirow{2}{*}{$\frac{\mathbf{N}}{16}$} & \multirow{2}{*}{$\frac{\operatorname{Mean}(\text { SD) }}{170.6(55.4)}$} & & & & \\
\hline & & & & & & \begin{tabular}{l|l} 
&, \\
\end{tabular} & & \\
\hline Bourbeau 2003 & 67 & $289.2(110)$ & 53 & $298.5(86)$ & & $\longrightarrow$ & $13.6 \%$ & $-9.3[-44.37,25.77]$ \\
\hline Bösch 2007 & 30 & $436(94)$ & 11 & 386 (99) & & 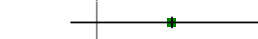 & $9.86 \%$ & $50[-17.48,117.48]$ \\
\hline Ghanem 2010 & 25 & $141.7(23.1)$ & 14 & $68.6(32.1)$ & & $\longrightarrow$ & $15.08 \%$ & $73.1[54,92.2]$ \\
\hline Monninkhof 2003 & 127 & $\begin{array}{r}415.5 \\
(104.7)\end{array}$ & 120 & $438.6(85.3)$ & & $\longrightarrow$ & $14.71 \%$ & $-23.1[-46.86,0.66]$ \\
\hline Moullec 2008 & 11 & $510.6(80.2)$ & 16 & $436.3(82.1)$ & & $\longrightarrow$ & $10.46 \%$ & $74.3[12.13,136.47]$ \\
\hline Ninot 2011 & 20 & $488.1(73.8)$ & 18 & $415.6(109)$ & & & $10.72 \%$ & $72.5[12.65,132.35]$ \\
\hline Wakabayashi 2011 & 42 & $492.2(90.5)$ & 43 & $\begin{array}{r}440.9 \\
(109.9)\end{array}$ & & & $12.73 \%$ & $51.3[8.54,94.06]$ \\
\hline 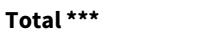 & 338 & & 291 & & & & $100 \%$ & $35.9[1.35,70.44]$ \\
\hline \multicolumn{9}{|c|}{ Heterogeneity: $\mathrm{Tau}^{2}=1964.68 ; \mathrm{Chi}^{2}=48.64, \mathrm{df}=7(\mathrm{P}<0.0001) ; \mathrm{I}^{2}=85.61 \%$} \\
\hline
\end{tabular}


Analysis 2.11. Comparison 2 Sensitivity analyses with inclusion of CCTs, Outcome 11 Mortality (with CCTs).

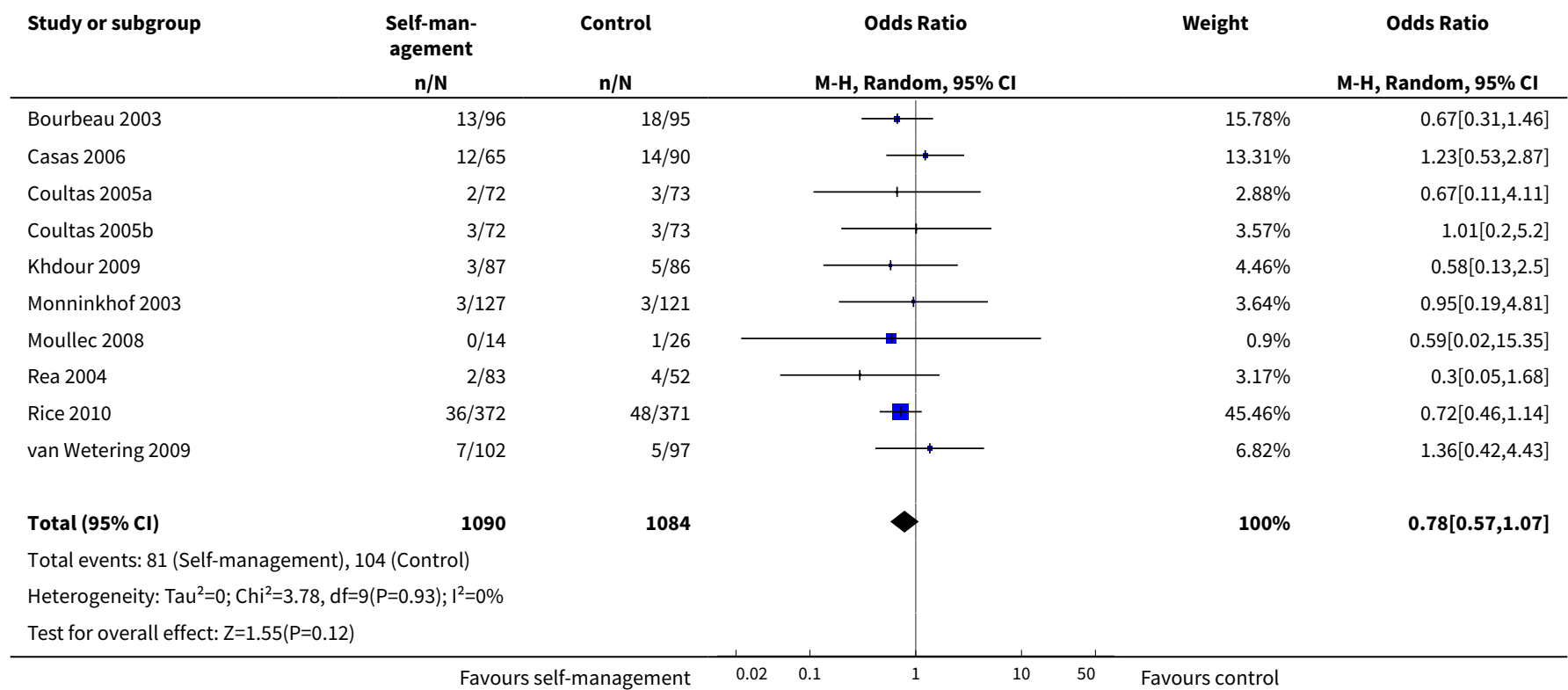

\section{Comparison 3. Subgroup analyses}

\begin{tabular}{|c|c|c|c|c|}
\hline Outcome or subgroup title & $\begin{array}{l}\text { No. of } \\
\text { studies }\end{array}$ & $\begin{array}{l}\text { No. of } \\
\text { partici- } \\
\text { pants }\end{array}$ & Statistical method & Effect size \\
\hline $\begin{array}{l}1 \mathrm{HRQOL} \text { : SGRQ total (subgroup } \\
\text { by follow-up) }\end{array}$ & 11 & & Mean Difference (IV, Random, 95\% CI) & Totals not selected \\
\hline $1.1>=12$ months of follow-up & 8 & & Mean Difference (IV, Random, 95\% CI) & $0.0[0.0,0.0]$ \\
\hline $1.2<12$ months of follow-up & 3 & & Mean Difference (IV, Random, 95\% CI) & $0.0[0.0,0.0]$ \\
\hline $\begin{array}{l}2 \text { Respiratory-related hospital } \\
\text { admissions (subgroup by fol- } \\
\text { low-up) }\end{array}$ & 9 & & Odds Ratio (M-H, Random, 95\% Cl) & Totals not selected \\
\hline $2.1>=12$ months of follow-up & 6 & & Odds Ratio (M-H, Random, 95\% Cl) & $0.0[0.0,0.0]$ \\
\hline $2.2<12$ months of follow-up & 3 & & Odds Ratio (M-H, Random, 95\% Cl) & $0.0[0.0,0.0]$ \\
\hline $\begin{array}{l}3 \mathrm{HRQOL} \text { : SGRQ total (subgroup } \\
\text { by exercise programme) }\end{array}$ & 11 & 1413 & Mean Difference (IV, Random, 95\% CI) & $-3.51[-5.37,-1.65]$ \\
\hline 3.1 With exercise programme & 3 & 430 & Mean Difference (IV, Random, 95\% CI) & $-2.13[-5.52,1.25]$ \\
\hline $\begin{array}{l}\text { 3.2 Without exercise pro- } \\
\text { gramme }\end{array}$ & 8 & 983 & Mean Difference (IV, Random, 95\% CI) & $-4.10[-6.33,-1.88]$ \\
\hline $\begin{array}{l}4 \text { Respiratory-related hospital } \\
\text { admissions (subgroup by exer- } \\
\text { cise programme) }\end{array}$ & 10 & 1749 & Odds Ratio (M-H, Random, 95\% Cl) & $0.57[0.43,0.75]$ \\
\hline
\end{tabular}




\begin{tabular}{|c|c|c|c|c|}
\hline Outcome or subgroup title & $\begin{array}{l}\text { No. of } \\
\text { studies }\end{array}$ & $\begin{array}{l}\text { No. of } \\
\text { partici- } \\
\text { pants }\end{array}$ & Statistical method & Effect size \\
\hline 4.1 With exercise programme & 3 & 477 & Odds Ratio (M-H, Random, 95\% Cl) & $0.75[0.37,1.53]$ \\
\hline $\begin{array}{l}4.2 \text { Without exercise pro- } \\
\text { gramme }\end{array}$ & 7 & 1272 & Odds Ratio (M-H, Random, 95\% Cl) & $0.54[0.41,0.71]$ \\
\hline $\begin{array}{l}5 \text { Exercise capacity: } 6 \mathrm{MW} \text { (sub- } \\
\text { group exercise programme) }\end{array}$ & 6 & & Mean Difference (IV, Random, 95\% CI) & Totals not selected \\
\hline 5.1 With exercise programme & 5 & & Mean Difference (IV, Random, 95\% CI) & $0.0[0.0,0.0]$ \\
\hline $\begin{array}{l}5.2 \text { Without exercise pro- } \\
\text { gramme }\end{array}$ & 1 & & Mean Difference (IV, Random, 95\% CI) & $0.0[0.0,0.0]$ \\
\hline $\begin{array}{l}6 \mathrm{HRQOL} \text { : SGRQ total (behav- } \\
\text { ioural components) }\end{array}$ & 11 & 1413 & Mean Difference (IV, Random, 95\% CI) & $-3.51[-5.37,-1.65]$ \\
\hline $\begin{array}{l}6.1 \text { With behavioural compo- } \\
\text { nents }\end{array}$ & 4 & 599 & Mean Difference (IV, Random, 95\% CI) & $-3.61[-7.65,0.44]$ \\
\hline $\begin{array}{l}6.2 \text { Without behavioural compo- } \\
\text { nents }\end{array}$ & 7 & 814 & Mean Difference (IV, Random, 95\% CI) & $-3.88[-6.31,-1.46]$ \\
\hline $\begin{array}{l}7 \text { Respiratory-related hospital } \\
\text { admissions (behavioural com- } \\
\text { ponents) }\end{array}$ & 10 & 1749 & Odds Ratio (M-H, Random, 95\% Cl) & $0.57[0.43,0.75]$ \\
\hline $\begin{array}{l}7.1 \text { With behavioural compo- } \\
\text { nents }\end{array}$ & 4 & 717 & Odds Ratio (M-H, Random, 95\% Cl) & $0.47[0.30,0.74]$ \\
\hline $\begin{array}{l}7.2 \text { Without behavioural compo- } \\
\text { nents }\end{array}$ & 6 & 1032 & Odds Ratio (M-H, Random, 95\% Cl) & $0.65[0.48,0.89]$ \\
\hline
\end{tabular}

Analysis 3.1. Comparison 3 Subgroup analyses, Outcome 1 HRQOL: SGRQ total (subgroup by follow-up).

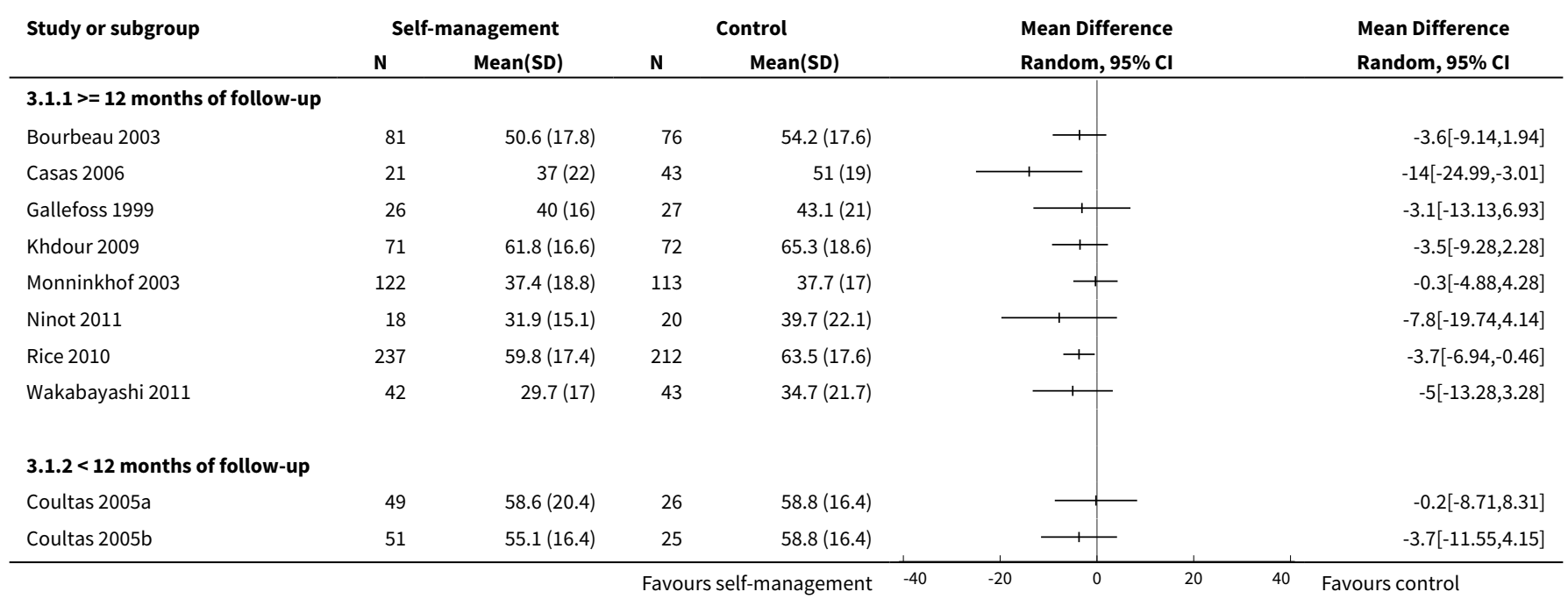




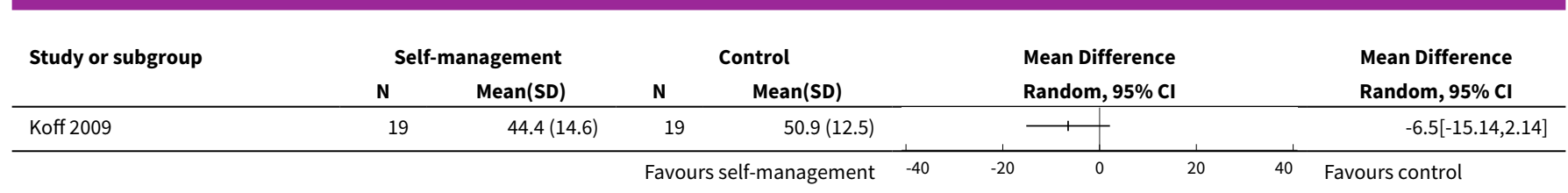

Analysis 3.2. Comparison 3 Subgroup analyses, Outcome 2 Respiratory-related hospital admissions (subgroup by follow-up).

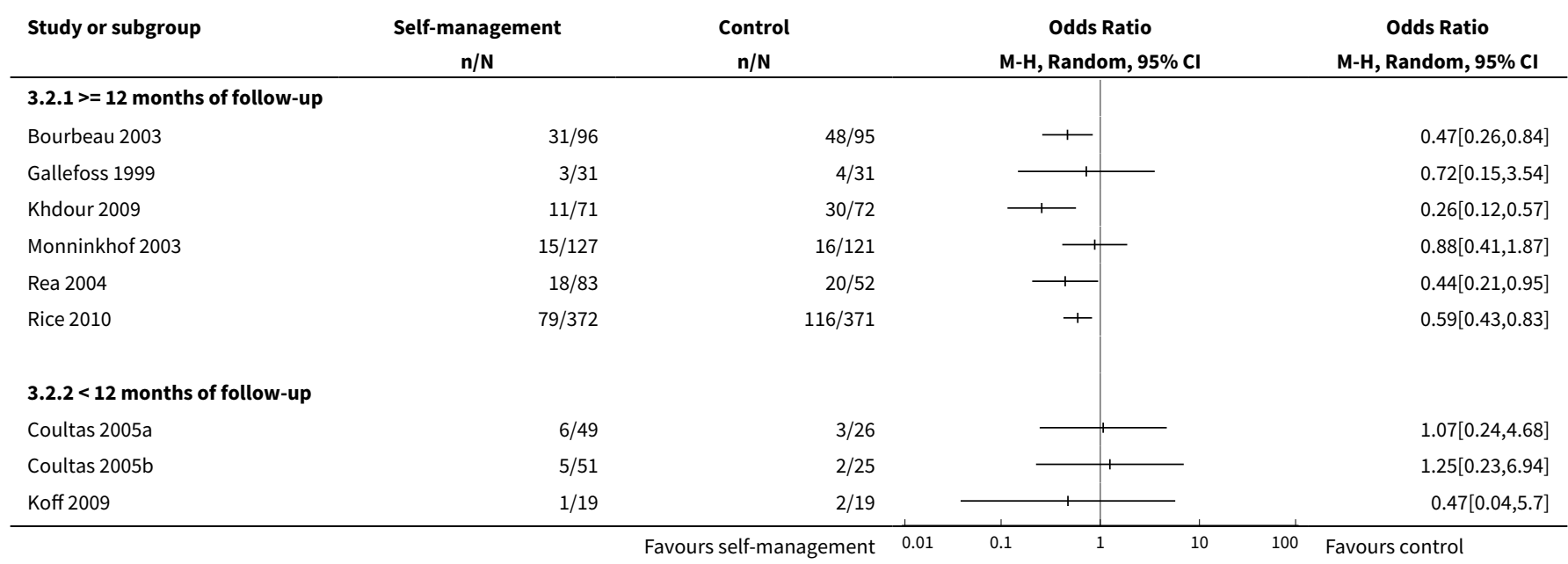

Analysis 3.3. Comparison 3 Subgroup analyses, Outcome 3 HRQOL: SGRQ total (subgroup by exercise programme).

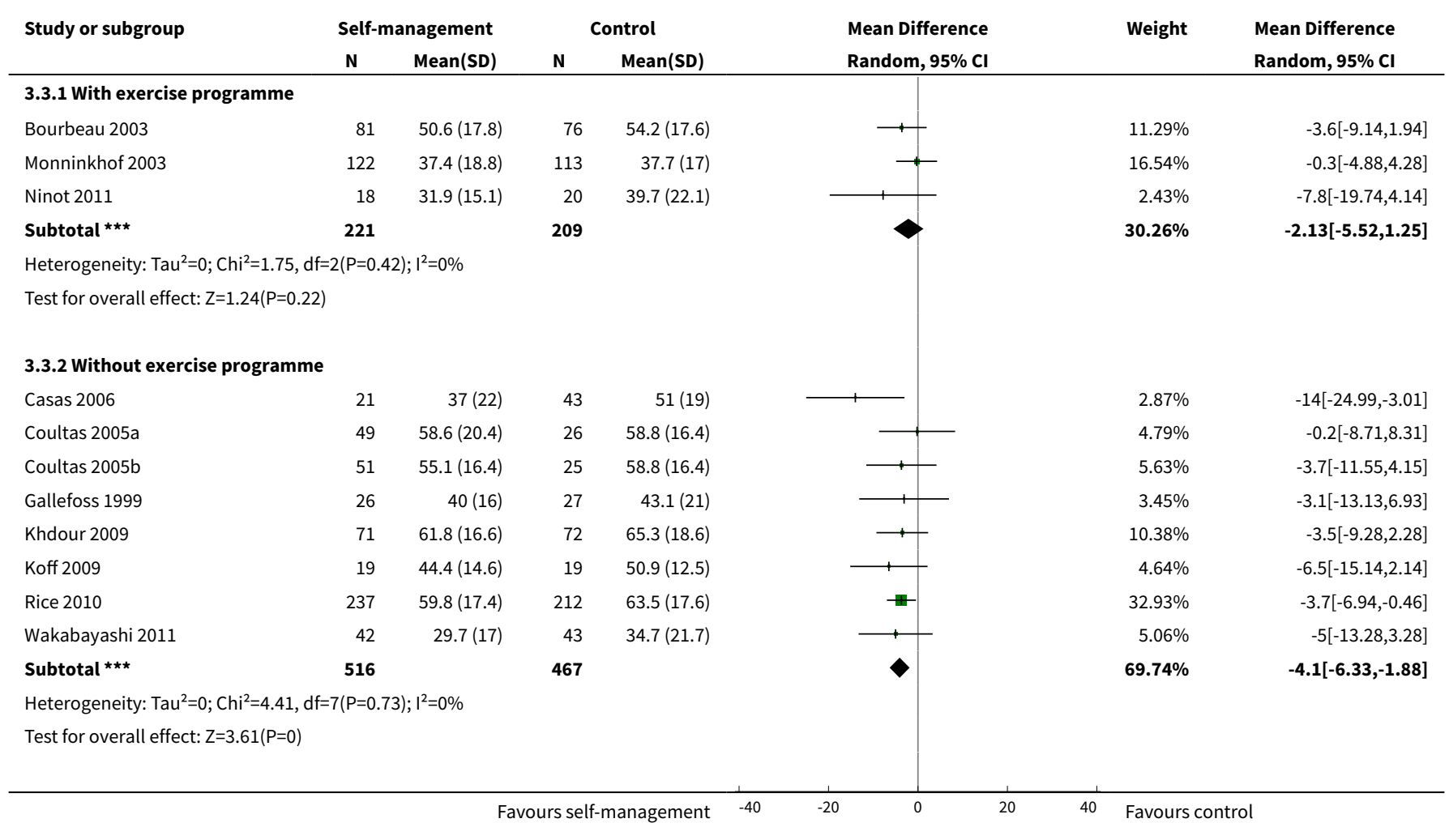




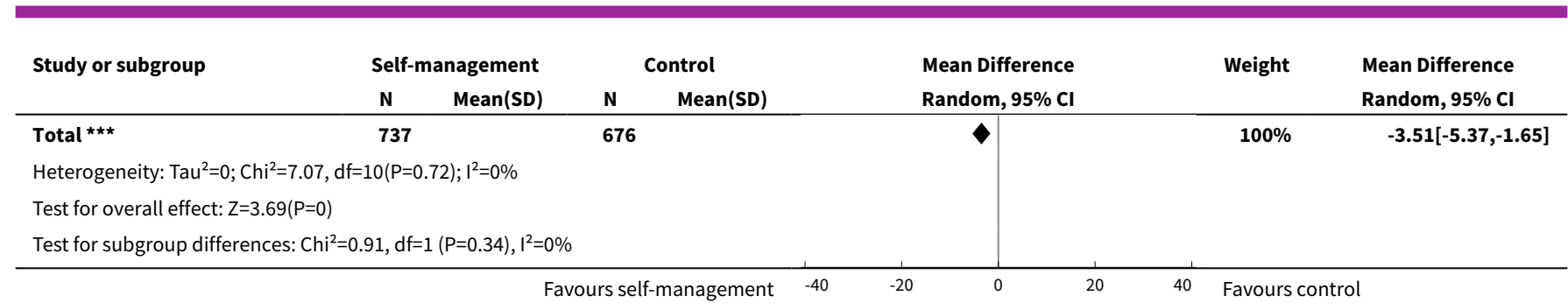

Analysis 3.4. Comparison 3 Subgroup analyses, Outcome 4 Respiratoryrelated hospital admissions (subgroup by exercise programme).

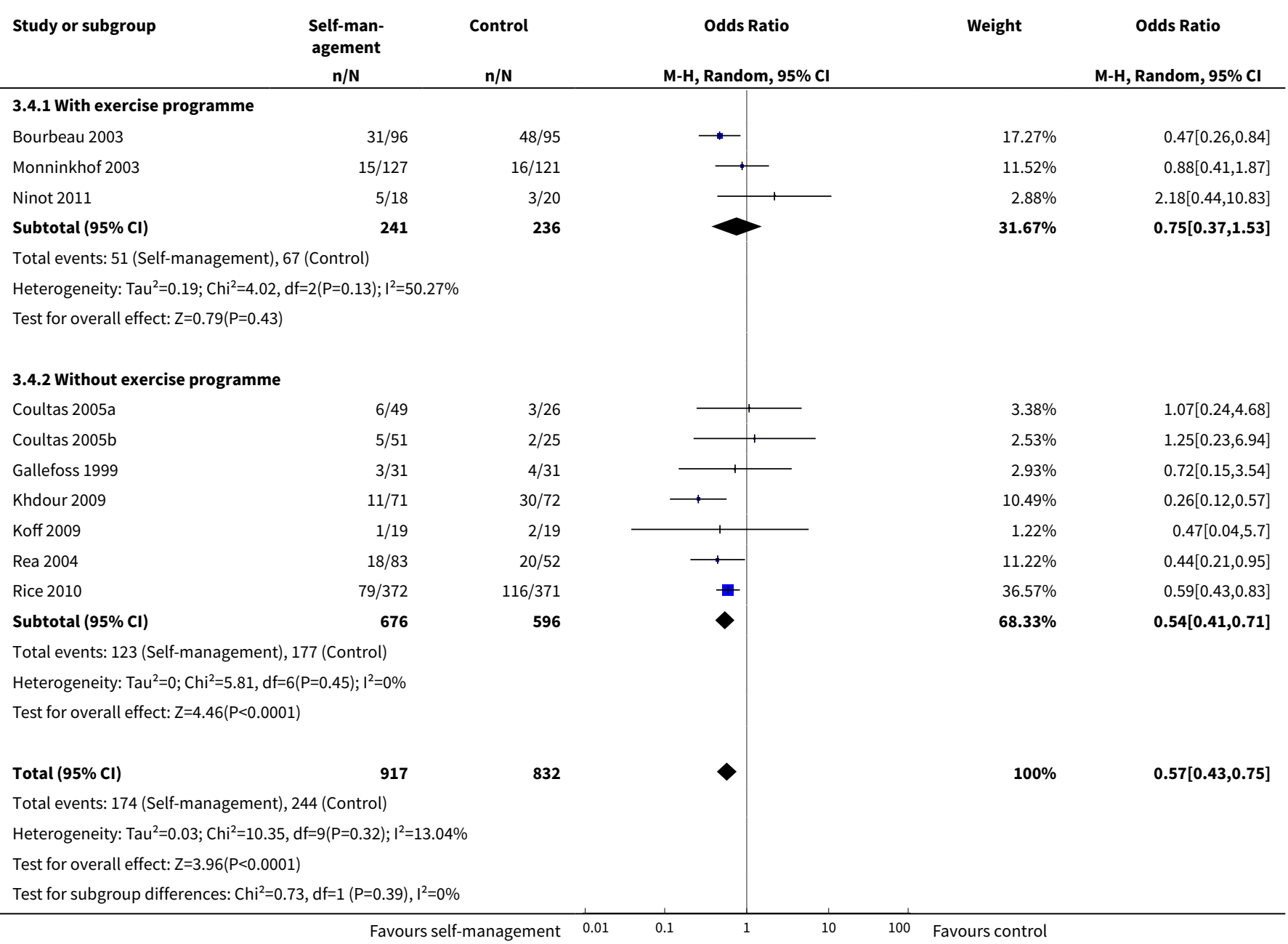

Analysis 3.5. Comparison 3 Subgroup analyses, Outcome 5 Exercise capacity: 6MW (subgroup exercise programme).

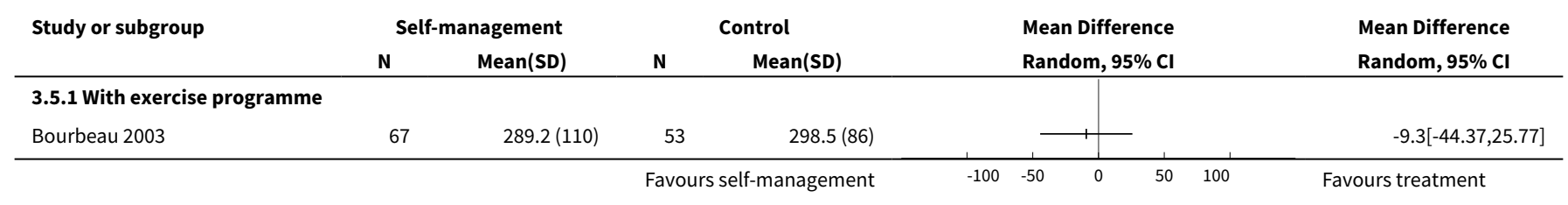




\begin{tabular}{|c|c|c|c|c|c|c|c|}
\hline \multirow{3}{*}{$\begin{array}{l}\text { Study or subgroup } \\
\text { Bösch } 2007\end{array}$} & \multicolumn{2}{|c|}{ Self-management } & \multicolumn{2}{|c|}{ Control } & \multirow{2}{*}{\multicolumn{2}{|c|}{$\begin{array}{l}\text { Mean Difference } \\
\text { Random, } 95 \% \mathrm{Cl}\end{array}$}} & \multirow{3}{*}{$\begin{array}{l}\begin{array}{l}\text { Mean Difference } \\
\text { Random, 95\% Cl }\end{array} \\
50[-17.48,117.48]\end{array}$} \\
\hline & \multirow{2}{*}{$\frac{\mathbf{N}}{30}$} & \multirow{2}{*}{$\frac{\text { Mean(SD) }}{436(94)}$} & \multirow{2}{*}{$\frac{\mathbf{N}}{11}$} & \multirow{2}{*}{$\frac{\text { Mean(SD) }}{386(99)}$} & & & \\
\hline & & & & & & 7 & \\
\hline Ghanem 2010 & 25 & $141.7(23.1)$ & 14 & $68.6(32.1)$ & & $\longrightarrow$ & $73.1[54,92.2]$ \\
\hline Monninkhof 2003 & 127 & $415.5(104.7)$ & 120 & $438.6(85.3)$ & & 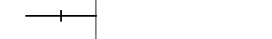 & $-23.12[-46.88,0.64]$ \\
\hline Ninot 2011 & 20 & $488.1(73.8)$ & 18 & $415.6(109)$ & & & $72.5[12.65,132.35]$ \\
\hline \multicolumn{8}{|c|}{ 3.5.2 Without exercise programme } \\
\hline Wakabayashi 2011 & 42 & $492.2(90.5)$ & 43 & $440.9(109.9)$ & & 1 & $51.3[8.54,94.06]$ \\
\hline
\end{tabular}

Analysis 3.6. Comparison 3 Subgroup analyses, Outcome 6 HRQOL: SGRQ total (behavioural components).

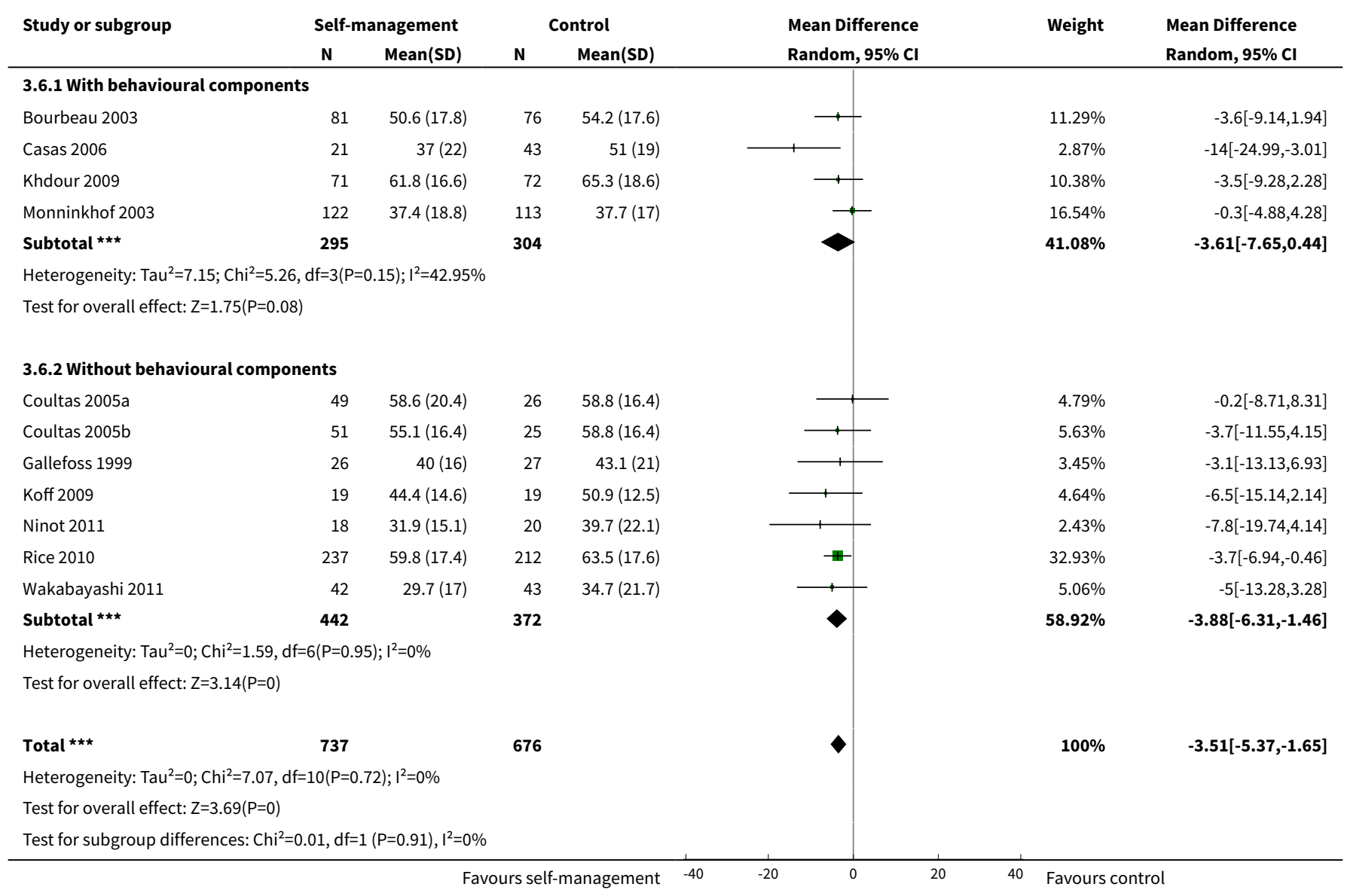

Analysis 3.7. Comparison 3 Subgroup analyses, Outcome 7 Respiratory-related hospital admissions (behavioural components).

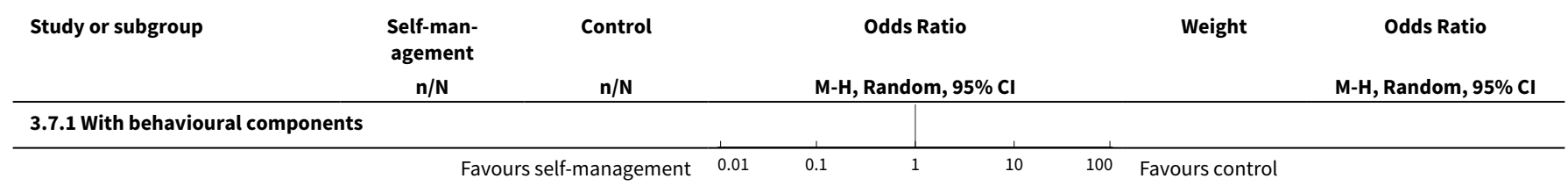




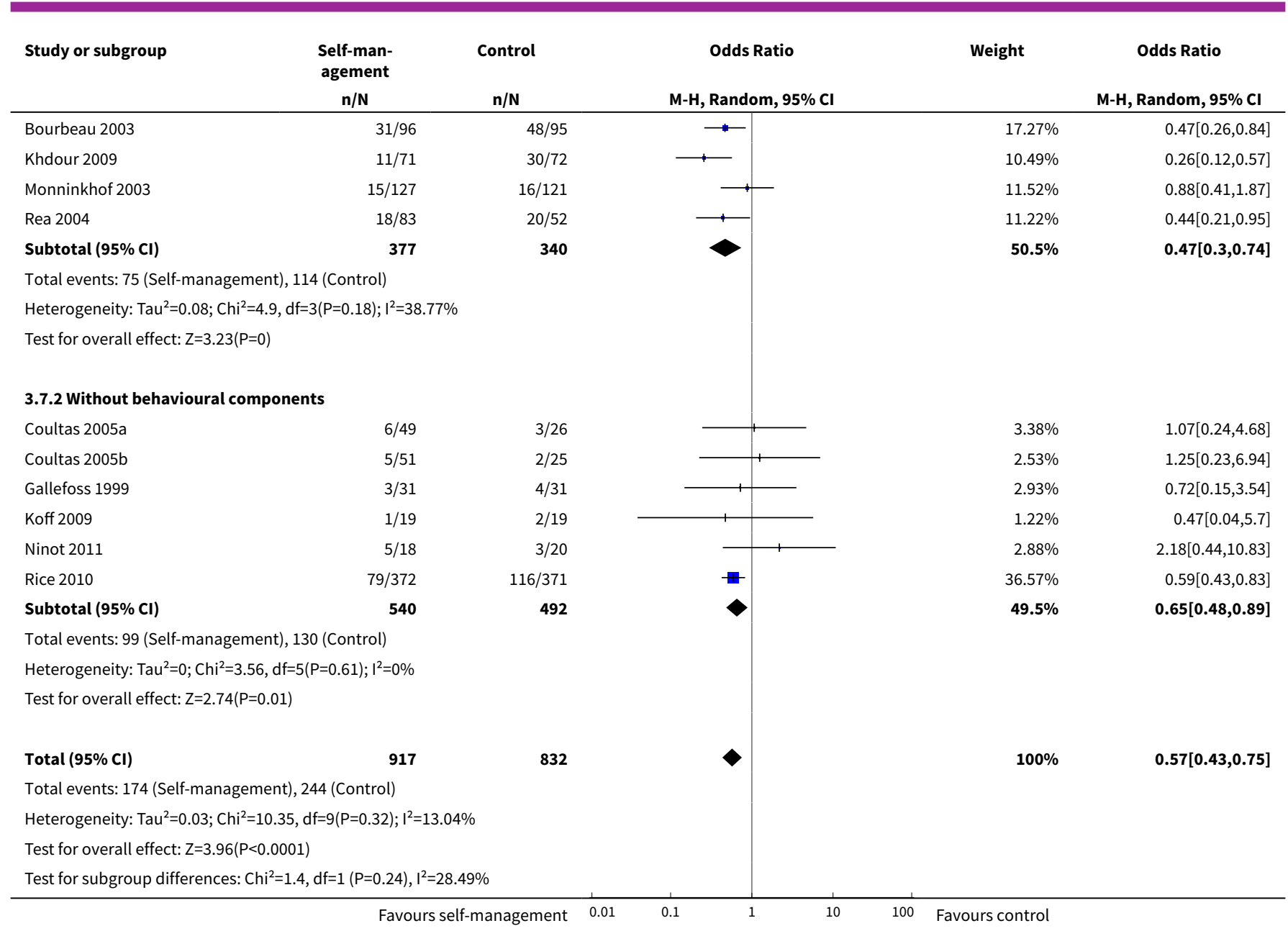

\section{ADDITIONAL TABLES}




\begin{tabular}{|c|c|c|c|c|c|c|c|c|c|c|}
\hline & $\begin{array}{l}\text { Inclu } \\
\text { parti } \\
\text { pants } \\
\text { (n) }\end{array}$ & & $\begin{array}{l}\text { Lost } \\
\text { follo } \\
(\%)\end{array}$ & $\begin{array}{l}0 \\
\text { v-up }\end{array}$ & $\begin{array}{l}\text { Age } \\
\text { (years) }\end{array}$ & & $\begin{array}{l}\text { Sex } \\
(\% \text { mal }\end{array}$ & & $\begin{array}{l}\text { FEV }_{1} \\
(\text { L or } \%)\end{array}$ & \\
\hline & $\begin{array}{l}\text { In- } \\
\text { ter- } \\
\text { ven- } \\
\text { tion }\end{array}$ & $\begin{array}{l}\text { Con- } \\
\text { trol }\end{array}$ & $\begin{array}{l}\text { In- } \\
\text { ter- } \\
\text { ven- } \\
\text { tion }\end{array}$ & $\begin{array}{l}\text { Con- } \\
\text { trol }\end{array}$ & Intervention & Control & $\begin{array}{l}\text { Inter- } \\
\text { ven- } \\
\text { tion }\end{array}$ & $\begin{array}{l}\text { Con- } \\
\text { trol }\end{array}$ & Intervention & Control \\
\hline \multicolumn{11}{|c|}{ Comparison with usual care } \\
\hline Akinci 2011 & 27 & 25 & 41 & 36 & $71.8(7.8)$ & $65.1(10.2)$ & n.a. & n.a & $0.9(0.3)$ & $1.0(0.4)$ \\
\hline Bösch 2007 & 38 & 12 & 21 & 8 & $63.8(8.4)$ & $64.6(6.8)$ & $\begin{array}{l}52 \text { (to- } \\
\text { tal } \\
\text { group) }\end{array}$ & n.a. & $1.3(0.5)$ & $1.4(0.5)$ \\
\hline Bourbeau 2003 & 96 & 95 & 10 & 17 & $69.4(6.5)$ & $69.6(7.4)$ & 52 & 59 & $1.0(0.3)$ & $1.0(0.3)$ \\
\hline Casas 2006 & 65 & 90 & 26 & 20 & $70(9)$ & $72(9)$ & 77 & 88 & $43(20)$ & $41(15)$ \\
\hline Chavannes 2009 & 79 & 73 & 14 & 18 & $64(11)$ & $63(11)$ & 59 & 67 & $62(19)$ & $66(16)$ \\
\hline Chuang 2011 & 141 & 141 & n.a. & n.a. & n.a. & n.a. & 35 & 35 & n.a. & n.a. \\
\hline Coultas 2005a & 72 & - & 29 & - & $68.3(6.6)$ & - & 43 & & $46.2(17.9)$ & - \\
\hline Coultas 2005b & 72 & 73 & 32 & 30 & $70.1(7.0)$ & $68.8(10.4)$ & 33 & 54 & $42.2(16.2)$ & $46.2(17.2)$ \\
\hline Emery 1998 & 25 & 25 & 8 & 0 & $67.4(5.9)$ & $67.4(7.1)$ & 40 & 48 & $1.1(0.5)$ & $1.0(0.4)$ \\
\hline Faulkner 2010 & 10 & 10 & 40 & 20 & $70.8(10.5)$ & $71.3(4.5)$ & 90 & 70 & $2.0(0.4)$ & $1.7(0.5)$ \\
\hline Gallefoss 1999 & 31 & 31 & 16 & 13 & $57(9)$ & $58(10)$ & 48 & 52 & $1.8(0.5)$ & $1.7(0.5)$ \\
\hline Ghanem 2010 & 25 & 14 & 0 & 0 & $57(11.6)$ & $56.4(9)$ & n.a. & n.a. & $0.8(0.4)$ & $0.6(0.2)$ \\
\hline Hill 2010 & 55 & 45 & 9 & 4 & $63.4(9.6)$ & $65.7(9.9)$ & 44 & 46 & $60.0(14.3)$ & $58.2(14.4)$ \\
\hline Khdour 2009 & 86 & 87 & 17 & 17 & $65.6(10.1)$ & $67.3(9.2)$ & 44 & 44 & $1.0(0.5)$ & $1.1(0.5)$ \\
\hline
\end{tabular}




\begin{tabular}{|c|c|c|c|c|c|c|c|c|c|c|}
\hline Kheirabadi 2008 & 21 & 21 & n.a. & n.a. & $56.6(5.7)$ & $56.2(4.1)$ & 62 & 76 & n.a. & n.a. \\
\hline Koff 2009 & 20 & 20 & 5 & 5 & $66.6(9.1)$ & $65.0(8.2)$ & 45 & 50 & $33.6(9.1)$ & $31.1(10.2)$ \\
\hline Monninkhof 2003 & 127 & 121 & 4 & 6 & $65(7)$ & $65(7)$ & 85 & 84 & $1.7(0.6)$ & $1.8(0.5)$ \\
\hline Moullec 2008 & 14 & 26 & 21 & 38 & $62.9(7.4)$ & $59.7(9.6)$ & 71 & 81 & $49.3(14.9)$ & $46.8(18.2)$ \\
\hline Ninot 2011 & 23 & 22 & 13 & 18 & $65(59-74)$ & 61 (56 to 65$)$ & 78 & 64 & 1.69 (1.17 to 2.01$)$ & 1.52 (1.06 to 1.85$)$ \\
\hline $\begin{array}{l}\text { Osterlund Efraimsson } \\
2006\end{array}$ & 26 & 26 & 0 & 0 & $66(9.4)$ & $67(10.4)$ & 50 & 50 & n.a. & n.a. \\
\hline Rea 2004 & 83 & 52 & 14 & 12 & $\begin{array}{l}68 \text { ( } 44 \text { to } 48 \text { ) (total } \\
\text { group) }\end{array}$ & n.a. & $\begin{array}{l}42 \text { (to- } \\
\text { tal } \\
\text { group) }\end{array}$ & n.a. & $1.2(0.5)$ & $1.1(0.5)$ \\
\hline Rice 2010 & 372 & 371 & 10 & 13 & $69.1(9.4)$ & $70.7(9.7)$ & 98 & 98 & $1.1(0.5)$ & $1.2(0.5)$ \\
\hline van Wetering 2009 & 102 & 97 & 25 & 17 & $65.9(8.8)$ & $67.2(8.9)$ & 71 & 71 & $58(17)$ & $60(15)$ \\
\hline Wakabayashi 2011 & 52 & 50 & 19 & 14 & $72.9(6.4)$ & $70.4(8.6)$ & 88 & 84 & $1.5(0.5)$ & $1.6(0.7)$ \\
\hline \multicolumn{11}{|l|}{ Head-to-head trials } \\
\hline Effing 2009 & 80 & 79 & 16 & 9 & $63.1(7.9)$ & $63.7(8.0)$ & 57 & 61 & $1.4(0.6)$ & $1.4(0.5)$ \\
\hline Effing 2011 & 80 & 79 & 8 & 14 & $62.9(8.1)$ & $63.9(7.8)$ & 58 & 58 & $1.4(0.5)$ & $1.4(0.5)$ \\
\hline Kara 2004 & 30 & 30 & n.a & n.a. & $61.1(11.3)$ & $61.4(11.1)$ & $\begin{array}{l}78 \text { (to- } \\
\text { tal } \\
\text { group) }\end{array}$ & n.a. & n.a. & n.a. \\
\hline Nguyen 2008 & 26 & 24 & 27 & 17 & $68.0(8.3)$ & $70.9(8.6)$ & 61 & 55 & $49.0(16.8)$ & $50.3(17.6)$ \\
\hline Nguyen 2009 & 9 & 8 & 0 & 0 & $72(9)$ & $64(12)$ & 33 & 37 & $46.7(18.7)$ & $34.4(15)$ \\
\hline Sassi-Dambron 1995 & 47 & 51 & 13 & 24 & $67.5(8.0)$ & $67.3(8.0)$ & 55 & 45 & $1.1(0.5)$ & $1.2(0.6)$ \\
\hline Stulbarg 2002 & $\begin{array}{l}40 \\
37\end{array}$ & 38 & $\begin{array}{l}10 \\
11\end{array}$ & 11 & $66.2(6.4) ; 67.2(7.6)$ & $65.7(6.8)$ & $50 / 38$ & 32 & $1.1(0.4) ; 1.2(0.3)$ & $1.0(0.3)$ \\
\hline
\end{tabular}



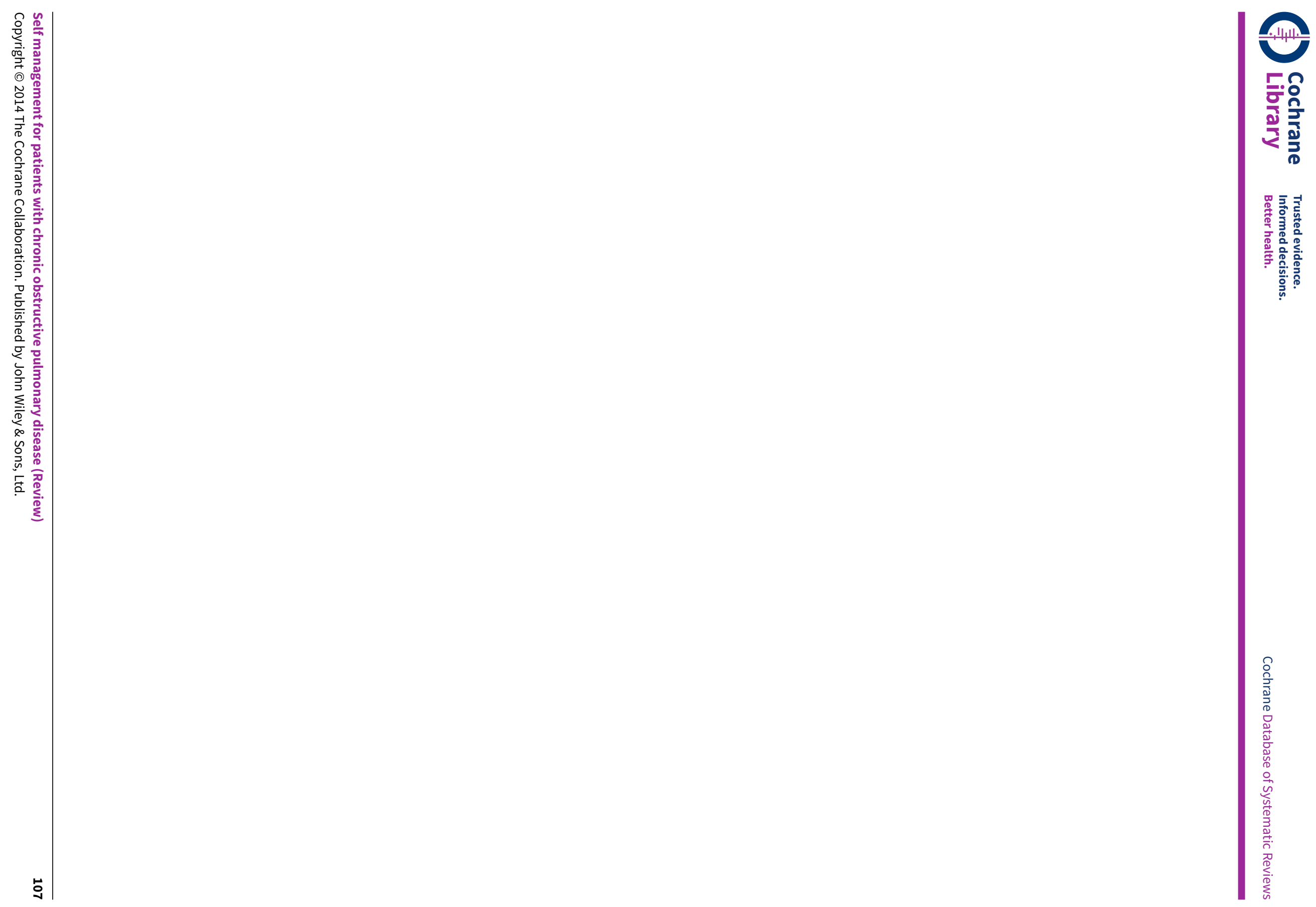
Table 2. Characteristics of interventions in included studies

\begin{tabular}{|c|c|c|c|c|c|}
\hline Author & $\begin{array}{l}\text { Fol- } \\
\text { low-up }\end{array}$ & Comparison & $\begin{array}{l}\text { Setting interven- } \\
\text { tion }\end{array}$ & Duration intervention & Content intervention \\
\hline
\end{tabular}

\section{Comparison with usual care}

\begin{tabular}{|c|c|c|c|c|c|}
\hline $\begin{array}{l}\text { Akinci } \\
2011\end{array}$ & $\begin{array}{l}\text { Three } \\
\text { months }\end{array}$ & $\begin{array}{l}\text { Nurse-led } \\
\text { home-based } \\
\text { pulmonary } \\
\text { rehab versus } \\
\text { usual care }\end{array}$ & $\begin{array}{l}\text { Home-based, in- } \\
\text { dividual, face-to- } \\
\text { face, educational } \\
\text { booklet }\end{array}$ & $\begin{array}{l}\text { Participant education: two to three } \\
\text { sessions of two to three hours, four } \\
\text { phone calls; exercise: daily, } 30 \text { to } \\
60 \text { minutes }\end{array}$ & $\begin{array}{l}\text { Education regarding the } \\
\text { disease, methods for smok- } \\
\text { ing cessation, use of med- } \\
\text { ication, coping with breath- } \\
\text { lessness, advice about exer- } \\
\text { cise and activities }\end{array}$ \\
\hline
\end{tabular}

\begin{tabular}{lllll}
\hline Bösch & 12 & COPD outpa- & Outpatient clin- & Four small-group sessions of 120 \\
2007 & months & tient educa- & ic, group-based & minutes \\
& & $\begin{array}{l}\text { tion program } \\
\text { (six to eight par- } \\
\end{array}$ & & ticipants), face-to- \\
& care & face
\end{tabular}

Education regarding the disease, smoking cessation, action plan with self treatment of exacerbations, advice about exercise, advice about nutrition, advice about medication, coping with breathlessness, travelling

\begin{tabular}{|c|c|c|c|c|}
\hline $\begin{array}{l}\text { Bourbeau } \\
2003\end{array}$ & $\begin{array}{l}24 \\
\text { months }\end{array}$ & $\begin{array}{l}\text { Self manage- } \\
\text { ment versus } \\
\text { usual care }\end{array}$ & $\begin{array}{l}\text { Home-based, indi- } \\
\text { vidual }\end{array}$ & $\begin{array}{l}\text { Seven to eight week * one hour; } \\
\text { first two months weekly telephone } \\
\text { calls; from then, once-a-month } \\
\text { telephone call. Exercise evalua- } \\
\text { tion (not mandatory) and exercise } \\
\text { teaching three times a week for } 30 \\
\text { to } 45 \text { minutes }\end{array}$ \\
\hline
\end{tabular}

COPD knowledge, breathing and coughing techniques, energy conservation during day-by-day activities, relaxation exercises, preventing and controlling symptoms through inhalation techniques, understanding and using plan of action for acute exacerbations, adopting a healthy lifestyle, leisure activities and travelling, a simple home exercise programme, long-term oxygen therapy when appropriate

\begin{tabular}{lllll}
\hline $\begin{array}{l}\text { Casas } \\
2006\end{array}$ & 12 & $\begin{array}{l}\text { Integrated } \\
\text { care versus } \\
\text { usual care }\end{array}$ & $\begin{array}{l}\text { Hospital-based } \\
\text { and home-based, } \\
\text { group sessions } \\
\text { and individual } \\
\text { sessions, face-to- } \\
\text { face }\end{array}$ & $\begin{array}{l}\text { One group session of two hours, } \\
\text { three individual sessions of } 40 \\
\text { minutes, and one to } 10 \text { sessions at } \\
\text { home of 20 minutes }\end{array}$ \\
& &
\end{tabular}

Education regarding the disease, smoking cessation, action plan with self treatment of exacerbations, advice about exercise, advice about nutrition, advice about medication, coping with breathlessness, travelling, end-of-life decision making, interpretation of medical testing, irritant avoidance, anxiety and panic control

\begin{tabular}{|c|c|c|c|c|c|}
\hline $\begin{array}{l}\text { Cha- } \\
\text { vannes } \\
2009\end{array}$ & $\begin{array}{l}12 \\
\text { months }\end{array}$ & $\begin{array}{l}\text { Integrated } \\
\text { disease man- } \\
\text { agement ver- } \\
\text { sus usual care }\end{array}$ & $\begin{array}{l}\text { General practise, } \\
\text { group sessions } \\
\text { and individual } \\
\text { sessions, face-to- } \\
\text { face, telephone }\end{array}$ & $\begin{array}{l}\text { One-month, twice-weekly individ- } \\
\text { ual education, five months twice } \\
\text { weekly one-hour training in group } \\
\text { sessions, one hour at home }\end{array}$ & $\begin{array}{l}\text { Education regarding the } \\
\text { disease, smoking cessa- } \\
\text { tion, action plan with self } \\
\text { treatment of exacerbations, } \\
\text { exercise programme, ad- }\end{array}$ \\
\hline
\end{tabular}


Table 2. Characteristics of interventions in included studies (Continued)

vice about nutrition, advice about medication

$\begin{array}{lllll}\text { Chuang } & 12 & \text { Partici- } & \text { Outpatient clinic, } \\ 2011 & \text { months } & \begin{array}{l}\text { pant-centric } \\ \text { COPD pro- } \\ \text { gramme ver- } \\ \text { individual }\end{array} & \begin{array}{l}\text { One face-to-face } 45 \text { minutes, } \geq 10 \\ \text { educational calls } 10 \text { to } 15 \text { minutes } \\ \text { each }\end{array} \\ & & \end{array}$

Education regarding the disease, smoking cessation, action plan with self treatment of exacerbations, advice about exercise, advice about nutrition, advice about medication, coping with breathlessness

\begin{tabular}{|c|c|c|c|c|c|}
\hline $\begin{array}{l}\text { Coultas } \\
\text { 2005a; } \\
\text { Coultas } \\
\text { 2005b }\end{array}$ & $\begin{array}{l}\text { Six } \\
\text { months }\end{array}$ & $\begin{array}{l}\text { Nurse-assist- } \\
\text { ed medical } \\
\text { management } \\
\text { (MM) or nurse- } \\
\text { assisted col- } \\
\text { laborative } \\
\text { management } \\
\text { (CM) versus } \\
\text { usual care }\end{array}$ & Primary care & $\begin{array}{l}\text { MM: } 124 \text { minutes (seven sessions); } \\
\text { CM: } 207 \text { minutes (eight sessions) }\end{array}$ & $\begin{array}{l}\text { Education regarding the } \\
\text { disease, smoking cessation, } \\
\text { action plan, advice about } \\
\text { medication }\end{array}$ \\
\hline $\begin{array}{l}\text { Emery } \\
1998\end{array}$ & $\begin{array}{l}\text { Two } \\
\text { months }\end{array}$ & $\begin{array}{l}\text { Education } \\
\text { and stress } \\
\text { management } \\
\text { (ESM) versus } \\
\text { usual care (ex- } \\
\text { clude EXESM) }\end{array}$ & $\begin{array}{l}\text { Duke University } \\
\text { Center for living, } \\
\text { group education }\end{array}$ & $\begin{array}{l}16 \text { one-hour-long educational lec- } \\
\text { tures, } 10 \text { one-hour group meetings } \\
\text { for stress management and social } \\
\text { support }\end{array}$ & $\begin{array}{l}\text { COPD knowledge, thera- } \\
\text { py, coping, interpreting pul- } \\
\text { monary function tests, un- } \\
\text { derstanding arterial blood } \\
\text { gases, stress management }\end{array}$ \\
\hline $\begin{array}{l}\text { Faulkner } \\
2010\end{array}$ & 10 weeks & $\begin{array}{l}\text { Health-en- } \\
\text { hancing phys- } \\
\text { ical activity } \\
\text { programme } \\
\text { versus usual } \\
\text { care }\end{array}$ & $\begin{array}{l}\text { University exer- } \\
\text { cise facility, group } \\
\text { sessions, face-to- } \\
\text { face, booklet }\end{array}$ & Eight sessions of 90 minutes & $\begin{array}{l}\text { Education regarding the } \\
\text { disease, exercise pro- } \\
\text { gramme, advice about ex- } \\
\text { ercise, coping with breath- } \\
\text { lessness }\end{array}$ \\
\hline $\begin{array}{l}\text { Gallefoss } \\
1999\end{array}$ & $\begin{array}{l}12 \\
\text { months }\end{array}$ & $\begin{array}{l}\text { Standardised } \\
\text { education } \\
\text { programme } \\
\text { and a self } \\
\text { management } \\
\text { programme } \\
\text { versus usual } \\
\text { care }\end{array}$ & $\begin{array}{l}\text { Outpatient clinic, } \\
\text { group and individ- } \\
\text { ual sessions, pa- } \\
\text { tient brochure }\end{array}$ & $\begin{array}{l}\text { Two two-hour group sessions, two } \\
\text { to four individual sessions of } 40 \\
\text { minutes }\end{array}$ & $\begin{array}{l}\text { COPD knowledge, medica- } \\
\text { tion, action plan, symp- } \\
\text { toms, exacerbations, in- } \\
\text { halation technique, smok- } \\
\text { ing cessation, relaxation, } \\
\text { coping }\end{array}$ \\
\hline $\begin{array}{l}\text { Ghanem } \\
2010\end{array}$ & $\begin{array}{l}\text { Two } \\
\text { months }\end{array}$ & $\begin{array}{l}\text { Home-based } \\
\text { pulmonary re- } \\
\text { habilitation } \\
\text { programme } \\
\text { versus usual } \\
\text { care }\end{array}$ & $\begin{array}{l}\text { Home-based, in- } \\
\text { dividual sessions, } \\
\text { face-to-face, book- } \\
\text { let }\end{array}$ & $\begin{array}{l}\text { Four individual sessions of one } \\
\text { hour, every other day exercise for } \\
\text { two months }\end{array}$ & $\begin{array}{l}\text { Education regarding the } \\
\text { disease, exercise pro- } \\
\text { gramme, advice about nu- } \\
\text { trition, advice about med- } \\
\text { ication }\end{array}$ \\
\hline Hill 2010 & $\begin{array}{l}\text { Three } \\
\text { months }\end{array}$ & $\begin{array}{l}\text { Brief dis- } \\
\text { ease-specif- } \\
\text { ic education } \\
\text { programme } \\
\text { versus usual } \\
\text { care }\end{array}$ & $\begin{array}{l}\text { Primary care prac- } \\
\text { tise, individual } \\
\text { sessions, face- } \\
\text { to-face, written } \\
\text { teaching manual }\end{array}$ & $\begin{array}{l}\text { Two individual sessions of one } \\
\text { hour }\end{array}$ & $\begin{array}{l}\text { Education regarding the } \\
\text { disease, (strategies for) } \\
\text { smoking cessation, recogni- } \\
\text { tion of an exacerbation, ad- } \\
\text { vice about exercise, advice } \\
\text { about medication }\end{array}$ \\
\hline
\end{tabular}




\section{Table 2. Characteristics of interventions in included studies (Continued)}

$\begin{array}{llll}\text { Khdour } & 12 & \text { Clinical phar- } & \text { Hospital (outpa- } \\ 2009 & \text { months } & \text { macy-led } & \text { tient clinic), indi- } \\ & \text { disease and } & \text { vidual sessions, } \\ & \text { medicine } & \text { face-to-face, tele- } \\ & \text { management } & \text { phone } \\ & \text { programme } & \\ & \text { versus usual } \\ & \text { care }\end{array}$

One session of one hour, reinforcement at each outpatient visit every six months, two telephone calls at three months and nine months

$\begin{array}{ll}\text { Kheiraba- } & \text { Three } \\ \text { di } 2008 & \text { months }\end{array}$

Self management and behaviour modification group education versus usual care

\begin{tabular}{|c|c|c|c|}
\hline Koff 2009 & $\begin{array}{l}\text { Three } \\
\text { months }\end{array}$ & $\begin{array}{l}\text { Proactive in- } \\
\text { tegrated care } \\
\text { versus usual } \\
\text { care }\end{array}$ & $\begin{array}{l}\text { Home-based, in- } \\
\text { dividual, face-to- } \\
\text { face, telecommu- } \\
\text { nication device }\end{array}$ \\
\hline
\end{tabular}

$\begin{array}{ll}\text { Mon- } & 12 \\ \text { ninkhof } & \text { months }\end{array}$

2003
Hospital (outpatient clinic), group sessions, face-toface, telephone
Eight group sessions of 60 to 90 minutes; participants were followed up by phone
Education regarding the disease, smoking cessation, action plan with self treatment of exacerbations, advice about exercise, advice about nutrition, advice about medication, coping with breathlessness
Education regarding the disease, smoking cessation, exercise programme, action plan, advice about exercise, advice about nutrition, advice about medication

Education regarding the disease, exercise programme, action plan, advice about exercise, advice about medication

COPD knowledge, inhalation technique, importance of exercise, relaxation, nutrition, coping with breathlessness, ergonomic posture and energy conservation during daily activities or work, communication and social relationships, guidelines for self treatment for exacerbations (action plans), a fitness program aimed at coping with disease, recognising individual capacity, social interactions and behavioural change

Education regarding the disease, smoking cessation, exercise programme, action plan, advice about exercise, advice about nutrition, advice about medication, coping with breathlessness

sus standard

aftercare/usual care

\begin{tabular}{llllll}
\hline $\begin{array}{l}\text { Ninot } \\
2011\end{array}$ & $\begin{array}{l}12 \\
\text { months }\end{array}$ & $\begin{array}{l}\text { Self manage- } \\
\text { ment pro- } \\
\text { gramme ver- } \\
\text { sus usual care }\end{array}$ & $\begin{array}{l}\text { Hospital on outpa- } \\
\text { tient basis, group } \\
\text { and Individual } \\
\text { sessions, face-to- } \\
\text { face, telephone }\end{array}$ & $\begin{array}{l}\text { Eight group sessions of two hours, } \\
\text { three phone calls }\end{array}$ & $\begin{array}{l}\text { Smoking cessation, exercise } \\
\text { programme, action plan, } \\
\text { advice about exercise, ad- } \\
\text { vice about nutrition, advice } \\
\text { about medication }\end{array}$ \\
\hline $\begin{array}{l}\text { Osterlund } \\
\text { Efraims- } \\
\text { son 2006 }\end{array}$ & $\begin{array}{l}\text { Three } \\
\text { to five } \\
\text { months }\end{array}$ & $\begin{array}{l}\text { Structured } \\
\text { educational } \\
\text { intervention }\end{array}$ & $\begin{array}{l}\text { Nurse-led prima- } \\
\text { ry healthcare clin- } \\
\text { ic, individual ses- } \\
\text { sions, face-to-face }\end{array}$ & $\begin{array}{l}\text { Two visits that lasted for about } \\
\text { one hour }\end{array}$ & $\begin{array}{l}\text { Education regarding COPD, } \\
\text { smoking cessation, action } \\
\text { plan, advice about exercise, } \\
\text { advice about nutrition, ad- }\end{array}$
\end{tabular}


Table 2. Characteristics of interventions in included studies (Continued)

versus usual

care

vice about medication, cop-

ing with breathlessness

\begin{tabular}{lllll}
\hline Rea 2004 & 12 & $\begin{array}{l}\text { Chronic dis- } \\
\text { months } \\
\text { ease manage- } \\
\text { ment versus } \\
\text { usual care }\end{array}$ & $\begin{array}{l}\text { Outpatient clinic, } \\
\text { GP, home-based, } \\
\text { individual }\end{array}$ & $\begin{array}{l}12 \text { monthly visits to practise nurse, } \\
\text { four three-monthly visits to GP, at } \\
\text { least one home visit of respiratory } \\
\text { nurse specialist and one following } \\
\text { hospital admissions }\end{array}$
\end{tabular}

An action plan detailing advice on how to manage worsening symptoms, when to call the GP, and self medication options decided by the GP. Information about smoking cessation and the use of inhalers was given. Annual influenza vaccination and attendance at a pulmonary rehabilitation programme were recommended

$\begin{array}{lllll}\text { Rice } 2010 & 12 & \begin{array}{l}\text { Simplified } \\ \text { months } \\ \text { disease man- } \\ \text { agement pro- } \\ \text { gramme ver- }\end{array} & \begin{array}{l}\text { Outpatient clinic, } \\ \text { group and individ- } \\ \text { ual sessions, face- } \\ \text { to-face. }\end{array} & \begin{array}{l}\text { One group session of one to } 1.5 \\ \text { hours, } 12 \text { monthly phone calls of }\end{array} \\ 10 \text { to } 15 \text { minutes }\end{array}$

sus usual care smoking cessation, action
Education regarding COPD, plan with self treatment, advice about exercise, advice about medication, coping with breathlessness

Education regarding COPD, smoking cessation, exercise programme, advice about exercise, advice about nutrition agement pro- tient education gramme ver- book sus usual care

$\begin{array}{ll}\text { Wak- } & 12 \\ \text { abayashi } & \text { months } \\ 2011 & \end{array}$

\section{Integrated} care focusing on participant information needs for the self management of COPD

versus usual

care
30 minutes of physiotherapy visits twice a week during the first four months, twice a day during 30 minutes at home, education duration unknown. Once-a-month physiotherapy during the following 20 months

\section{Outpatient clin- ic, individual ses- \\ Six monthly individual sessions of at least 30 minutes} sions, face-to-face, booklet

Education regarding COPD, smoking cessation, action plan with self treatment, advice about exercise, advice about nutrition, advice about medication, coping with breathlessness

\section{Head-to-head trials}

\begin{tabular}{llllll}
\hline Kara 2004 & $\begin{array}{l}\text { Two } \\
\text { months }\end{array}$ & $\begin{array}{l}\text { Structured ed- } \\
\text { ucation pro- } \\
\text { gramme ver- } \\
\text { sus educa- } \\
\text { tional advice }\end{array}$ & $\begin{array}{l}\text { Hospital (outpa- } \\
\text { tient clinic), group } \\
\text { and individual } \\
\text { sessions, face- } \\
\text { to-face, written } \\
\text { teaching manual }\end{array}$ & $\begin{array}{l}\text { 60 to } 70 \text { minutes, later } 35 \text { to } 40 \\
\text { minutes three or four times per } \\
\text { week in small groups }\end{array}$ & $\begin{array}{l}\text { Education regarding the } \\
\text { disease, smoking cessa- } \\
\text { tion, exercise programme, } \\
\text { advice about exercise, ad- } \\
\text { vice about nutrition, advice } \\
\text { about medication, coping } \\
\text { with breathlessness }\end{array}$ \\
\hline $\begin{array}{lllll}\text { Stulbarg } \\
2002\end{array}$ & $\begin{array}{l}\text { 12 } \\
\text { months }\end{array}$ & $\begin{array}{l}\text { Dyspnoea self } \\
\text { management }\end{array}$ & $\begin{array}{l}\text { Home-based } \\
\text { walking, } \\
\text { hospital-based } \\
\text { self management } \\
\text { education (?) }\end{array}$ & $\begin{array}{l}\text { Three hours in four sessions over } \\
\text { eight weeks, walk at least four } \\
\text { times per week for minimum of } 20\end{array}$ & $\begin{array}{l}\text { Individualised dyspnoea } \\
\text { self management educa- } \\
\text { minutes } \\
\text { tion, home-walking pre- } \\
\text { scription }\end{array}$ \\
& & & &
\end{tabular}




\section{Table 2. Characteristics of interventions in included studies (Continued)}

$\begin{array}{ll}\text { Dyspnoea self } & \text { Home-based } \\ \text { management } & \text { walking, }\end{array}$ and exposure hospital-based (?) self management education and exposure
Three hours in four sessions over eight weeks, walk at least four times per week for minimum of 20 minutes, four nurse-coached treadmill exercise sessions for 30 minutes once every other week for eight weeks
Dyspnoea self Home-based Three hours in four sessions over management walking, and training hospital-based (?) self management education and training eight weeks, walk at least four times per week for minimum of 20 minutes, 24 nurse-coached treadmill exercise sessions for 30 minutes three times per week for eight weeks

Nguyen Six Mo- Outpatient clin- One individual session of 30 to 45

2009 months

bile-coached cell phonebased exercise persistence intervention ic- and homebased, individual sessions, face-toface, booklet, telephone minutes, at least one or two phone calls of 10 minutes, 150 minutes of moderate-intensity endurance exercise over three to five sessions per week for six months
Individualised dyspnoea self management education, home-walking prescription, exposure to exercise-induced dyspnoea

Individualised dyspnoea self management education, home-walking prescription, exercise training
Mobile-self Outpatient clinmonitored ex- ic- and homeercise persistence intervention based, individual sessions, face-toface, booklet, telephone
One individual session of 30 to 45 minutes, standard (self monitored) text message, 150 minutes of moderate-intensity endurance exercise over three to five sessions per week for six months
Action plan, advice about exercise and exercise programme with collaborative monitoring of symptoms and exercise and ongoing reinforcement feedback
Action plan, advice about exercise and exercise programme with self monitoring

$\begin{array}{lll}\text { Nguyen } & \text { Six } & \text { Dyspnoea self } \\ 2008 & \text { months } & \begin{array}{l}\text { management } \\ \text { programme } \\ \text { face-to-face }\end{array}\end{array}$

Outpatient clinicand home-based, group and individual sessions, faceto-face, telephone
1.5- to two-hour face-to-face consultation, six one-hour weekly group sessions of structured education of dyspnoea management strategies face-to-face, four times/ wk 30 minutes endurance, three times/wk arm strengthening, reinforcement via telephone weekly in month one, biweekly in months two through six

\section{Dyspnoea} self management programme Internet-based

\section{Outpatient clinic} and home-based, group and individual sessions, faceto-face, Internet
1.5- to two-hour face-to-face consultation, six one-hour weekly group sessions of structured education of dyspnoea management strategies via chat

four times/wk 30 minutes endurance, three times/wk arm strengthening,

reinforcement via email weekly in month one, biweekly in months two through six
Exercise programme, action plan, advice about exercise, advice about medication, coping with breathlessness
Exercise programme, action plan, advice about exercise, advice about medication, coping with breathlessness

\begin{tabular}{|c|c|c|c|c|c|}
\hline $\begin{array}{l}\text { Sas- } \\
\text { si-Dambron }\end{array}$ & $\begin{array}{l}12 \\
\text { months }\end{array}$ & $\begin{array}{l}\text { Dyspnoea } \\
\text { management }\end{array}$ & $\begin{array}{l}\text { Group sessions, } \\
\text { face-to-face }\end{array}$ & Six weekly sessions & $\begin{array}{l}\text { Education regarding the } \\
\text { disease, advice about ex- }\end{array}$ \\
\hline
\end{tabular}


Table 2. Characteristics of interventions in included studies (Continued)

ercise, coping with breathlessness

$\begin{array}{lll}\begin{array}{l}\text { General } \\ \text { health educa- }\end{array} & \begin{array}{l}\text { Group sessions, } \\ \text { face-to-face }\end{array} & \begin{array}{l}\text { Six weekly general health educa- } \\ \text { tion sessions }\end{array}\end{array}$

face-to-face tion

Six weekly gen
tion sessions
Four weekly, two-hour smallgroup self management sessions with three follow-up phone calls, 11-month training, first six months two/wk at physiotherapy practise, one/wk at home, last five months one/wk at physiotherapy practice, one/wk at home

Four weekly, two-hour small$\begin{array}{lll}\text { ment pro- } & \text { ic, group and in- } & \text { group self management sessions } \\ \text { gramme } & \text { dividual sessions, } & \text { with three follow-up phone calls }\end{array}$ face-to-face, telephone, booklet
Topics not directly related to lung disease: exercise, general medications, durable power of attorney, nutrition, Alzheimer's disease, medical insurance

Education regarding COPD, action plan, advice about exercise, advice about nutrition, advice about medication, coping with breathlessness, exercise programme

Education regarding COPD, action plan, advice about exercise, advice about nutrition, advice about medication, coping with breathlessness

Education regarding COPD, action plan with self treatment of exacerbations, advice about exercise, advice about nutrition, advice about medication, coping with breathlessness

Education regarding COPD, action plan, advice about exercise, advice about nutrition, advice about medication, coping with breathlessness

Table 3. Number of studies reporting outcome

Studies with usu- Head-to-head trial care als

\section{Primary outcomes}

\begin{tabular}{lcc}
\hline Health-related quality of life scores & 20 & 4 \\
\hline Number of hospital admissions: respiratory-related & 12 & 1 \\
\hline Number of hospital admissions: all-cause & 10 & 1 \\
\hline
\end{tabular}

\section{Secondary outcomes}


Table 3. Number of studies reporting outcome (Continued)

\begin{tabular}{lll} 
Symptom scores & 10 & 3 \\
\hline Number of courses of oral corticosteroids or antibiotics & 2 & 2 \\
\hline Use of rescue medication & 3 & 4 \\
\hline Number of exacerbations & 5 & 0 \\
\hline Hospitalisation days: respiratory-related & 8 & 0 \\
\hline Hospitalisation days: all-cause & 8 & 1 \\
\hline Emergency department visits & 8 & 0 \\
\hline Doctor and nurse visits & 3 & 0 \\
\hline Days lost from work & 12 & 3 \\
\hline Lung function & 10 & 5 \\
\hline Exercise capacity & 2 & 2 \\
\hline Anxiety and depression & 1 & 4 \\
\hline Self efficacy & 2 & 2 \\
\hline
\end{tabular}

Table 4. Study-specific number needed to treat for an additional beneficial outcome (NNTB) of respiratory-related hospital admissions

\begin{tabular}{|c|c|c|c|}
\hline Study & $\begin{array}{l}\text { Baseline risk } \\
\text { ( } \% \text { control) }\end{array}$ & $\begin{array}{l}\text { Follow-up } \\
\text { (weeks) }\end{array}$ & NNTB $(95 \% \mathrm{CI})$ \\
\hline Bourbeau 2003 & 51 & 52 & $8(5$ to 14$)$ \\
\hline Coultas 2005a; Coultas 2005b & 10 & 24 & 26 (19 to 45$)$ \\
\hline Gallefoss 1999 & 13 & 52 & 20 (15 to 35$)$ \\
\hline Khdour 2009 & 42 & 52 & $8(6$ to 15$)$ \\
\hline Koff 2009 & 11 & 12 & 24 (18 to 42$)$ \\
\hline Monninkhof 2003 & 13 & 52 & $20(15$ to 34$)$ \\
\hline Ninot 2011 & 15 & 52 & $18(13$ to 31$)$ \\
\hline Rea 2004 & 38 & 52 & $9(6$ to 16$)$ \\
\hline Rice 2010 & 31 & 52 & $10(7$ to 18$)$ \\
\hline
\end{tabular}




\section{APPENDICES}

\section{Appendix 1. Sources and search methods for the Cochrane Airways Group Specialised Register (CAGR)}

\section{Electronic searches: core databases}

\begin{tabular}{ll}
\hline Database & Frequency of search \\
\hline CENTRAL & Monthly \\
\hline MEDLINE (Ovid) & Weekly \\
\hline EMBASE (Ovid) & Weekly \\
\hline PSyCINFO (Ovid) & Monthly \\
\hline CINAHL (EBSCO) & Monthly \\
\hline AMED (EBSCO) & Monthly \\
\hline
\end{tabular}

\section{Handsearches: core respiratory conference abstracts}

\begin{tabular}{ll}
\hline Conference & Years searched \\
\hline American Academy of Allergy, Asthma and Immunology (AAAAI) & 2001 onwards \\
\hline American Thoracic Society (ATS) & 2001 onwards \\
\hline Asia Pacific Society of Respirology (APSR) & 2004 onwards \\
\hline British Thoracic Society Winter Meeting (BTS) & 2000 onwards \\
\hline Chest Meeting & 2003 onwards \\
\hline European Respiratory Society (ERS) & $1992,1994,2000$ onwards \\
\hline International Primary Care Respiratory Group Congress (IPCRG) & 2002 onwards \\
\hline Thoracic Society of Australia and New Zealand (TSANZ) & 1999 onwards \\
\hline
\end{tabular}

\section{MEDLINE search strategy used to identify trials for the CAGR}

\section{COPD search}

1. Lung Diseases, Obstructive/

2. exp Pulmonary Disease, Chronic Obstructive/

3. emphysema\$.mp. 
4. (chronic\$ adj3 bronchiti\$).mp.

5. (obstruct\$ adj3 (pulmonary or lung\$ or airway\$ or airflow\$ or bronch\$ or respirat\$)).mp.

6. COPD.mp.

7. COAD.mp.

8. COBD.mp.

9. AECB.mp.

10. or/1-9

\section{Filter to identify RCTs}

1. exp "clinical trial [publication type]"/

2. (randomised or randomised).ab,ti.

3. placebo.ab,ti.

4. dt.fs.

5. randomly.ab,ti.

6. trial.ab,ti.

7. groups.ab,ti.

8. or/1-7

9. Animals/

10. Humans/

11.9 not $(9$ and 10$)$

12. 8 not 11

The MEDLINE strategy and RCT filter are adapted to identify trials in other electronic databases

\section{Appendix 2. Search terms for Cochrane Airways Group Register}

educat $^{\star}$ or self-manag* or "self manag" or self-car* or "self car" ${ }^{\star}$ or train* or instruct* or "patient cent" or patient-cent* or patientfocus ${ }^{\star}$ or "patient focus" or patient-education or "patient education" or "management plan*" or "management program*" or behavior or behaviour" or "disease management ${ }^{\star}$ " or management ${ }^{\star}$ or self-efficacy or empower

[Limited to records in the Register coded as 'COPD']

\section{WHAT'S NEW}

\begin{tabular}{lll}
\hline Date & Event & Description \\
\hline 7 July 2014 & Amended & We amended the data for all-cause hospitalisations. This out- \\
& come now favours the self-management group (OR 0.60 95\% Cl \\
& 0.45 to 0.89$)$ and the review was revised accordingly. \\
\hline
\end{tabular}

\section{H I S T O R Y}

Protocol first published: Issue 2, 2001

Review first published: Issue 1, 2003 


\begin{tabular}{lll}
\hline Date & Event & Description \\
\hline 31 August 2011 & New search has been performed & New literature search run \\
\hline 31 August 2011 & $\begin{array}{l}\text { New citation required and conclusions } \\
\text { have changed }\end{array}$ & $\begin{array}{l}\text { Complete rewrite of the review conducted. Summary of findings } \\
\text { table added. 14 new studies added. New risk of bias assessment } \\
\text { completed for all included studies. References in background } \\
\text { updated }\end{array}$ \\
& Change of title-'education' removed \\
\hline
\end{tabular}

\begin{tabular}{lll}
\hline 25 March 2008 & Amended & Converted to new review format. \\
\hline 21 August 2007 & $\begin{array}{l}\text { New citation required and conclusions } \\
\text { have changed }\end{array}$ & $\begin{array}{l}\text { New studies: N = } 7 \text { (Bourbeau 2003; Boxall 2005; Coultas 2005a; } \\
\text { Coutas 2005b; Martin 2004; Monninkhof 2003; Rea 2004) }\end{array}$ \\
& $\begin{array}{l}\text { What these studies have added: } \\
\text { Data on health related quality of life; exacerbations (hospitalisa- } \\
\text { tions, requirement for oral steroids); lung function (FEV1). }\end{array}$ \\
& $\begin{array}{l}\text { Quality of life scores and respiratory-related hospital admission } \\
\text { now show significant benefits. Lung function parameters do not } \\
\text { show a significant difference. Steroid-treated exacerbations were } \\
\text { not significantly different. }\end{array}$ \\
& $\begin{array}{l}\text { How this has changed the review: } \\
\text { The review now demonstrates that from the self-management } \\
\text { interventions assessed in the studies assembled in the review, } \\
\text { patients were less likely to require hospital admissions when } \\
\text { treated with this type of intervention. There was a small im- } \\
\text { provement in total quality of life scores measured by the St } \\
\text { George's Respiratory Questionnaire. There were no indications } \\
\text { of detrimental effects in other outcome parameters. The effects } \\
\text { of different components of self-management interventions and } \\
\text { their requisite intensity requires more research. }\end{array}$ \\
\hline
\end{tabular}

\section{CONTRIBUTIONS OF AUTHORS}

M. Zwerink: co-ordinating the update of the review. Performing all steps belonging to data collection of the update, including data management; analysis of data and interpretation of data; writing the update.

M. Brusse-Keizer: screening retrieved papers against inclusion criteria; extracting data; appraising quality of papers for the update; providing a methodological perspective;writing the update.

P. van der Valk: screening retrieved papers against inclusion criteria; providing a clinical perspective; critically revising the review.

G. Zielhuis: major contributor in conceiving and writing the original review, and the first update. Reviewing the current update.

E. Monninkhof: major contributor in conceiving and writing the original review, and the first update. Reviewing the current update.

J. van der Palen: conceiving of the original review; screening retrieved papers against inclusion criteria; providing a methodological perspective; critically revising the review.

P. Frith: providing a clinical perspective; critically revising the review; reviewing English language as a native speaker.

T. Effing: screening search results against inclusion criteria; screening retrieved papers against inclusion criteria; extracting data; supporting data management and data analysis; interpreting data; writing the update.

\section{DECLARATIONSOF INTEREST}

Netherlands Asthma Foundation provided funding for this review but in no way was able to influence the results of the review. 


\section{SOURCES OF SUPPORT}

\section{Internal sources}

- No sources of support supplied

\section{External sources}

- Netherlands Asthma Foundation, Netherlands.

- New source of support, Other.

\section{INDEX TERMS}

\section{Medical Subject Headings (MeSH)}

*Patient Education as Topic; *Self Care; Health Status; Hospitalization [statistics \& numerical data]; Outcome Assessment, Health Care; Patient Compliance; Program Evaluation; Pulmonary Disease, Chronic Obstructive [ ${ }^{\star}$ therapy]; Quality of Life; Randomized Controlled Trials as Topic

\section{MeSH check words}

Humans 